Florida International University FIU Digital Commons

6-11-2018

\title{
Novel Structural Health Monitoring and Damage Detection Approaches for Composite and Metallic Structures
}

Shervin Tashakori

stash002@fiu.edu

DOI: $10.25148 /$ etd.FIDC006883

Follow this and additional works at: https:// digitalcommons.fiu.edu/etd

Part of the Electro-Mechanical Systems Commons, Manufacturing Commons, Signal Processing Commons, $\underline{\text { Structural Engineering Commons, and the Structures and Materials Commons }}$

\section{Recommended Citation}

Tashakori, Shervin, "Novel Structural Health Monitoring and Damage Detection Approaches for Composite and Metallic Structures" (2018). FIU Electronic Theses and Dissertations. 3753.

https://digitalcommons.fiu.edu/etd/3753 


\section{FLORIDA INTERNATIONAL UNIVERSITY}

Miami, Florida

\section{NOVEL STRUCTURAL HEALTH MONITORING AND DAMAGE DETECTION APPROACHES FOR COMPOSITE AND METALLIC STRUCTURES}

A dissertation submitted in partial fulfillment of

The requirements for the degree of

DOCTOR OF PHILOSOPHY

in

MECHANICAL ENGINEERING

by

Shervin Tashakori 
To: Dean John L. Volakis

College of Engineering and Computing

This dissertation, written by Shervin Tashakori, and entitled Novel Structural Health Monitoring and Damage Detection Approaches for Composite and Metallic Structures, having been approved in respect to style and intellectual content, is referred to you for judgment.

We have read this dissertation and recommend that it be approved.

$\begin{array}{r}\text { Cesar Levy } \\ \hline \text { Dwayne McDaniel } \\ \hline \text { Yiding Cao } \\ \hline \text { Igor Tsukanov } \\ \hline \text { Ibrahim Nur Tansel, Major Professor }\end{array}$

Date of Defense: June 11, 2018

The dissertation of Shervin Tashakori is approved.

Dean John L. Volakis

College of Engineering and Computing

Andrés G. Gil

Vice President for Research and Economic Development and

Dean of the University Graduate School

Florida International University, 2018 
(C) Copyright 2018 by Shervin Tashakori

All rights reserved. 


\section{ACKNOWLEDGMENTS}

Firstly, I would like to express my sincere gratitude to my advisor Prof. Tansel for the continuous support of my Ph.D. study and related research, for his patience, motivation, and immense knowledge. His guidance helped me in all the time of research and writing of this thesis. I could not have imagined having a better advisor and mentor for my Ph.D. study.

Besides my advisor, I would like to thank the rest of my thesis committee: Prof. Levy, Prof. Cao, Prof. McDaniel and Prof. Tsukanov, for their invaluable suggestions, comments, and support throughout all stages of my academic work which incented me to widen my research from various perspectives.

My sincere thanks also go to Dr. McDaniel and Applied Research Centre who provided me an opportunity to join their team as a research assistant, and who gave me access to the laboratory and research facilities. Without they precious support it would not be possible to conduct this research.

I thank my fellow lab mates Dr. Amin Baghalian and Dr. Volkan Senyurek for the discussions and the sleepless nights we were working together before deadlines, and for all the fun we have had in the last five years. Also, I thank the staff of the Mechanical Engineering Department. In particular, I am grateful to Mariam Barrueco, and Mabel Fernandez for their help and support. I would like to acknowledge the University Graduate School, Florida International University for providing support for this research in the form of Doctoral Evidence Acquisition (DEA) and Dissertation Year Fellowships (DYF). I would like to thank the Graduate \& Professional Student Committee (GPSC) for the support received through conference travel grants to present my research at conferences. 
Last but not the least, I would like to thank my family: my parents and my brothers for supporting me emotionally throughout writing this thesis and my life in general. 


\section{ABSTRACT OF THE DISSERTATION \\ NOVEL STRUCTURAL HEALTH MONITORING AND DAMAGE DETECTION APPROACHES FOR COMPOSITE AND METALLIC STRUCTURES}

\section{By}

Shervin Tashakori

Florida International University, 2018

Miami, Florida

\section{Professor Ibrahim Nur Tansel, Major Professor}

Mechanical durability of the structures should be continuously monitored during their operation. Structural health monitoring (SHM) techniques are typically used for gathering the information which can be used for evaluating the current condition of a structure regarding the existence, location, and severity of the damage. Damage can occur in a structure after long-term operating under service loads or due to incidents. By detection of these defects at the early stages of their growth and nucleation, it would be possible to not only improve the safety of the structure but also reduce the operating costs.

The main goal of this dissertation is to develop a reliable and cost-effective SHM system for inspection of composite and metallic structures. The Surface Response to Excitation (SuRE) method is one of the SHM approaches that was developed at the FIU mechatronics lab as an alternative for the electromechanical impedance method to reduce the cost and size of the equipment. In this study, firstly, the performance of the SuRE method was evaluated when the conventional piezoelectric elements and scanning laser vibrometer were used as the contact and non-contact sensors, respectively, for monitoring the presence of loads on the surface. Then, the application of the SuRE method for the characterization 
of the milling operation for identical aluminum plates was investigated. Also, in order to eliminate the need for a priori knowledge of the characteristics of the structure, some advanced signal processing techniques were introduced. In the next step, the heterodyne method was proposed, as a nonlinear baseline free, SHM approach for identification of the debonded region and evaluation of the strength of composite bonds. Finally, the experimental results for both methods were validated via a finite element software.

The experimental results for both SuRE and heterodyning method showed that these methods can be considered as promising linear and nonlinear SHM approaches for monitoring the health of composite and metallic structures. In addition, by validating the experimental results using FEM, the path for further improvement of these methods in future researches was paved. 


\section{TABLE OF CONTENTS}

CHAPTER $\quad$ PAGE

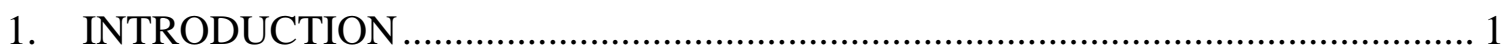

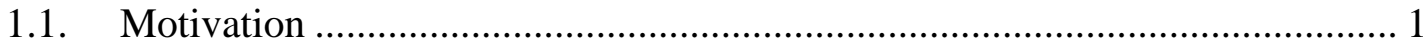

1.2. General Principles of SHM Approaches ........................................................ 2

1.3. Linear and nonlinear SHM approaches ................................................... 5

1.4. Most Commonly Used Transducers in SHM and NDT/NDE Systems .............. 6

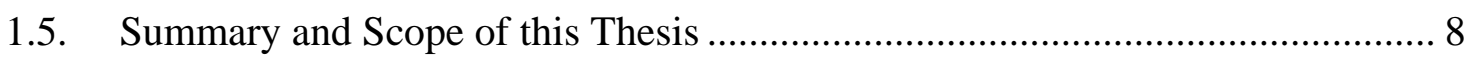

2. THEORETICAL BACKGROUND …............................................................. 10

2.1. Surface response to the excitation (SuRE) method as a linear method............. 10

2.2. Heterodyning effect as a nonlinear method................................................ 12

3. IMPLEMENTATION OF LINEAR METHODS .............................................. 16

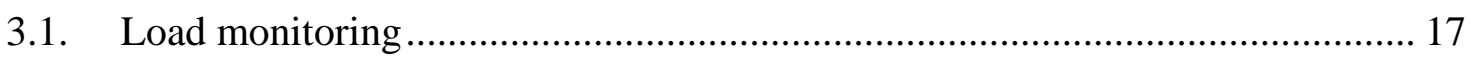

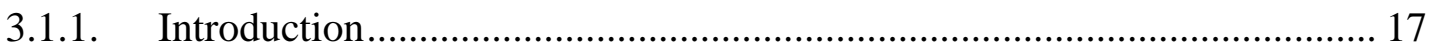

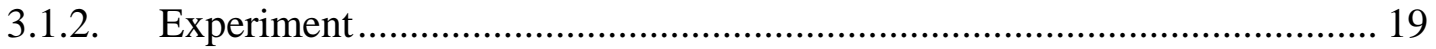

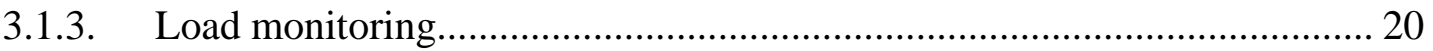

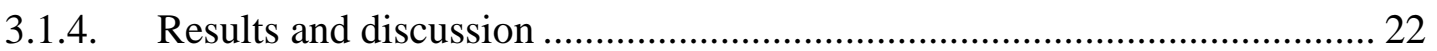

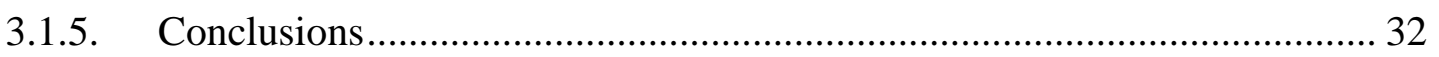

3.2. Characterization of milling operation for identical aluminum plates ................ 33

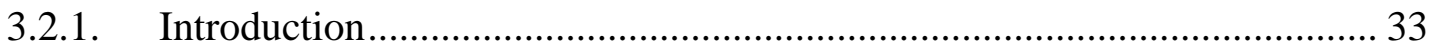

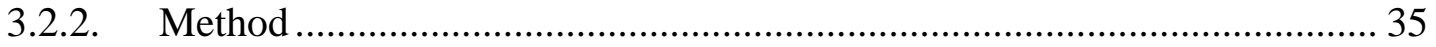

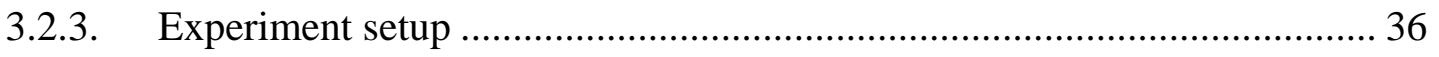

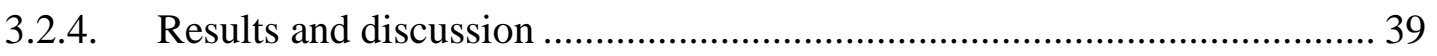

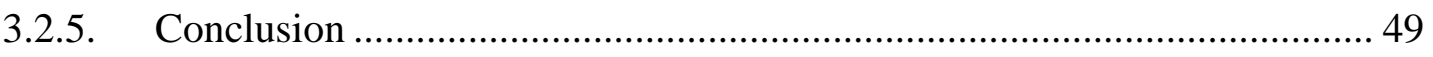

3.3. Damage Detection of 3D Printed Mold Using SuRE Method ........................ 51

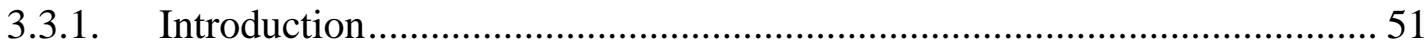

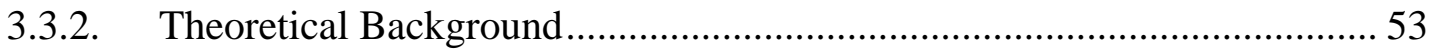

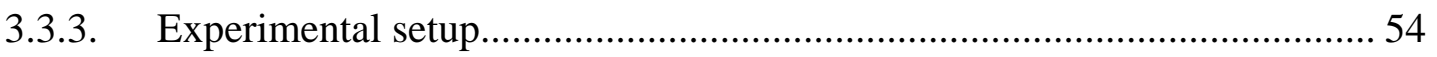




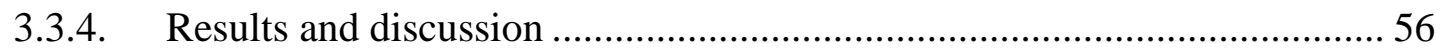

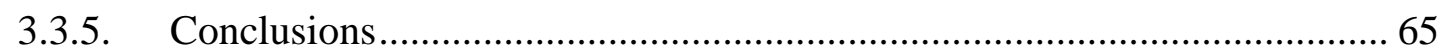

3.4. Composites bond inspection using SuRE methods ........................................ 66

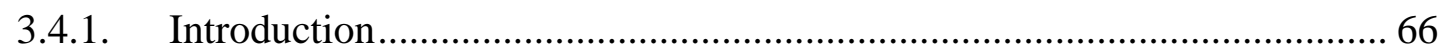

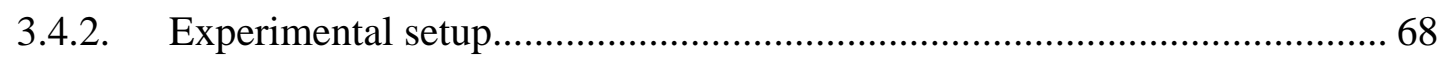

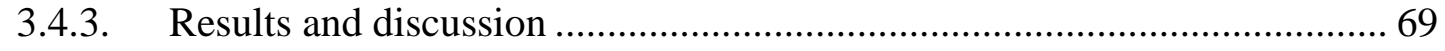

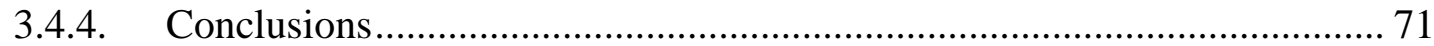

3.5. Validation of SuRE method using Comsol software …………........................ 72

3.5.1. Experimental setup................................................................................. 72

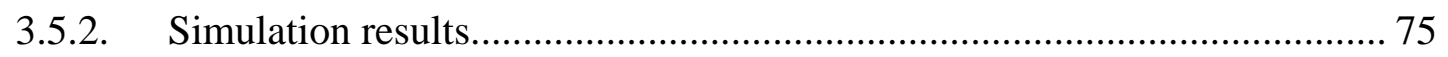

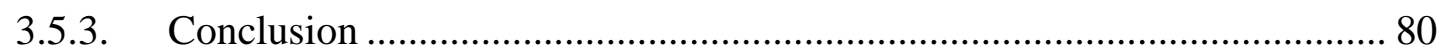

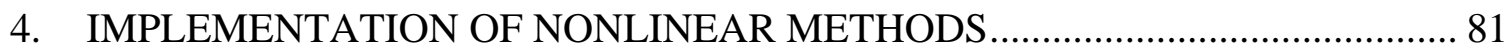

4.1. Monitoring the Health of Adhesively Bonded and Fastened Composite Joints 82

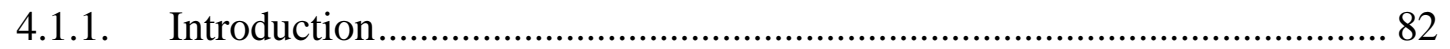

4.1.2. Implementation of the Heterodyne Effect into SHM................................. 85

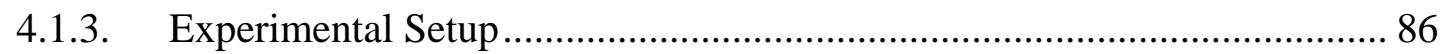

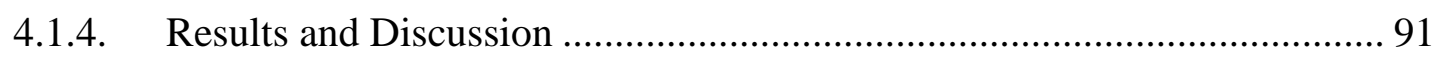

4.1.4.1. Detection of composites debonding by using heterodyne effect............. 91

4.1.4.2. Evaluation of the compressive forces on the composite plates............... 94

4.1.4.3. Detection of various contamination levels in composite bonds ............... 98

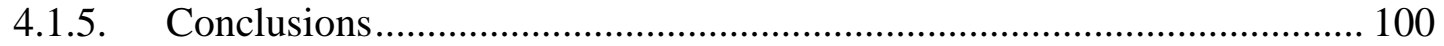

4.2. Validation of heterodyning method using Comsol software ............................ 103

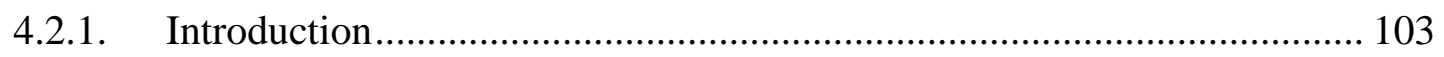

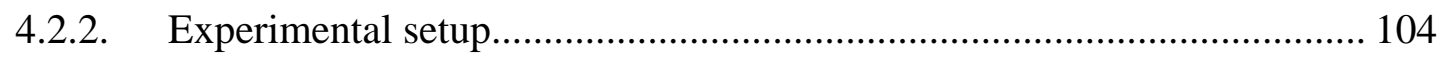

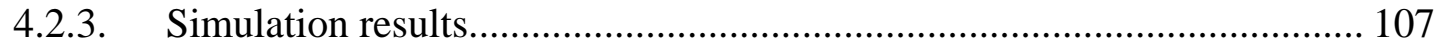

4.2.3.1. Aluminum plates ................................................................................ 107

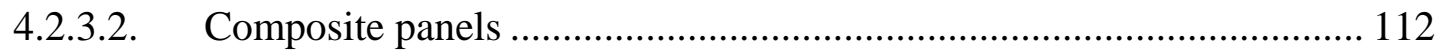

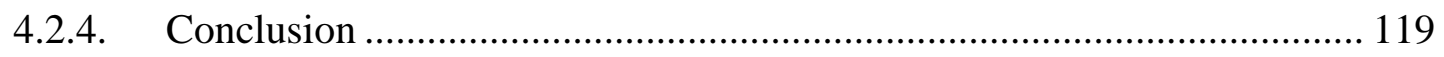

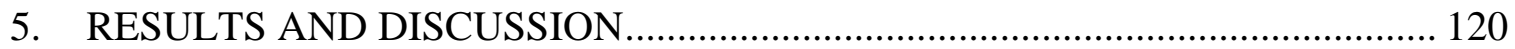




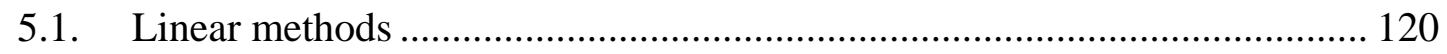

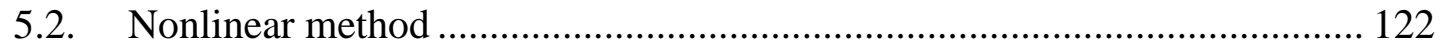

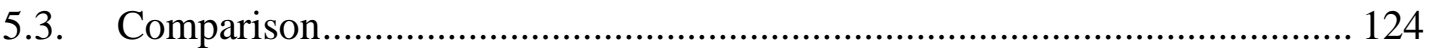

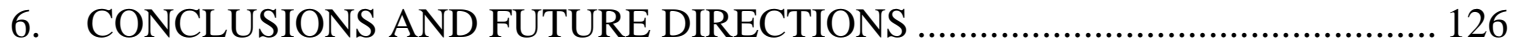

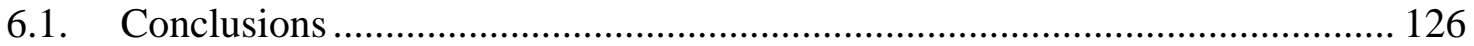

6.2. Recommendations for Future Research .................................................... 129

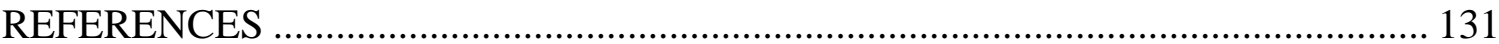

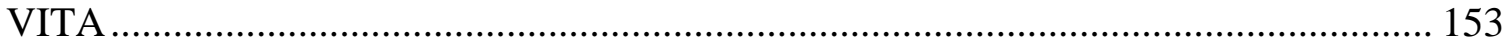




\section{LIST OF TABLES}

TABLES

PAGE

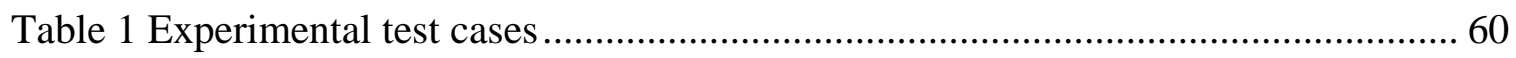

Table 2 Dimensions of plates and PZTs ..................................................................... 73

Table 3 Dimensions of plates and PZTs .................................................................. 105

Table 4 Amplitude of the spike at the frequency of the difference ............................... 118

Table 5 Load monitoring using PZT for data collection.............................................. 120

Table 6 Load monitoring using laser vibrometer for data collection.............................. 121

Table 7 SSD values in milling operation .................................................................... 121

Table 8 5th Momentum result in central point.............................................................. 122

Table 9 SSD values for different contamination sizes................................................... 122

Table 10 Detection of debonding ......................................................................... 123

Table 11 Evaluation of the compressive forces on the composite plates ....................... 123

Table 12 Detection of different sizes of contamination............................................. 123 


\section{LIST OF FIGURES}

FIGURES

PAGE

Figure 1 Passive and Active SHM methods 3

Figure 2 Lamb wave dispersion curves for two different Poisson's ratios] 4

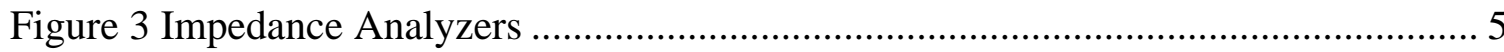

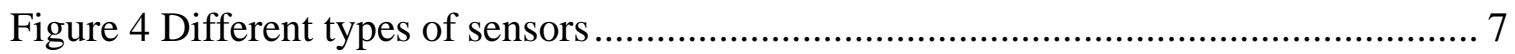

Figure 5. Transfer of surface excitation from one plate to the other. ............................ 14

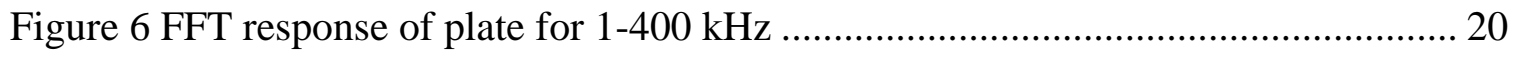

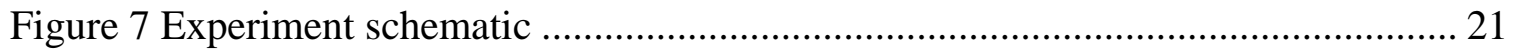

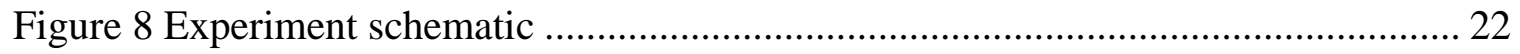

Figure 9 Experimental setup for single load into the center of the plate ........................ 23

Figure 10 Comparing FFT of different applying forces using PZT for data collection ... 23

Figure 11 comparing SSD of different applying forces using PZT for data collection .... 24

Figure 12 comparing FFT of different applying forces using laser vibrometer for data collection.

Figure 13 comparing SSD of different applying forces using laser vibrometer for data collection.

Figure 14 Experimental setup two loads 
Figure 15 comparing FFT of different applying forces using PZT for data collection .... 26

Figure 16 comparing SSD of different applying forces using PZT for data collection .... 27

Figure 17 comparing FFT of different applying forces using laser vibrometer for data collection

Figure 18 Comparing SSD of different applying forces using laser vibrometer for data

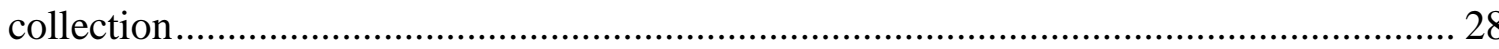

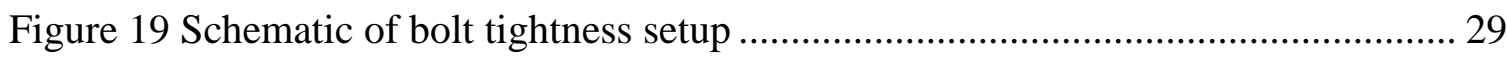

Figure 20 comparing FFT of different applying forces using PZT for data collection .... 30

Figure 21 comparing SSD of different applying forces using PZT for data collection .... 30

Figure 22 Comparing FFT of different applying forces using laser vibrometer for data

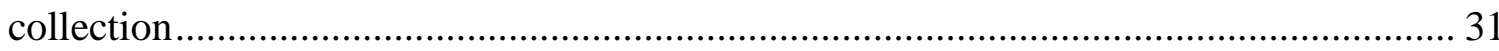

Figure 23 Comparing SSD of different applying forces using laser vibrometer for data

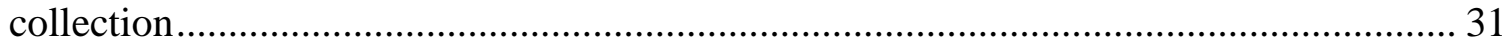

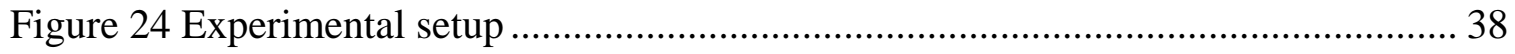

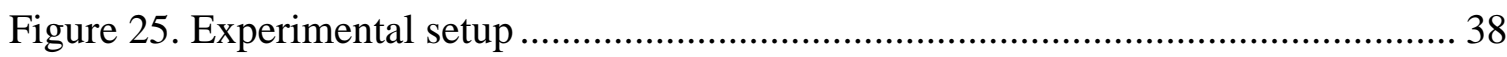

Figure 26. SSD result for change in the length of the milling operation ........................ 39

Figure 27. Geometric mean result for change in the length of the milling operation....... 40

Figure 28. SSD result for change in the width of the milling operation ........................ 41

Figure 29. Harmonic mean result for change in the width of the milling operation......... 42 
Figure 30. 5th Momentum result for change in the length of milling operation in central point

Figure 31 th Momentum result for change in the width of milling operation in central point

Figure 32 RMS result for change in the length of the milling operation 44

Figure 33 RMS result for change in the width of the milling operation 45

Figure 34 STD result for change in the length of the milling operation 45

Figure 35 STD result for change in the width of the milling operation. 46

Figure 36 Kurtosis result for change in the length of the milling operation 47

Figure 37 Kurtosis result for change in the width of the milling operation. 47

Figure 38 Skewness result for change in the length of the milling operation. 48

Figure 39 Skewness result for change in the width of the milling operation 49

Figure 40 3D Printed Mold 55

Figure 41 Attached PZTs on the back of the 3D printed mold 55

Figure 42 Experimental setup 56

Figure 43 Frequency response and SSD values for load monitoring. 57

Figure 44 Frequency response and SSD values for load monitoring 58

Figure 45 Frequency response and SSD values for load monitoring. 58 
Figure 46 Frequency response and SSD values for load monitoring

Figure 47 Created damage shown in three colors .......................................................... 61

Figure 48 The spectrums calculated by the FFT kHz ………………............................. 62

Figure 49 SSD values for damage detection or wear information................................. 62

Figure 50 The spectrums calculated by the FFT.......................................................... 63

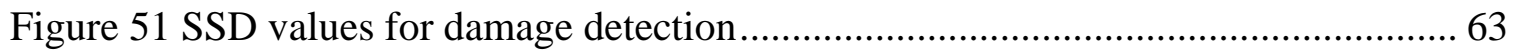

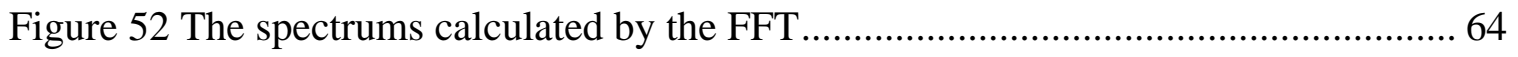

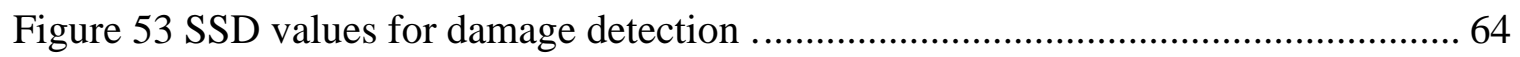

Figure 54 Schematic of the bond inspection in composite plates using the SuRE

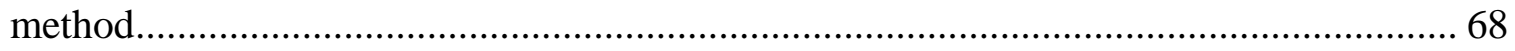

Figure 55 Comparing the spectrums obtained from four different experiments ............. 70

Figure 56 SSD results at different levels of simulated contamination............................. 70

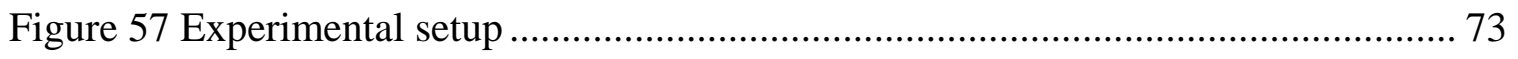

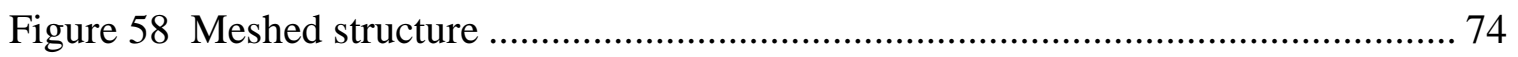

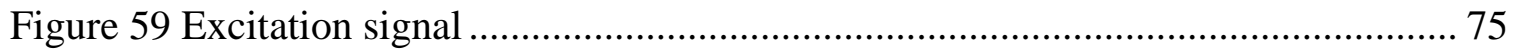

Figure 60 Time domain response for pristine plate ……................................................ 76

Figure 61 Frequency domain response for pristine plate ............................................... 76 
Figure 62 Time domain response for a plate with $9 \mathrm{~cm} \times 2 \mathrm{~cm} \times 2 \mathrm{~mm}$ milling 77

Figure 63 Frequency domain response for a plate with $9 \mathrm{~cm} \times 2 \mathrm{~cm} \times 2 \mathrm{~mm}$ milling $\ldots . . .77$

Figure 64 Time domain response for a plate with $9 \mathrm{~cm} \times 2 \mathrm{~cm} \times 2.5 \mathrm{~mm}$ milling 78

Figure 65 Frequency domain response for a plate with $9 \mathrm{~cm} \times 2 \mathrm{~cm} \times 2.5 \mathrm{~mm}$ milling.. 78

Figure 66 Time domain response for a plate with $9 \mathrm{~cm} \times 2 \mathrm{~cm} \times 3 \mathrm{~mm}$ milling 79

Figure 67 Frequency domain response for a plate with $9 \mathrm{~cm} \times 2 \mathrm{~cm} \times 3 \mathrm{~mm}$ milling.... 79

Figure 68 Summation of the squares of the difference (SSD) for different size of the milling operation 80

Figure 69. Schematic of the experimental setup for detection of delamination 88

Figure 70. Schematic of the joint inspection in composite panels using heterodyning effect 89

Figure 71 Schematic of the bond inspection in composite panels using heterodyning effect

Figure 72 Time-frequency spectrum for determination of the optimum excitation frequency 92

Figure 73 Comparing FFT results between perfect contact and in presence of debonding.. 93

Figure 74 Time-frequency spectrum for identification of the debonded region. 94

Figure 75 Time-frequency spectrum to determine optimum excitation frequency 95 
Figure 76 Comparing the spectra of the signal of the sensor at different compressive forces.

Figure 77 Spectrogram of the sensor at the bottom plate 98

Figure 78 Time-frequency spectrum to determine optimum excitation frequency 99

Figure 79 Comparing FFT results between different levels of contamination 100

Figure 80 Experimental setup 105

Figure 81 Meshed structure 106

Figure 82 time domain plot for single frequency excitation signal 108

Figure 83 frequency domain plot for single frequency excitation signal 108

Figure 84 time domain plot for the response signal for single frequency excitation...... 109

Figure 85 frequency domain plot for the response signal for single frequency excitation signal 109

Figure 86 response of the system when there is no debonding. 110

Figure 87 frequency response of the system for 0.005 um distance between two plates 111

Figure 88 frequency response of the system for 0.012 um distance between two plates 112

Figure 89 Time domain plot for single frequency excitation signal 113

Figure 90 Frequency domain plot for single frequency excitation signal 113

Figure 91 Time-Frequency domain plot for single frequency excitation signal. 114 
Figure 92 Frequency domain plot for single frequency excitation signal

Figure 93 Time domain plot for double frequency excitation signals with no debonding.....

Figure 94 Frequency domain plot for double frequency excitation signals with no debonding.

Figure 95 Time domain plot for double frequency excitation signals with 0.005 um debonding

Figure 96 Frequency domain plot for double frequency excitation signals with 0.005 um debonding.

Figure 97 Time domain plot for double frequency excitation signals with 0.012 um debonding.

Figure 98 Frequency domain plot for double frequency excitation signals with 0.012 um debonding 


\section{CHAPTER 1}

\section{INTRODUCTION}

\subsection{Motivation}

Structural health monitoring (SHM) is the process of gathering wide-ranging information from a structure in order to illustrate the current state of the structure and indicate the existence, location, and severity of damage when damage occurs [1]. In recent years, there has been a growing understanding of these damage prognosis systems and their significant impact on aerospace, civil and mechanical structures [2]-[10].

Statistic data show that only in the United States, the cost of the service and maintenance of facilities is more than $\$ 200$ billion each year. For instance, about a third of bridges in the US require repairs or replacement. Also, maintenance and repairs of commercial aircraft are almost equal to a quarter of the operating costs [11]. Based on statistics provided by the U.S. Department of Transportation (DOT), in the span of 20 years (1997-2016), only in oil, gas, and hazardous liquid industries, there have been 11496 incidents which caused 324 death and 1331 injuries and a total cost of \$7,050,142,502 [12]. The Columbia Space Shuttle tragedy is another example that demonstrates a crucial need for effective and accurate SHM systems in aerospace structures to guarantee high levels of reliability and safety [13].

Extreme incidents or lasting performance under service loads, such as fatigue and corrosion, may damage a structure and result in a failure. Damage can have a significant impact on the physical properties of the structure, such as mass and stiffness, and deteriorate its functioning. Therefore, by detection of the damage at early stages, it would be possible to not only improve the safety, reliability, and integrity of the structure but also 
minimize the cost of maintenance and the possibility of the catastrophic failures. while current inspection methods have shown a lot of potentials and have several benefits, they may not be applicable in certain scenarios and it seems that the necessity of providing a more accurate and effective SHM method for a certain type of damages is undeniable [14].

\subsection{General Principles of SHM Approaches}

Structural health monitoring technology has the potential to change the maintenance procedures by replacing the schedule-based procedure with the condition-based procedure and in this way, reduce the time duration that structures are offline. Therefore, the operations will be more cost-effective and labor requirements will be minimized.

In the recent years, composite materials have won a significant popularity in airspace design due to their high strength-to-weight ratio in comparison with conventional materials. However, their need for adhesive bonding in addition to riveting and bolting can reduce the benefits of using these materials on aircraft structures and with the daily increase of application of these materials in commercial and military aircraft, the longevity of composite bonds has become a substantial factor in the aerospace industry. Structural health monitoring techniques can raise the confidence levels for using these materials in the aerospace industry by detecting damage in early stages.

Essentially, an SHM system includes a network of sensors for collecting the data, the data acquisition device to transfer the collected data to the processor and the processing system for analyzing the data and evaluating the health of the structure. SHM methods can be

divided into passive and active methods (Figure 1). Passive SHM methods do not contain any actuators as part of their systems and evaluate the structural health by using a variety of operational parameters [2]. Among the passive methods, Acoustic Emission (AE) is one 
of the most popular for identification of developing defects in planar composite materials [15]-[18]. Acoustic Emissions are created by the generation of transient waves due to the rapid release of strain energy within the damaged composites after a defect is developed. Active methods, however, excite the system using appropriate excitation signals and monitor the response of the system. These methods are the most effective SHM methods for estimation of the location, severity, and type of defects [19]-[24].

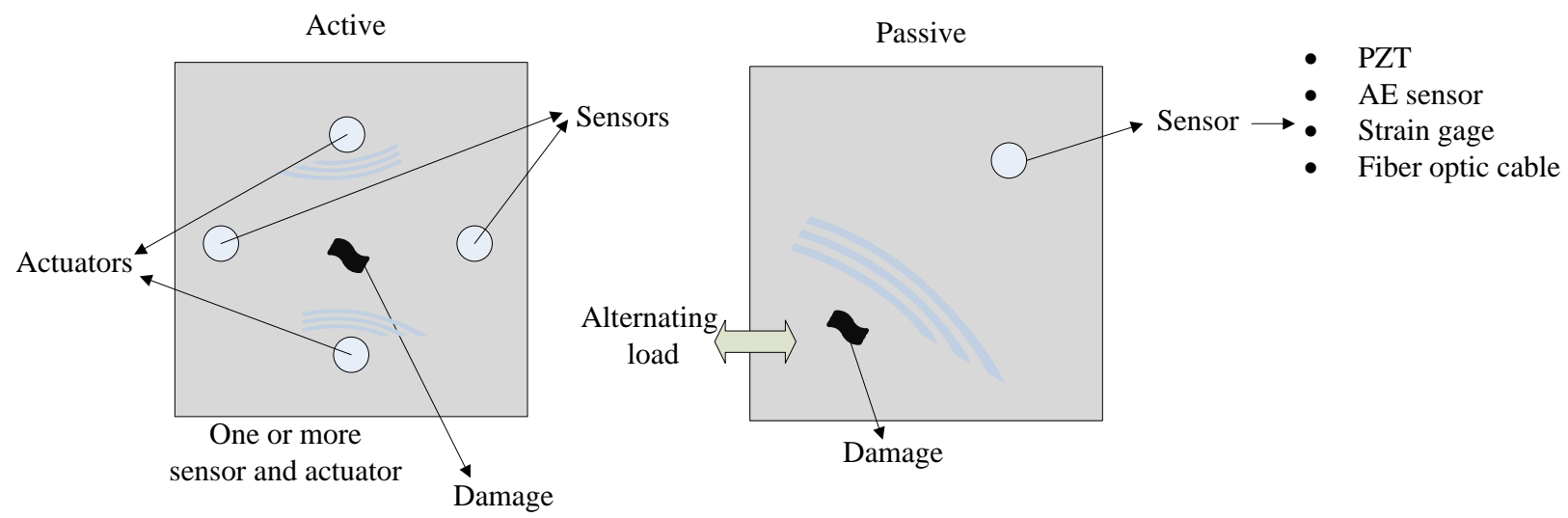

Figure 1 Passive and Active SHM methods

Active methods use ultrasound waves since they can propagate in any media except a vacuum. Bulk waves and guided-waves are two ultrasonic waves that are mostly used in SHM active methods. Bulk waves are more easily understood since they have constant speed at each frequency, but on the other hand, they only can be used for point by point measurements. Guided-waves (GW) are used for the monitoring of larger structures due to their long-distance propagation capability. The group and phase velocity of GW change with the frequency and mode of excitation. Therefore, a wave can propagate with different speeds along the structure and the propagation of the wave at different speeds will result in 
wave distortion which makes it complicated and difficult to analyze (Figure 2). In reality, each one of the frequencies and modes (anti-symmetric and symmetric) of excitation signal are sensitive to the certain type of damage and makes the selection of excitation frequency mode extremely crucial for single excitation frequency approaches. Lamb waves methods are the most established approaches among single excitation frequency approaches specifically in the plate and shell-like structures.

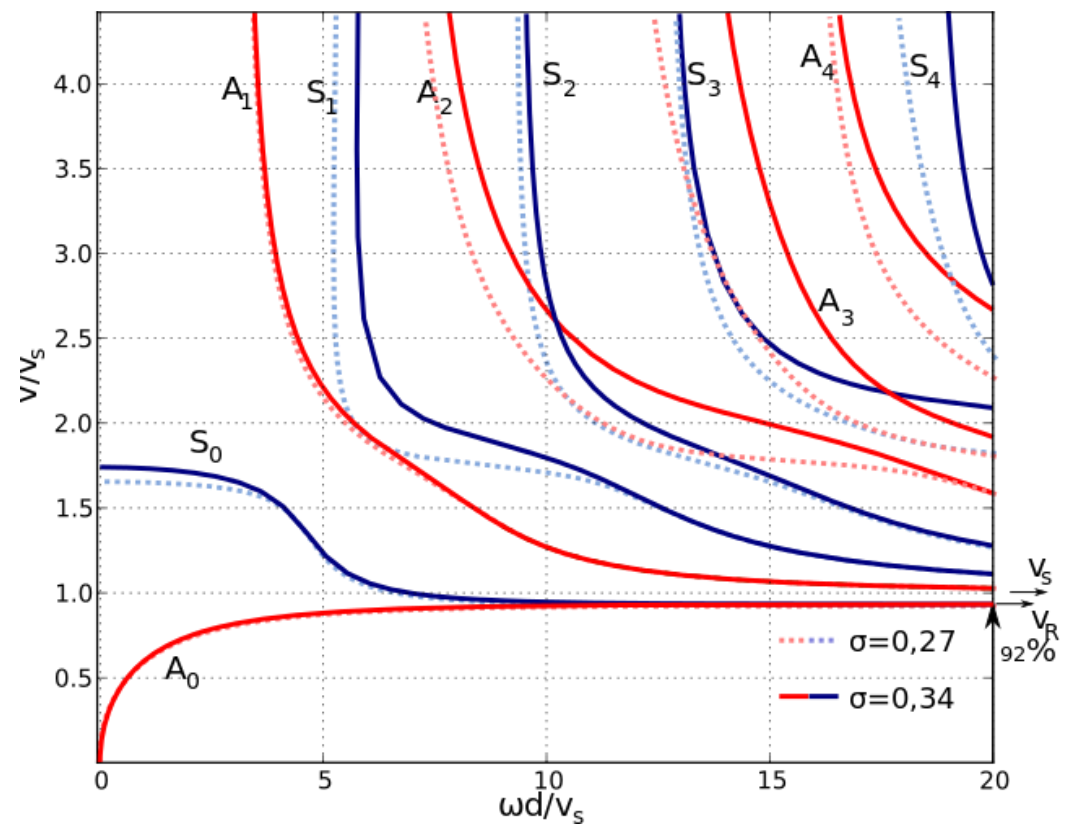

Figure 2 Lamb wave dispersion curves for two different Poisson's ratios (A: Antisymmetric, S: Symmetric) $[25,26]$

Also, it would be possible to excite the structure with the wide range of frequencies and evaluate the health of the structure based on the frequency response of the system. The Electromechanical Impedance (EMI) method is the well-known technique among broadband frequency approaches. It has been shown that the defects will change the mechanical impedance of the structure and as a result, the frequency response of the structure will change. However, there are some drawbacks to this method. The main 
processor of EMI method is an Impedance Analyzer. This device is considered bulky and costly for many applications. In recent years, few cheaper and more compact alternatives for the EMI method have been introduced.
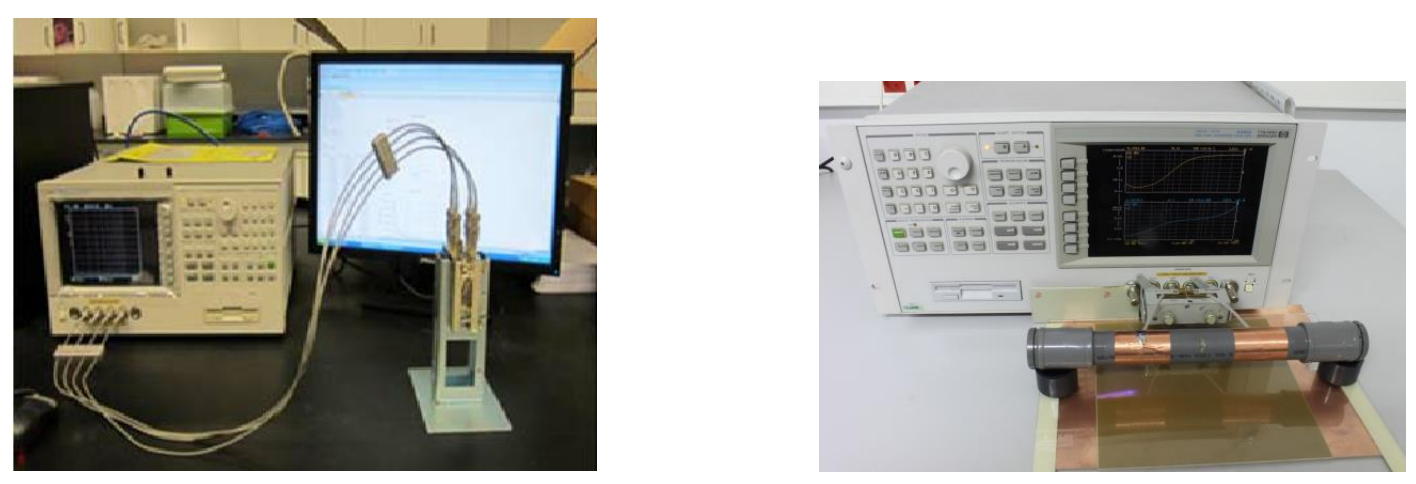

Figure 3 Impedance Analyzers

\subsection{Linear and nonlinear SHM approaches}

As opposed to the aforementioned linear SHM approaches, which are primarily focused on the linear characteristics of the structures including time of flight, reflections from defects and the impedance of the structures, there are nonlinear methods. Recently, researches have shown that some types of damage including debonding, cracks and delamination change the linear behavior of structure into nonlinear. It is possible to detect the development of these defects by recognition of the nonlinear behavior [34-39]. In these methods, there is no need for collection of the reference (baseline) data from the pristine structure for further processing. Nonlinear elastic wave spectroscopy (NEWS) methods are most prevalent approaches in this area and are able to detect the nonlinear behavior of structures at early stages [40-52]. The application of harmonics and sum and difference frequency is the main 
factor for damage detection in these methods. In these methods, the structure is excited continuously using two signals with two separate frequencies simultaneously, and health inspection of the structure is based on the harmonics of the two waves, and their sum and difference frequencies. Pristine structures are linear in their response to the two waves, while the damaged ones are converted to highly nonlinear systems which can be shown by harmonics and sideband generation [27].

Non-linear wave modulation spectroscopy (NWMS) and non-linear resonant ultrasound spectroscopy (NRUS) are well-known NEWS methods. In the NWMS approach, two different actuators are used to excite the structure at very low and high frequencies. NRUS is a resonance-based technique which can detect the nonlinearity in damaged structures. In NRUS, the resonant frequency of the structure is considered as the main factor and the elastic nonlinearity can be detected by a shift in the resonance frequency [28].

Although the selection of appropriate excitation frequencies plays a pivotal role in the progress of damage detection, researchers were not able to come up with a practical and efficient approach for the assortment of proper frequency combinations.

\subsection{Most Commonly Used Transducers in SHM and NDT/NDE Systems}

The most common transducers in the SHM systems and the NDT/NDE industry including fiber optic sensors, piezoelectric sensors, and magnetostrictive sensors play a pivotal role in the monitoring of the numerous physical or chemical parameters related to the health and durable service life of structures.

Fiber optic sensors are one of the most popular sensors in smart structures applications due to their small size, the possibility of networking with a large number of sensors, flexibility 
to be bonded on the surface or embedded in the structure, higher bandwidth capability [29], [30]. However, their high price has been their main disadvantage in some applications. Magnetostrictive sensors are another promising transducer in guided-wave SHM methods [31]. They are flexible to be bonded on the surface or embedded in the structure, capable of being used as both a sensor and actuator and not expensive. However, they have not been studied enough and the characterization of this type of transducers is still under evaluation. Hertzian contact transducers and lasers are another type of transducers for the offline monitoring of the structures but they are not useful for SHM due to the size, specifically in the aerospace industry where the mass and size of the transducers are essential factors [32], [33]. PZTs are most commonly used transducers in structural health monitoring applications. They are not only light, small and inexpensive, they are also convenient and capable of being used as both a sensor and actuator.
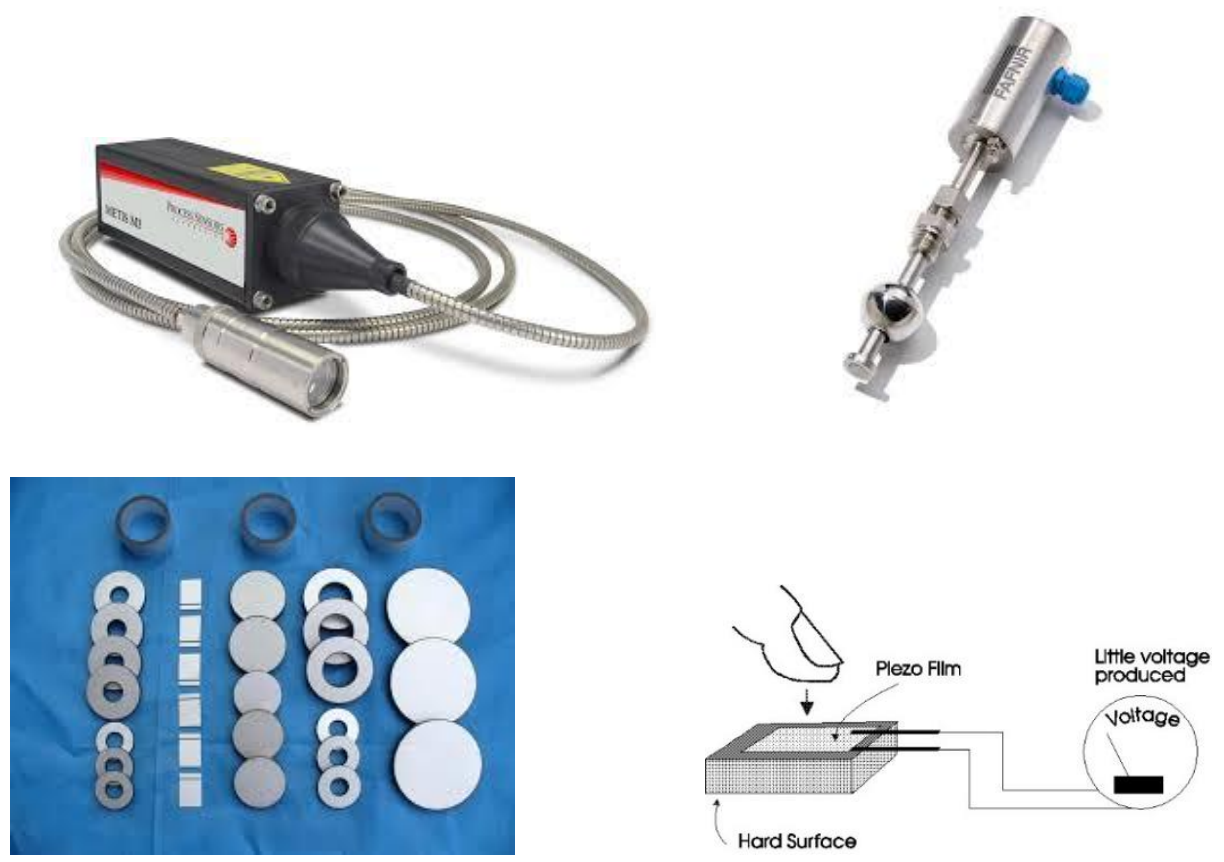

Figure 4 Different types of sensors 


\subsection{Summary and Scope of this Thesis}

The main goal of this dissertation is to improve and modify the existing SHM approaches for new applications and also develop a reliable and cost-effective SHM system for bond inspection. Since ceramic piezoelectric wafer transducers are mostly smaller and more compact compared to the common transducers which are used in nondestructive evaluation approaches, they are the most popular option for SHM researchers. In this study, PZT transducers were chosen as actuators and sensors for all experimental setups. In the course of experiments, several signal-processing techniques in time and frequency domains were utilized.

Objectives of the study are as follows:

- It has been shown that the dynamic response of the structure is not only sensitive to defects but is also sensitive to loading. The performance of the surface response to the excitation method as a low-cost alternative for Electromechanical Impedance based methods in some load monitoring applications was investigated (sensing data in a fraction of a second by triggering technique and using Power Spectral Density (PSD) technique to filter low-frequency noise).

- The quality of the part may be evaluated while geometric features such as holes and slots are created during the machining process. The feasibility of the modified SuRE method was evaluated for inspection of the quality of the machined features on aluminum plates.

- Composite materials have gained popularity in high tech applications due to their high strength-to-weight ratio and durability against corrosion. Composite parts may be joined by using adhesive bonding and/or fasteners including rivets and 
bolts. Weakening or partial separation of bonded regions or delamination drastically reduce the strength of the structure and may lead to failure. A low cost and reliable SHM approach for bond inspection of composite materials based on heterodyning effect were developed.

- By using finite element simulation software, a theoretical justification for the validity of SuRE and heterodyning method was provided.

These four areas are individually addressed in the subsequent chapters of this thesis. In the end, the main contributions of this thesis are summarized and future possible directions of research are suggested. 


\section{CHAPTER 2}

\section{THEORETICAL BACKGROUND}

The theoretical backgrounds for the SuRE and heterodyne effect are explained in the following section by considering a simple experimental setup as a linear and nonlinear methods, respectively.

\subsection{Surface response to the excitation (SuRE) method as a linear method}

In the electro-Mechanical based methods, Piezoelectric lead Zirconate Titanate (PZT) transducers are used as the actuator. Based on their characteristic feature, they are able to excite the surface of the structure in a broad frequency range in response to an applied electric field. On the other hand, they are also able to be used as a sensor and generate electric charge in response to an applied mechanical stress. By creating a defect in the structure, the mechanical impedance of the structure will change and this change will reflect on the response of the system which is the electrical signal of the PZT that is used for recording the response of the system. By monitoring the response signal of the structure, we are able to detect the presence of structural damage at early stages.

Shown below is the strain formulation for a constitutive model of a general onedimensional piezoelectric material which show their ability to generate an electrical charge in proportion to an externally applied force $[34,35]$ :

$$
\begin{aligned}
\text { Integrating } & \left\{\begin{array}{l}
Q \\
\Delta
\end{array}\right\}=\left\{\begin{array}{cc}
C & n d_{33} \\
n d_{33} & 1 / K_{a}
\end{array}\right\}\left\{\begin{array}{l}
V \\
f
\end{array}\right\} \\
\left\{\begin{array}{l}
D \\
S
\end{array}\right\}=\left\{\begin{array}{cc}
\xi^{T} & d_{33} \\
d_{33} & s^{E}
\end{array}\right\}\left\{\begin{array}{l}
E \\
T
\end{array}\right\} & \text { OR } \\
\left\{\begin{array}{l}
Q \\
f
\end{array}\right\} & =\left\{\begin{array}{cc}
C\left(1-k^{2}\right) & n d_{33} K_{a} \\
-n d_{33} K_{a} & K_{a}
\end{array}\right\}\left\{\begin{array}{l}
V \\
\Delta
\end{array}\right\}
\end{aligned}
$$


In these equations, $\mathrm{D}$ is electrical flux density, $\mathrm{S}$ is a mechanical strain, $\varepsilon^{T}$ is permittivity in constant stress, $\mathrm{d}$ is piezoelectric charge coefficient, $S^{E}$ is compliance in constant electrical field, $\mathrm{E}$ is electrical field, $\mathrm{T}$ is mechanical stress, $\mathrm{V}$ is voltage, $\mathrm{f}$ is total force, $\mathrm{C}$ is capacitance measured with no force, $\mathrm{Ka}$ is stiffness when $\mathrm{V}=0, \mathrm{k}$ is electromechanical coupling factor, $\mathrm{Q}$ is the total charge of electrodes of the transducer, and $\Delta$ is the total elongation.

In this thesis, a modified surface response to excitation (SuRE) method has been implemented for monitoring and identifying different levels of load on a structure and characterization of milling operation for identical aluminum plates. Normally, in the SuRE method, the surface of a structure is excited by a sweep sine wave over a certain frequency range using a piezoelectric transducer and an additional piezoelectric transducer is used on the other side of the structure to sense the dynamic response of the system. The frequency spectrum of the signal $(\mathrm{x}(\mathrm{t}))$ is then obtained by using Fast Fourier Transform (FFT) [36]. The frequency response of the structure is consistent as long as there is no change in the system. However, when the condition changes, in terms of applying load or appearance of the defect, a different frequency spectrum is obtained.

In order to quantify the difference between pristine and damaged structure, the sum of the squared differences (SSD) of FFT of frequency response is calculated, as shown in equation (1):

$$
S S D=\sum_{i=1}^{m}\left|B_{m \times 1}-R_{m \times 1}\right|^{2}
$$

Here, $B$ and $R$ are the FFT of baseline and loaded structure responses, respectively, and also $m$ denotes the size of FFT. 
In the load monitoring study, instead of FFT approach for calculating damage metric, power spectral density (PSD) of the frequency domain data was employed to decrease the effect of noise and also to increase the resolution of primary features:

$$
P S D=\frac{1}{f} \times|X(f)|^{2}
$$

\subsection{Heterodyning effect as a nonlinear method}

Many communication systems and optical measurement devices use the heterodyning method to transfer information between different frequency bands without any information loss. The main component of a heterodyne system is the nonlinear component which is called the mixer. Diodes and transistors are the typical nonlinear components of electrical engineering applications, which are used as the mixer. For the implementation of the heterodyning method in SHM applications, the structure is excited at two different frequencies. As long as the structure is in pristine condition, these two frequencies are the main components in the response of the structure to the excitation. That is, when two metal plates are held together with well-tightened bolts, the contact surfaces have elastic deformations and behave like a unit solid plate. Well-built composite plates also behave in a similar manner either they are used as a single panel or they are held together with well-built joints. Adhesives or fasteners may be used for holding composite plates together. The following equation represents the general form of the excitation signals and also response signals:

$$
v_{0}=a v_{1} \pm b v_{2}=a \sin \left(\omega_{1} t\right) \pm b \sin \left(\omega_{2} t\right)
$$


Where $\mathrm{a}$ and $\mathrm{b}$ are the amplitudes of the signals and $\omega_{1}, \omega_{2}$ are the angular frequencies of the excitation signals. If a defect such as a crack, loose bolt or delamination exists in the system, there is not perfect contact between surfaces of plates or layers and very small gaps appear at the debonded or delaminated regions of the composite plates. In the absence of the appropriate surface pressure, the surfaces of plates held together with the bolts are in light contact with each other. Therefore, the waves created by the excitation signals on one plate propagate to the other surface after going through some certain alterations which cause the nonlinear behavior of the structure when it is subjected to bitonal excitation. The signals which move to the mating plate or layer with the influence of the defect will have nonlinear characteristics. The following equation represents the general expected form of the response in the second plate:

$$
\begin{aligned}
& v_{0}=a v_{1} \pm b v_{2} \pm c\left(v_{1} \pm v_{2}\right)^{2} \pm d\left(v_{1} \pm v_{2}\right)^{3} \pm \mathrm{K} \\
& =a \sin \left(\omega_{1} t\right) \pm b \sin \left(\omega_{2} t\right) \pm c \cos \left(2 \omega_{1} t\right) \pm d \cos \left(2 \omega_{2} t\right) \pm e \cos \left(\left(\omega_{1}+\omega_{2}\right) t\right) \pm f \cos \left(\left(\omega_{1}-\omega_{2}\right) t\right) \pm \mathrm{K}
\end{aligned}
$$

Equation 4, represents the nonlinear response of the structure which contains the harmonic signals at two original excitation frequencies $\left(\omega_{1}, \omega_{2}\right)$ and the new frequencies at the summation and subtraction of the original excitation frequencies. The schematic of the wave transmission process between the surfaces of two adjacent plates with a small gap is presented in Figure5 and is explained via numerical simulation. 


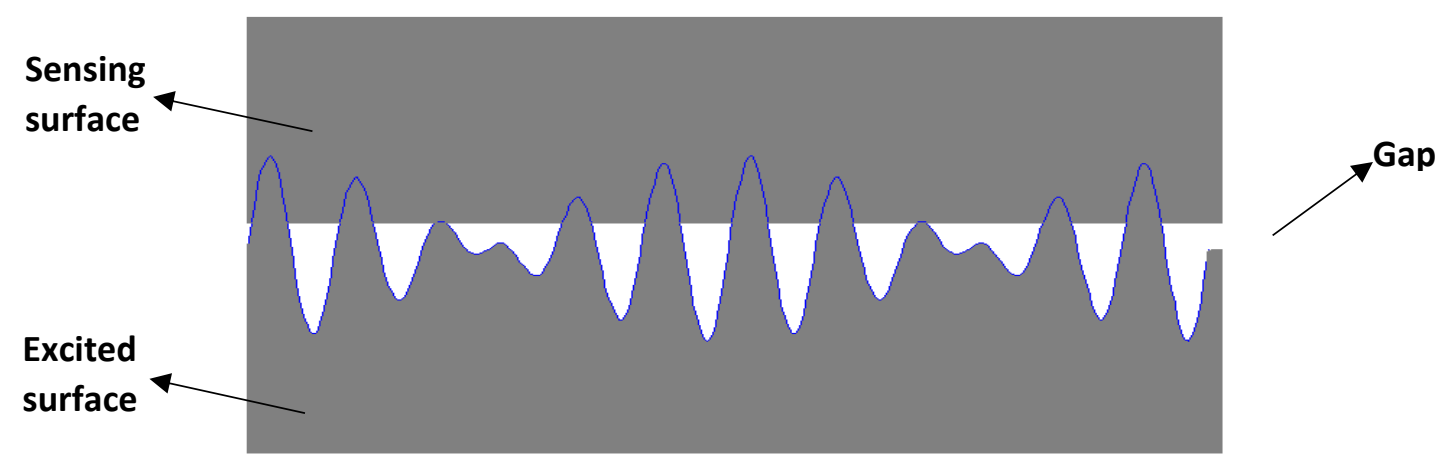

(a)

$$
\begin{aligned}
& v_{1}=\sin \left(\omega_{1} t\right) \\
& v_{2}=\sin \left(\omega_{2} t\right)
\end{aligned}
$$
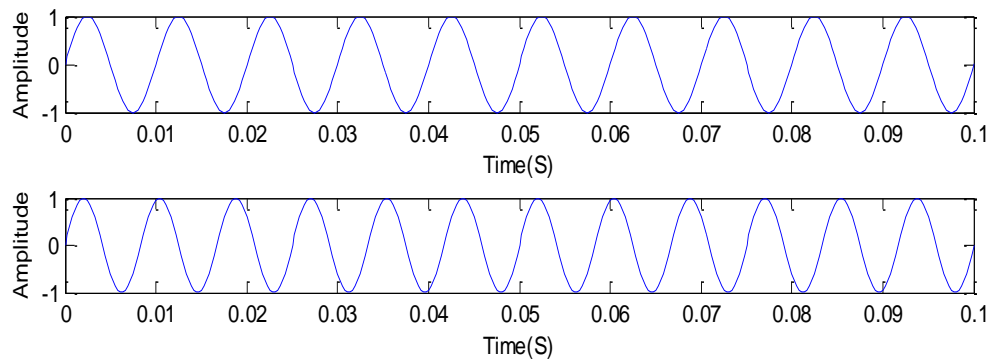

Time domain signal (Linear)

$$
v_{0}=v_{1} \pm v_{2}
$$

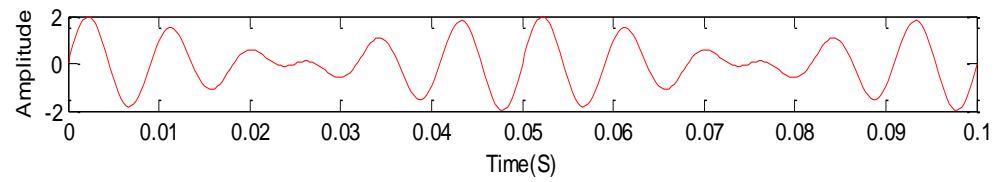

Time domain signal(Nonlinear)

$$
v_{0}=a v_{1} \pm b v_{2} \pm c\left(v_{1} \pm v_{2}\right)^{2} \pm d\left(v_{1} \pm v_{2}\right)^{3} \pm \mathrm{K}
$$

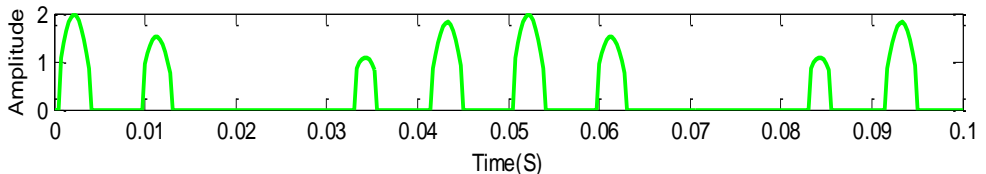

Frequency domain signal(Nonlinear)

$$
\begin{aligned}
& v_{0}(\omega)=a \delta\left(\omega-\omega_{1}\right) \pm b \delta\left(\omega-\omega_{2}\right) \\
& \pm c \delta\left(\omega-\left(\omega_{1}+\omega_{2}\right)\right) \pm d \delta\left(\omega-\left(\omega_{1}-\omega_{2}\right)\right) \pm \mathrm{K}
\end{aligned}
$$

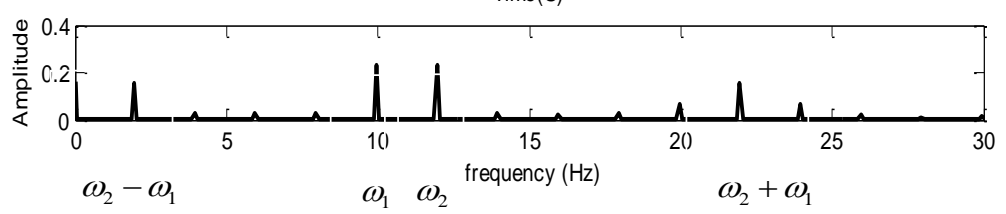

(b)

Figure 5. Transfer of surface excitation from one plate to the other a) Partial transmission of the excitation signal from one plane to the other one b) Expressions and the corresponding waves.

Two harmonic signals $v_{1}=\sin \left(\omega_{1} t\right)$ and $v_{2}=\sin \left(\omega_{2} t\right)$ were added in order to generate the surface waves at the bottom plate. The top surface will be subjected to excitation only if the waves of the bottom plate reach it. The transferred waves to the top surface are 
indicated with dark blue lines in Figure1a. The frequency spectrum of the transferred wave was calculated and presented at the bottom of the Figure 5b. In this graph, the new frequency components at the summation and subtraction of the excitation frequencies in addition to the original excitation frequencies can be seen. 
CHAPTER 3

3. IMPLEMENTATION OF LINEAR METHODS 


\subsection{Load monitoring}

Surface response to excitation (SuRE) method is a low-cost alternative to the electromechanical impedance-based structural health monitoring (SHM) technique. The SuRE method uses one piezoelectric transducer to excite the surface of a structure with a sweep sine wave. Piezoelectric sensors or scanning laser vibrometer could be used to monitor the dynamic response of the structure.

In this study, the performance of the SuRE method was evaluated when the conventional piezoelectric elements and scanning laser vibrometer were used as a contact and noncontact sensors, respectively, for monitoring the presence of loads on the surface. In order to determine the accuracy and reliability of both monitoring approaches in detecting changes in the level of applied load, three different experimental setups were studied. The response of system in the presence of single and double loads and its performance in detecting tightness in nut and bolt system were investigated. The spectrum of the dynamic response is collected at the optimal operating condition. Any significant change of the spectral characteristics may indicate defects, improper loading or loose fasteners. The performance of the SuRE method using contact and non-contact sensors indicated that both variations of the method could be successfully used in load monitoring applications.

\subsubsection{Introduction}

In the last few decades, active SHM techniques especially guided waves based methods such as wave transition methods [37-39] and Impedance based methods [40, 41] have

received a lot of interest. Timely detection of defects using SHM methods plays a pivotal role in maintaining the required level of integrity and safety in different industries. It is 
well established that dynamic characteristics of a structure are sensitive to certain changes in structure. Over the last few years, many studies have been performed to improve the understanding on the interaction between defects and changes in the dynamic response of structures. A considerable amount of research in this field mainly focused on damage detection and localization in plate structures [42-50].

In the Electromechanical Impedance (EMI) method, the health of the structure will be investigated by measuring the mechanical impedance of the structure using piezoelectric transducers [49]. However, impedance analyzers are extremely costly and there have been attempts at replacing with cheaper alternatives such as cheaper electronic circuits [51-54]. Also, other variations of this method, such as the SuRE method, have been recently introduced which eliminated the need for the impedance analyzer [54-57].

It has been shown that the dynamic response of a structure is not only sensitive to defects but it is also sensitive to loading [44,47,58]. Annamdas et al. used the electromechanical impedance method for monitoring of load on a carbon steel gear specimen [59]. The US Army Construction Engineering Research Laboratory also reported the use of the electromechanical impedance method in load monitoring application for unreinforced masonry wall specimens and masonry wall reinforced with composite overlays [60]. Electromechanical impedance approaches have been also utilized in the monitoring of boltjoints structures and investigation of loose bolts [61, 62]. However, the interaction between loads and dynamic response of structures, which normally is recorded by bonded piezoelectric transducers, is not well understood yet. In this experiment, the performance of the SuRE method as a low-cost alternative for EMI based methods in some load 
monitoring applications was studied. The conventional piezoelectric elements and scanning laser vibrometer were used in the course of the experiments. Successful performance of the SuRE method in load monitoring applications in three different scenarios, including the response of the system in the presence of a single load and double loads and its performance in detecting tightness in a nut and bolt system in aluminum plate, was shown.

\subsubsection{Experiment}

In the SuRE method-based structural health monitoring, the range of excitation is typically between 1-250 kHz. The choice of appropriate excitation band highly depends on the characteristic length of damage to be detected. Therefore, the wavelength of excitation has to be smaller than the characteristic length of the damage of interest. However, when it comes to load monitoring, the prior supposition is not applicable anymore since the damage is associated with a change in the value of the force and there is no characteristic length to be measured. In this study, first, a very broad excitation range is used to acquire the general response of the system. Then, by analyzing the response, the frequency range containing the first 50 peaks is chosen for further examination. This is because this area shows a greater dynamic interaction within the excitation range. It has to be noted that having a higher response amplitude does not necessarily mean that the area is going to be sensitive to changes in loading. Therefore, this area has to be narrowed down to a shorter range of frequency where it shows monotonic behavior to any increase or decrease in applied load which could be done using trial-and-error method. 
In this study, the response of the plate to a sweep sine wave in excitation range of 1-400 $\mathrm{kHz}$ is obtained and shown in Figure 6. The sampling frequency was chosen to be 5 times larger than the highest excitation frequency.
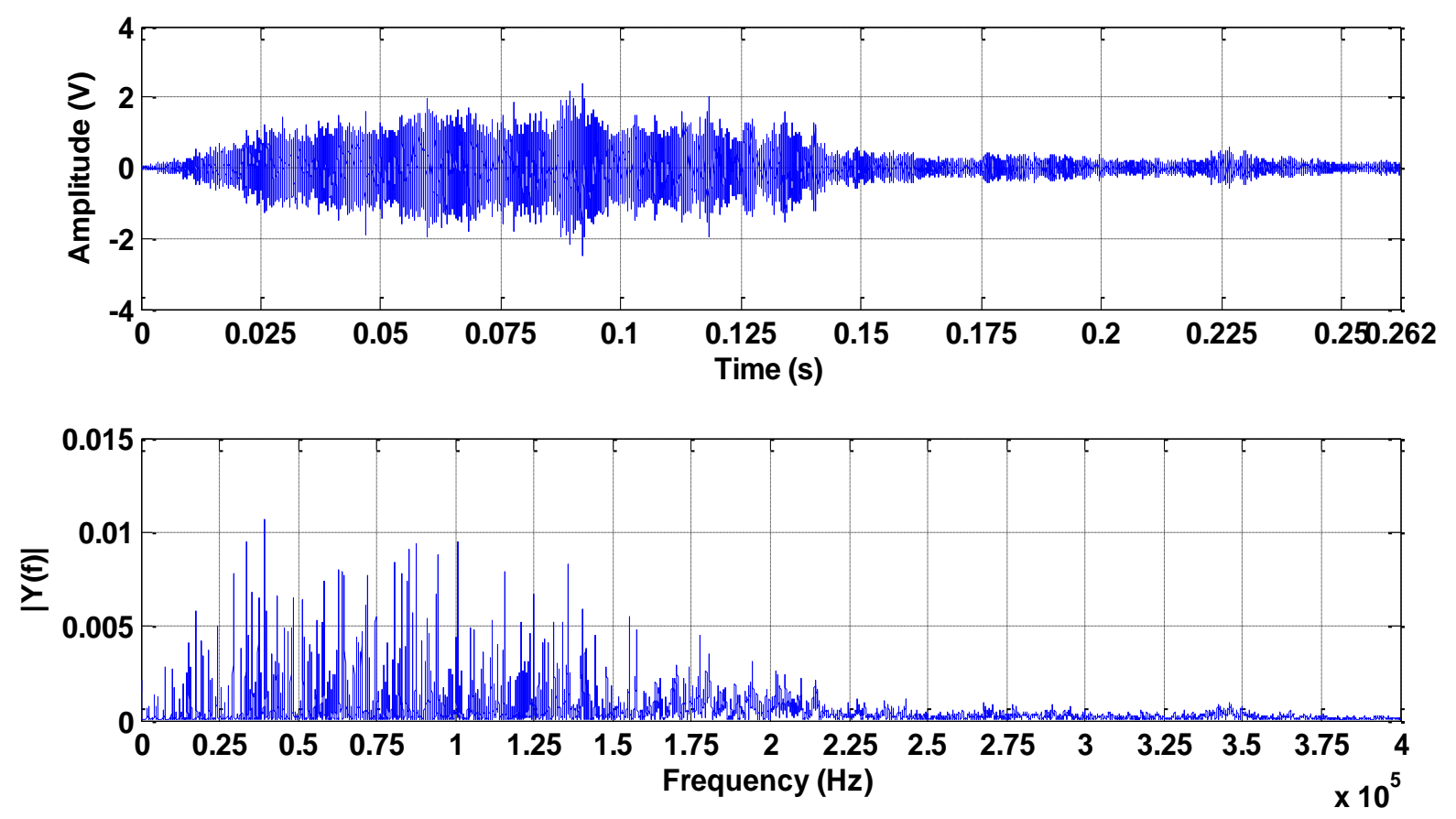

Figure 6 FFT response of plate for $1-400 \mathrm{kHz}$

From Figure 6, it can be seen that the range of 1-200 kHz has a higher dynamic interaction within the excitation range and it is chosen for further examination. Then, this area is narrowed down to $1-50 \mathrm{kHz}$ by the trial-and-error method. The results of that are shown in the following sections.

\subsubsection{Load monitoring}

In this study, weights and bolts were used in order to study the effectiveness of load monitoring using the SuRE method. Non-contact and contact methods of data acquisition using laser vibrometer and piezoelectric sensors were applied. In the course of the 
experiments, different combinations of loading positions and types were examined. A schematic of the experimental setup is shown in Figures 7, 8.

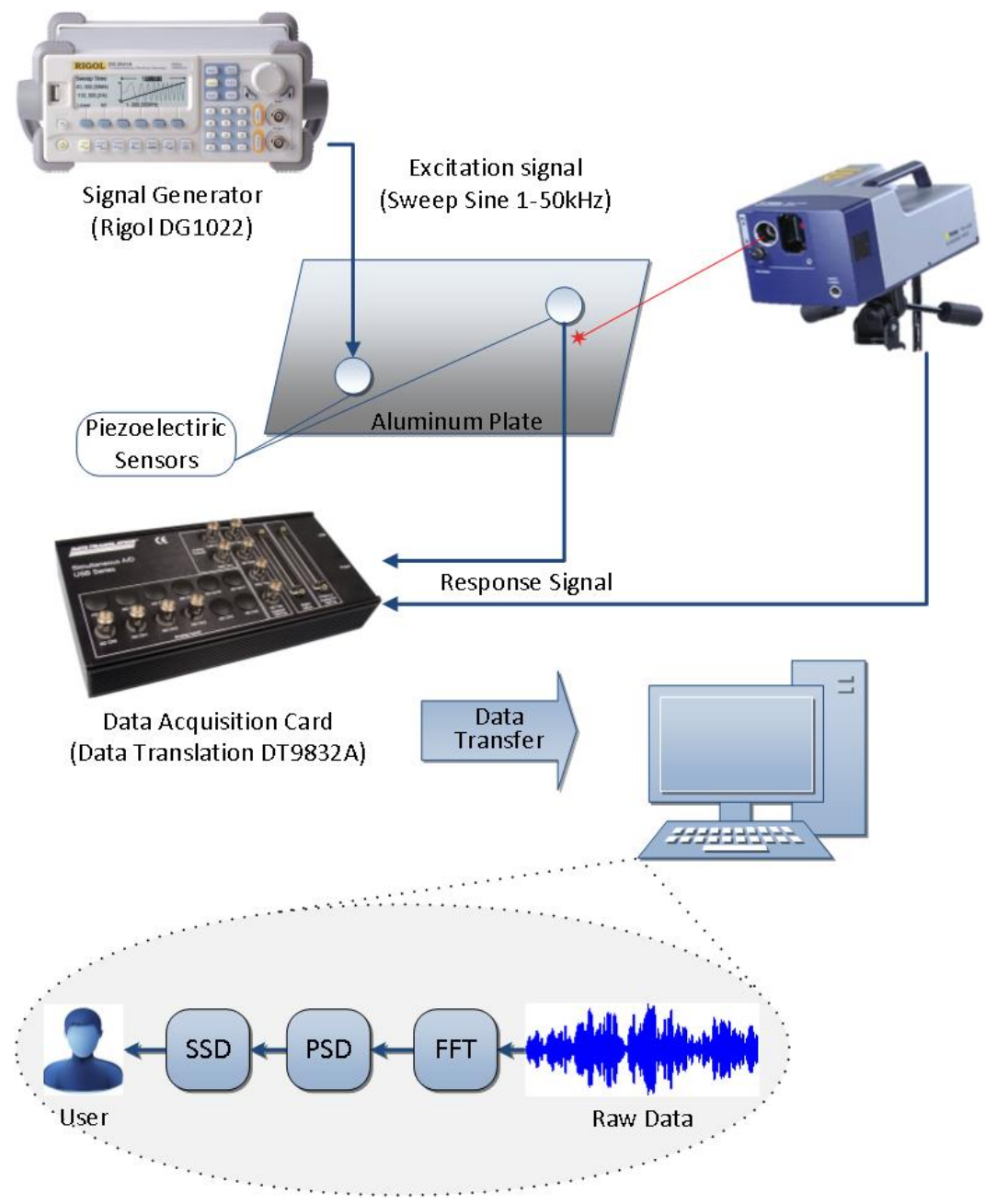

Figure 7 Experiment schematic 


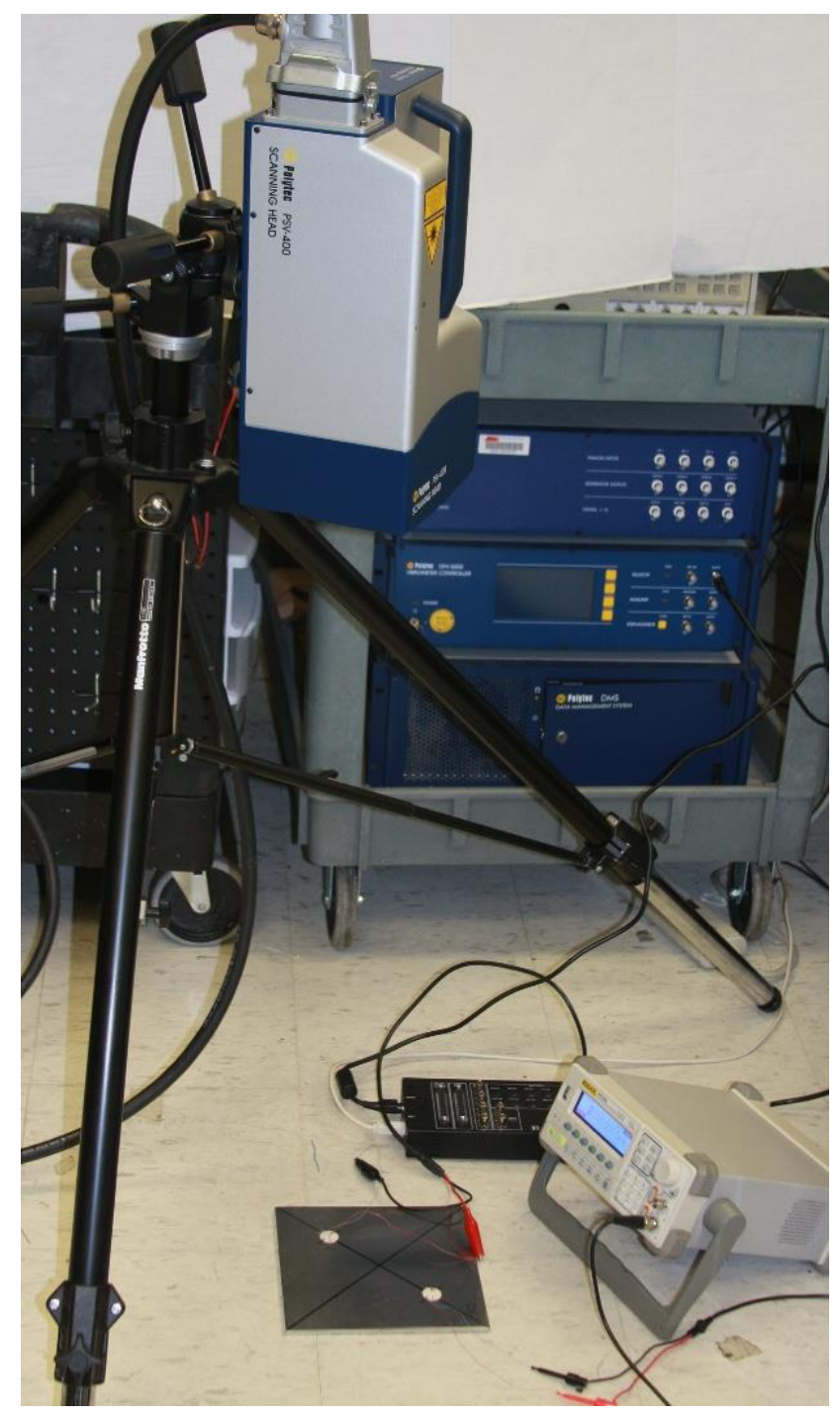

Figure 8 Experiment schematic

\subsubsection{Results and discussion}

\subsubsection{Application of a single load at the center of a plate}

In this test, applied force was increased from F1 to F3 using 1 lbs. steps. The schematic and experimental setup is shown in Figure 9. The collected results from piezoelectric sensors and the laser vibrometer are shown in Figures 10, 11, 12 and 13. 

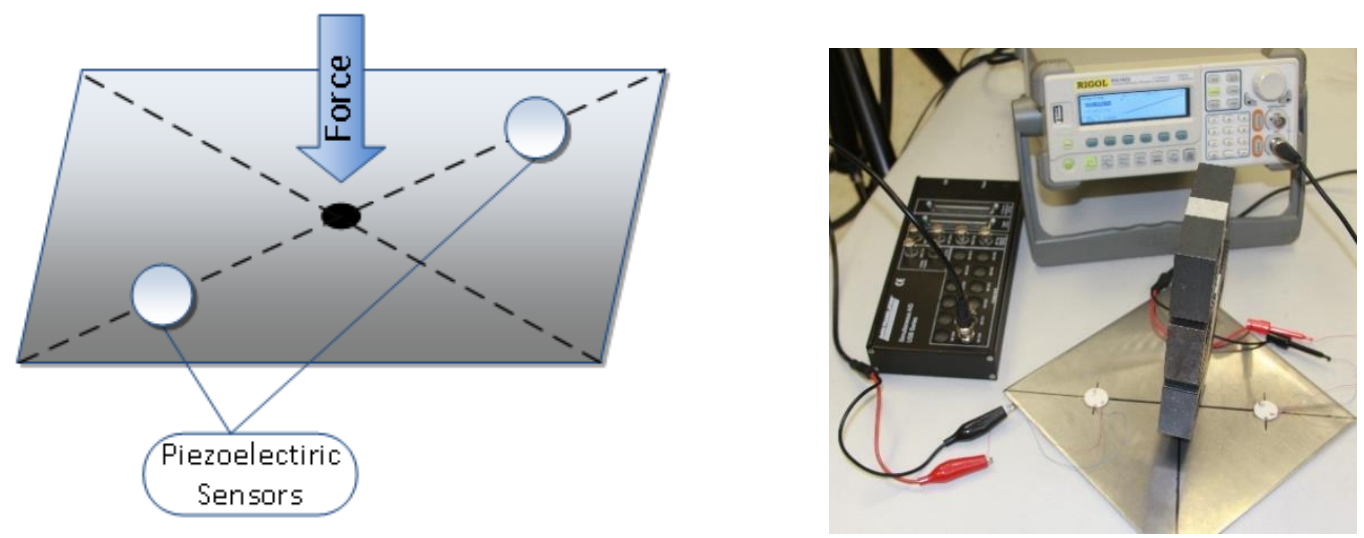

Figure 9 Experimental setup for single load into the center of the plate

Using PZT for data collection, PSD of the frequency response of the plate for baseline (no load) and each of the applied loads was acquired. Results are plotted in Figures 10, 11 and it can be seen as the load is increased, the amplitude of the PSD monotonically decreases. The peak at $30 \mathrm{kHz}$ is magnified to demonstrate the dominant trend that could be seen in the majority of other peaks of the spectrum.

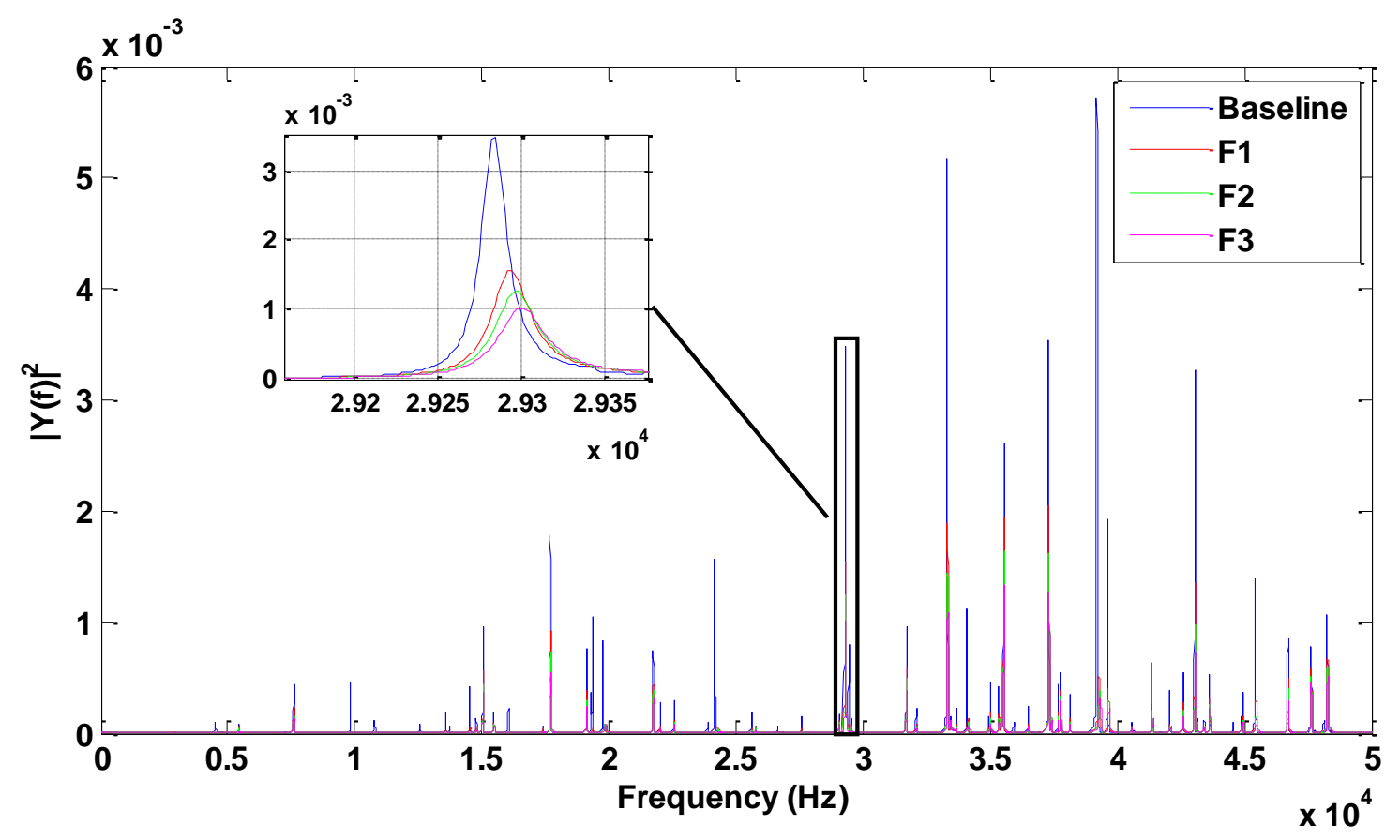

Figure 10 Comparing FFT of different applying forces using PZT for data collection 


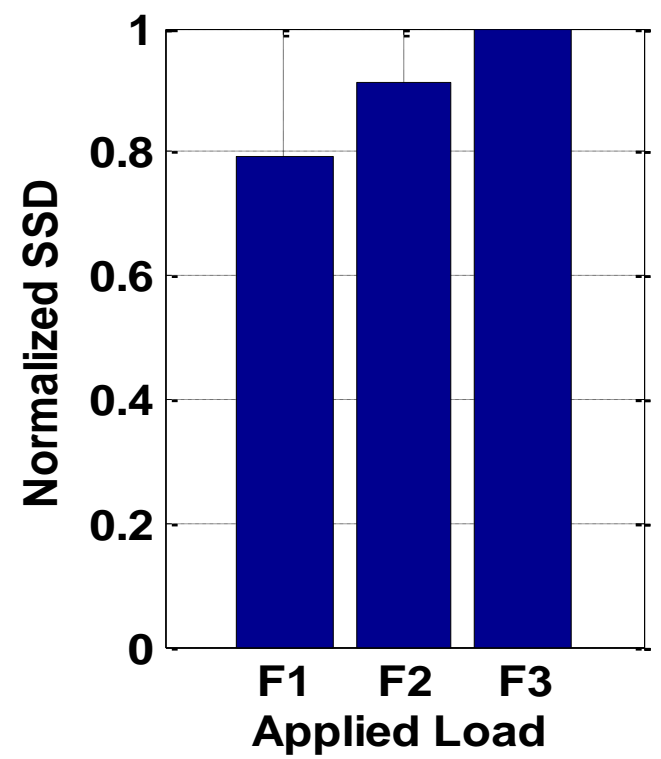

Figure 11 comparing SSD of different applying forces using PZT for data collection

In a non-contact approach, a laser vibrometer was utilized for collecting the response. After calculating PSD of responses for each step of loading, the same behavior was observed, as can be seen in Figure 12, 13.

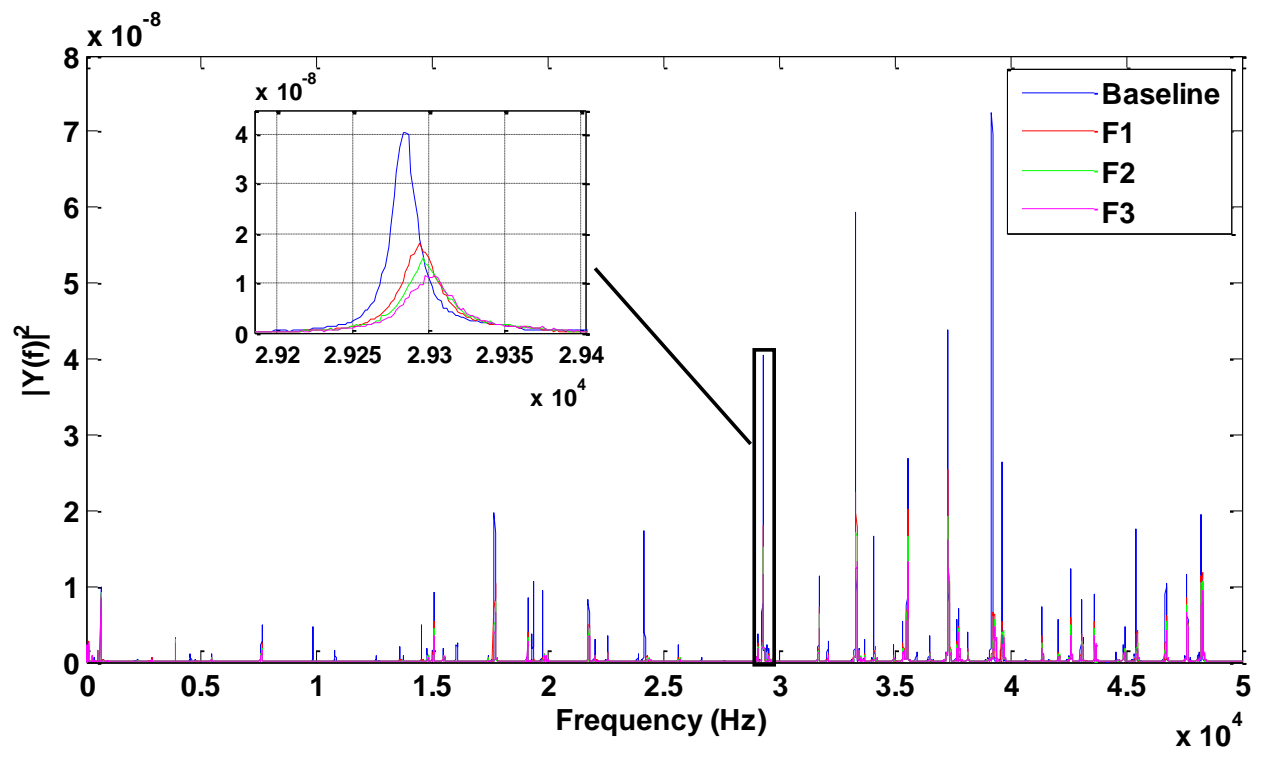

Figure 12 comparing FFT of different applying forces using laser vibrometer for data collection 


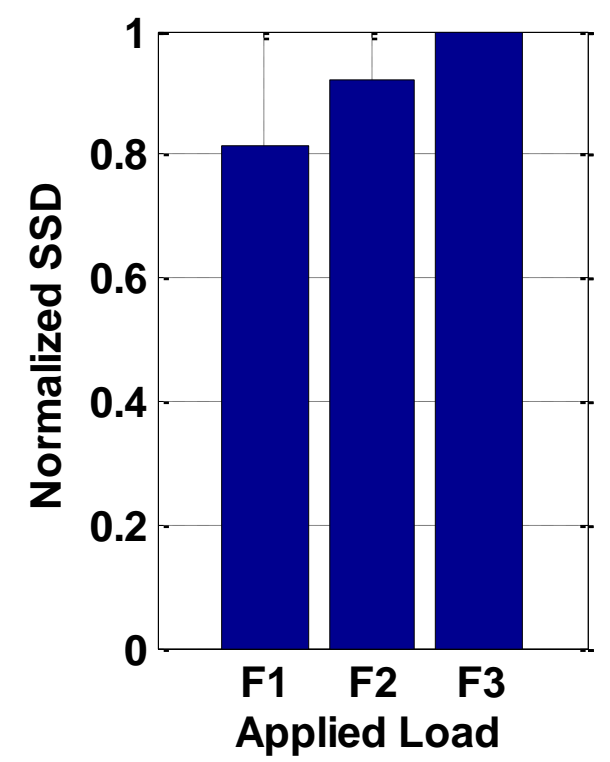

Figure 13 comparing SSD of different applying forces using laser vibrometer for data collection

\subsubsection{Application of two sets of loads}

To show the capability of the SuRE method in monitoring multiple loads, two loads were simultaneously applied in different locations of the aluminum plate. Applied loads were increased from $\mathrm{F} 1$ to $\mathrm{F} 3$ using $0.5 \mathrm{lbs}$. steps in each point. The schematic of the experimental setup is shown in Figure 14. The collected results from piezoelectric sensors and the laser vibrometer are shown in Figures 15 and 16, respectively. 

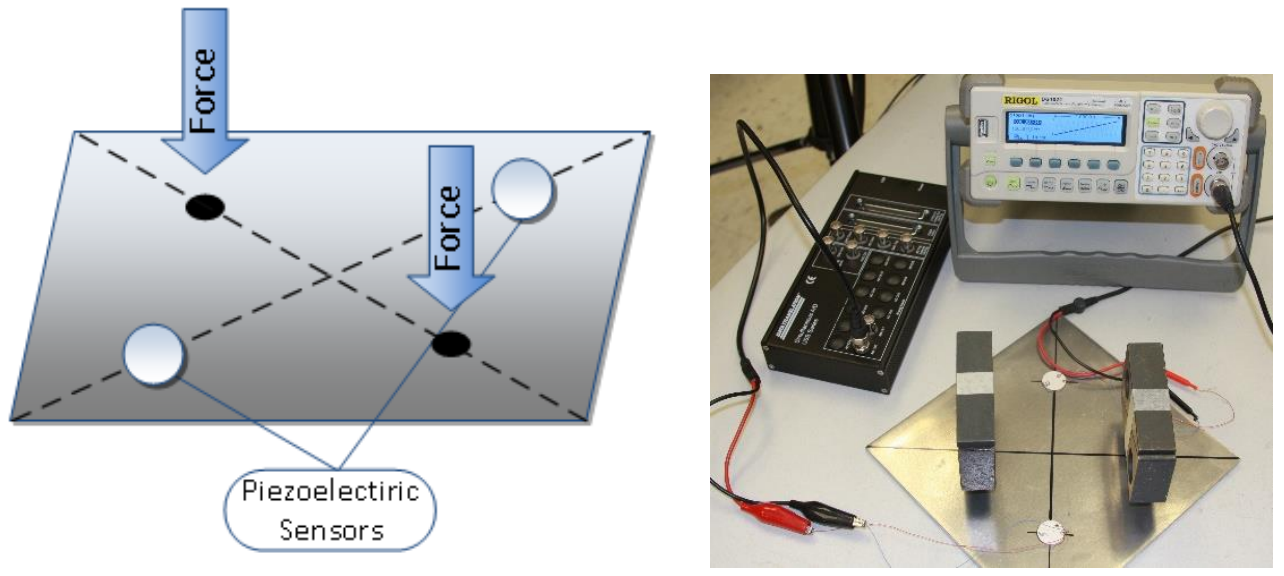

Figure 14 Experimental setup two loads

Similar to the application of a single load, a PZT was used for excitation and a second piezo recorded the response of the plate for baseline and each of the steps after applying loads. PSD of recorded signals is represented in Figure 15, 16.

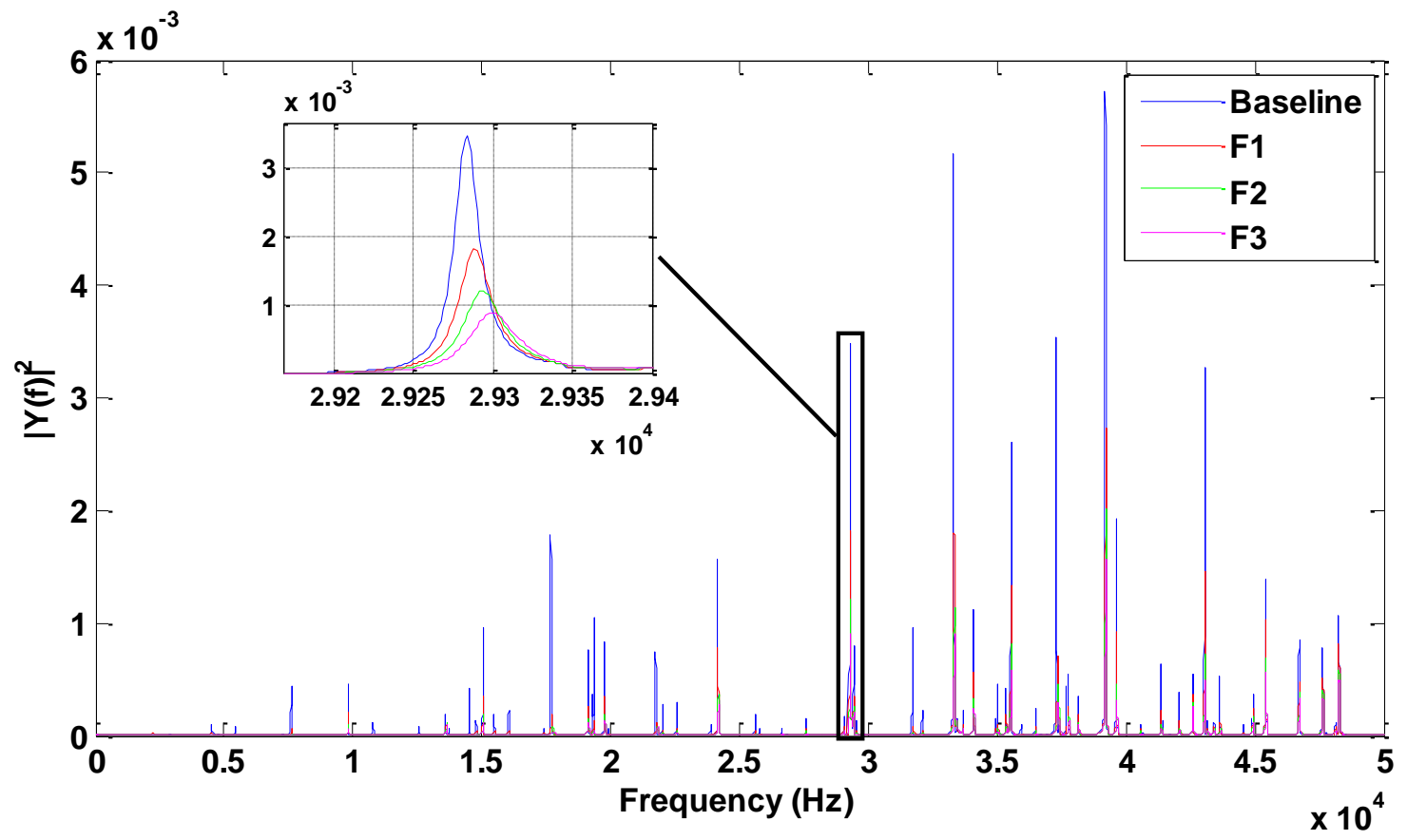

Figure 15 comparing FFT of different applying forces using PZT for data collection 


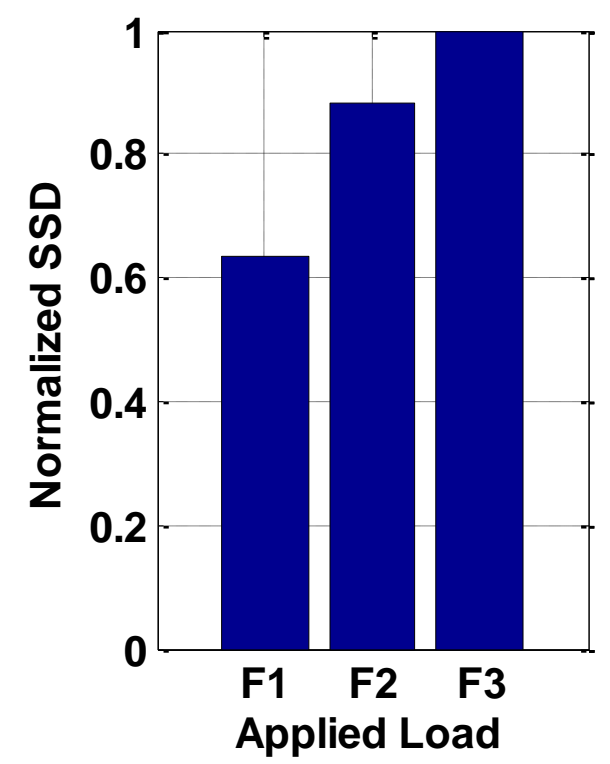

Figure 16 comparing SSD of different applying forces using PZT for data collection In order to examine the validity of the SuRE method for monitoring the presence of multiple loads with the aid of non- contact sensors, a laser vibrometer was utilized for collecting the response, as shown in Figure 17, 18.

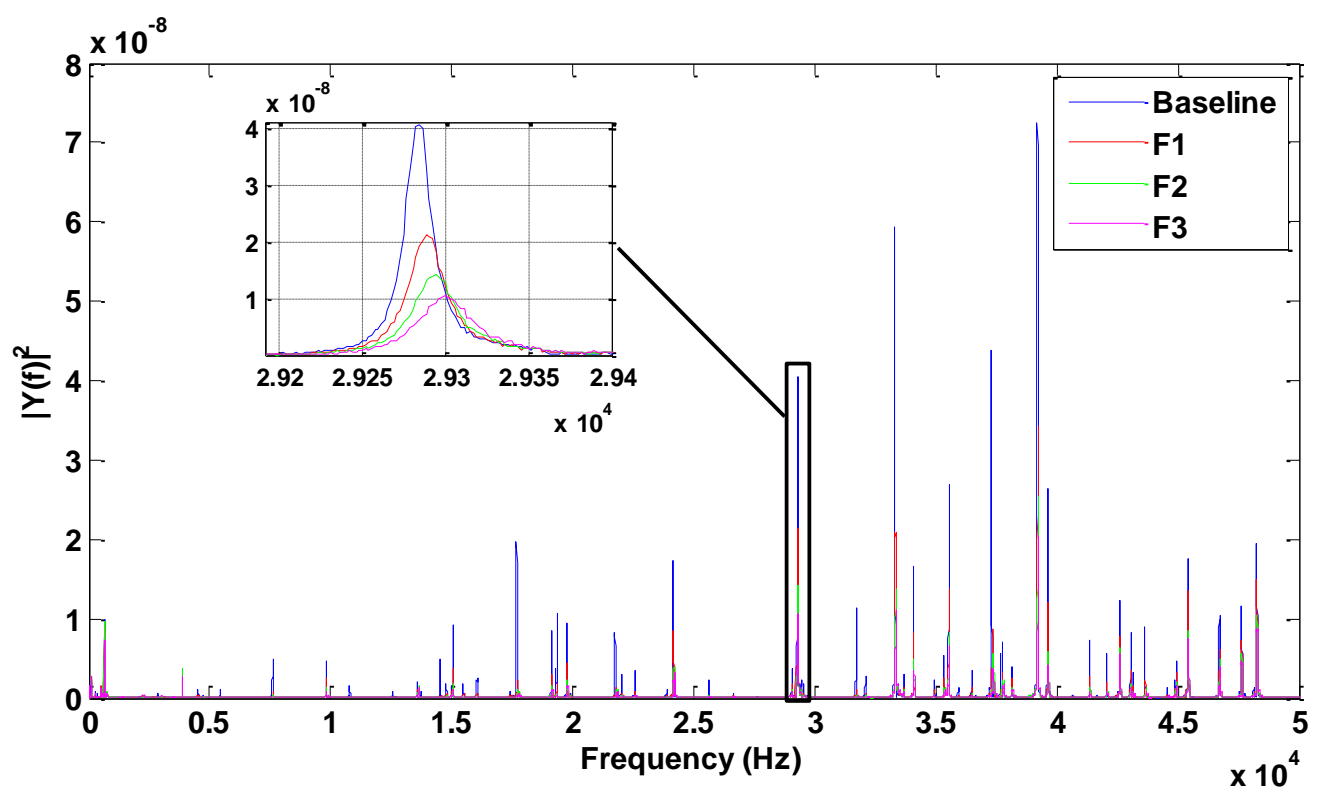

Figure 17 comparing FFT of different applying forces using laser vibrometer for data collection 


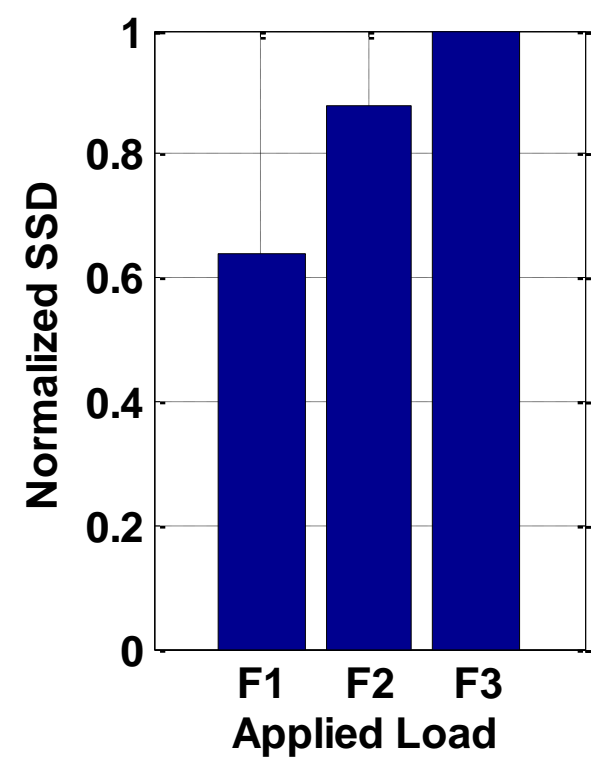

Figure 18 Comparing SSD of different applying forces using laser vibrometer for data collection

It can be seen that the aluminum plate shows similar behavior when it is subjected to multiple loads. That is, amplitudes of the PSD of response signals decrease as the applied force is increased from F1 to F3.

\subsubsection{Application of the SuRE method in finding a loose bolt}

In another study, the SuRE method was applied to monitor the state of tightness in mechanical fasteners. A system of a nut and bolt was utilized to vary the tightness of a bolting system in 4 steps using predetermined torques from $2-5 \mathrm{Nm}$ in $1 \mathrm{Nm}$ steps, as can be seen in Figure 19. 


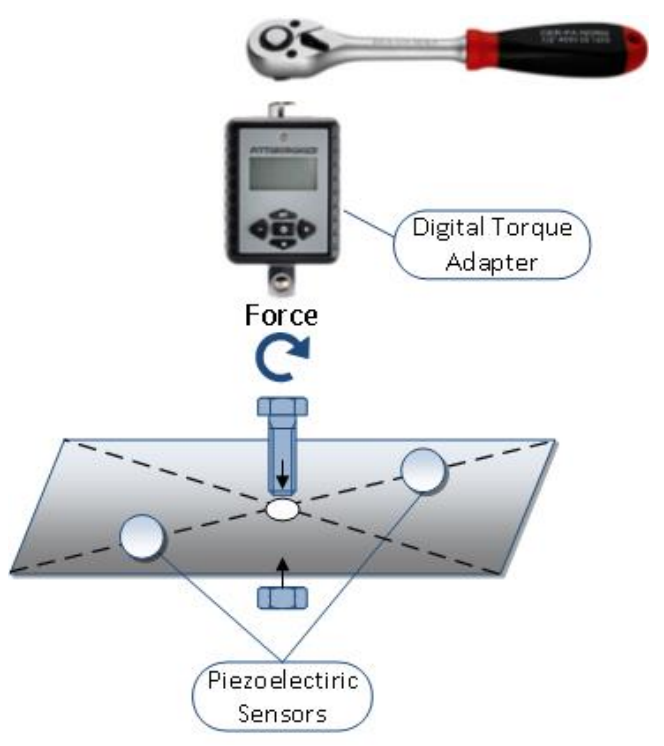

Figure 19 Schematic of bolt tightness setup

A PZT was used for excitation and another piezo and the laser vibrometer recorded the response of the plate for baseline and after increasing torque in each of the 4 steps; the PSD of recorded signals for the PZT and the laser vibrometer are shown in Figures 20, 21, 22 and 23, respectively. It is observed that the system shows a monotonic behavior regarding the change in applied torque. That is, by increasing the torque, amplitude of the PSD monotonically increases. This indicates the potential of application of the SuRE method for finding loose bolts in more complicated systems and critical applications. 


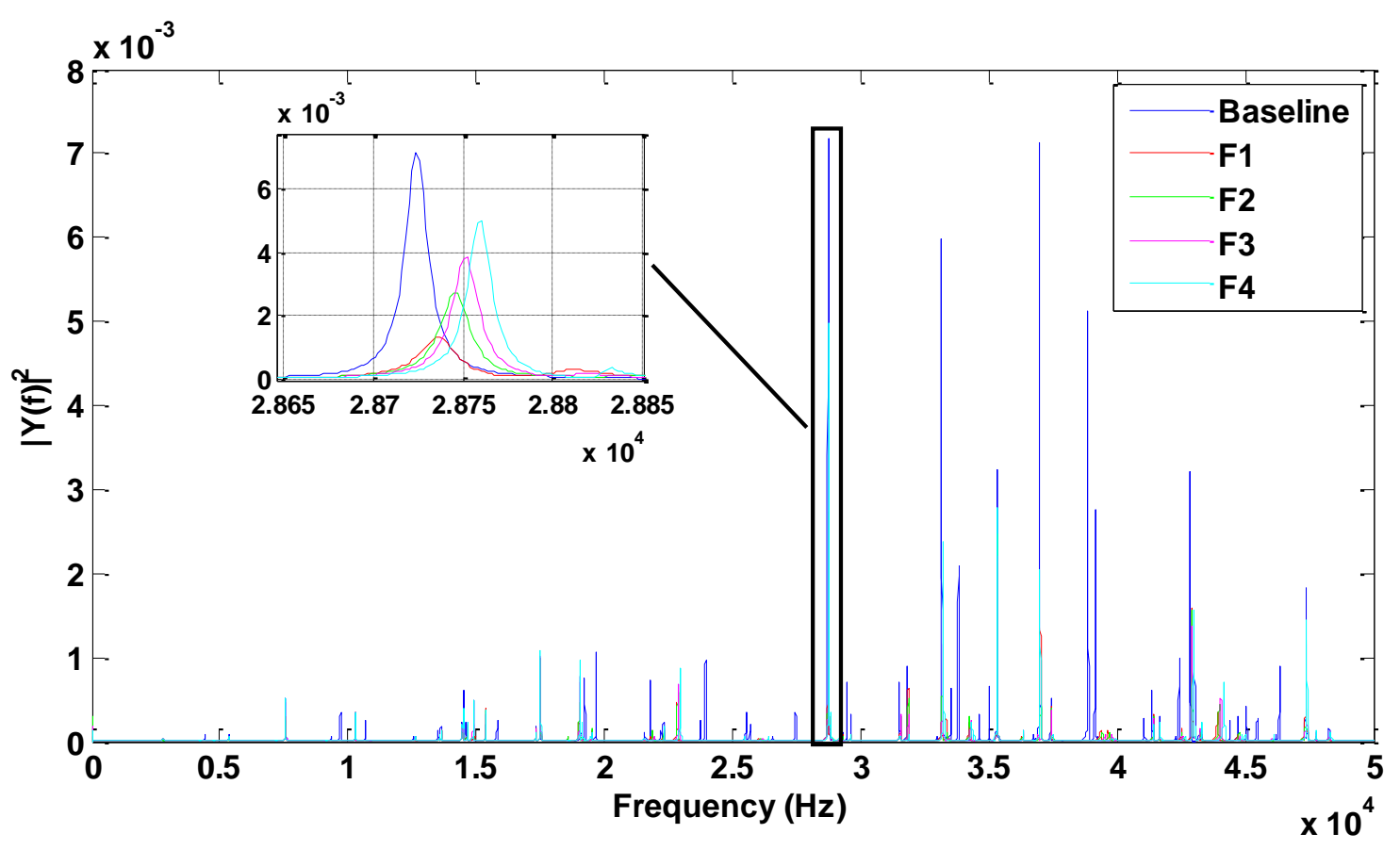

Figure 20 comparing FFT of different applying forces using PZT for data collection

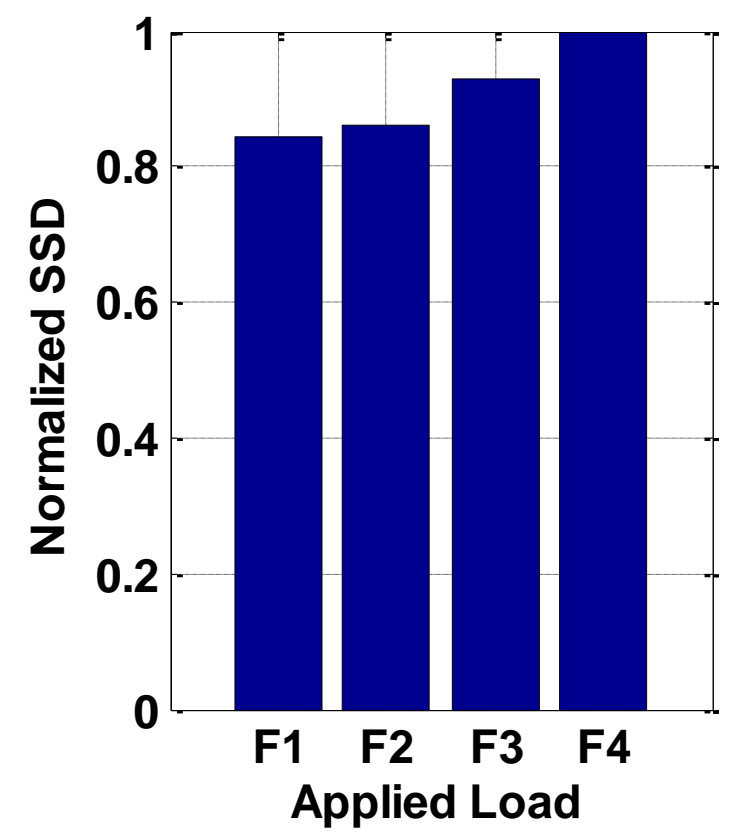

Figure 21 comparing SSD of different applying forces using PZT for data collection 


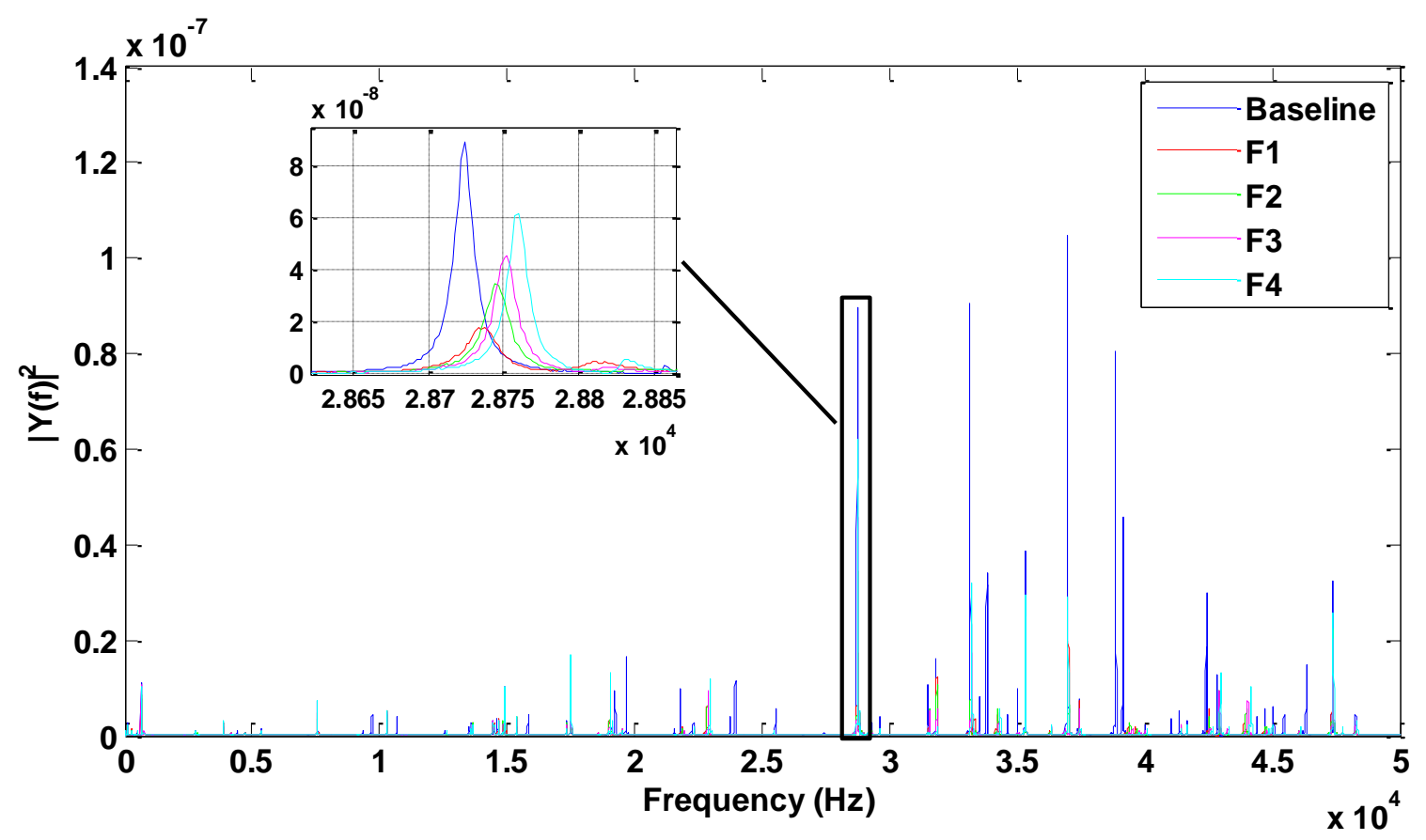

Figure 22 Comparing FFT of different applying forces using laser vibrometer for data collection

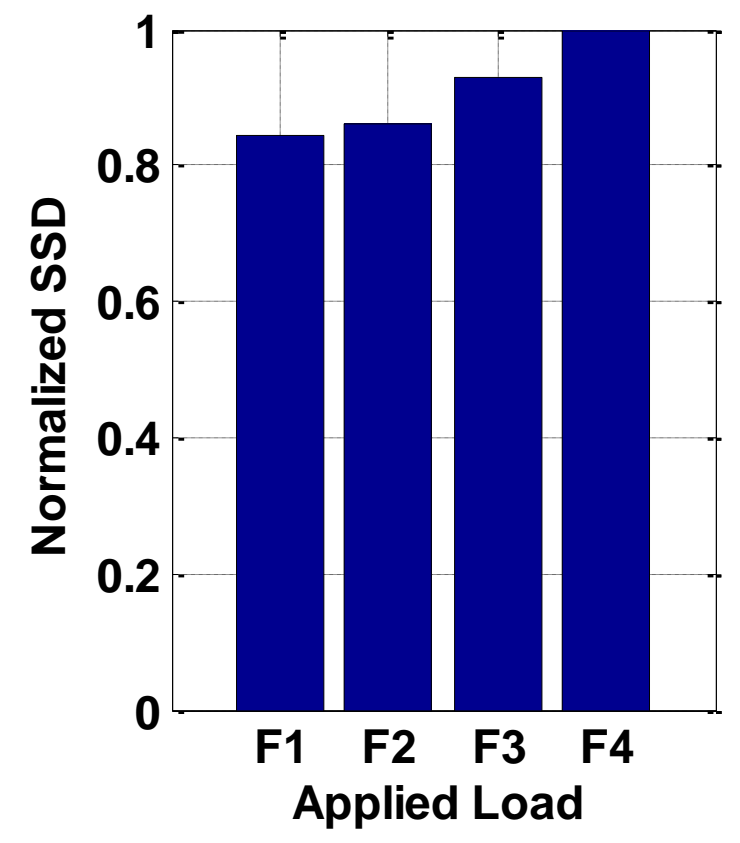

Figure 23 Comparing SSD of different applying forces using laser vibrometer for data collection 


\subsubsection{Conclusions}

The purpose of this study was to validate the possibility of using the SuRE method for load monitoring applications. A surface bonded piezoelectric disk was used as an exciter to excite surface waves on an aluminum plate. The laser scanning vibrometer and PZT transducer were used, respectively, as non-contact and contact receivers to measure response signals at scanning points. In the load monitoring approach, the PSD of responses was used for calculation of SSD. In the course of the experiments, in both contact and noncontact sensing, after applying different variation of loads, it was observed that SuRE method shows a monotonic behavior to changes in applied load; that is, as the applied load is increased, the SSD values will also be increased and reasonable sensitivity to change of load could be observed. It can be seen that the calculated PSD of response signals through contact and non-contact sensors are conspicuously similar in the pattern except for the fact that the amplitude of the laser response is much smaller than the amplitude of PZT response. That implies massive networks of surface bonded sensors that are normal in impedance-based monitoring of large structures could be avoided by using non-contact sensors. As a result, the SuRE method seems to be a promising approach in the development of non-contact load monitoring systems especially for applications that bonded sensors will interfere with their normal performance. 


\subsection{Characterization of milling operation for identical aluminum plates}

Surface response to excitation (SuRE) method is a low-cost alternative approach to the electromechanical impedance (EMI) method and it was developed for structural health monitoring (SHM) demands. The SuRE method uses one piezoelectric transducer to excite the surface of a structure with a sweep sine wave, and one or more piezoelectric sensors or scanning laser vibrometer for monitoring the dynamic response of the system. Once a change with the potential to lead to a structural failure is introduced to a structure, some mechanical properties are altered; therefore, the original frequency spectrum is changed. In this study, the ability of the SuRE method to verify the safety and uniformity of identical structures after each milling operation, was investigated. Therefore, the SuRE method was used to characterize different size milling operations on identical aluminum plates. In order to determine the efficiency and effectiveness of the SuRE method, change of milling operation size in two different dimensions were investigated. By increasing the size of milling in three steps and obtaining Fast Fourier Transformation (FFT) and then calculating of the sums of the squares of the differences (SSD) of the spectrums, the change of the spectrums was evaluated. Also, in order to get rid of the need for baseline data in comparison of structures with different conditions, some advanced techniques such as Geometric mean, Harmonic mean and 5th momentum were introduced. In this experimental setup, one piezoelectric transducer as an exciter and a scanning laser vibrometer as a sensor were used.

\subsubsection{Introduction}

It is vital for structures to safely work during their service life. However, defects can precipitate a breakdown period for the structures and reduce their effectiveness. By 
monitoring and mending these sorts of damages in structure, the functional age of the structure can be improved. Over last few years, establishing a testing method to monitor the uniformity of structures in production lines has been considered as a primary issue. In order to detect faults in production lines, a number of non-destructive methods have been presented which try to improve accuracy and reliability in health monitoring of structures and also minimize the expense of the process [63-65].

It seems that in terms of experimental errors, frequency responses of structures would be more robust than their mode shapes and also when it comes to measurement they require less effort for analyzing data.

Active structural health monitoring methods are the most powerful SHM methods for estimation of the location, severity, and type of defects. These methods excite the system using appropriate excitation signals and monitor the response of the system. Among active SHM methods, Electromechanical Impedance (EMI) method examines the health of the structure by measuring the mechanical impedance of the structure using piezoelectric transducers although impedance analyzers are extremely costly and it has been tried to be replaced by cheaper alternatives such as cheaper electronic circuits. Other variations of this method such as the SuRE method have been recently introduced which eliminate the need for an impedance analyzer [66-73].

Obtaining relevant information and recognizing patterns from sensor data in structural health monitoring and load monitoring of mechanical structures have always been crucial challenges for researchers. Most of the existing methods compare the characteristics of the data taken when the system was in perfect condition with the new data [74-89]. To remove 
the need for baseline measurement, it would be better to use other features which can define a saturation point for quality assurance.

In this study, the ability of the SuRE method to verify the safety and uniformity of identical structures after each mechanical operation was shown. Therefore, the SuRE method was used to characterize different size milling operations on identical aluminum plates. Also, in order to get rid of the need for baseline measurement, some advanced techniques such as Geometric mean, Harmonic mean and 5th momentum were introduced. These methods don't need to collect the data in the perfect conditions and using it as a reference (baseline) for inspection later.

\subsubsection{Method}

In this study, in order to inspect the uniformity of identical structures after each mechanical operation, surface response to excitation (SuRE) method has been utilized. Also, this method has been modified by using signal processing and data analysis approaches to adapt this method for a different variety of applications. In the SuRE method, the surface of the structure is excited by a sweep sine wave over a certain frequency range using a piezoelectric transducer and a laser vibrometer or another piezoelectric transducer are used on the other side of the structure to sense the dynamic response of the system. The frequency spectrum of the signal is then obtained by using Fast Fourier Transform (FFT). The frequency response of the structure will be consistent as long as there are no changes in the system and whenever condition change, in terms of applying load or existence of a defect, the frequency spectrum changes can be observed. 
In order to quantify these changes, the squared difference of frequency response after the changes with respect to the frequency response of pristine is considered:

$$
S D_{m \times 1}=\left\|B_{m \times 1}-R_{m \times 1}\right\|^{2}
$$

Here, $B$ and $R$ are the baseline and response data after changes matrices and also $m$ denoted size of FFT. The sum of the squared differences (SSD) would be calculated from:

$$
S S D=\sum_{i=1}^{m}\left\|B_{m \times 1}-R_{m \times 1}\right\|^{2}
$$

As you can see, in the SSD calculation, the current data is compared with the baseline signal. In order to eliminate the need for baseline in comparison of structures with different conditions, some advanced techniques such as Geometric Mean, Harmonic Mean, and 5th Momentum were also utilized:

$$
\text { Geomean }=\left(\prod_{i=1}^{m} x_{i}\right)^{1 / m}
$$

$$
5^{\text {th }} \text { momentum }=\frac{\sum_{i=1}^{N}\left(x_{i}-\frac{\sum_{i=1}^{N} x_{i}}{N}\right)^{5}}{N-1}
$$

\subsubsection{Experiment setup}

In SuRE method-based structural health monitoring, the range of excitation is typically between 1-250 kHz; the choice of appropriate band highly depends on the characteristic length of damage to be detected and therefore the wavelength of excitation has to be smaller 
than the characteristic length of damage of interest. In this study, first, a very broad excitation range is used to acquire the general response of the system. Then, by analyzing the response, the frequency range containing the first 50 peaks is chosen for further examination. This is due to the fact that this area shows a greater dynamic interaction within the excitation range. It should be noted that having a higher response amplitude does not necessarily mean that the area is going to be sensitive to changes. Therefore, this area has to be narrowed down to a shorter range of frequency where it shows monotonic behavior to any increase or decrease in the size of the damage and this could be done using a trialand-error method. For this study, this area is narrowed down to $1-50 \mathrm{kHz}$ by the trial-anderror method. The results of that are shown in following sections.

In this study, two identical plates were used in order to study the effectiveness of the SuRE method in the characterization of milling operations. A laser vibrometer as a non-contact method of data acquisition was applied. In the course of the experiments, different size of milling operation in two different dimensions of width and length were examined. A schematic of the experimental setup is shown in Figure 24. 


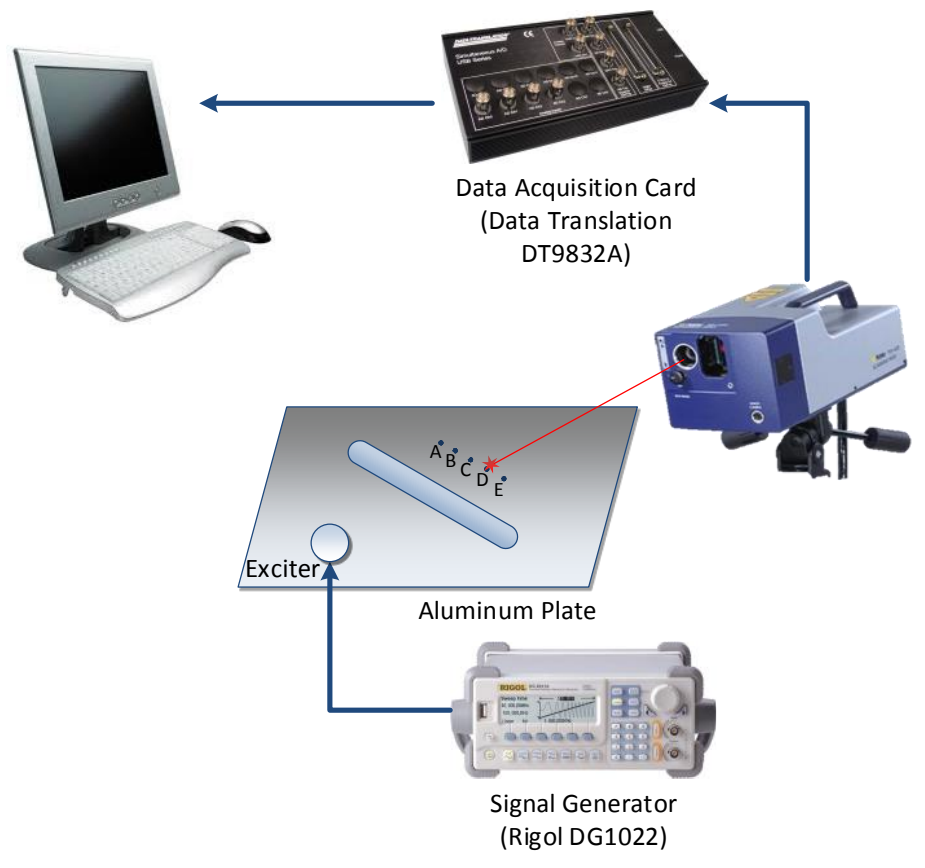

Figure 24 Experimental setup
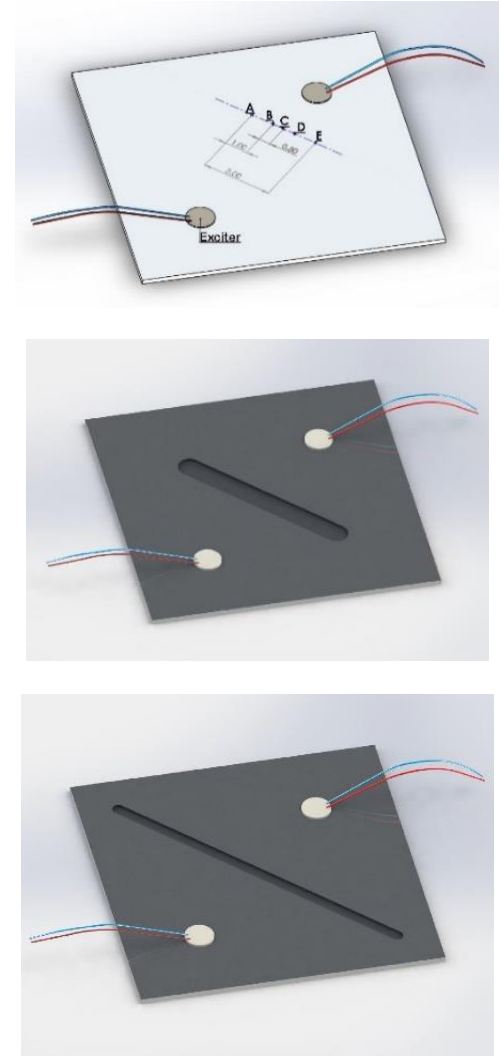

Figure 25. Experimental setup 


\subsubsection{Results and discussion}

\subsubsection{Change in the length of the milling operation}

For identification of the changes in the length of milling operation, two experiments were performed. In this test, the length of the milling operation was increased from 3 to 5 inches. The collected results from the laser vibrometer are shown in Figure 26. Using laser vibrometer for data collection, FFT of the frequency response of the plate for baseline (no damage) and each of the milling size was acquired. SSD results are plotted in Figure 26 and it can be seen as the length of the milling is increased, SSD value monotonically increases.

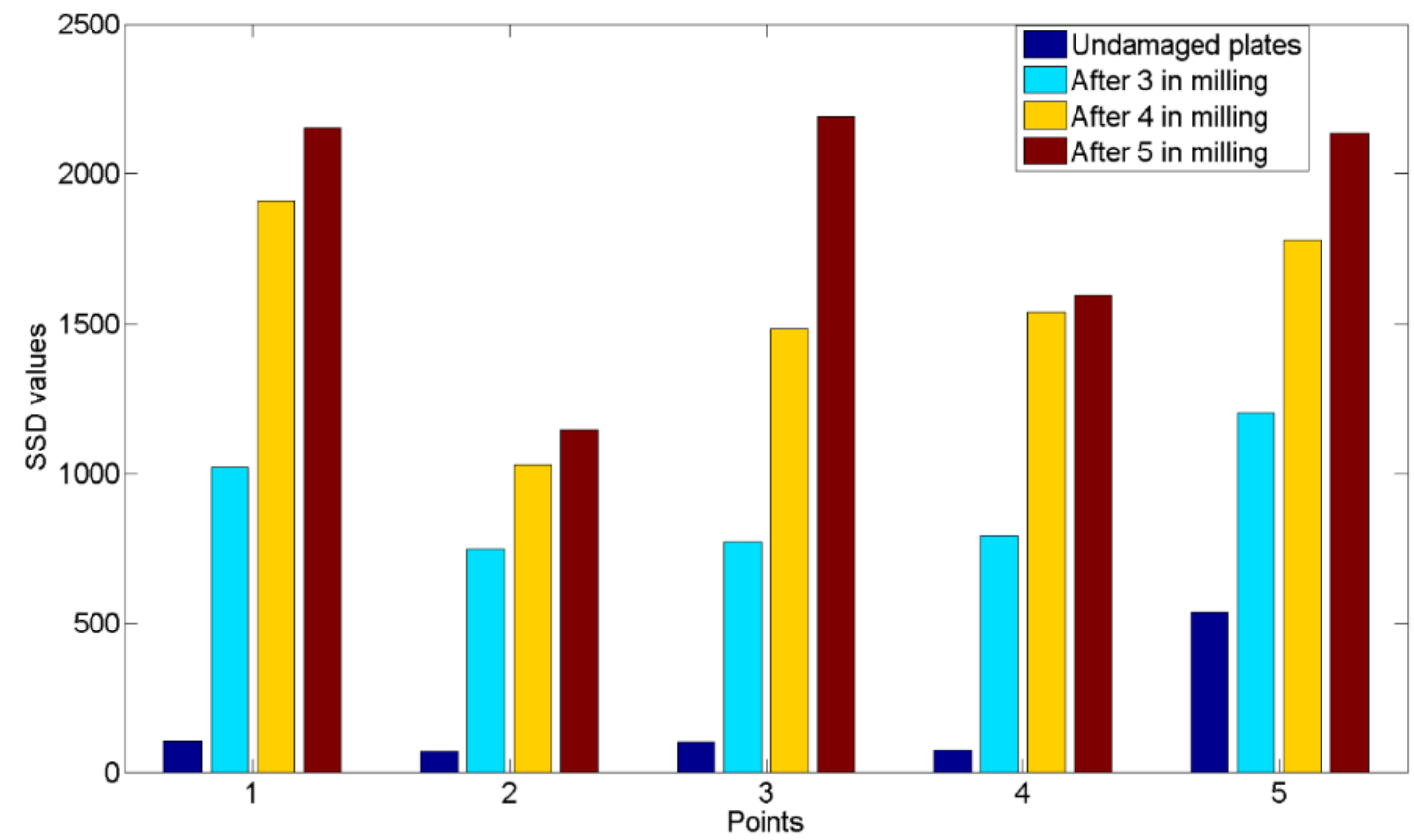

Figure 26. SSD result for change in the length of the milling operation

In order to get rid of the need for baseline data, this time instead of SSD, geometric mean was used. It can be seen in Figure 27, as the length of the milling is increased, geometric 
mean decreases. Although there is a correspondence between the result of the geomean and the SSD approach, it is obvious that SSD has better accuracy. However, geomean can be considered a promising approach in the cases that baseline data is not available.

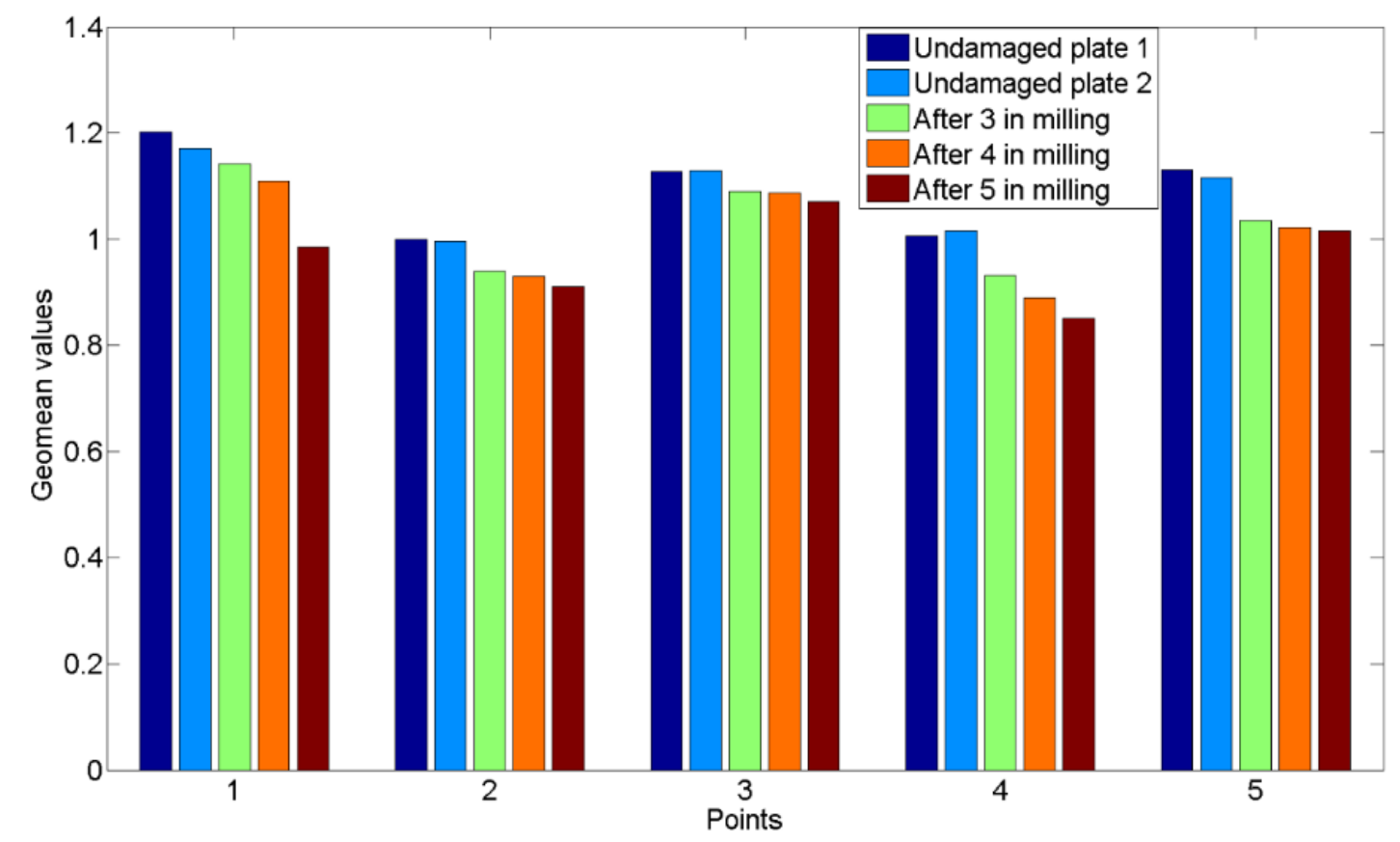

Figure 27. Geometric mean result for change in the length of the milling operation

\subsubsection{Change in the width of the milling operation}

In another experiment, the SuRE method was applied to detect the change in the width of the milling operation. The width of milling operation was increased in 4 steps from 0.3 to 1 inch. The collected results from the laser vibrometer, FFT of the frequency response of the plate for baseline (no damage) and each of the milling size was acquired. It can be seen in Figure 28, as the width of the milling is increased, SSD value monotonically increases. 


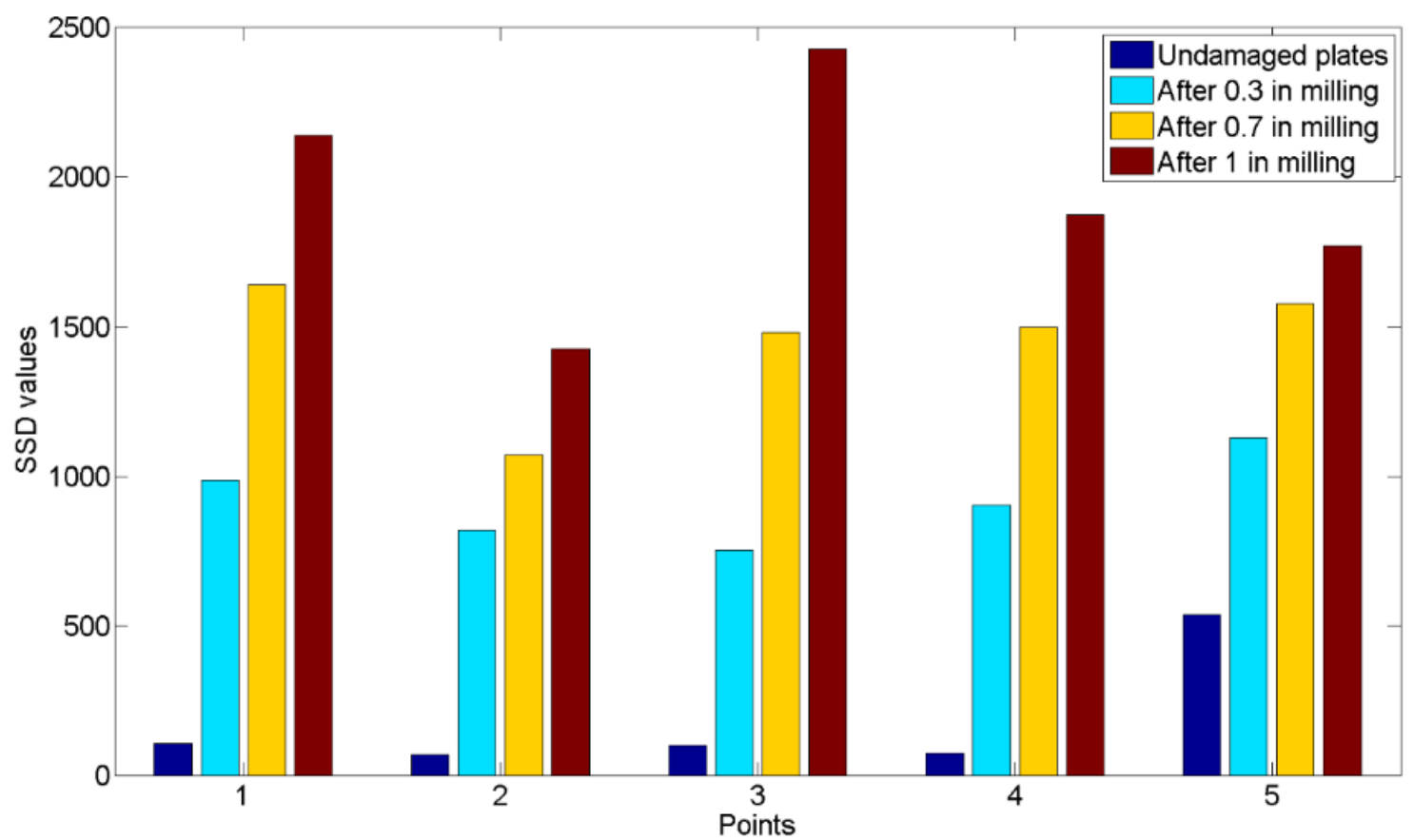

Figure 28. SSD result for change in the width of the milling operation

In order to eliminate the need for baseline data, the harmonic mean was also utilized. As shown in Figure 29, there is a similar pattern for both the SSD and the harmonic mean. By calculating the harmonic mean of responses for different widths of milling, it can be seen that as the width of the milling is increased, the harmonic mean also increases. The harmonic mean may not have the accuracy of SSD approach but in some applications that there is no access to baseline data, it can be extremely useful. 


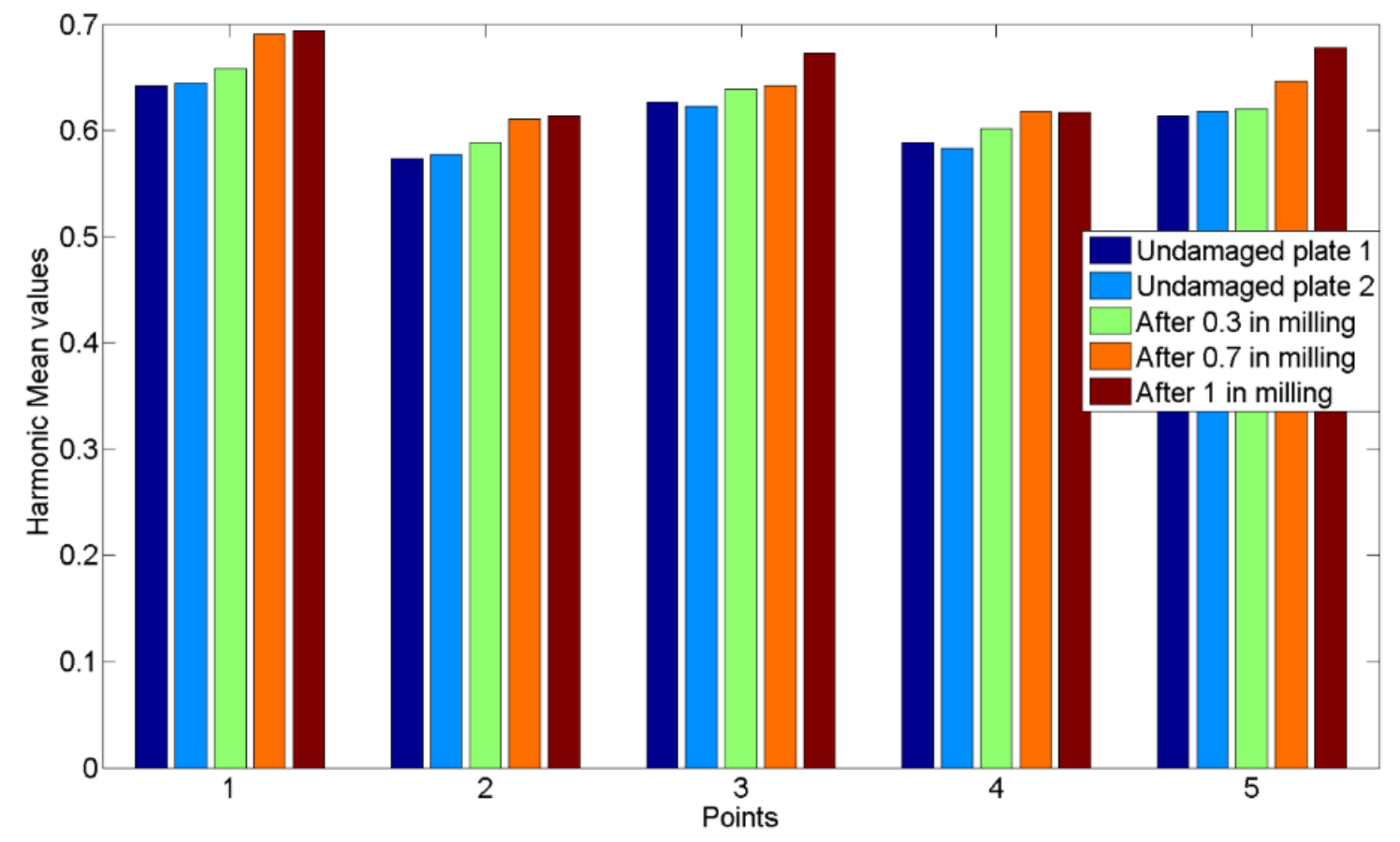

Figure 29. Harmonic mean result for change in the width of the milling operation

Finally, other options available for analyzing the data were investigated. The 5th momentum was one of the most reliable functions for single point analysis. Surprisingly, the 5th momentum showed potential for observing changes in both dimensions. As can be seen in Figure 30, the 5th momentum gives a sharp result in the central point for the changes in the length of the milling operation. By looking at Figure 31, the same word can be applied to 5th momentum when it comes to in the width of the milling operation. Using just the central point for receiving the response signal, the 5th momentum value shows that by increasing the width or length of milling operation, the 5th momentum value increased rapidly. 


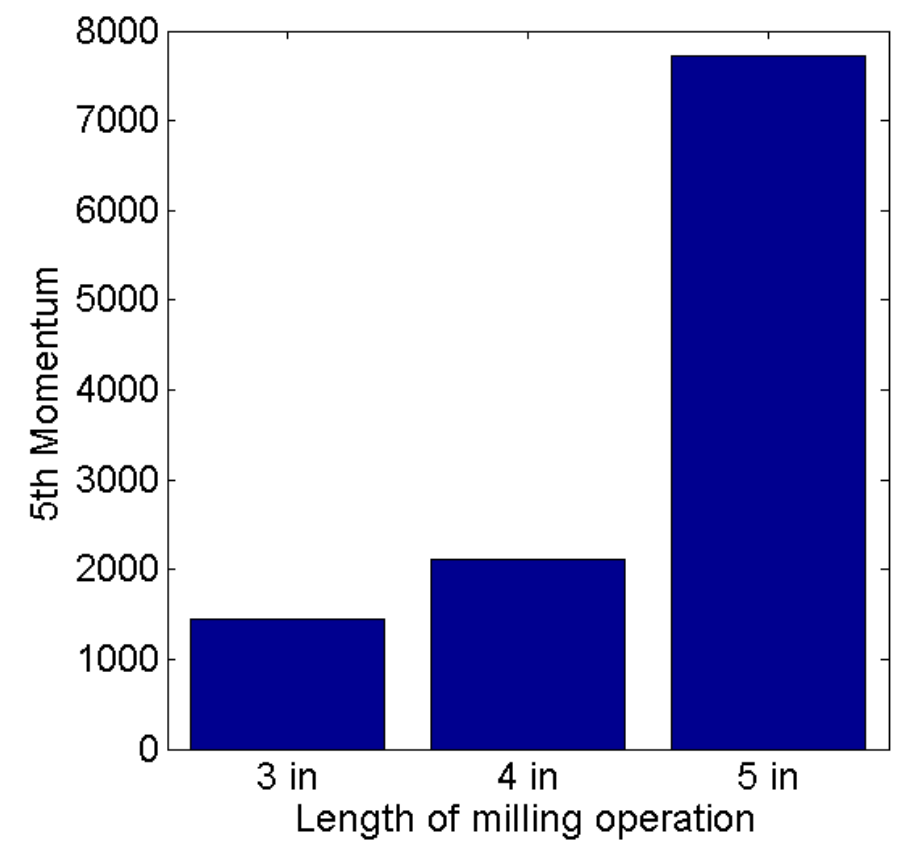

Figure 30. 5th Momentum result for change in the length of milling operation in central point

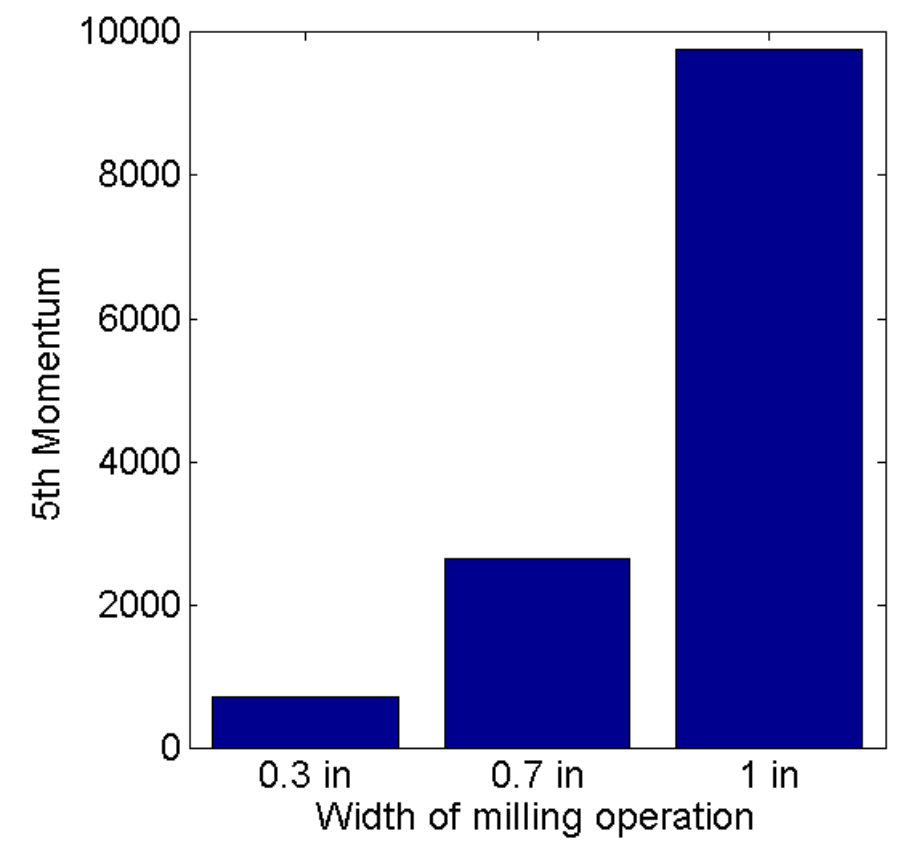

Figure 31 5th Momentum result for change in the width of milling operation in central point 
Taking into account the objective of this study, in addition to the mentioned approaches, several different approaches were tested for better comprehension of the different extraction features methods and to understand which ones are more accurate. The following shows results for a few methods which were investigated using five-point sensors for the collection of the data:

Root Mean Square (RMS): The RMS is always the same as or just a little bit larger than the average of the unsigned values.

$$
R M S=\sqrt{\frac{\sum_{n=1}^{N}(x(n))^{2}}{N}}
$$

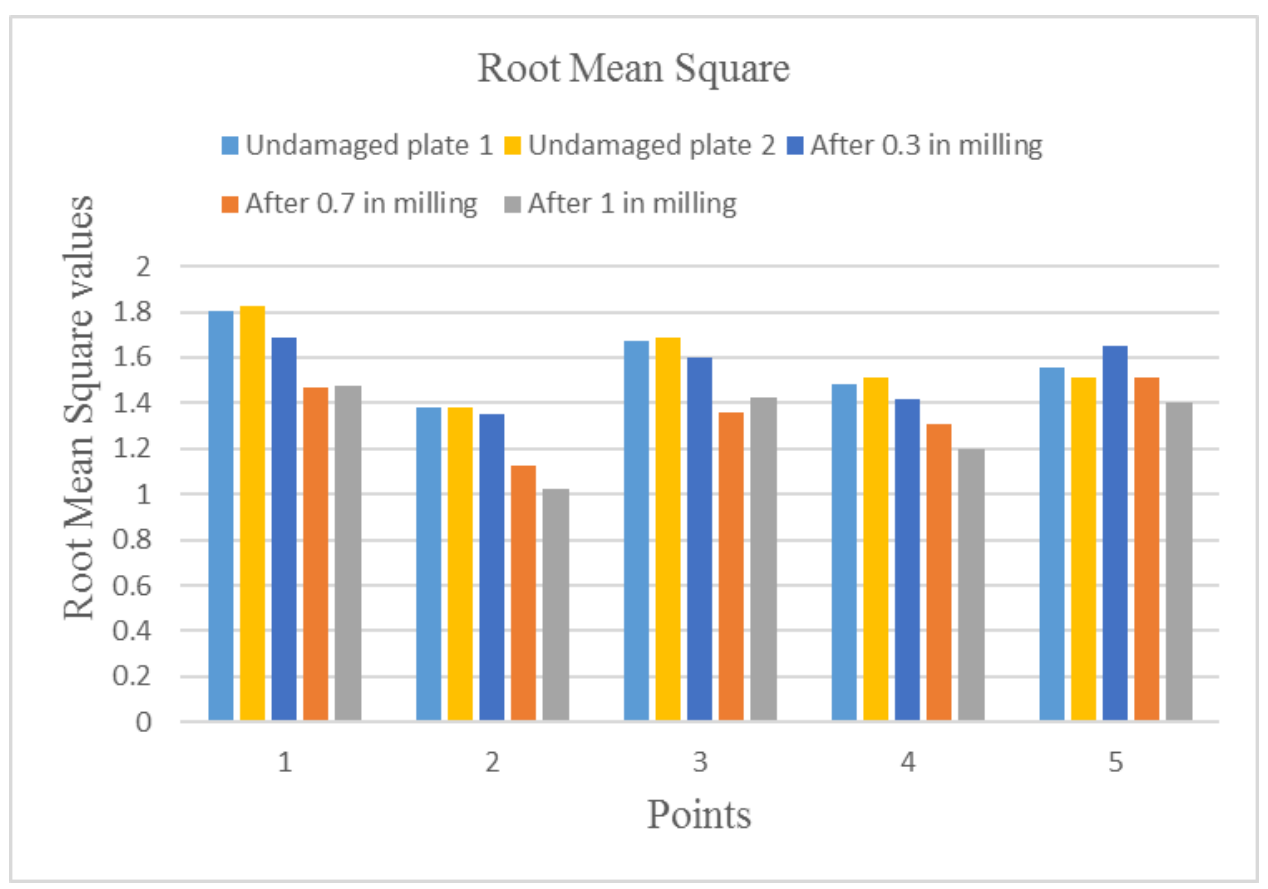

Figure 32 RMS result for change in the length of the milling operation 


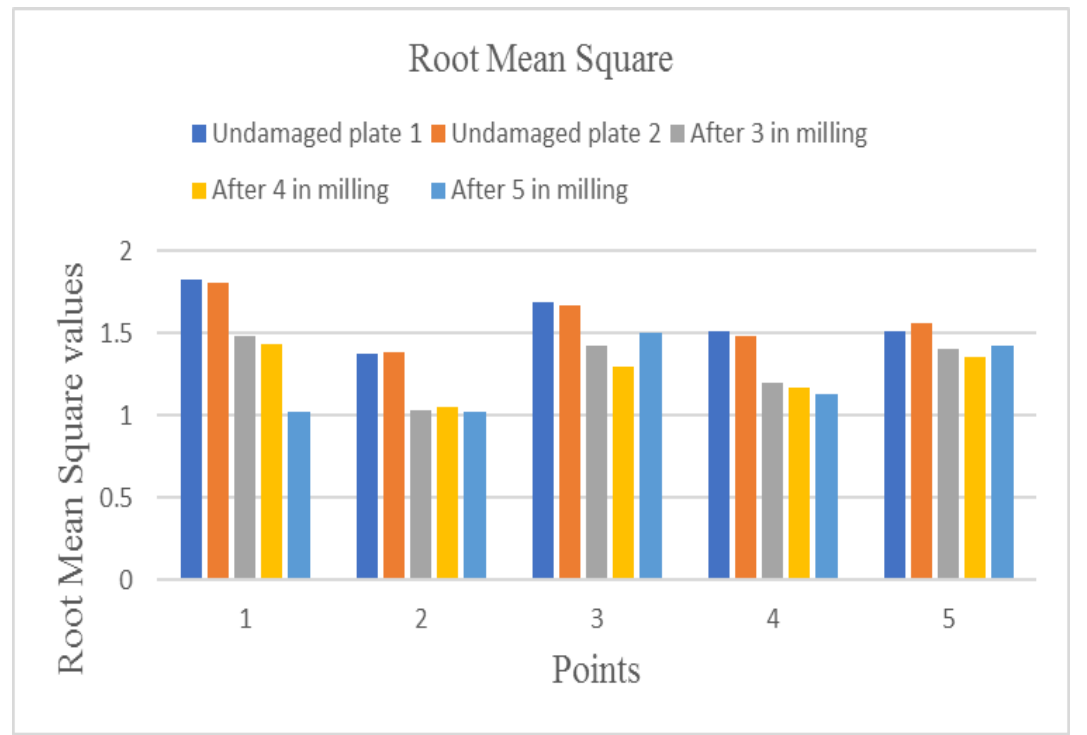

Figure 33 RMS result for change in the width of the milling operation

Standard Deviation (STD): A Standard deviation is a number which shows how much a set of data are spread out from the mean.

$$
S T D=\sqrt{\frac{\sum_{n=1}^{N}(x(n)-\operatorname{Mean}(x(n)))^{2}}{N-1}}
$$

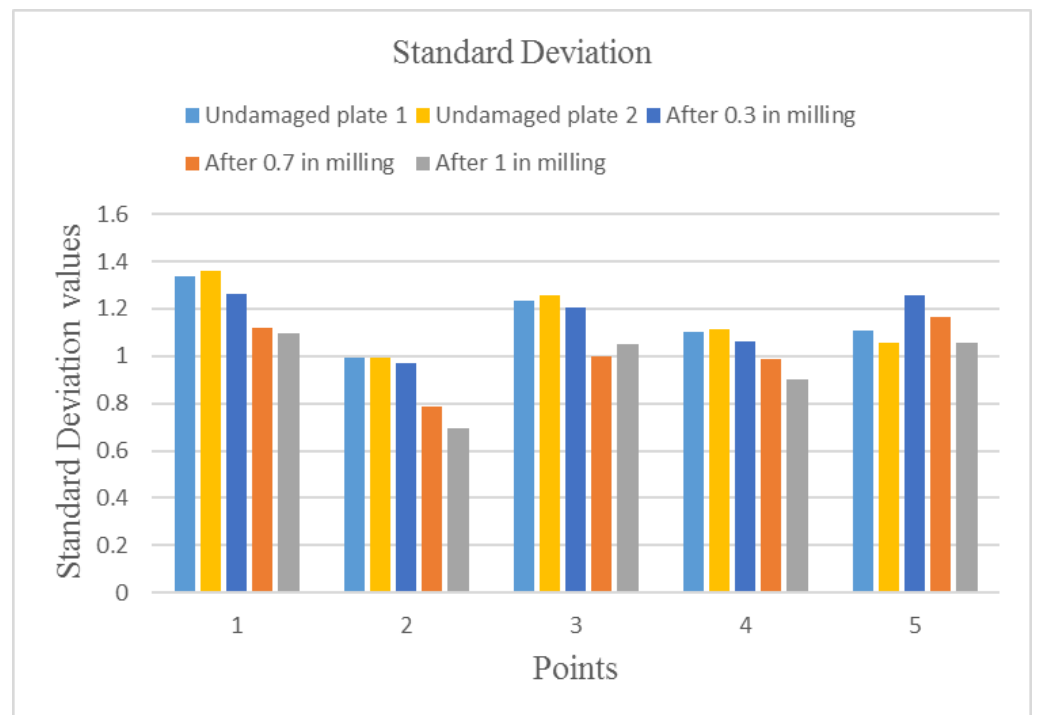

Figure 34 STD result for change in the length of the milling operation 


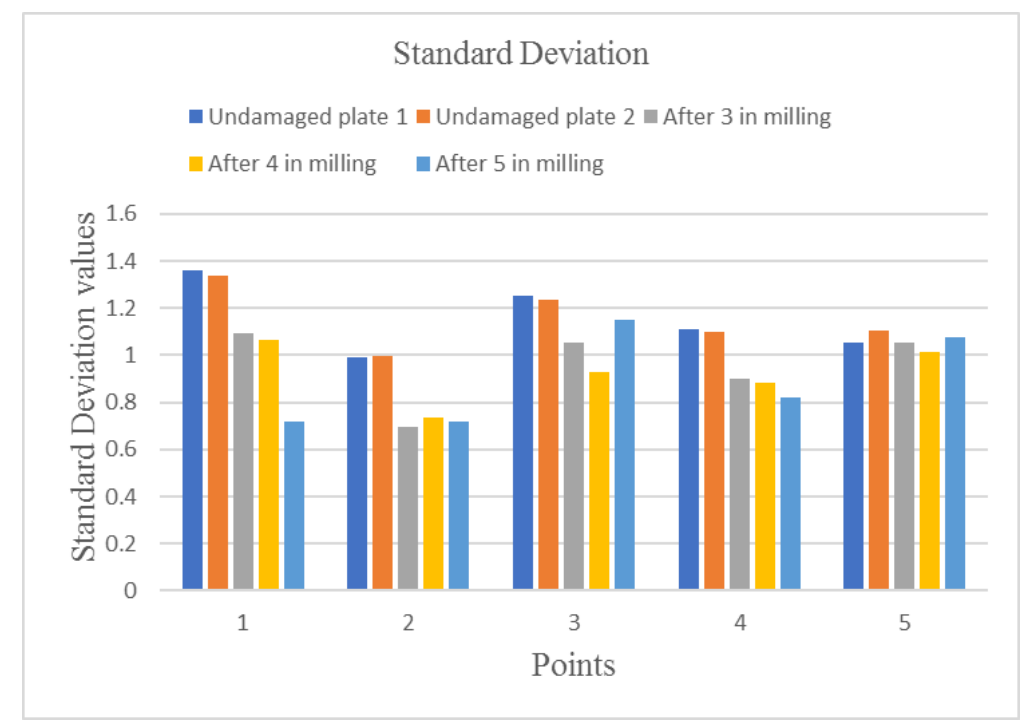

Figure 35 STD result for change in the width of the milling operation

Kurtosis: Kurtosis characterizes the relatively uneven or flat distribution compared with the normal distribution. Positive Kurtosis means a relatively peaked distribution when the negative value indicates a relatively flat distribution.

$$
\text { Kurtosis }=\frac{\sum_{n=1}^{N}(x(n)-\operatorname{Mean}(x(n)))^{4}}{(N-1) \cdot(\operatorname{STD}(x(n)))^{4}}=\frac{\sum_{n=1}^{N}(x(n)-\operatorname{Mean}(x(n)))^{4}}{(N-1) \cdot\left(\frac{\sum_{n=1}^{N}(x(n)-\operatorname{Mean}(x(n)))^{2}}{N-1}\right)^{2}}
$$




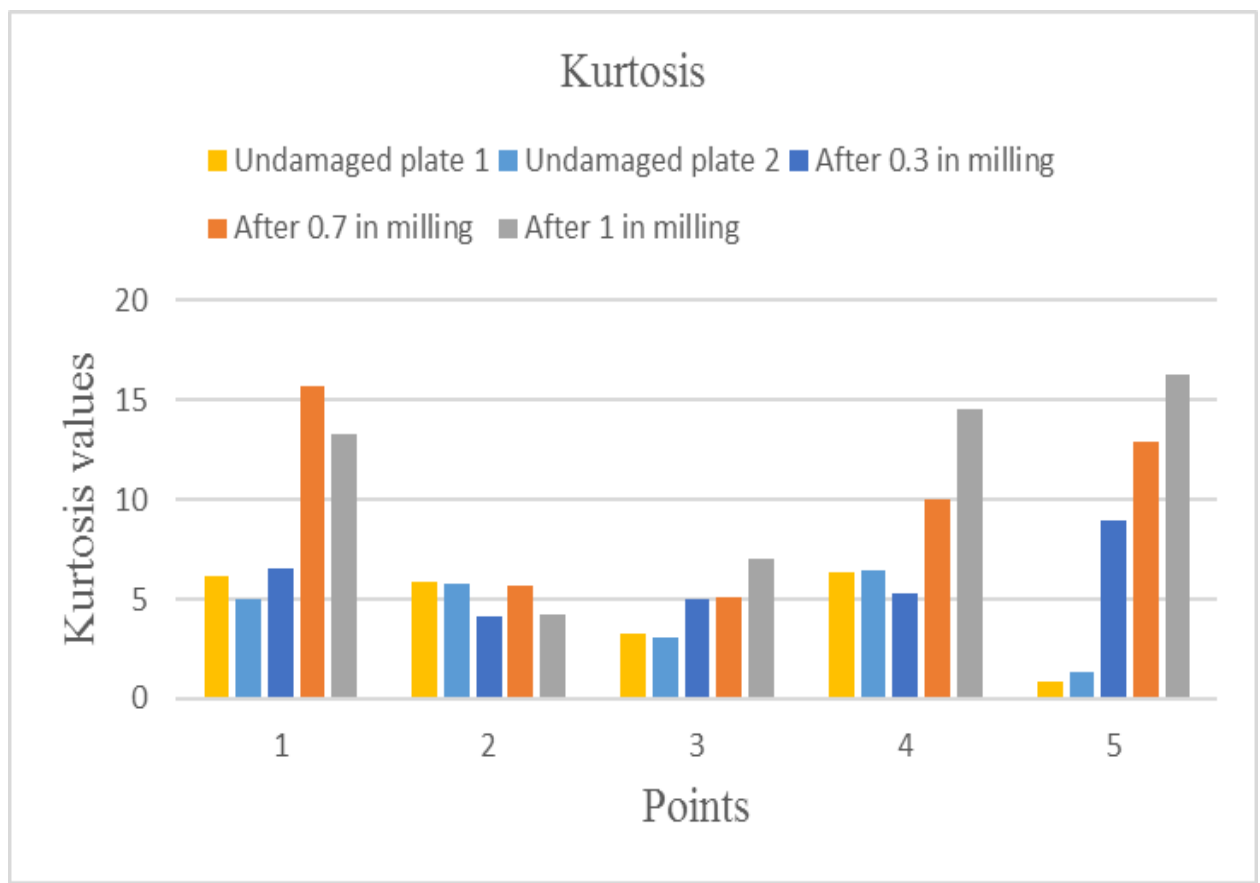

Figure 36 Kurtosis result for change in the length of the milling operation

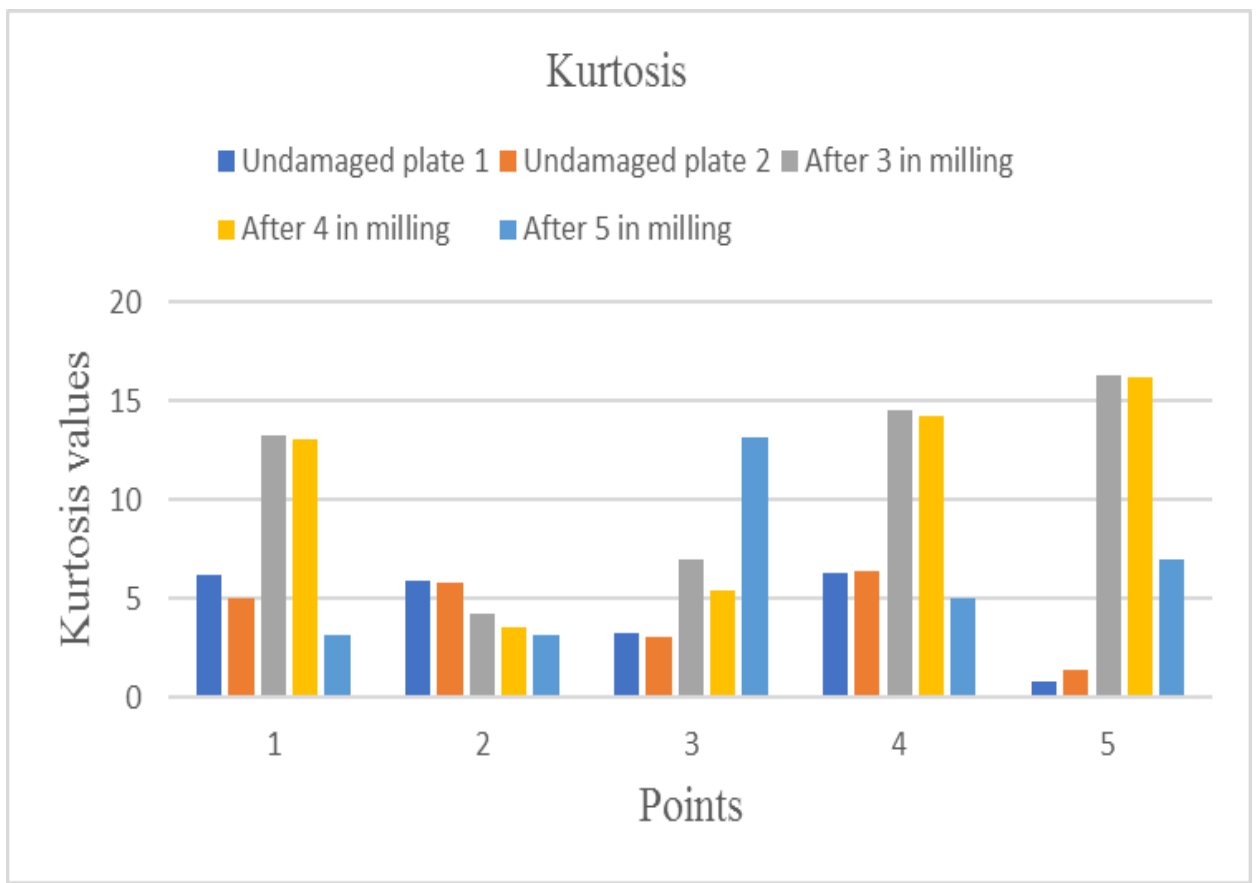

Figure 37 Kurtosis result for change in the width of the milling operation 
Skewness: Skewness describes the degree of asymmetry of a distribution around its mean. Positive Skewness shows a distribution with an asymmetric tail extending towards positive values when the negative Skewness indicated a distribution with an asymmetric tail extending towards negative values. Skewness is a measure of the asymmetry of the data around the sample mean. If skewness is negative, the data are spread out more to the left of the mean than to the right. If skewness is positive, the data are spread out more to the right. The skewness of the normal distribution (or any perfectly symmetric distribution) is zero.

$$
\text { Skewness }=\frac{\sum_{n=1}^{N}(x(n)-\operatorname{Mean}(x(n)))^{4}}{(N-1) \cdot(\operatorname{STD}(x(n)))^{3}}=\frac{\sum_{n=1}^{N}(x(n)-\operatorname{Mean}(x(n)))^{4}}{(N-1) \cdot\left(\frac{\sum_{n=1}^{N}(x(n)-\operatorname{Mean}(x(n)))^{2}}{N-1}\right)^{3 / 2}}
$$

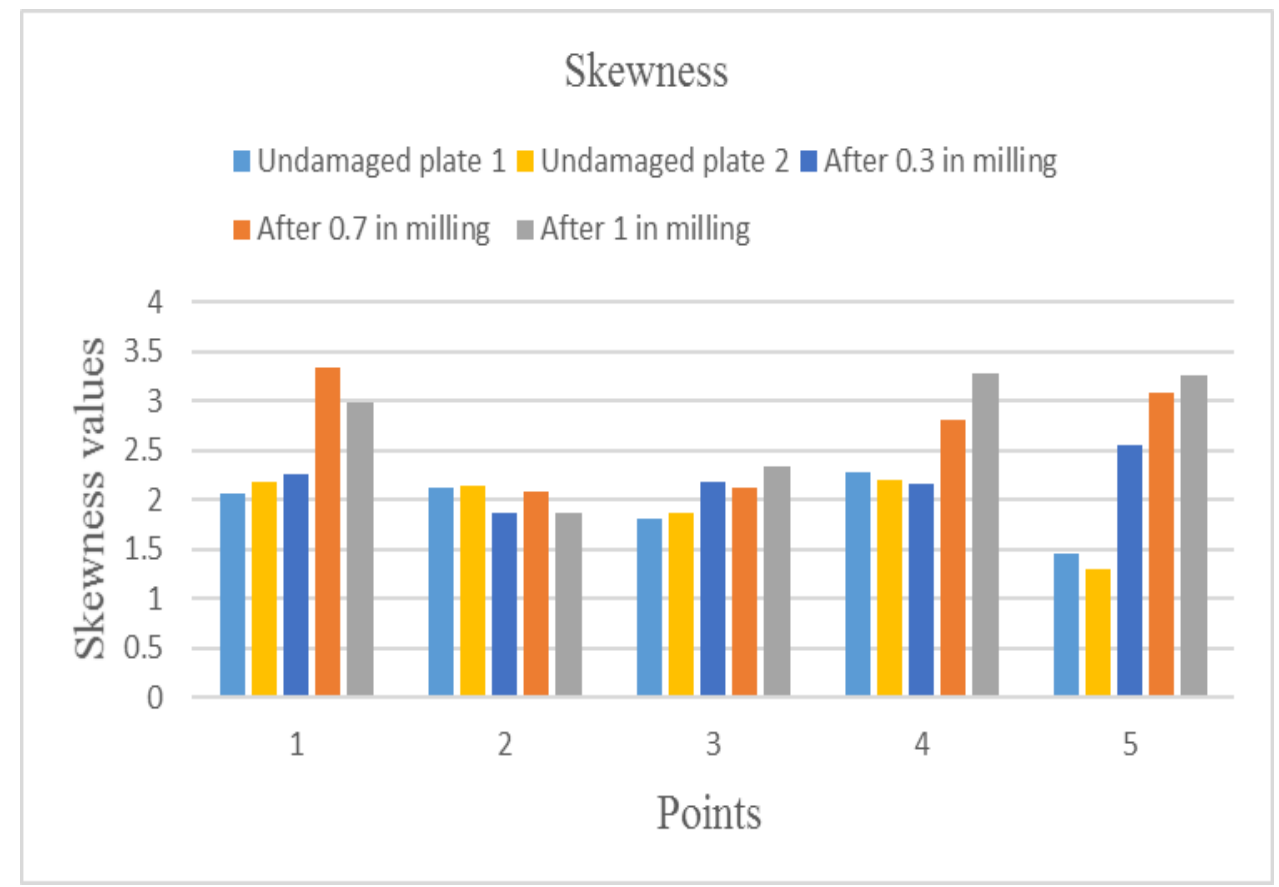

Figure 38 Skewness result for change in the length of the milling operation 


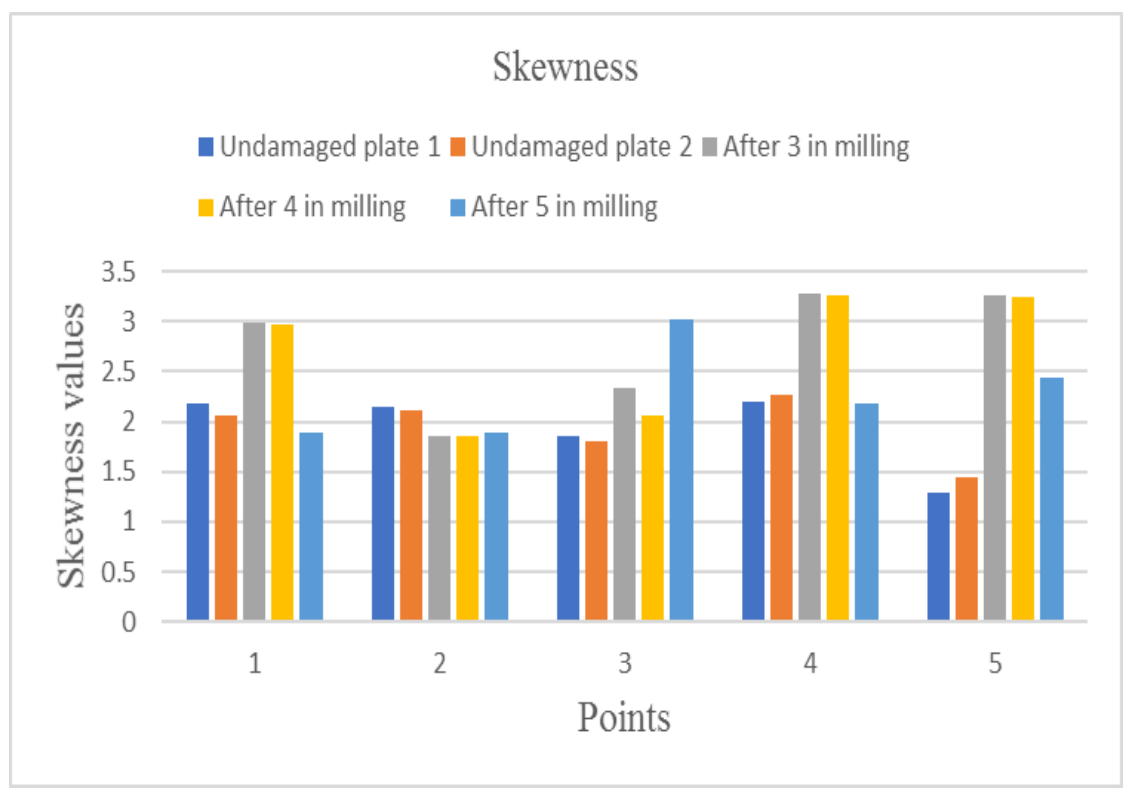

Figure 39 Skewness result for change in the width of the milling operation

\subsubsection{Conclusion}

The purpose of this study was to evaluate the possibility of using different damage indexes for the SuRE method in the monitoring of milling operations. A surface bonded piezoelectric disk was used as an exciter to excite the surface of an aluminum plate. The laser scanning vibrometer was used as a non-contact sensor to measure response signals at five scanning points. In the course of the experiments, it was observed that the SuRE method shows a monotonic behavior to changes in both width and length of milling operation; that is, as the width or length of milling operation is increased, the SSD values also increases and it is reasonably sensitive to the change of width or length of a milling operation. However, in order to eliminate the need for baseline or reference signals, instead of SSD, geometric and harmonic mean were used as criteria for comparing different size of the milling operation. It was seen that by an increase of the length of milling operations, 
geometric mean increases gradually and also by increasing the width of milling operations, harmonic mean decreases gradually. As it can be seen in the results, although geometric and harmonic mean is not as sensitive as SSD value to the change of the length and width of milling operation, respectively, they can be used as an alternative for SSD in some SHM applications. By using just the central point for receiving the response signal, 5th momentum value showed a promising result for change in both length and width of the milling operation and by increasing the width or length of the milling operation, the 5th momentum value increased rapidly. As a result, the SuRE method seems to be a promising approach in the monitoring of milling operation and moreover, geometric mean, harmonic mean and 5th momentum value could be a promising alternative for SSD value, in the SuRE method, especially when the baseline or reference signal is not available. 


\subsection{Damage Detection of 3D Printed Mold Using SuRE Method}

The life of conventional steel plastic injection molds is very long but manufacturing cost and time are prohibitive for using this approach to prepare the molds of prototypes or parts to be produced in limited numbers. Recently developed 3D printers are capable to convert the digital files of three dimensional solid objects into the actual parts. Depending on the 3D printer final product could be a polymer or metal. Manufacture of polymer parts with the $3 \mathrm{D}$ printers is much cheaper, faster and convenient. However, the life of a polymer mold could be less than a hundred parts. If a polymer mold fails during the injection molding process the accident could be costly and life-threatening since very large forces and temperatures are involved.

Many Structural Health Monitoring (SHM) methods were developed for the sheet metals of airplane fuselages. In this study, the feasibility of the inspection of 3D printed molds with the surface response to excitation (SuRE) method was investigated. First, the SuRE method was used to evaluate if the variation of the strain could be monitored when loads were applied to the center of the 3D printed molds. After the successful results were obtained, the SuRE method was used to monitor the artificial damages created at the 3D printed mold. The results showed that the proposed method can be used to monitor the condition of the 3D printed molds.

\subsubsection{Introduction}

Molded composite structures are increasingly used in aerospace, mechanics, automotive, and many other applications owing to the low weight, superior fracture behavior, long 
service life, and longevity [90-94]. These mechanical properties were studied in varieties of composite applications by other researchers [95-96]. Also, other research projects have been conducted for Structural Health Monitoring (SHM) methods to detect the structural defects before failures take place [97-100]. Recently, additive manufacturing systems are going to be the leadership advanced manufacturing in molded composite structures due to the significant ability to create the very complex parts of molded composite structures which cannot be manufactured by the conventional methods [101-105]. In the additive manufacturing systems, parts are built layer by layer in their cabinet by following the Computer Aided Design (CAD) drawings with no material waste.

Although the significance of the health monitoring of various type of molded composite is accepted and warmly embraced by engineering companies in general and related experts in particular, the load monitoring and defect detection for the rapid prototype molded composite is a controversial issue and a matter of discussion. These days, 3D printers have a beneficial role in producing various types of rapid prototype molded composite component. Different technologies have been developed to produce the molded composite component which is a by-product of 3D printers [106-110]. Lower price and higher efficiency of 3D printer compared with other rapid prototyping technologies consider as the most significant merits of it [111]. Oftentimes, the molded composite segments may face with different types of defect either during the manufacturing process or in the course of their service life. Howsoever, the latter stage covers the most percentage of the possibility for wearing occurrence caused by loading force during in-service use [112-114]. On a closer scrutiny, most of the publications are dealing with the severity of negative influence of wearing on rapid prototyping molded composites. Under certain 
circumstances, mechanical wearing should be taken into consideration as the most effective factors for structural health monitoring of in the rapid prototype molded composite structures, particularly in the long-term cycling cases study. Consequently, in order to tackle wearing caused by dynamic load, various teams and researchers have put their concentrations on understanding load monitoring and defect detection in the molded composite [115].

In this study surface response to excitation (SuRE) was utilized for load monitoring and damage detection in composite molds. The SuRE method is a cheaper alternative for Electromechanical Impedance (EMI) approach. This method excites the structure with a sweep sin wave and creates waves on the surface. The wave generation, propagation and receiving performance are different at each frequency. These efficiencies change when the surface has any transformation including defects, cracks, loading, holes, welding, and coating. In this experiment, the effect of different sizes of transducers on the result was investigated two different sizes of piezoelectric transducers (PZT).

\subsubsection{Theoretical Background}

The SuRE method was developed as a low-cost alternative to the electromechanical impedance method which uses the related instrument to evaluate the characteristics of single piezoelectric element attached to the structure. SuRE method excites the surface at one point and monitors the surface waves at another point. Any sensor and exciter pair may be used but piezoelectric elements or PZTs are widely used since they are cheap and readily available. One of the PZT is used to excite the surface in a wide range of frequencies 
and the dynamic response of the surface on the other side is recorded using another PZT. Frequency domain data is obtained with the help of the Fast Fourier Transformation (FFT). The change of the frequency domain characteristics is compared with the baseline to understand if there are any changes to the structure.

The sum of the squared differences (SSD) of the amplitudes of the spectrums is calculated according to the following equation. The SSD is the quantitative description of the difference between the collected data and the baseline obtained when the structure was in the pristine condition:

$$
S S D=\sum_{i=1}^{m}\left|B_{m \times 1}-R_{m \times 1}\right|^{2}
$$

In this equation, $\mathrm{B}$ and $\mathrm{R}$ are the amplitudes of the baseline data and responses of the structure. Generally, the SSD values increase when the defect gets bigger.

\subsubsection{Experimental setup}

Acrylonitrile butadiene styrene (ABS) is one of the widely used materials in additive manufacturing. In this study, one of the parts of a mold with the 5 " $\times 6$ " $\times 0.75$ " inch dimensions were printed by using the small office 3-D printer. The shape of the part is presented in Figure1. The mold was prepared for injection molding of a dog bone shaped part and two rectangular prism-shaped samples. The Fused Deposition Modeling (FDM) method was used to manufacture the part by using the ABS material with 50\% fill ratio. 


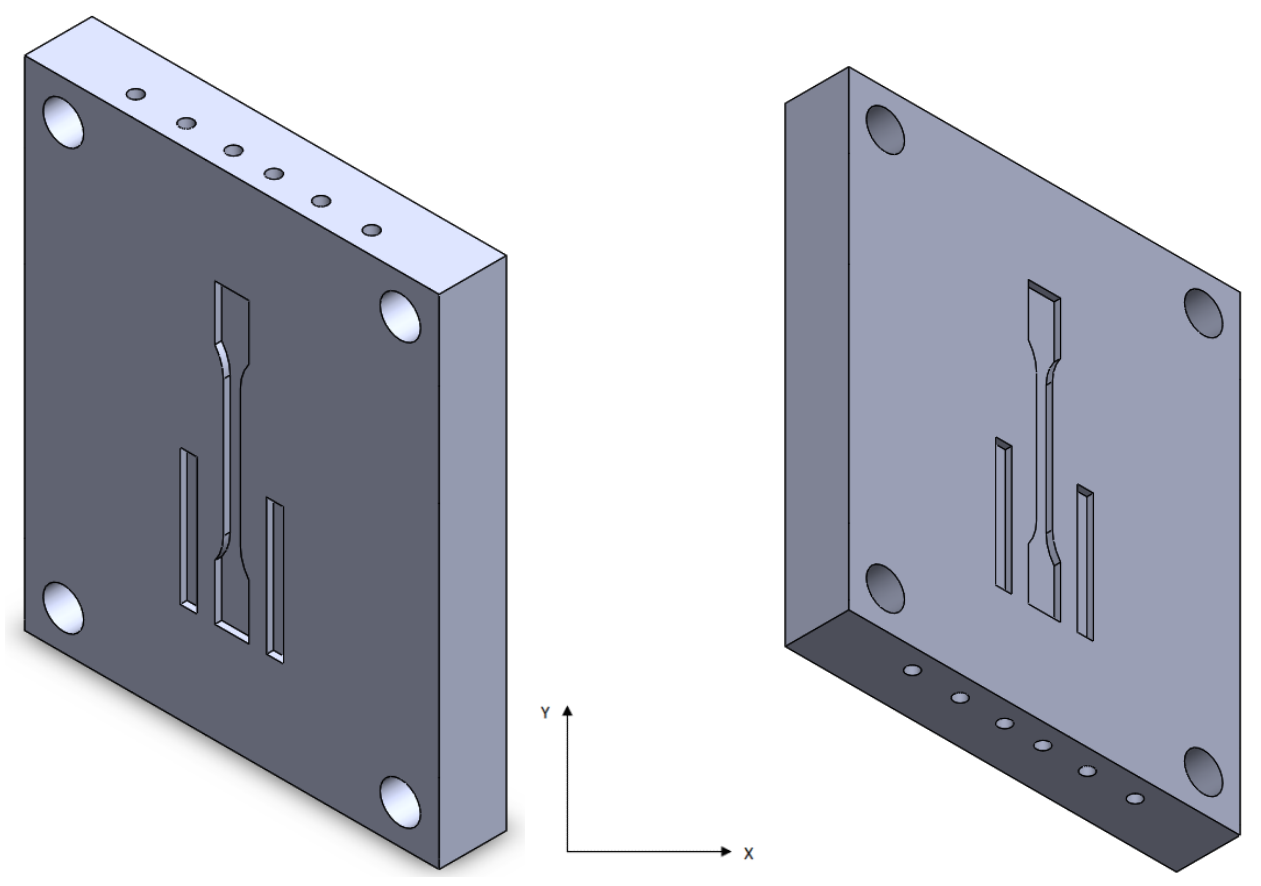

Figure 40 3D Printed Mold

Two sets of piezoelectric transducers with different sizes $(0.75$ " and 0.25 ', diameters) were attached on the back side of the mold. For each set, one PZT worked as exciter while the other one was used as the sensor (Figure 2).
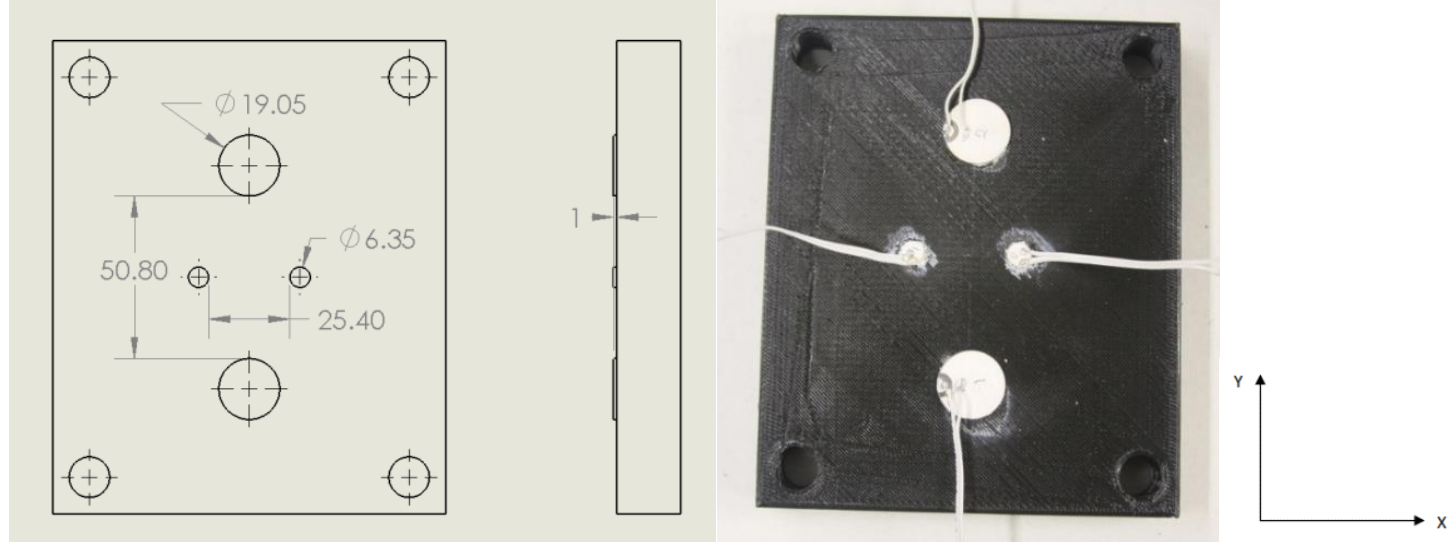

Figure 41 Attached PZTs on the back of the 3D printed mold. Drawing (left) and actual part with PZTs (right). 
The experiments were repeated twice. First, the structure was excited in a wide frequency range $(20 \mathrm{kHz}-600 \mathrm{kHz})$ in order to find the optimum excitation frequency range. The spectrum of the surface response was studied. Based on the height of the amplitude of the FFT response, the frequency range between $100 \mathrm{kHz}$ and $1145 \mathrm{kHz}$ was chosen for the PZTs with 0.75 " diameter. The excitation frequency range between $20 \mathrm{kHz}$ and $420 \mathrm{kHz}$ was selected for the PZTs with 0.25 " diameter. The experimental setup is shown in Fig 3 .

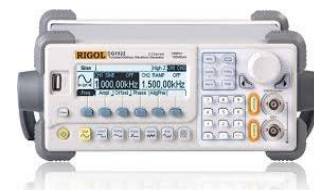

Signal Generator (RigolDG1022)

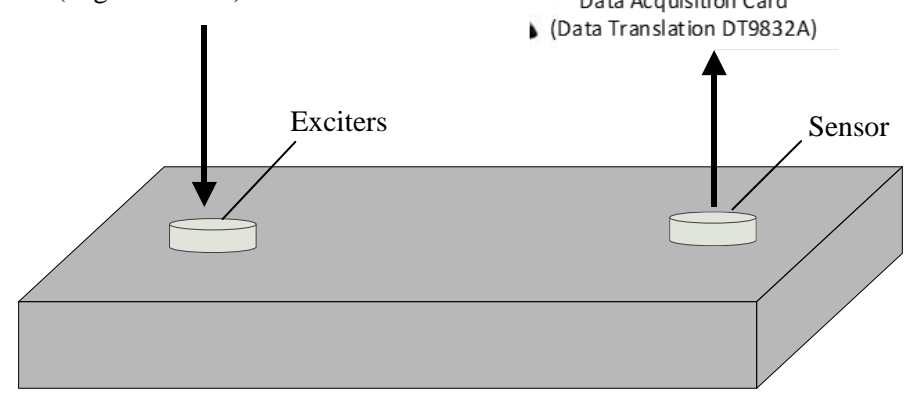

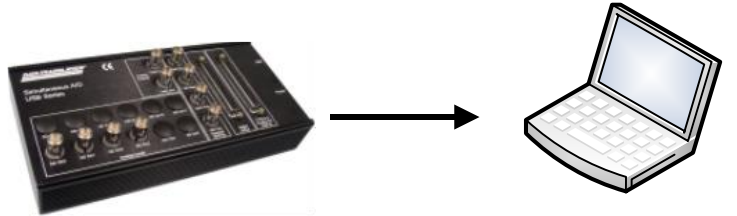

Data Acquisition Card

Figure 42 Experimental setup

\subsubsection{Results and discussion}

Most of the SHM methods work very effectively on the sheet metal surfaces. The created surface waves quickly disappear on the composite materials. Excitation of a thick 50\% filled block and collection of meaningful data were challenging. When a part is damaged, it cannot be repaired. The effect of different loads can be studied without damaging the part and the SuRE method sensed the loading changes effectively in our previous studies. First, the effect of loading on the structure was investigated. After we observed that the 
frequency response changed at different loading conditions, various damages were created on the 3D printed molds and the performance of the SuRE method was evaluated.

\section{a) Evaluation of SuRE method by detection of the force applied in the center of the mold}

For evaluation of the performance of the SuRE method different loads were put at the middle of the mold (Figure 4). The structure was excited between $100 \mathrm{kHz}$ and $145 \mathrm{kHz}$ by using one 0.75 " diameter PZT. The surface response was monitored with the same size PZT which was attached to the other side of the mold. The baseline data was collected and FFT spectrums were calculated. Then, $1 \mathrm{lb}$., $2 \mathrm{lb}$, and $3 \mathrm{lb}$ load were applied. The surface response was collected at each loading level. Finally, all the loads were removed and data was collected at the same conditions the baseline data was recorded. The spectral characteristics of the response were collected for all the cases by using the FFT method and presented in Figure5. The SSD values were calculated to represent the difference between the baseline and each test case with and without the load (Figure 5).

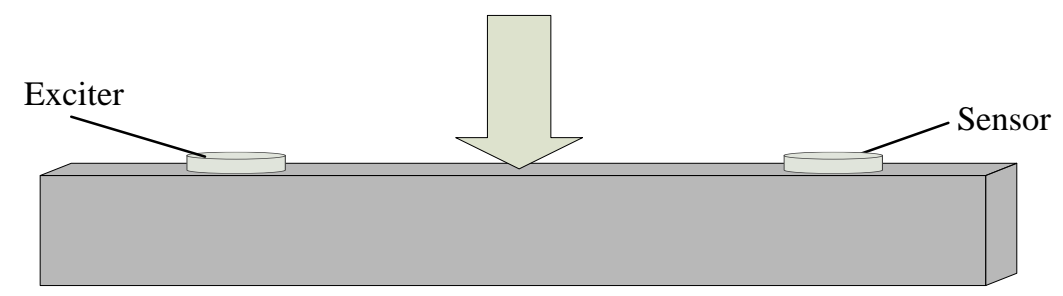

Figure 43 Frequency response and SSD values for load monitoring when 0.75 diameter PZTs were utilized 


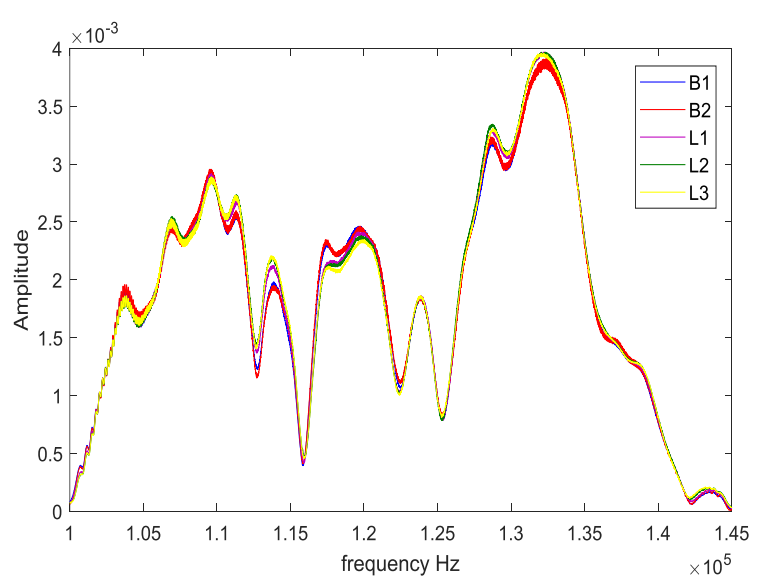

a) FFT

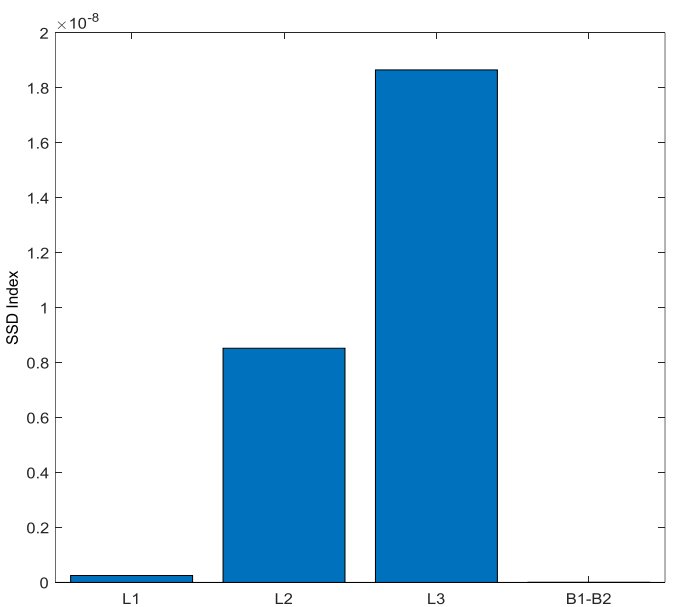

b) $S S D$

Figure 44 Frequency response and SSD values for load monitoring when 0.75 diameter PZTs were utilized

The same process was repeated when two 0.25 " diameter PZTs were utilized as sensor and exciter to study the effect of different size transducers. The PZTs was excited between 20 kHz and $420 \mathrm{kHz}$. The results for small PZTs are shown in Figures 6, 7.

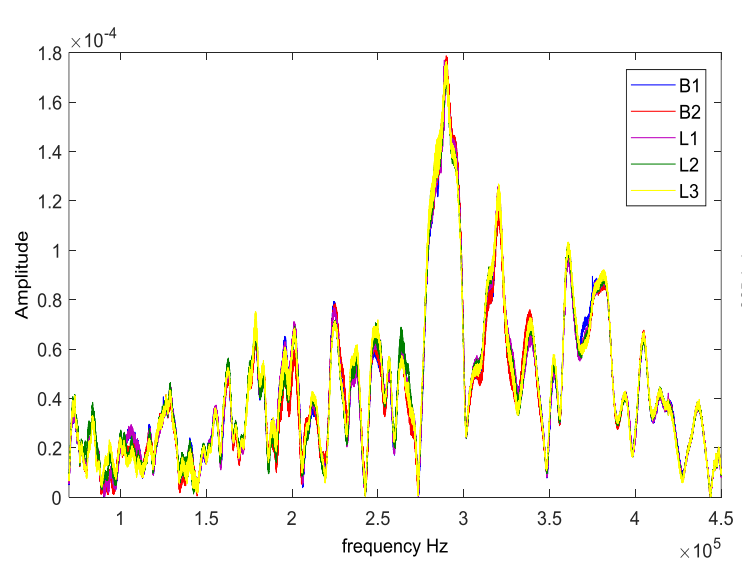

a) FFT

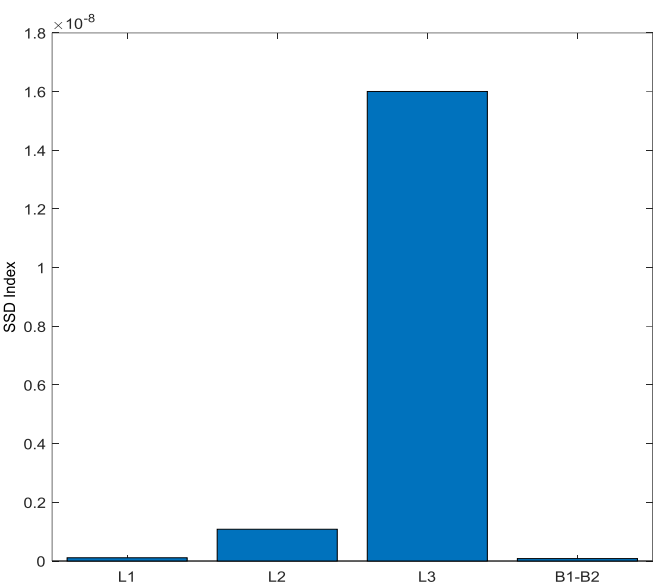

b) $S S D$

Figure 45 Frequency response and SSD values for load monitoring when 0.25 diameter PZTs and $20 \mathrm{kHz}-420 \mathrm{kHz}$ frequency range were utilized 


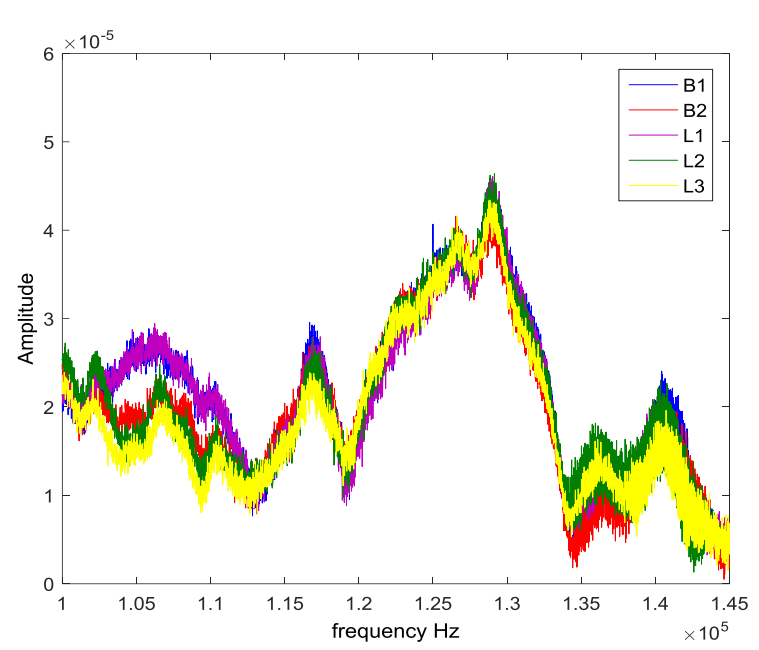

a) FFT

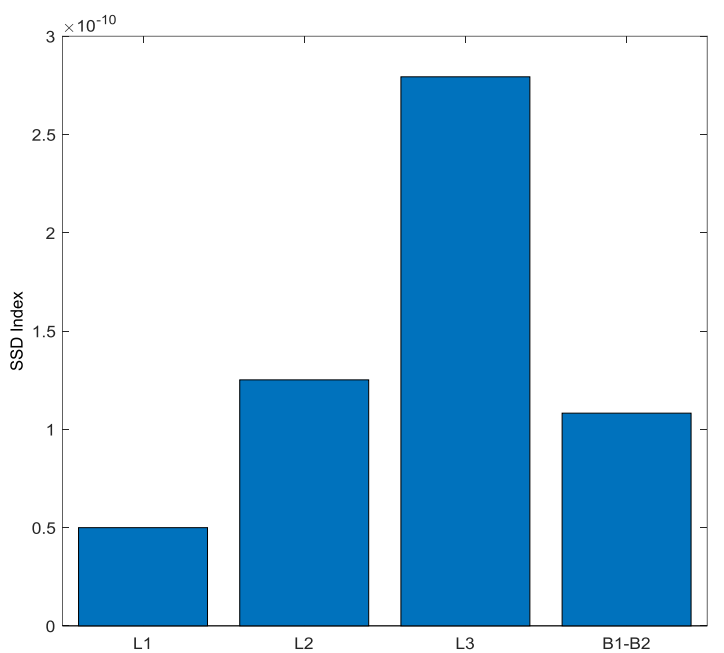

b) $S S D$

Figure 46 Frequency response and SSD values for load monitoring when 0.25 diameter PZTs and $100 \mathrm{kHz}-145 \mathrm{kHz}$ frequency range were utilized

\section{b) Damage detection}

Dremel rotary tool kit with a grinding head was used to create damage at one of the cavity with 0.2 " width and 1.6" length (Figure8.a). The damage was created at the left side of the cavity with the hand tool to simulate the damage or wear of the mold artificially. Little slots were created with 0.5 " length (Y direction). The width of the slots was (X direction) $0.05 ", 0.01 "$ and $0.015 "$ at three simulated wear cases. The artificial damage or wear was also created on the right side of the cavity. The length of the slot was 1.6 " this time in the Y direction. The width of the slot was also $0.05 \%, 0.01$ " and $0.015 "$ in the $\mathrm{X}$ direction at three additional simulated wear cases. The tested wear cases are presented in Table 1. 
Table 1 Experimental test cases

Experiments at different Damage at the left side Damage at the right side wear or damage levels

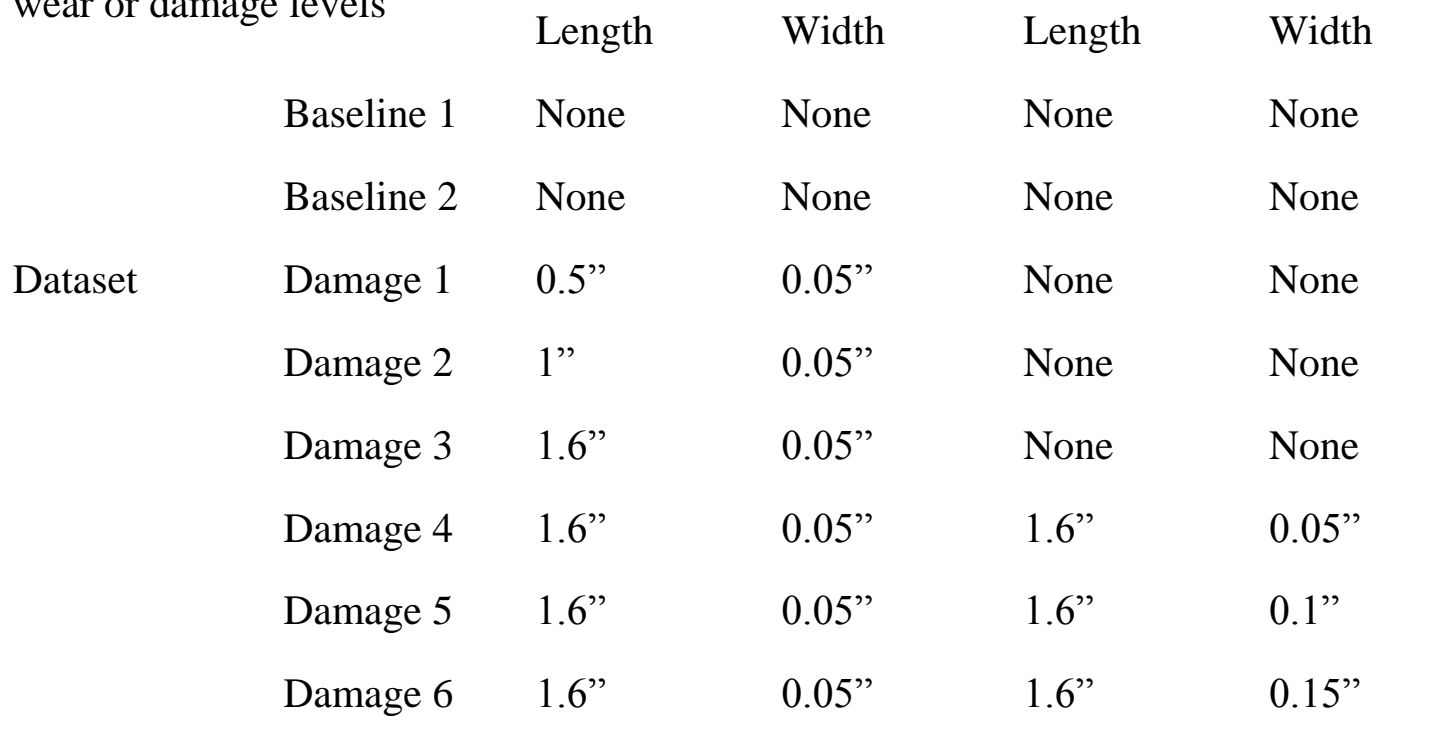

The experimental data were collected with the PZTs with 0.75 " diameter first. The mold was excited in $100 \mathrm{kHz}$ to $145 \mathrm{kHz}$ frequency range with a sweep sine wave. The baseline data were collected twice without any damage.

The experimental data was also collected with the PZTs with 0.25 " diameter. The baseline data was also collected twice with these smaller PZTs. The excitation frequency range of the sweep sine wave was $20 \mathrm{kHz}$ to $420 \mathrm{kHz}$. These experiments were also repeated when the excitation frequency range of the sweep sine wave was reduced to $100 \mathrm{kHz}$ to $145 \mathrm{kHz}$ range.

The right cavity of the mold was damaged as described in the first paragraph and Table 1 at six different levels. Experimental data was collected with the PZTs with 0.75 " and 0.25 " 
diameters in the indicated frequency ranges. The FFT of the data were calculated for each case and the SSD values were calculated. The FFT amplitude and SSD values for the PZTs with 0.75 " diameter are presented in Figure9 and Figure10 respectively.

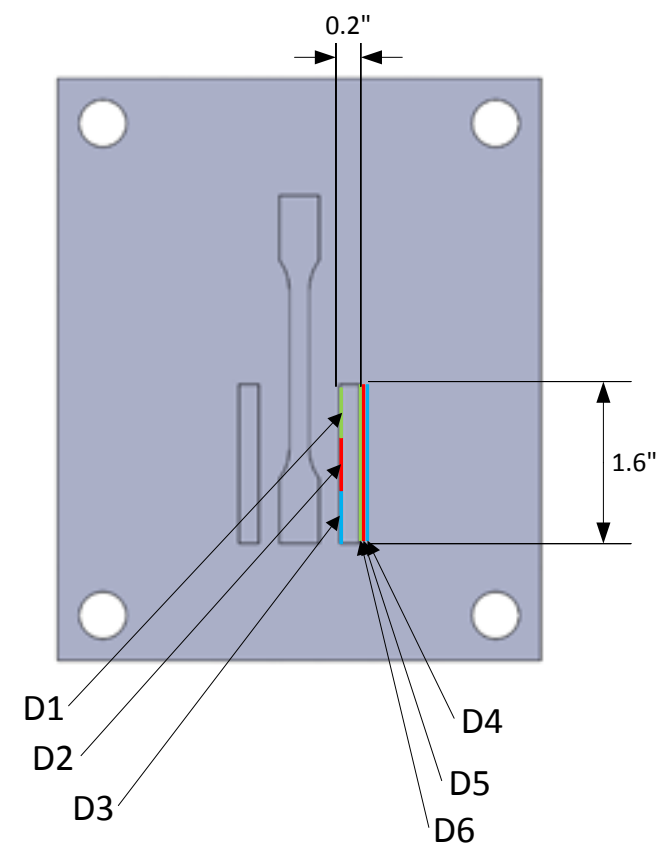

a) Drawing of the mold

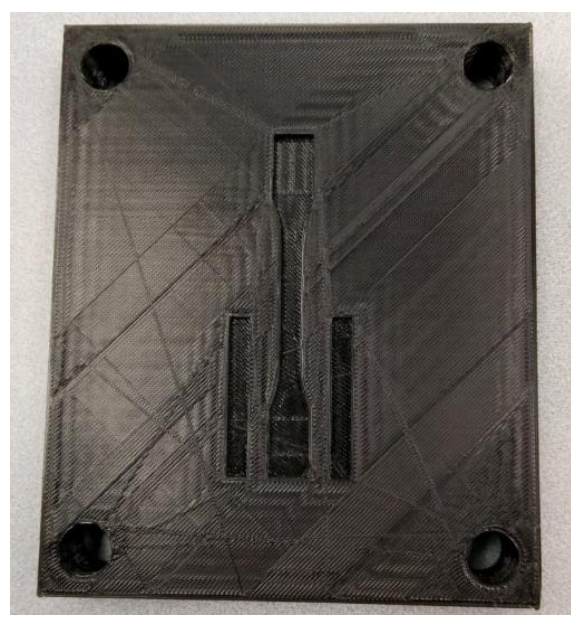

b) Perfect mold

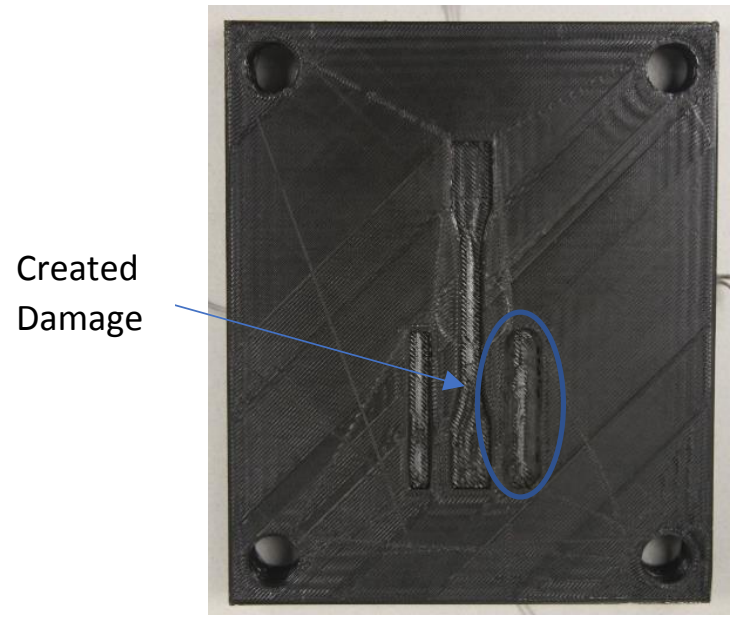

c) The damaged cavity

Figure 47 Created damage shown in three colors 


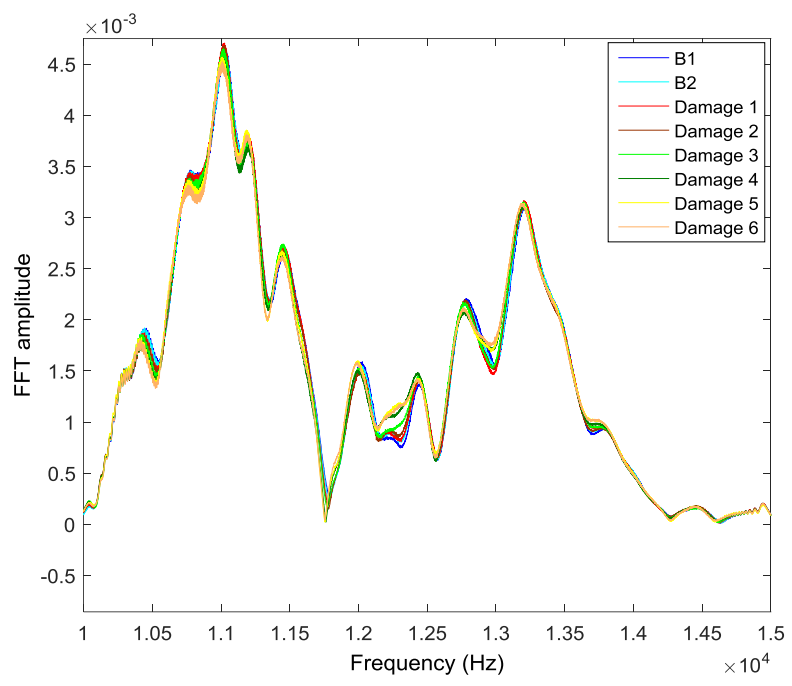

Figure 48 The spectrums calculated by the FFT when the PZTs with 0.75 " diameter were used at different artificial damage or wear levels. The excitation signal was a sweep sine wave between $100 \mathrm{kHz}$ and $145 \mathrm{kHz}$

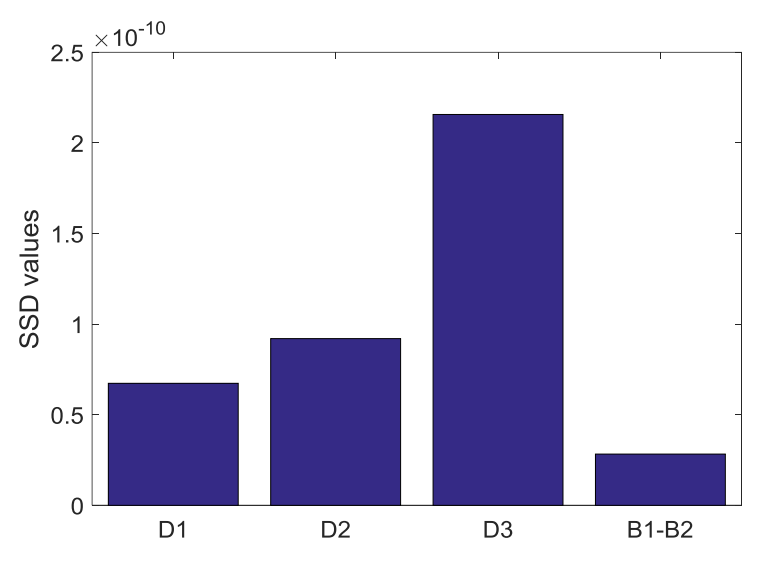

a) Damages 1 - 3

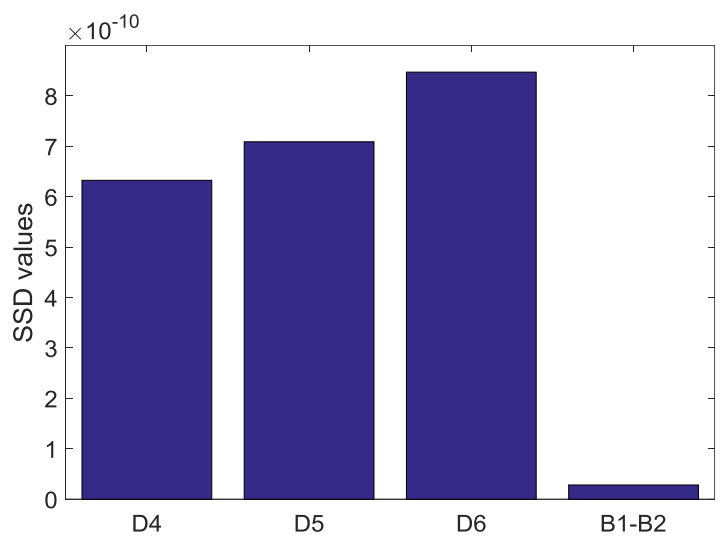

b) Damages 4 - 6

Figure 49 SSD values for damage detection when 0.75 diameter PZTs were used. The excitation signal was a sweep sine wave between $100 \mathrm{kHz}$ and $145 \mathrm{kHz}$. See the Table 1 for the artificially created damage or wear information. 
The FFT amplitude and SSD values for the PZTs with 0.25 " diameter are presented in Figure11 and Figure12 respectively when the frequency of the sweep sine wave changed between $20 \mathrm{kHz}$ to $420 \mathrm{kHz}$.

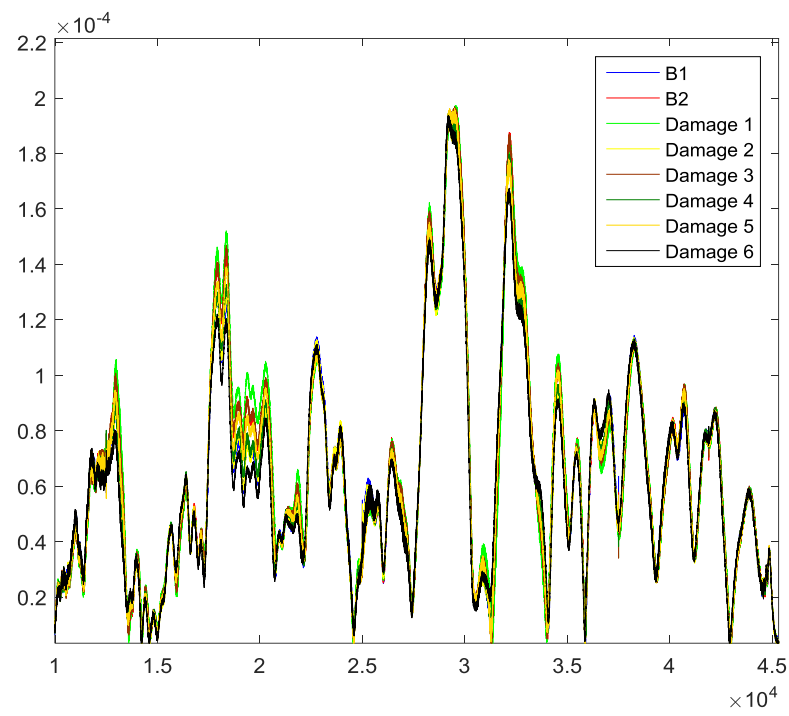

Figure 50 The spectrums calculated by the FFT when the PZTs with 0.25 " diameter were used at different artificial damage or wear levels. The excitation signal was a sweep sine wave between $20 \mathrm{kHz}$ and $420 \mathrm{kHz}$.

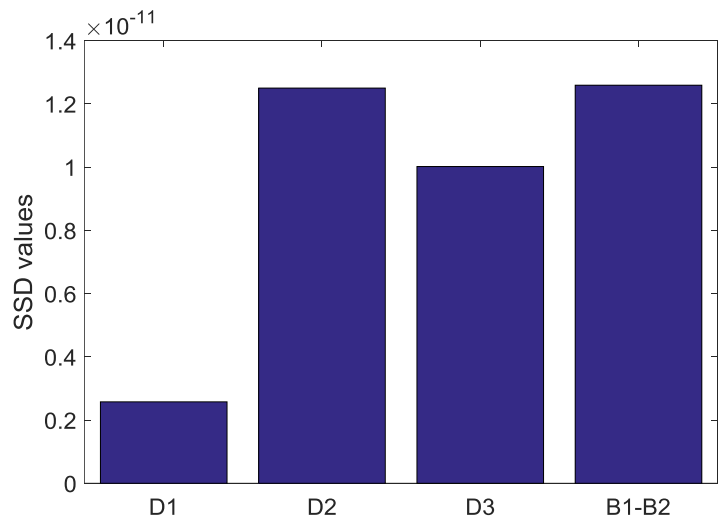

a) Damages 1 - 3

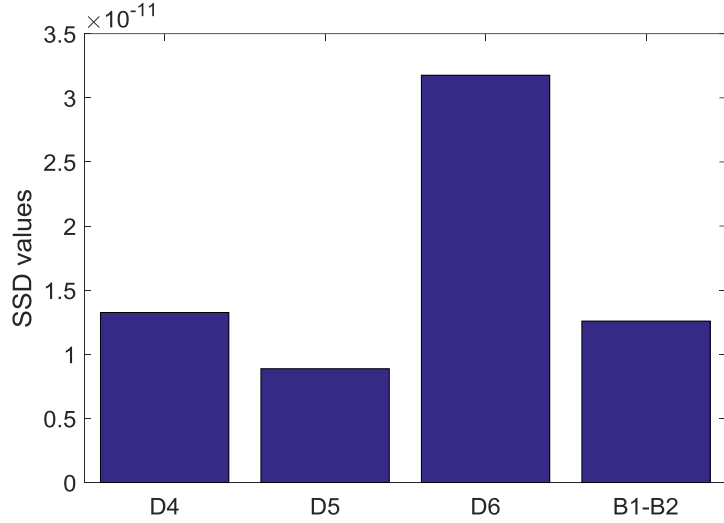

b) Damages 4 - 6

Figure 51 SSD values for damage detection when 0.25 diameter PZTs were used. The excitation signal was a sweep sine wave between $20 \mathrm{kHz}$ and $420 \mathrm{kHz}$. See the Table 1 for the artificially created damage or wear information. 
The FFT amplitude and SSD values for the PZTs with 0.25 " diameter are presented in Figure13 and Figure14 respectively when the frequency of the sweep sine wave changed between $100 \mathrm{kHz}$ to $145 \mathrm{kHz}$.

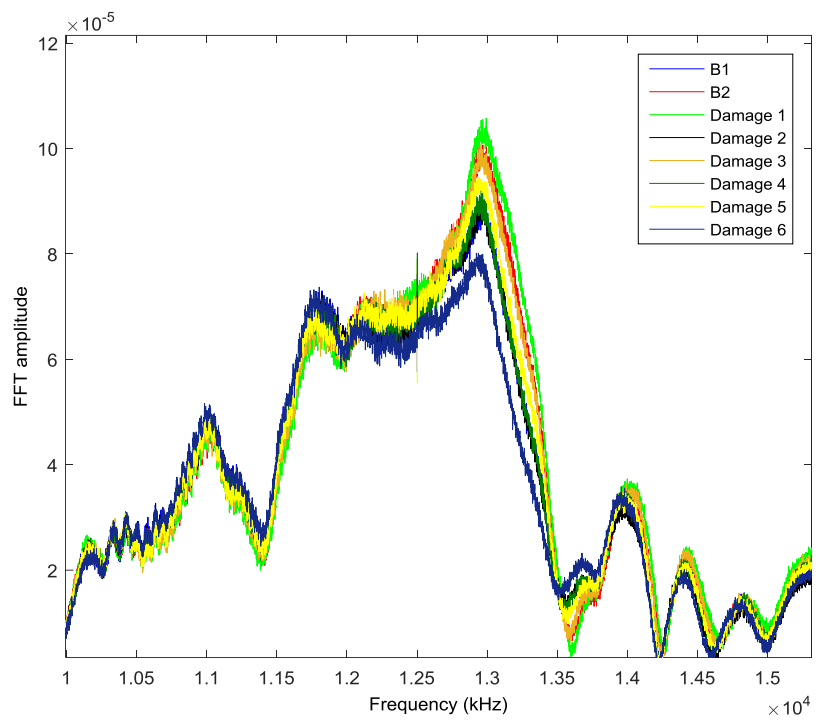

Figure 52 The spectrums calculated by the FFT when the PZTs with 0.25 " diameter were used at different artificial damage or wear levels. The excitation signal was a sweep sine wave between $100 \mathrm{kHz}$ and $145 \mathrm{kHz}$.

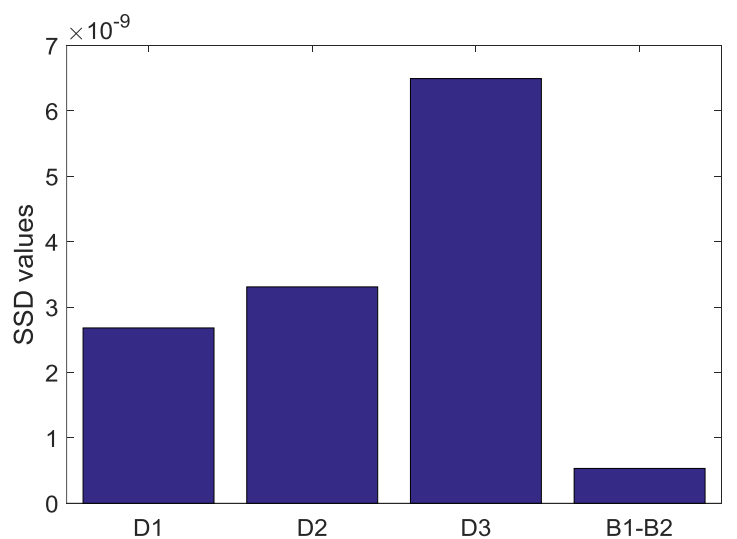

a) Damages 1 - 3

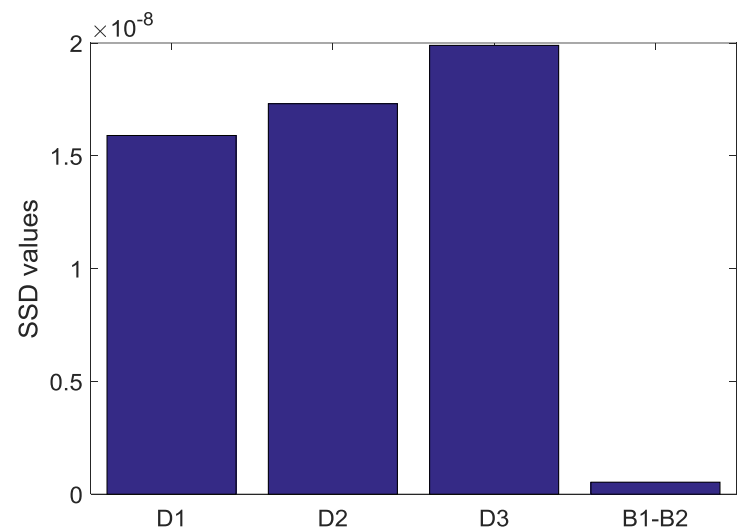

b) Damages 4 - 6

Figure 53 SSD values for damage detection when 0.25 diameter PZTs were used. The excitation signal was sweep sine wave between $100 \mathrm{kHz}$ and $145 \mathrm{kHz}$. See the Table 1 for the artificially created damage or wear information. 


\subsubsection{Conclusions}

Being one of the latest innovative technology, 3D printing technology has been revolutionary in engineering, product design, and manufacturing. For the specific types of mold which are going to be used for limited cycles, 3D printed molds seem more costeffective. In these types of application, monitoring the quality of the mold after each cycle in order to have high accuracy sounds vital.

In this study, first, the performance of the SuRE method was evaluated by monitoring the applied force on the center of the mold. Then, the surface response to excitation (SuRE) method was used for the detection of simulated wearing in 3D printed mold. One of the PZT attached to the 3D printed mold was used to excite the surface of the mold at a broad frequency range. Second PZT was used to monitor the response of the system. As it was shown in results, the sum of the squares of the differences (SSD) values increased with the increase in the size of the damage. The SSD index was reasonably sensitive to the changes of the damage size. In addition, it was shown that different sizes of PZTs have no major impact on the result as long as the appropriate range of frequency is being used.

The SuRE method assessed the change of the damage size based on the frequency response of the structure. The experimental results show that the SuRE method can be considered as a promising method for detection of small changes in 3D printed molds. 


\subsection{Composites bond inspection using SuRE methods}

With increasing utilization of the composite materials in commercial and military applications, the longevity of composite bonds has become a crucial concern of the aerospace industry. In spite of the previous studies in the literature for characterization of bonding condition in composite materials, implementation of more advanced structural health monitoring (SHM) techniques are still required to ensure flight safety and quick inspections of structures. In this study, the surface response to excitation (SuRE) method was used for studying various simulated contamination levels. Results of the experimental studies showed that the proposed methods could be efficiently utilized for evaluating bonding strength of composite materials.

\subsubsection{Introduction}

Composite materials have found numerous applications in automotive, industrial, aerospace, civil, and mechanical engineering applications due to their excellent strength to weight ratio and resistance to corrosion [116-120]. Particularly, Carbon Fiber Reinforced Plastics (CFRP) have been widely used in the aerospace industry because of these benefits. Investigation of the longevity of the composite materials is of great importance in these critical applications [121-123]. Two important areas of concern regarding the usage of the composite materials are delamination and debonding of composite joints. Debonding and delamination would severely reduce the strength of the composite structures and may lead to catastrophic failures $[124,125]$.

Non-destructive testing (NDT) methods were proposed for inspection of Composite materials during their service lives [126-128]. Application of various NDT methods, such 
as visual testing (VT or VI), ultrasonic testing (UT), thermography, radiographic testing (RT), electromagnetic testing (ET), acoustic emission (AE), and shearography testing in the evaluation of composite bonds have been reviewed by Gholizadeh [129]. Boopathy et al. [117] discussed the merits of the NDT methods for inspecting the composite structures of the aircraft. Two approaches have been developed to detect various types of bond damages in composites by considering the surface or internal defects [129, 130]. Detection of the defects of the composite structures by using piezoceramic sensors has been studied by Kessler and Spearing [65]. Structural health monitoring (SHM) methods were implemented for online monitoring of composite structures [131-135]. Two inspection methods for the composite bond were analyzed by Crane and Dillingham [116]. They included a brief review of inspection methods for the adhesive bonds. Lissenden and Rose [120] embedded piezoelectric fibers into the composite materials and experimentally evaluated its performance. Sensor embedded composite structures have great potential for implementation in military applications.

Electromechanical Impedance (EMI) method is one of the most popular linear SHM method. Surface response to excitation (SuRE) method is the cheaper alternative of the EMI approach, and give the user freedom for selection of the sensor and the location of the monitored response [136-140]. The SuRE method detects the developing structural defects by monitoring the variation of the frequency response of the structure when it is excited by using a sweep sine wave in a broad frequency range. In this study, SuRE method is used for inspection of the bonds of composite joints. 


\subsubsection{Experimental setup}

To evaluate the performances of the SuRE method, contamination between two plates were simulated. Two square carbon fiber composite plates with $11.75 " \times 11.75 " \times 0.06 "$ dimensions were held together by using four nickel-plated magnet pairs each with 1" diameter and $3 / 8 "$ thickness. Aluminum foils were used to act like simulated contamination or debonding. Two PZT disks with the distance of 6" were attached to the top plate. One of them was used as an exciter, and the other one was used as the sensor. Three different sizes of aluminum foils were used to act as the contaminant by separating the composite plates. The diameter and the thickness of the PZT disks were 0.8" and 0.04" respectively. The signals of the PZT disk were recorded at $1 \mathrm{MHz}$ sampling rate.

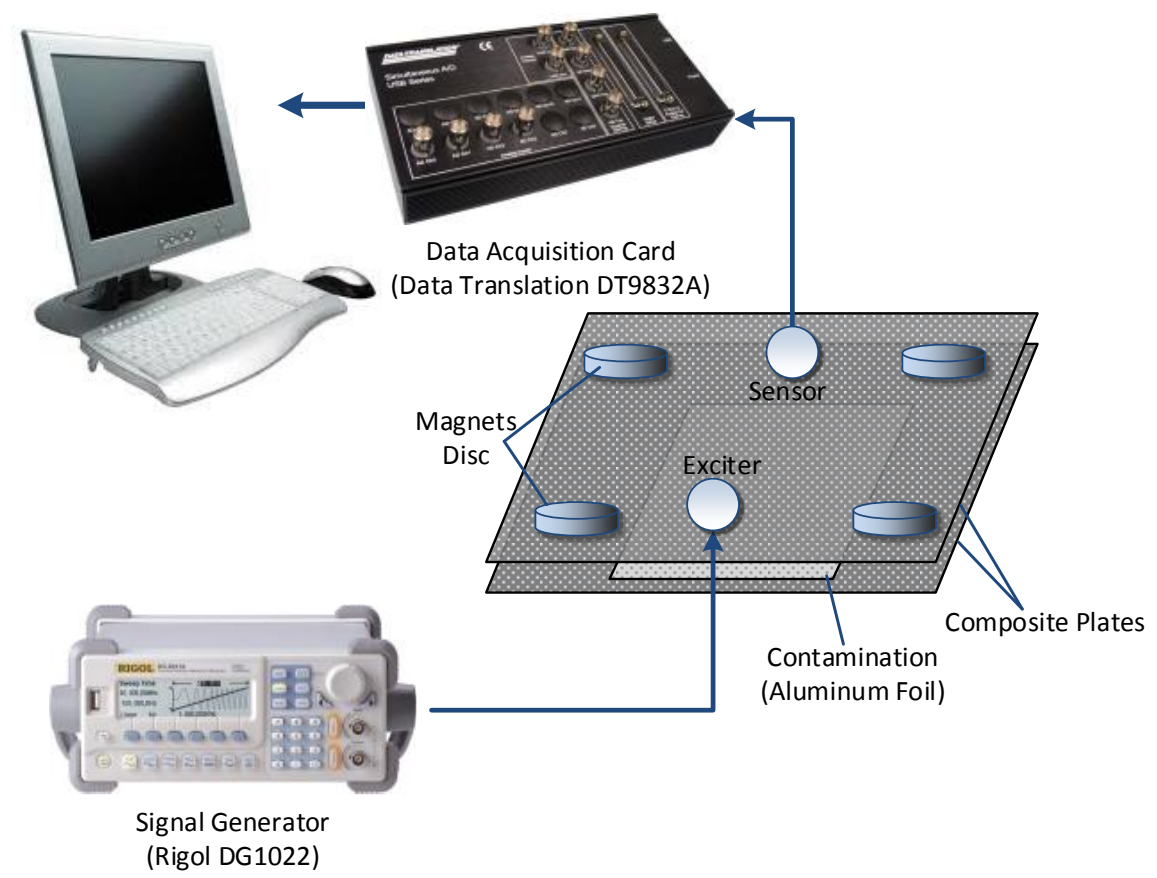

Figure 54 Schematic of the bond inspection in composite plates using the SuRE method 


\subsubsection{Results and discussion}

Two sets of experiments were performed to detect the size of simulated contamination between two composite plates when composite plates were held together using magnet pairs. In the course of the experiment, it was shown that heterodyne effect and SuRE method can efficiently detect the simulated contaminations in the composite bonds as nonlinear and linear SHM methods, respectively

Experimental setup in Figure2 was used. A sweep-sine wave from $10 \mathrm{kHz}$ to $370 \mathrm{kHz}$ was applied to the PZT on the top plate (Figure5). The other PZT at the bottom plate was used as the sensor. The baseline data was collected when the composite plates were held together without any aluminum foil between them. The spectrum of the signal was calculated by using the FFT. The experiment was repeated three times with the different size of aluminum foil were sandwiched between the plates. The spectrums collected at the four tests are presented in Figure5. Experiments were performed without any foil, and three different sizes of foils were sandwiched between the plates. 


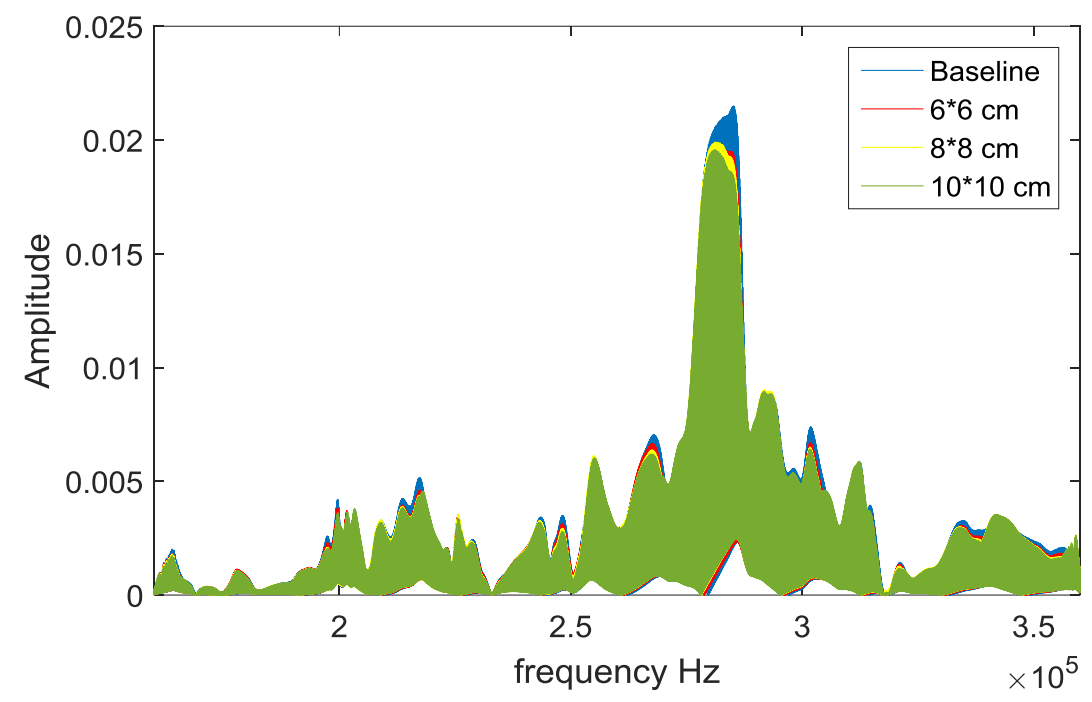

Figure 55 Comparing the spectrums obtained from four different experiments to evaluate the performance of the SuRE method.

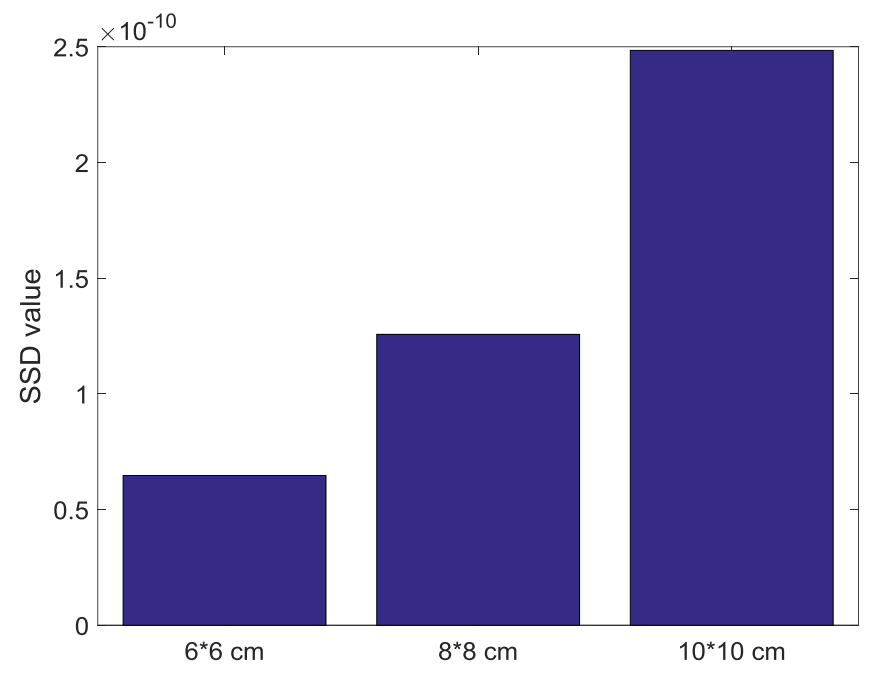

Figure 56 SSD results at different levels of simulated contamination

The SSD increased when the size of the simulated contamination between two composite plates increased. The results indicated that the SuRE method can be used for detection of simulated contamination between the plates. 


\subsubsection{Conclusions}

Composite materials are joined together with adhesives in many applications. Several SHM methods have been developed for detection of weak bonding and delamination which can lead to failure. The SuRE method assessed the change of the response characteristics or linear behavior.

The surface response to excitation (SuRE) method was used for the detection of simulated contamination between two composite plates with a linear SHM method. A PZT attached to the top plate was used to excite the surface of the top composite plate at a broad frequency range. Second PZT on the same plate was used to monitor the surface waves. The sum of the squares of the differences SSD increased with the increase of the size of the simulated contamination between two composite plates. The SSD index was reasonably sensitive to the changes of the simulated contamination size.

Based on the results, use of SuRE methods is feasible for detecting separation between the joined composite plates with sturdy fasteners or adhesives. The SuRE method was highly sensitive to the simulated contamination and size of it. However, it requires a baseline or reference data. 


\subsection{Validation of SuRE method using Comsol software}

In this study, a simple experimental setup including an aluminum plate and two piezo electric transducers attached on the top of the plate as sensor and exciter are modeled. The structure is excited in the broad frequency range using sweep sine wave and response of the system is recorded with the help of a set of probe points. By calculating sum of the square of the differences (SSD), changes in the frequency response of the system due to different size of the simulated milling operation are investigated. COMSOL Multi-physics software was utilized to develop a numerical model for the simulation of our experimental setup.

\subsubsection{Experimental setup}

The model in this study used piezoelectric device module of COMSOL to simulate piezoelectric transducers which were used as both sensor and actuator. Figure 64 shows the simple schematic of a $28 \mathrm{~cm} \times 8 \mathrm{~cm}$ aluminum plate with a thickness of $4 \mathrm{~mm}$ along with two cylindrical piezoelectric transducers with the radius of $2 \mathrm{~cm}$ bonded on top of it. One of the PZT transducers is going to be the sweep frequency exciters. On the other side of the plate, the sensing PZT was attached. As it was explained in previous chapters, a sweep sine wave with a broad frequency range will be applied to the exciter and the receiver will collect the response of the system on the other side of the plate. 


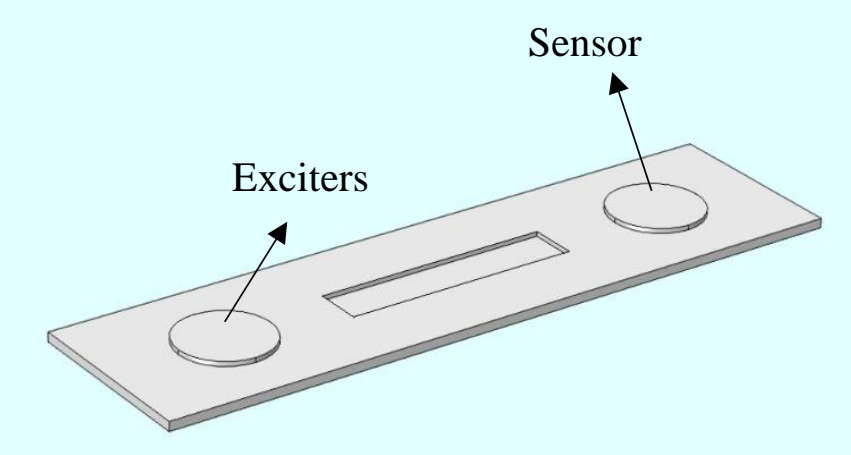

Figure 57 Experimental setup

Table 2 Dimensions of plates and PZTs

\begin{tabular}{|c|c|}
\hline Name & Value \\
\hline Length of plates & $0.28 \mathrm{~m}$ \\
\hline Width of plates & $0.08 \mathrm{~m}$ \\
\hline Height of plates & $0.004 \mathrm{~m}$ \\
\hline Radius of PZTs & $.02 \mathrm{~m}$ \\
\hline Height of PZTs & $0.002 \mathrm{~m}$ \\
\hline Voltage & $20 \mathrm{~V}$ \\
\hline
\end{tabular}

The model was created in COMSOL's piezoelectric device module and the time-dependent study was used. Lead Zirconate Titanate (PZT-4) with a density of $7500 \mathrm{~kg} / \mathrm{m}^{\wedge} 3$ was the chosen material for PZT transducers. The boundary condition of all four sides of the plate defined fixed constraints and everywhere else was free. The lower surface of PZTs which is attached to the plates was considered as ground with a zero charge and upper surface of 
exciters was charged with the sweep sine waves. The upper surface of the sensor was connected to the probe to be monitored. As it can be seen in Figure 5-1, the model meshed with free tetrahedral elements when the minimum mesh size was set 5400 um and the maximum mesh size was set at $30000 \mathrm{um}$.

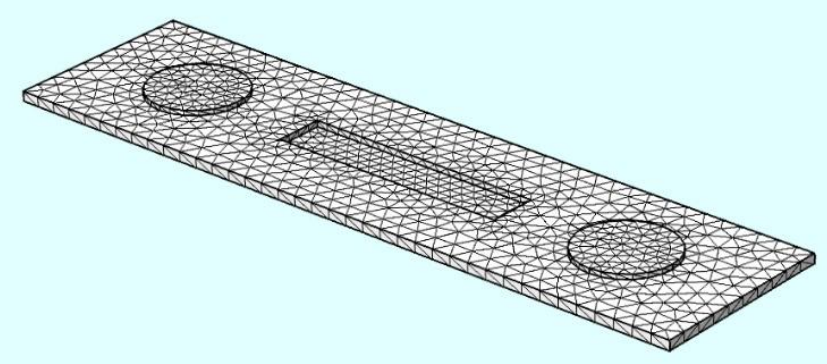

Figure 58 Meshed structure

In the SuRE method, the structure is excited with the wide range of frequencies and the response of the system will be captured. Then, the Fast Fourier Transform (FFT) of the response signal will be calculated. To simulate this process, a sweep sine wave was applied to the PZT exciter and in time domain study, the response signal was captured. Then, by using the time to frequency study, the FFT of the response signal was obtained. 


\subsubsection{Simulation results}

In Figure below, the time domain plot for input signal has been shown. As it can be seen, a sweep sine wave with the frequency range of $10 \mathrm{kHz}$ to $100 \mathrm{kHz}$ was applied to the PZT exciter.

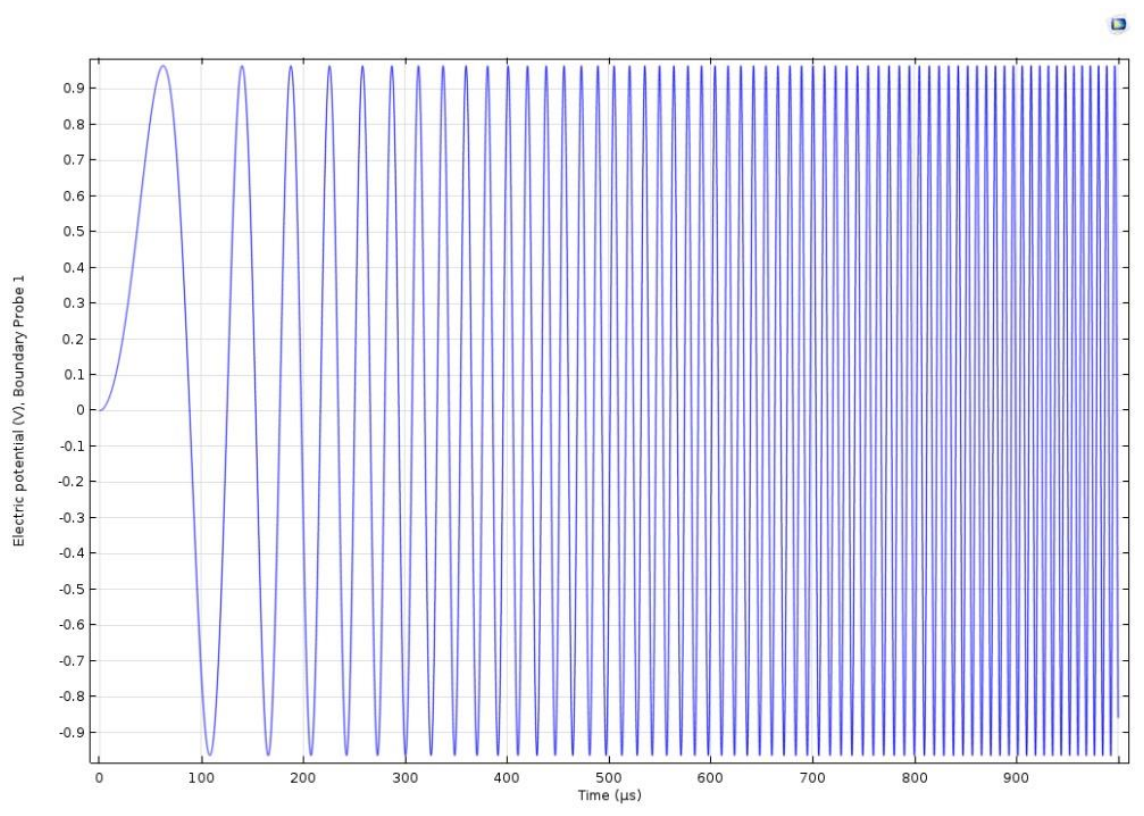

Figure 59 Excitation signal

Then, the response signal from the probe points was obtained when there was no damage on the surface of the plate. Time and frequency response of the plate has been shown in Figures below: 


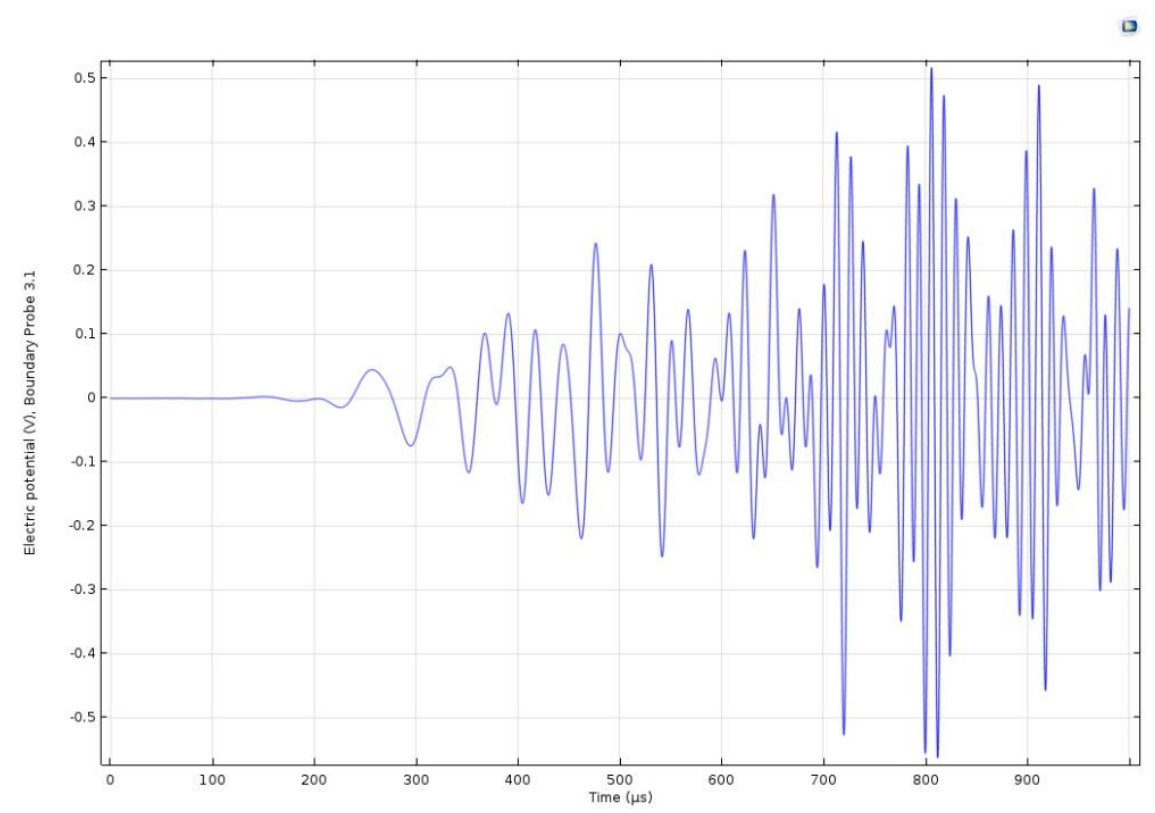

Figure 60 Time domain response for pristine plate

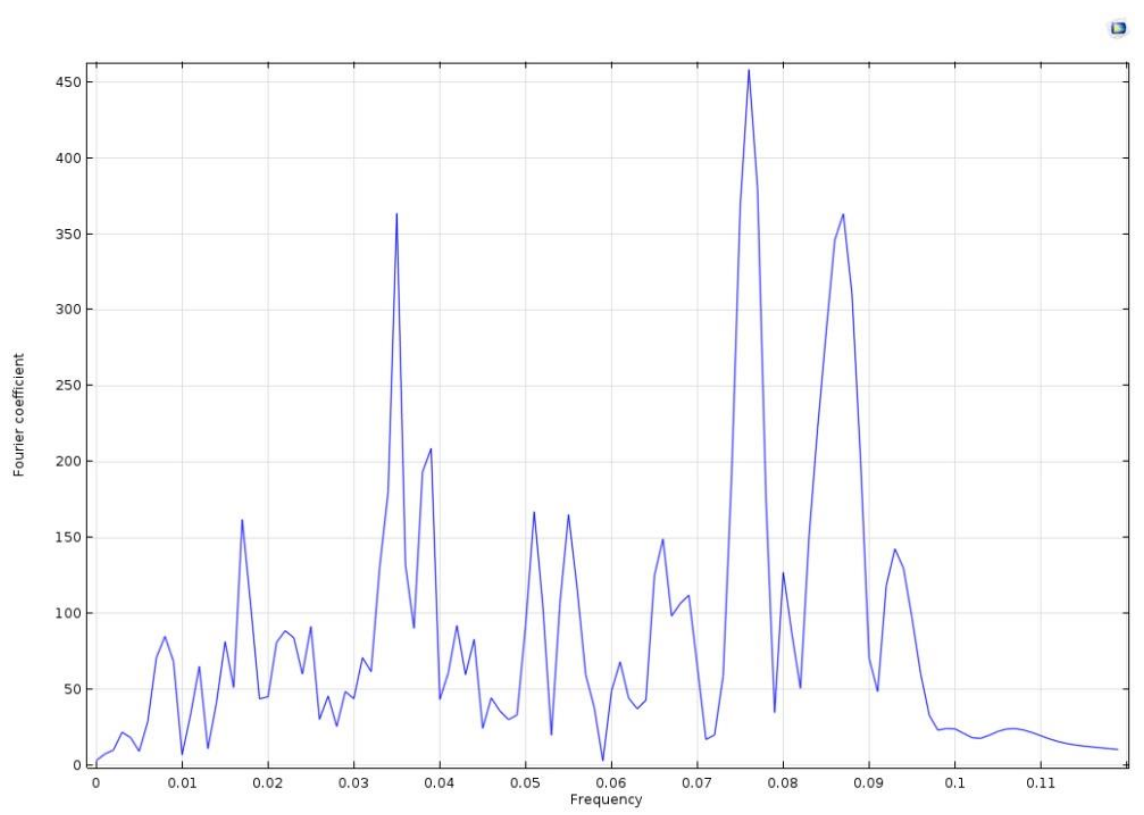

Figure 61 Frequency domain response for pristine plate

Then, a simulated milling operation with the size of $9 \mathrm{~cm} \times 2 \mathrm{~cm} \times 2 \mathrm{~mm}$ was applied on the surface of the aluminum plate. Here is the time and frequency response of the structure: 


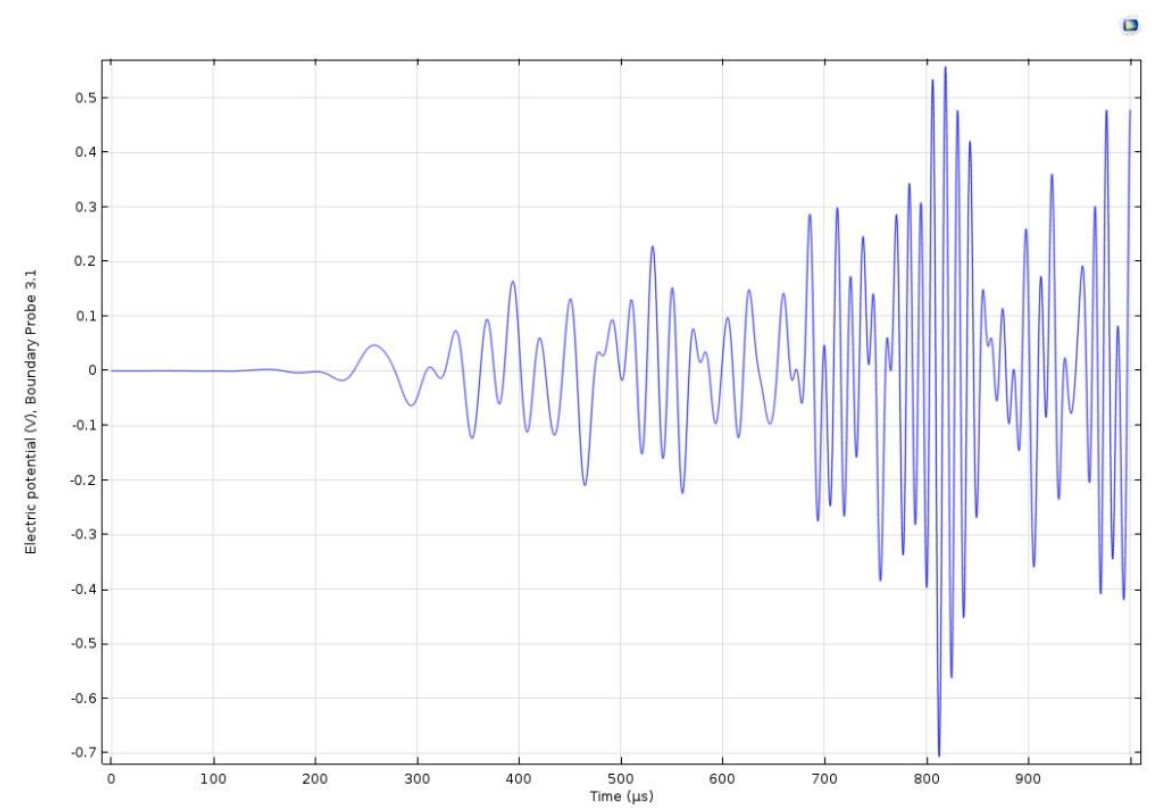

Figure 62 Time domain response for a plate with $9 \mathrm{~cm} \times 2 \mathrm{~cm} \times 2 \mathrm{~mm}$ milling

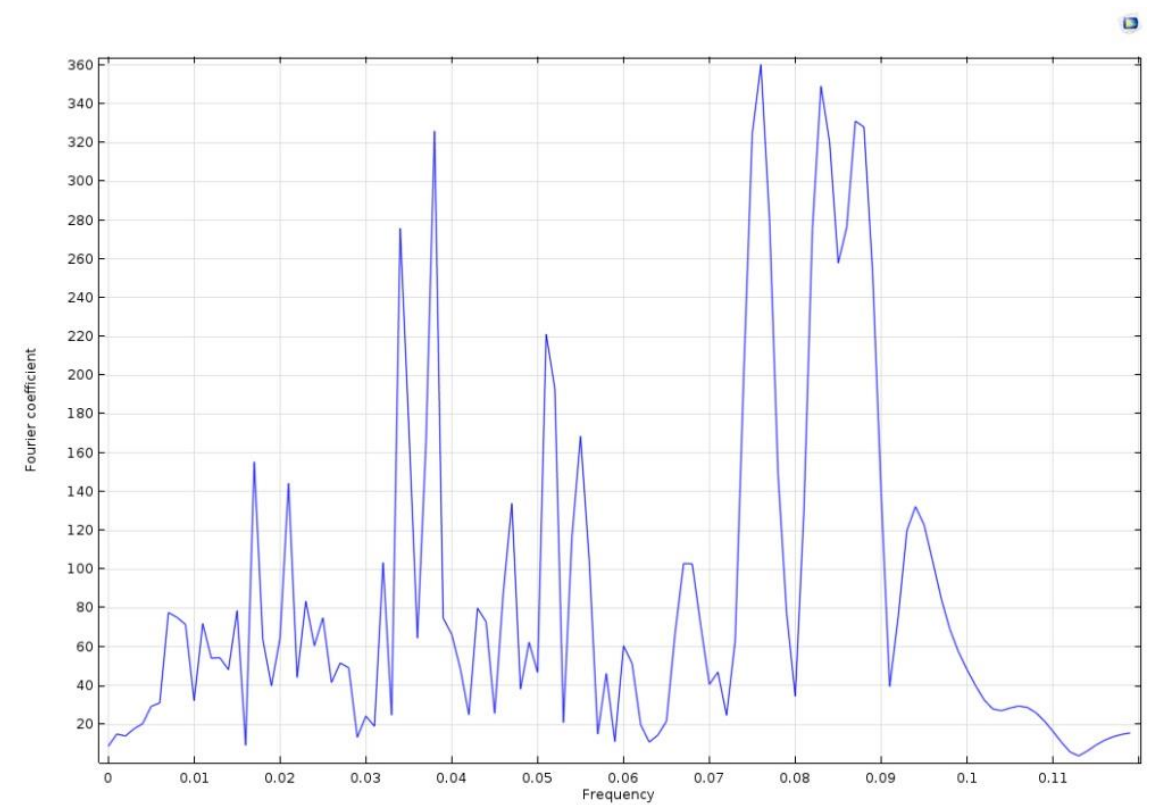

Figure 63 Frequency domain response for a plate with $9 \mathrm{~cm} \times 2 \mathrm{~cm} \times 2 \mathrm{~mm}$ milling

In the next step, the depth of the milling operation was increased to the $2.5 \mathrm{~mm}$. Time domain response was captured and FFT of the signal was calculated: 


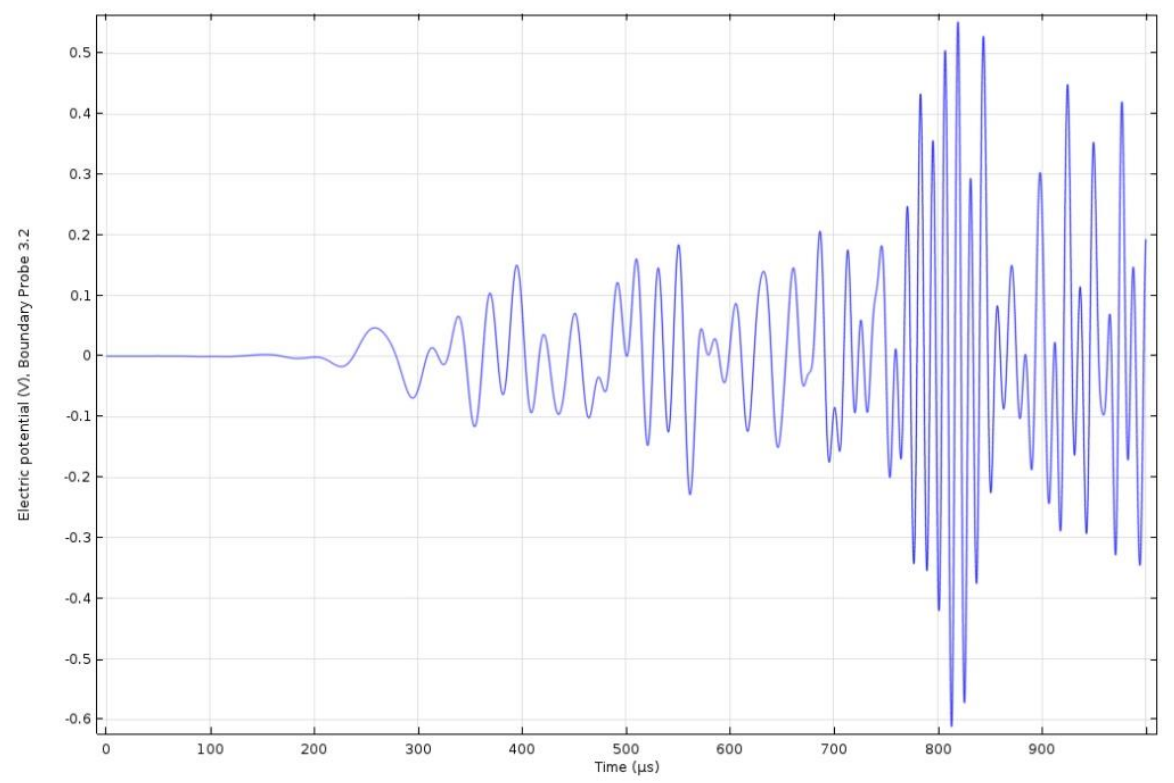

Figure 64 Time domain response for a plate with $9 \mathrm{~cm} \times 2 \mathrm{~cm} \times 2.5 \mathrm{~mm}$ milling

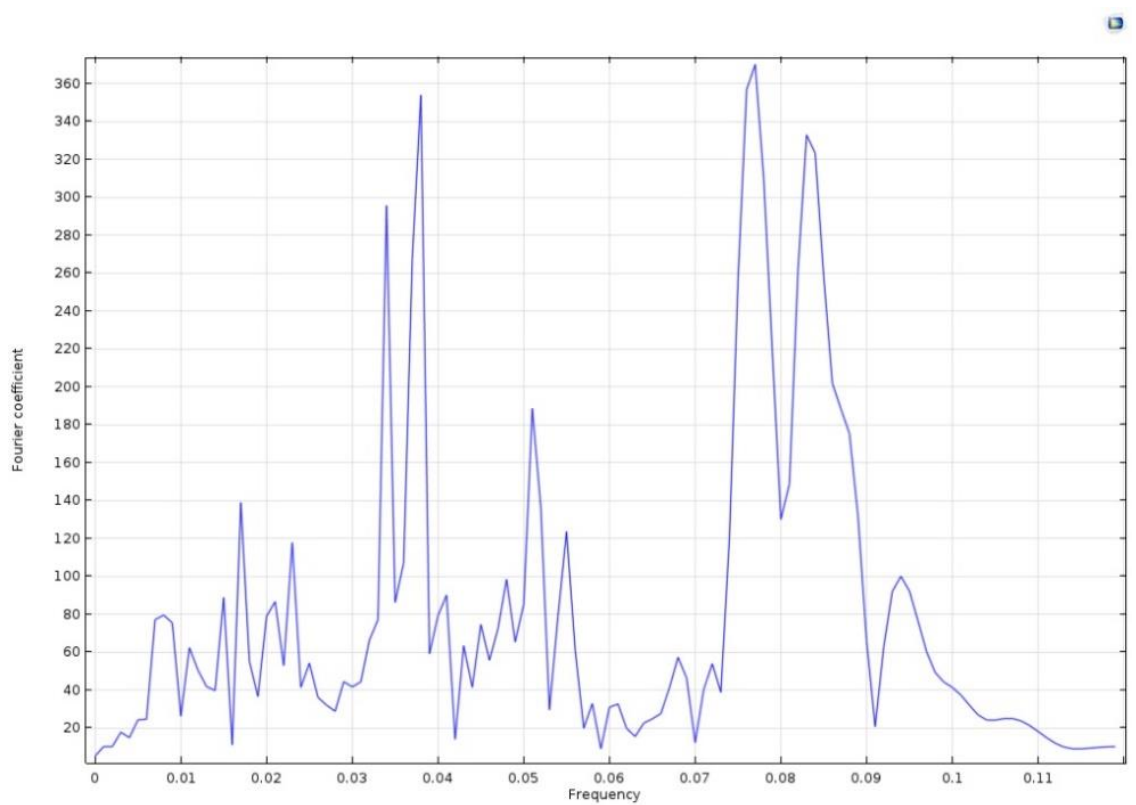

Figure 65 Frequency domain response for a plate with $9 \mathrm{~cm} \times 2 \mathrm{~cm} \times 2.5 \mathrm{~mm}$ milling

Finally, by increasing the depth of the milling operation to $3 \mathrm{~mm}$ and recording the response of the structure, changes in the frequency response were investigated: 


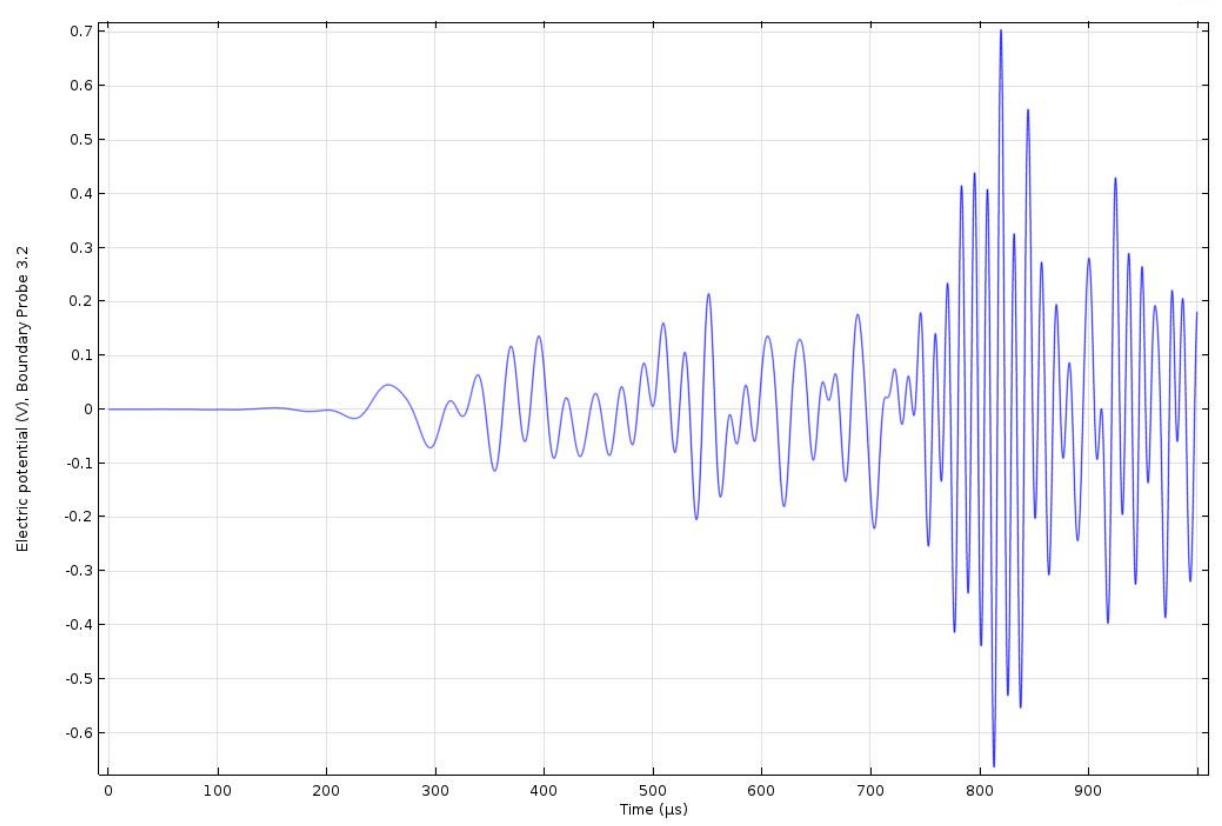

Figure 66 Time domain response for a plate with $9 \mathrm{~cm} \times 2 \mathrm{~cm} \times 3 \mathrm{~mm}$ milling

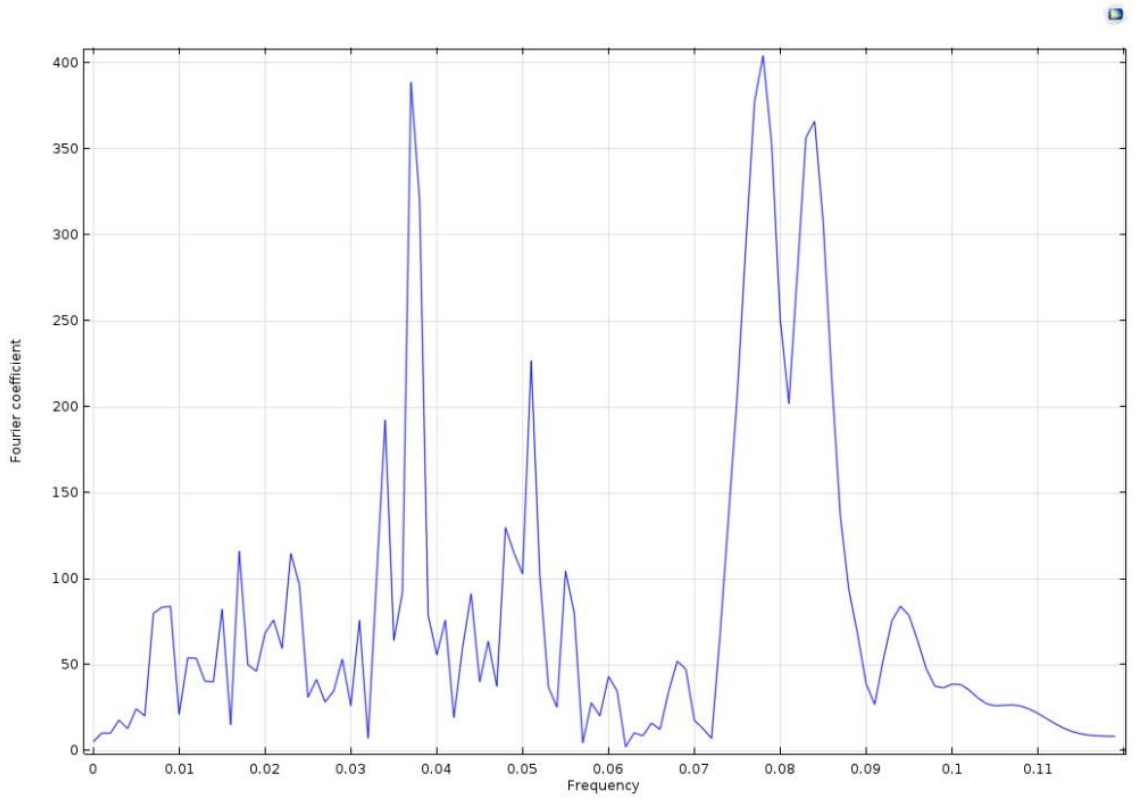

Figure 67 Frequency domain response for a plate with $9 \mathrm{~cm} \times 2 \mathrm{~cm} \times 3 \mathrm{~mm}$ milling 
In order to compare the frequency response of the structure in the presence of various size of milling operation and also quantify this difference, the sum of squares of difference (SSD) index for each size of milling was calculated:

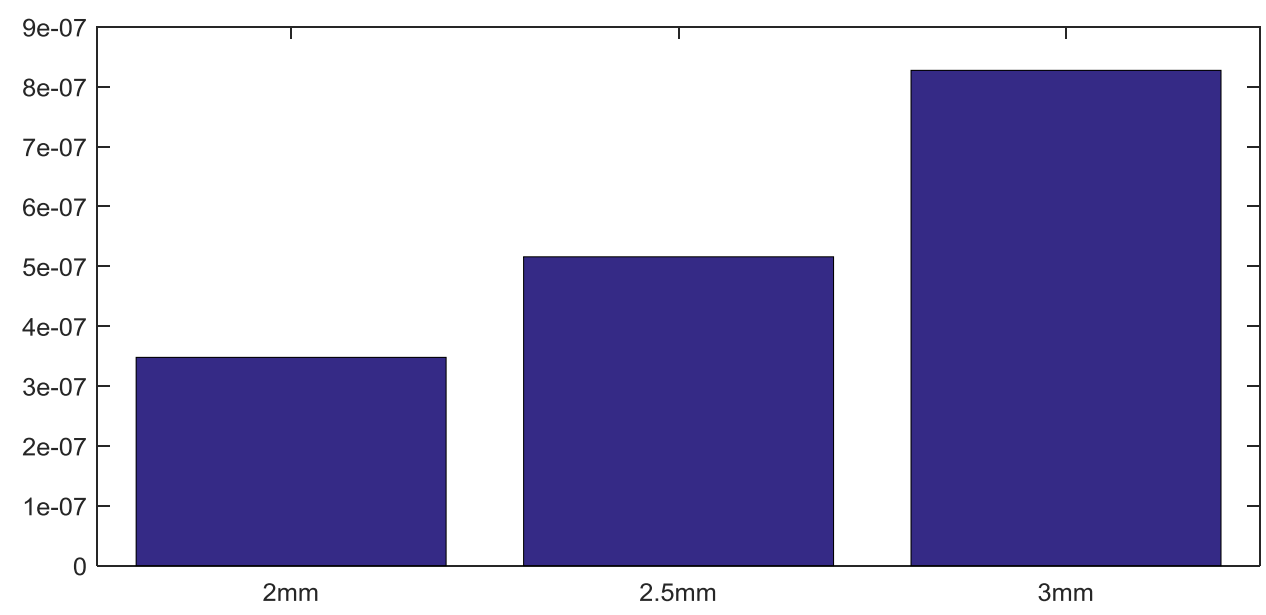

Figure 68 Summation of the squares of the difference (SSD) for different size of the milling operation

\subsubsection{Conclusion}

In this study, the experimental result of the SuRE method for the investigation of different size of milling operation on aluminum plate was validated by the help of a finite element software. COMSOL Multi-physics software was utilized to develop a numerical model for the simulation of the SuRE method when a simple experimental setup including aluminum plates with two PZT transducer bonded on the surface.

The structure was excited using a broad range of frequencies. Then, the response of the system for pristine plate and plates with three different sizes of simulated milling operation was captured. The frequency response of the structure for each one of them was obtained and SSD values were calculated. As it was shown in the results, by increasing the depth of milling operation in each step, SSD value also increased. 
CHAPTER 4

4. IMPLEMENTATION OF NONLINEAR METHODS 


\subsection{Monitoring the Health of Adhesively Bonded and Fastened Composite Joints}

Composite materials are a preferred choice when high strength/weight ratio and resistance to corrosion are needed. For assembly, composite parts are joined by using adhesives and/or fasteners. Due to the increased use of composites, there is a need for reliable and affordable structural health monitoring (SHM) methods for the detection of weakened bonds and loosened fasteners.

The heterodyne effect may be utilized for the evaluation of debonded area when the linear characteristics of the system changes to nonlinear as a result of light contact in the bonding zone and this nonlinear system responds to appropriate bitonal excitations with new frequencies. Nonlinear elastic wave spectroscopy (NEWS) methods are using the same concept although they are limited to the combination of a high and a low frequency. The heterodyne method allows the engineers to have control over the new output frequencies as indicators of nonlinearity in the target structure.

In this study, implementation of the heterodyne method is proposed for identification of the debonded region and evaluation of the compressive forces applied to facing plates. The proposed SHM method proved to be effective in both scenarios. Then, in another experimental setup, heterodyning effect method is implemented for exploring various contamination levels in composite bonds. Results show that the proposed method can be used effectively in the composite bond inspection.

\subsubsection{Introduction}

Composite materials have gained popularity in high tech applications due to their high strength-to-weight ratio and durability against corrosion. Composite parts may be joined by using adhesive bonding and/or fasteners including rivets and bolts. Weakening or 
partial separation of bonded regions or their delamination drastically reduce the strength of the structure and may lead to failure [141-143]. Similarly, fasteners may loosen during the service life of structures and cannot hold the parts with the required strength. Structural health monitoring (SHM) methods have been developed for early detection of growing defects and/or for scheduling maintenance operations at the right time to minimize the process cost and downtime. Although several SHM methods already exist, developing new methods to simplify the instrumentation, signal processing, and data management are crucial. In this study, implementation of the heterodyning method is proposed for inspection of the composite joints that are bonded with adhesives or held together with fasteners. The proposed SHM method is used for identification of the debonded regions and evaluation of the compressive forces applied to the plates by fasteners. Finally, it was tried to investigate the level of contamination in composite bonds using SuRE method which uses electro-mechanical impedance signatures of the structure and heterodyning method which works based on the change of the characteristic of the structure from linear to nonlinear.

Typically, SHM methods can be divided into two primary groups, these are termed active or passive, depending on if an exciter is used during inspection [144-146]. Among the passive methods, Acoustic Emission (AE) is one of the most popular methods for identification of developing defects in planar composite materials [147-149]. Acoustic Emissions are created by the generation of transient waves due to the rapid release of strain energy within the damaged composites after a defect is developed. Active methods, however, excite the system using appropriate excitation signals and monitor the response of the system. These methods are the most effective SHM methods for estimating the 
location, severity, and type of defects [150-153]. Active methods can furtherly be categorized into linear and nonlinear methods. The majority of active linear methods compare the characteristics of the data taken from a system in a pristine condition with the data at a later time for identification of defect [154-156]. In these type of methods, linear characteristics of structures, such as time of flight of the excitation waves between the actuator and the sensor, reflections from the defects and changes of the impedance of the attached Lead zirconate titanate (PZT) transducers are considered as main parameters for fault detection. However, using these methods for damage detection in early stages of defect growth and nucleation can be problematic and challenging.

Recently, researchers have shown that some types of damage including debonding, cracks, and delaminations change the linear behavior of structure into nonlinear. It is possible to detect the development of these defects by recognition of the nonlinear behavior [157-161]. In these methods, there is no need for collection of the reference (baseline) data from the pristine structure for further processing. Nonlinear elastic wave spectroscopy (NEWS) methods are most prevalent approaches in this area and are able to detect the nonlinear behavior of structures at early stages [162-173]. Non-linear wave modulation spectroscopy (NRUS) and non-linear resonant ultrasound spectroscopy (NWMS) are well-known NEWS methods. In NWMS approach, two different actuators are used to excite the structure at very low and high frequencies. Although the selection of appropriate excitation frequencies plays a pivotal role in the progress of damage detection, researchers were not able to come up with a practical and efficient approach for an assortment of proper frequency combinations. 
In linear SHM systems, the primary focus is on monitoring the response in excitation frequencies. A certain type of damages, such as cracks, debonding and delamination cause the structure to behave as a nonlinear system and respond with newer frequencies. When these non-linear systems are excited with bitonal excitation, the new frequencies appear in the response of the system at the difference, summation and some other harmonics of the two excitation frequencies. This phenomenon is known as the heterodyne effect [174-178] and has been effectively used by electrical engineers to create new frequencies at desired frequency range in communication systems. This method uses relatively low voltage excitation signal and it is not limited to the combination of a high and a low frequency which can simplify the selection of excitation frequencies.

\subsubsection{Implementation of the Heterodyne Effect into SHM}

In this study, the implementation of the heterodyne method for SHM of composites is proposed. Two approaches were considered for joining composite plates: Bonding with adhesives and fasteners. The proposed SHM method was employed to detect the debonding and weakening of the joints.

For the implementation of the heterodyne effect in SHM, one of the plates was excited with two and also three excitation frequencies. Identical PZT disks were used as excitation source and sensors in this study. Two harmonic signals may be applied to two different exciters or in order to reduce the number of exciters, a modulated signal containing the required frequencies may be applied to a single exciter. The transmitted signal is then measured in the adjoining plate. The frequency spectrum of the monitored signal is calculated. When the system is linear, spikes are not expected at new frequencies. 
However, development of the new spikes corresponds to the presence of the debonding or having weakly held plates with fasteners.

Different frequency combinations and modes interact differently with a potential defect. Therefore, different levels of nonlinear mixing occur when different frequency combinations are used. Selection of the appropriate excitation frequencies is critical for ensuring an accurate and effective monitoring process. In this study, initially, a sweep sine wave in a broad range of frequencies was applied to one of the exciters on the system with an artificially made defect. Then the response signal was sampled and the time-frequency plot was obtained. Noticeable spikes were observed in the Short-Time Fourier Transform (STFT) of the response at some harmonics of the excitation frequencies. These are the frequencies that the system is already showing a high level of nonlinearity. Therefore, these areas are selected as the most suitable frequency range for applying heterodyning method.

\subsubsection{Experimental Setup}

In this study, three separate experimental setups were used to evaluate the performance of the proposed SHM methods. The first setup was designed to detect debonding in a composite coupon by using the heterodyning effect method. In the second setup, the heterodyning method was utilized to evaluate the compressive forces holding two composite plates together. Finally, for exploring bond strength in composite materials, various contamination levels in composite bonds were investigated using both heterodyning method and surface response to excitation method. Identical piezoelectric 
disks with a 10-mm diameter and a 2-mm thickness were used for the excitation and sensing in all experimental setups.

\subsubsection{Detection of composites debonding by using heterodyne effect}

In the first experiment, two 1" x 10" unidirectional prepreg carbon fiber composite coupons with the thickness of $0.1 "$ are manufactured and bonded together by using 3M AF 555 Structural film adhesive. To create a 2-inch-long debonding, no adhesive was applied to the left side of the bonded coupons. The diagram of the experimental setup is presented in Figure 2 and shows the debonding at the left side of the coupon. Three piezoelectric disks were attached to the bonded coupons, with the middle disk acting as the exciter. The objective of the experiment was to study the alteration of the signals received by the piezoelectric disks attached to the opposite ends due to nonlinear behavior of the structure.

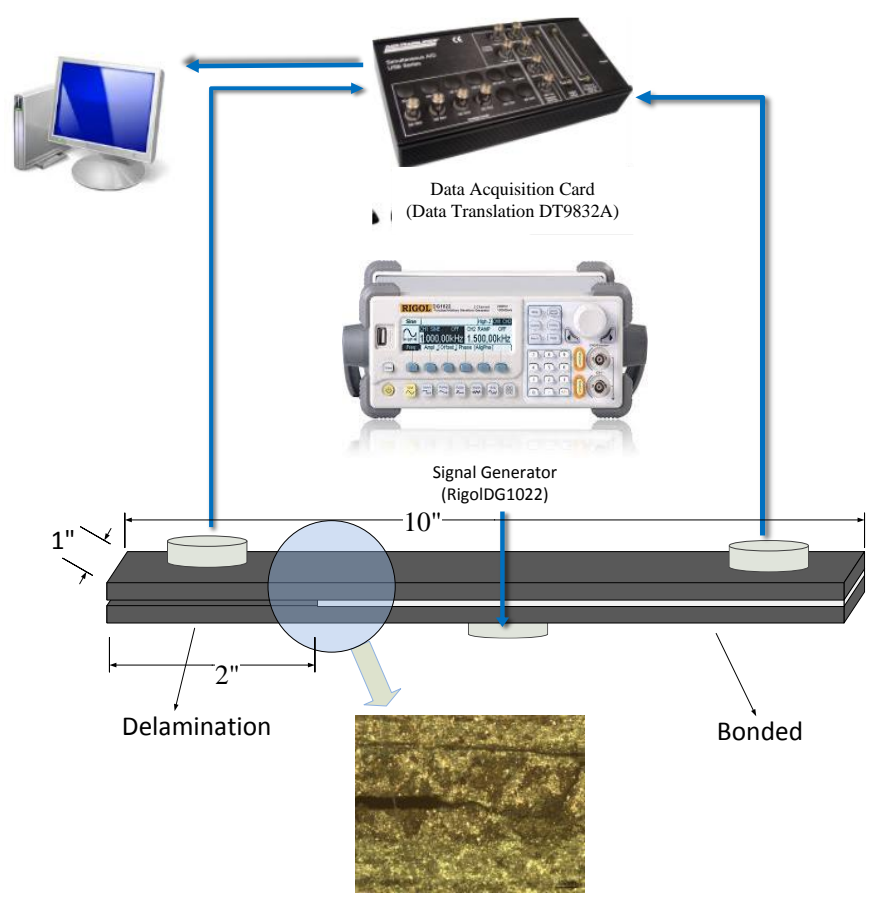

(a) 


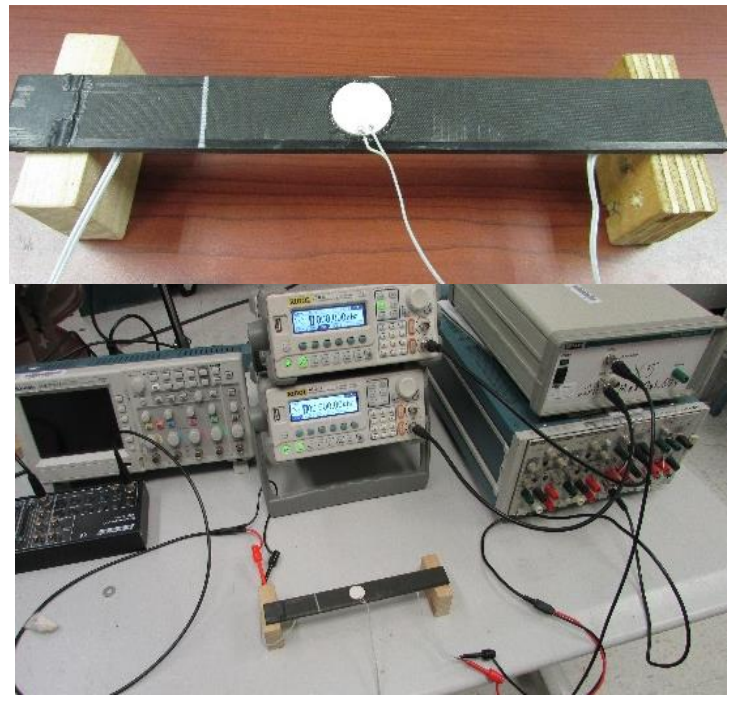

(b)

Figure 69. Schematic of the experimental setup for detection of delamination

\subsubsection{Evaluation of the compressive forces on the composite plates}

The second experiment was designed to evaluate the compressive forces used to hold two composite plates together. Two $11.75 "$ x $11.75 "$ carbon fiber composite panels were held together by using seven pairs of nickel-plated magnets (Figure68) each with 1" diameter and 3/8" thickness. The separation force of two magnets was measured to be 46.61lbs when touching. The configuration of the magnet pairs is shown in Figure68. Two PZT disks were attached to the top panel to excite the system with two harmonic waves. Another PZT disk was attached to the center of the bottom panel which acts as a sensor. The diameter and the thickness of the PZT disks were 0.8 " and $0.04 "$ respectively. The signals of the PZT disk at the center were recorded using a $1 \mathrm{MHz}$ sampling rate. 


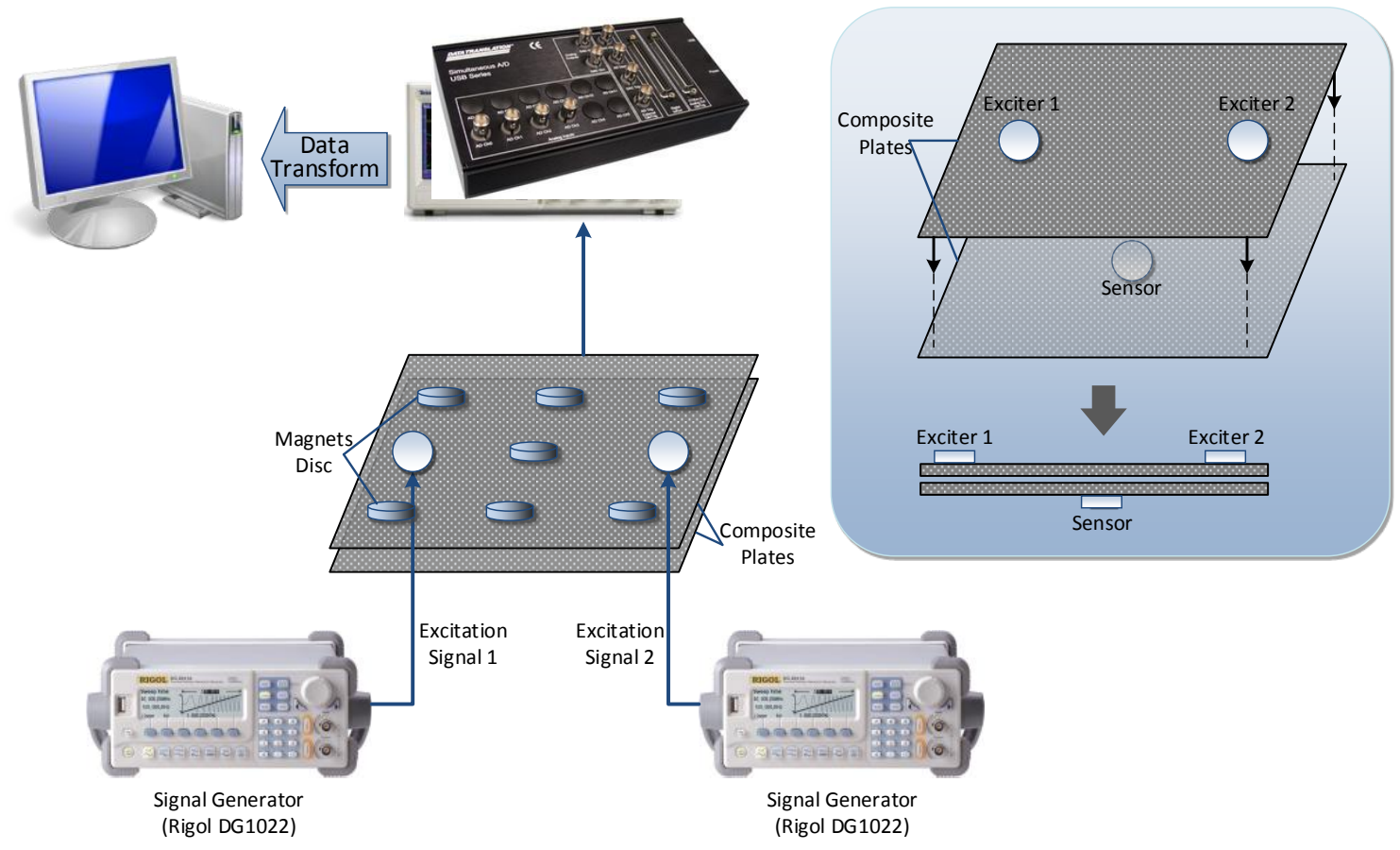

(a)

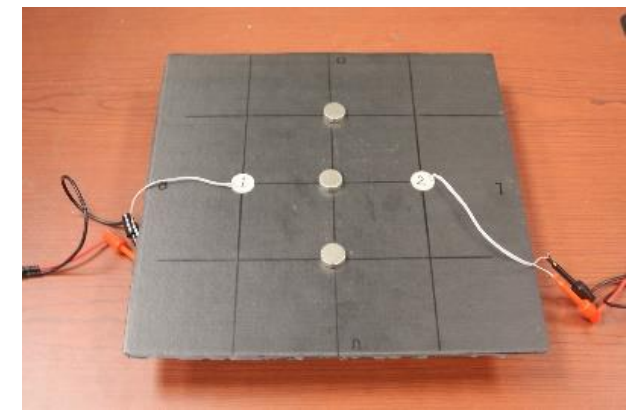

(b)

Figure 70. Schematic of the joint inspection in composite panels using heterodyning effect

\subsubsection{Detection of various contamination levels in composite bonds}

The third experimental setup was made to detect various contamination level in composite bonds. In this setup four nickel-plated magnet pairs each with 1 " diameter and 3/8" thickness were used to hold two 11.75" x 11.75" carbon fiber composite panels together. 
The configuration of the magnet pairs can be seen in Figure69. First, two PZT disks were attached to the top panel to excite the system with two harmonic waves. Another PZT disk was attached to the center of the bottom panel which acts as a sensor. Three different sizes of aluminum foils were employed to be considered as a contamination between two composite panels. The diameter and the thickness of the PZT disks were 0.8 " and $0.04 "$ respectively. The signals of the PZT disk at the center were recorded using a $1 \mathrm{MHz}$ sampling rate.

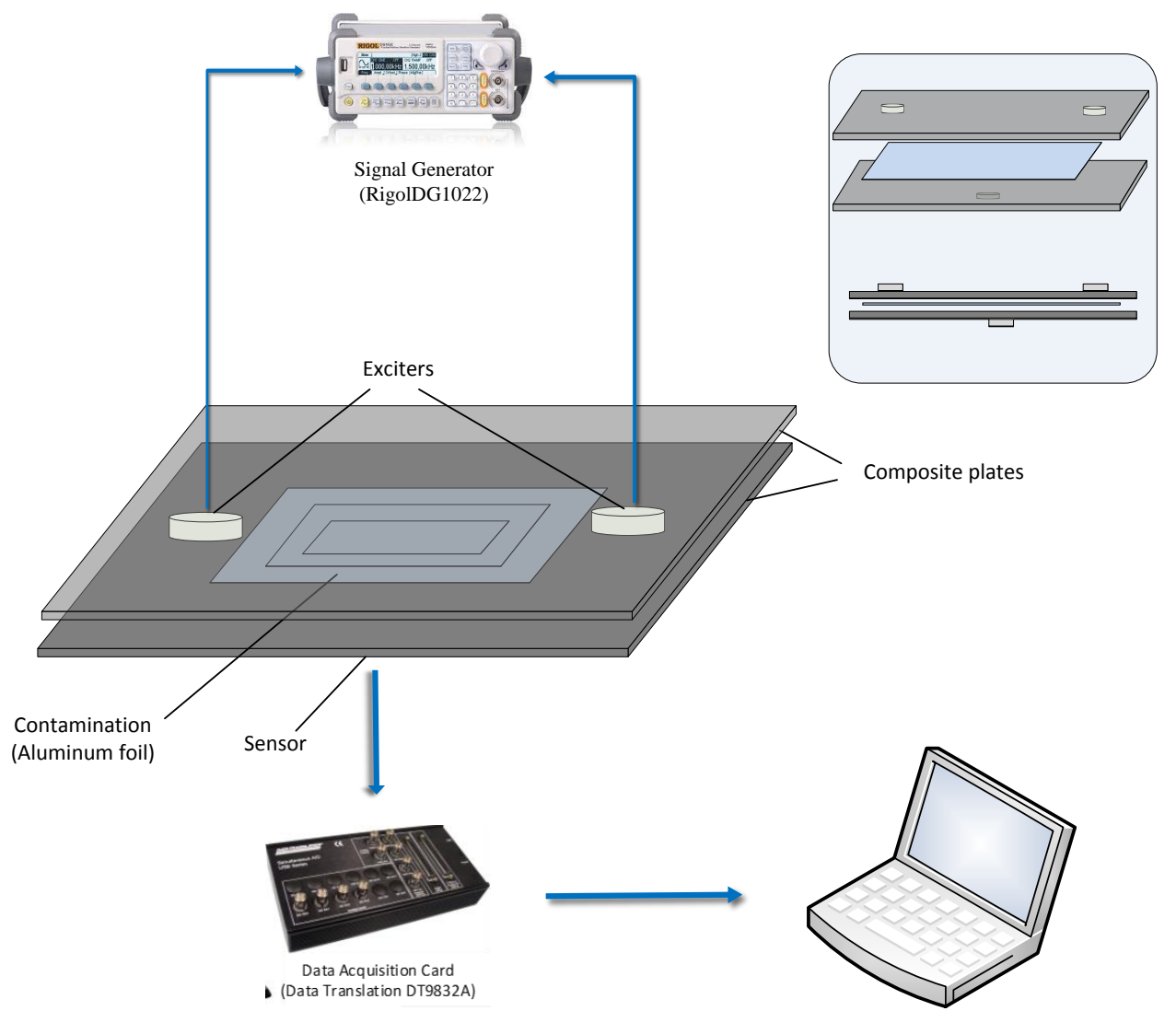

Figure 71 Schematic of the bond inspection in composite panels using heterodyning effect 


\subsubsection{Results and Discussion}

\subsubsection{Detection of composites debonding by using heterodyne effect}

For identification of the debonded region of two composite coupons, the following experiment was conducted in two steps using the experimental setup in Figure67. The optimal frequencies for excitation of the system were determined in the first place. The debonded region was then identified by using the optimal excitation frequencies.

The PZT in the middle of the top coupon was excited with a sweep sine wave in the range of $20 \mathrm{kHz}$ to $600 \mathrm{kHz}$. The signal of the PZT at the left side (same side with the debonded region) was sampled at $2 \mathrm{MHz}$ and the STFT of the response was obtained. The major nonlinear behavior of the system was observed around $250 \mathrm{KHz}$ where the lower and higher harmonics such as 125 and $375 \mathrm{KHz}$ of it show powerful spikes (Figure70). Therefore, the proposed SHM system used this frequency $(250 \mathrm{KHz})$ and also two other frequencies with a $20 \mathrm{kHz}$ difference $(230 \mathrm{kHz}$ and $270 \mathrm{kHz})$ as the excitation frequencies to remain in the nonlinear region. Briefly, the proposed SHM system excited the structure by addition of the three harmonic signals at $230 \mathrm{kHz}, 250 \mathrm{kHz}$ and $270 \mathrm{kHz}$. The response of the system at the frequency of difference $(20 \mathrm{kHz})$, which is the maximum audible frequency, were monitored for detection of debonding. 


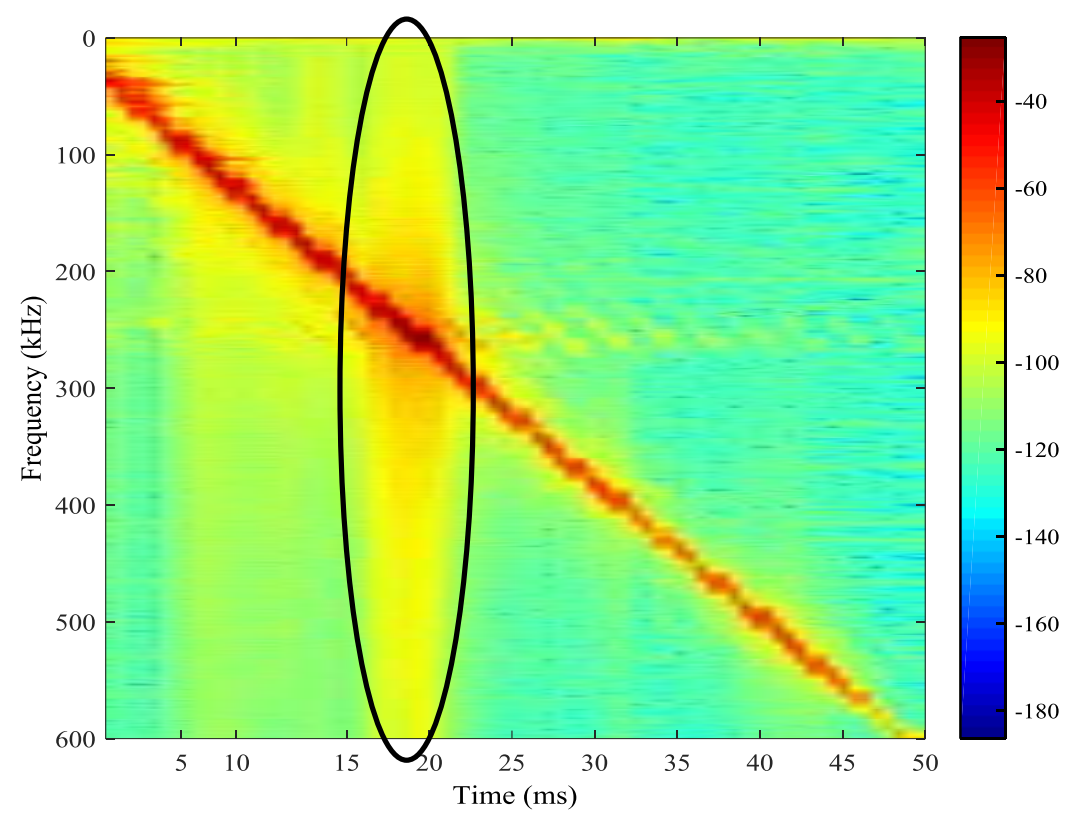

Figure 72 Time-frequency spectrum for determination of the optimum excitation frequency

The experiment for identification of the debonded region was performed when the PZT at the middle of the top composite coupon was excited via a signal created by adding 230 $\mathrm{kHz}, 250 \mathrm{kHz}$ and $270 \mathrm{kHz}$ harmonic waves for $5 \mathrm{~ms}$ when the peak to peak voltage of excitation frequencies was set on $35 \mathrm{~V}$. The spectrums of the signals were obtained using Fast Fourier transformation (FFT) and presented in Figure 70. Only the excitation signals at $230 \mathrm{kHz}, 250 \mathrm{kHz}$, and $270 \mathrm{kHz}$ were observed at the response signal on the right side of the coupon when there is perfect contact between two composite layers. However, a small spike was observed at $20 \mathrm{kHz}$ when the spectrum of the response of the system on the left side (location of debonding) was inspected. 


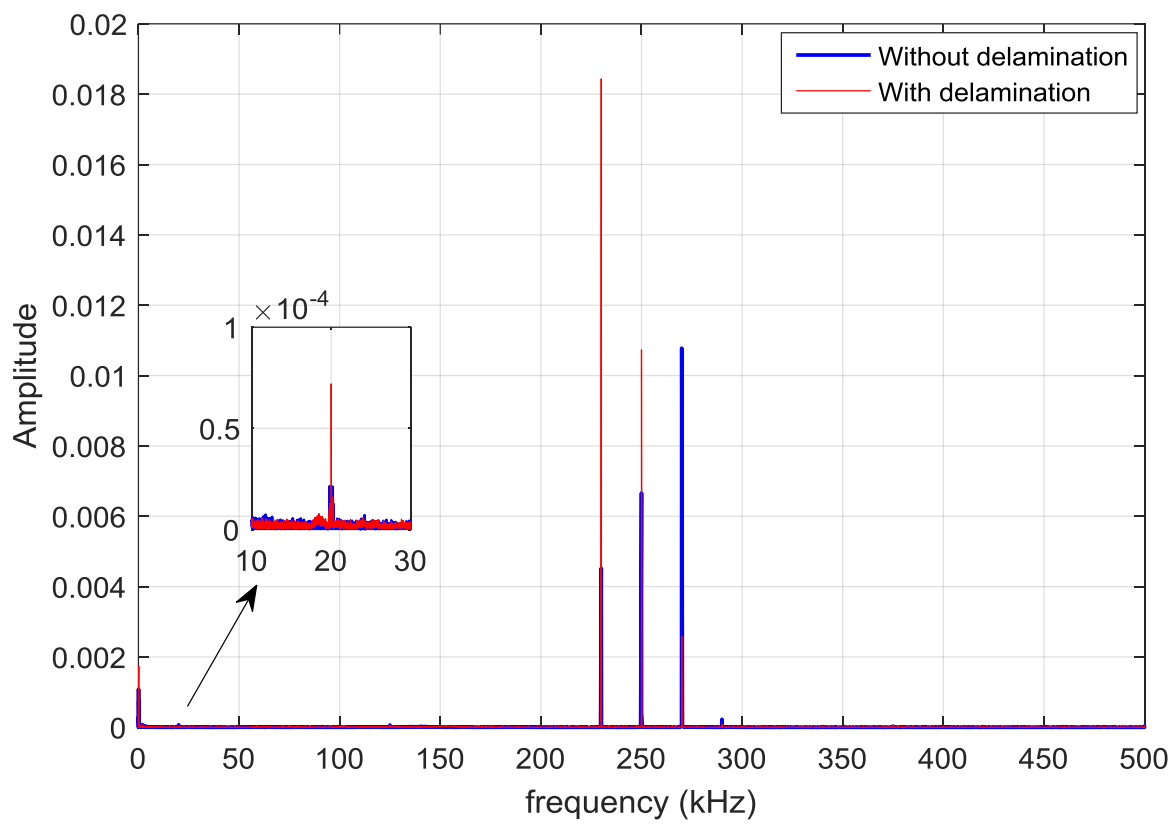

Figure 73 Comparing FFT results between perfect contact and in presence of debonding

The time-frequency plots of the PZTs at both ends are presented in Figure 8. Only the excitation frequencies appeared in time-frequency spectrum (Figure72a) of the right sensor since the right side of the coupon was bonded perfectly. On the left side of the coupon, in addition to the excitation frequencies, a line at the difference of the excitation frequencies (20 kHz) appeared (Fig 72b). The results confirmed that the debonded regions can be identified by using the heterodyne effect. 


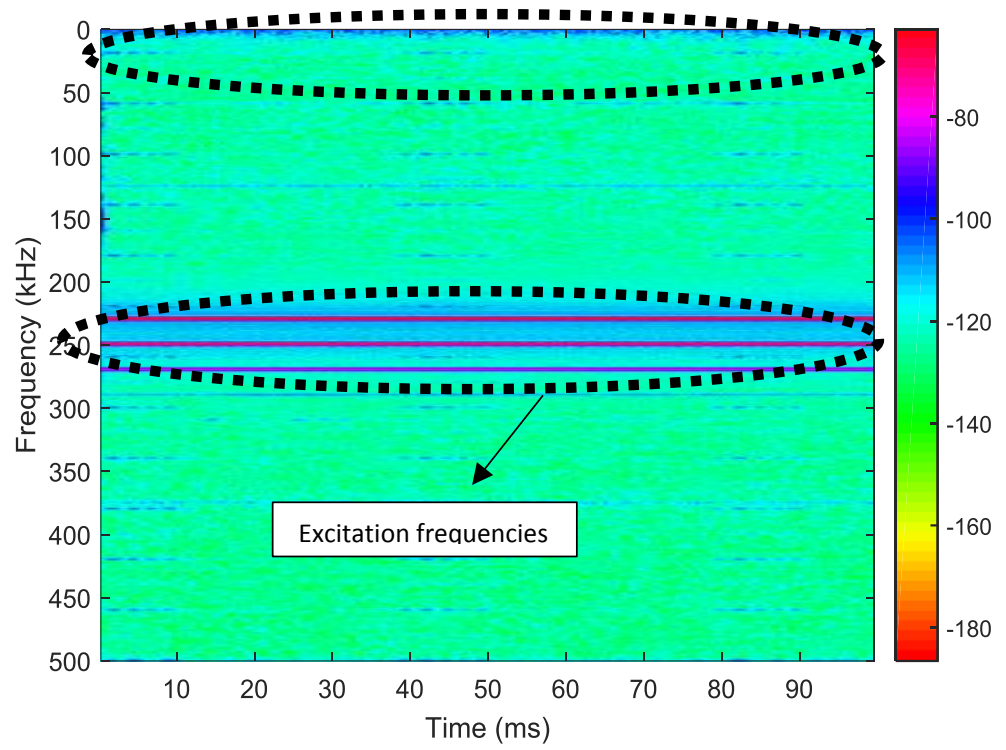

a) Spectrogram of right PZT

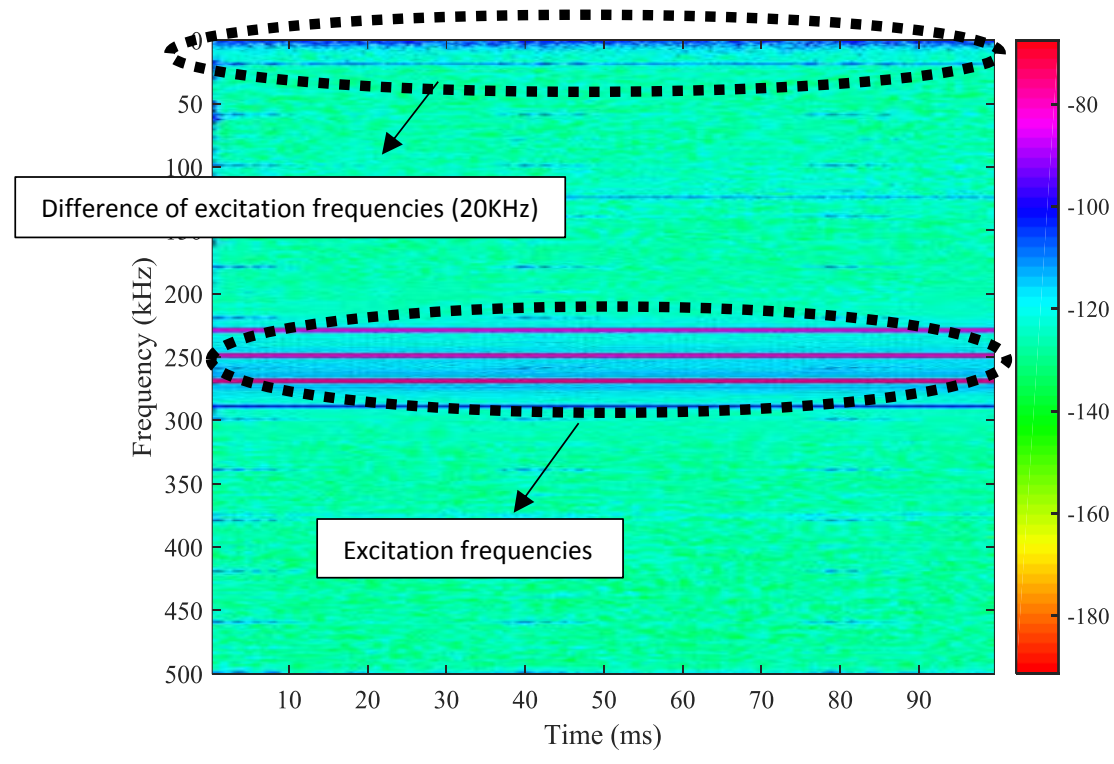

b) Spectrogram of left PZT

Figure 74 Time-frequency spectrum for identification of the debonded region

\subsubsection{Evaluation of the compressive forces on the composite plates}

Three experimental procedures were performed in this study by using the experimental setup in Figure68. The first procedure determined the optimal excitation frequencies. The 
second procedure used the selected excitation frequencies to investigate the relationship between the compressive force on the plates and the amplitude of the spike at the difference of the excitation frequencies. A series of experiments were performed when two composite plates were held together with a different number of magnet pairs. Lastly, it was shown that heterodyning effect can be created by selecting the excitation frequencies from another nonlinear region other than the ones previously determined.

A composite plate was placed on the second plate and the experimental setup in Figure68 was prepared. The PZT on the top plate was excited with a sweep sine wave from $50 \mathrm{kHz}$ to $350 \mathrm{kHz}$. The spectrogram of the PZT signal at the bottom is presented in Figure73. The structure showed the major nonlinear behavior around $120 \mathrm{kHz}$ and $135 \mathrm{kHz}$. These frequencies were selected as the excitation signal for the second procedure.

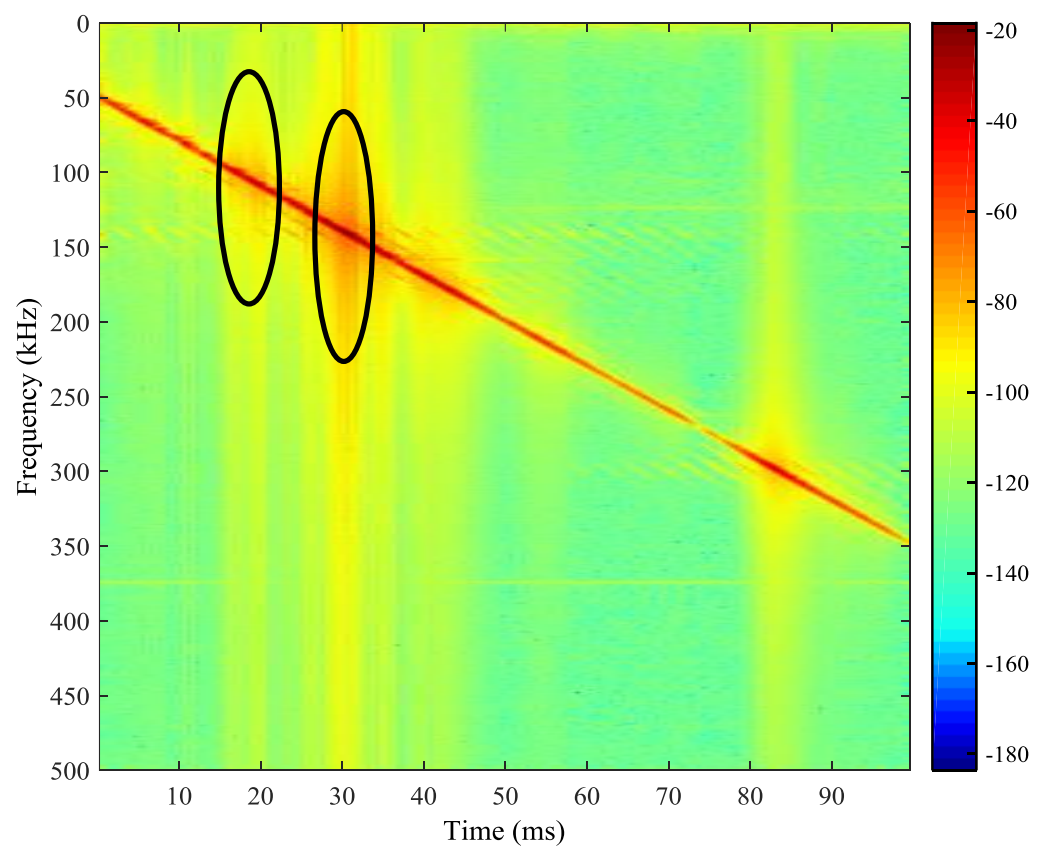

Figure 75 Time-frequency spectrum to determine optimum excitation frequency 
In this step, two PZTs on the top plate were excited with $120 \mathrm{kHz}$ and $135 \mathrm{kHz}$ separately using $35 \mathrm{~V}$ peak to peak voltage for excitation frequencies. The signal of the PZT attached to the bottom plate was sampled at $1 \mathrm{MHz}$ and its spectrum was calculated for four different compressive forces. First, the baseline was obtained when there were no magnets which means the top plate applied only its own weight. Later, the experiment was repeated when the plates were held together with 3, 5 and 7 pairs of magnets. The spectrums of the PZT signals at the bottom was calculated using FFT and is presented in Figure74.a. In the plot, the spikes around three key frequencies $(15 \mathrm{kHz}, 120 \mathrm{kHz}$, and $135 \mathrm{kHz})$ are separately presented. The amplitude of the spike at the difference of the frequencies, $15 \mathrm{kHz}$, decreased when the compressive force was increased (Figure74b).

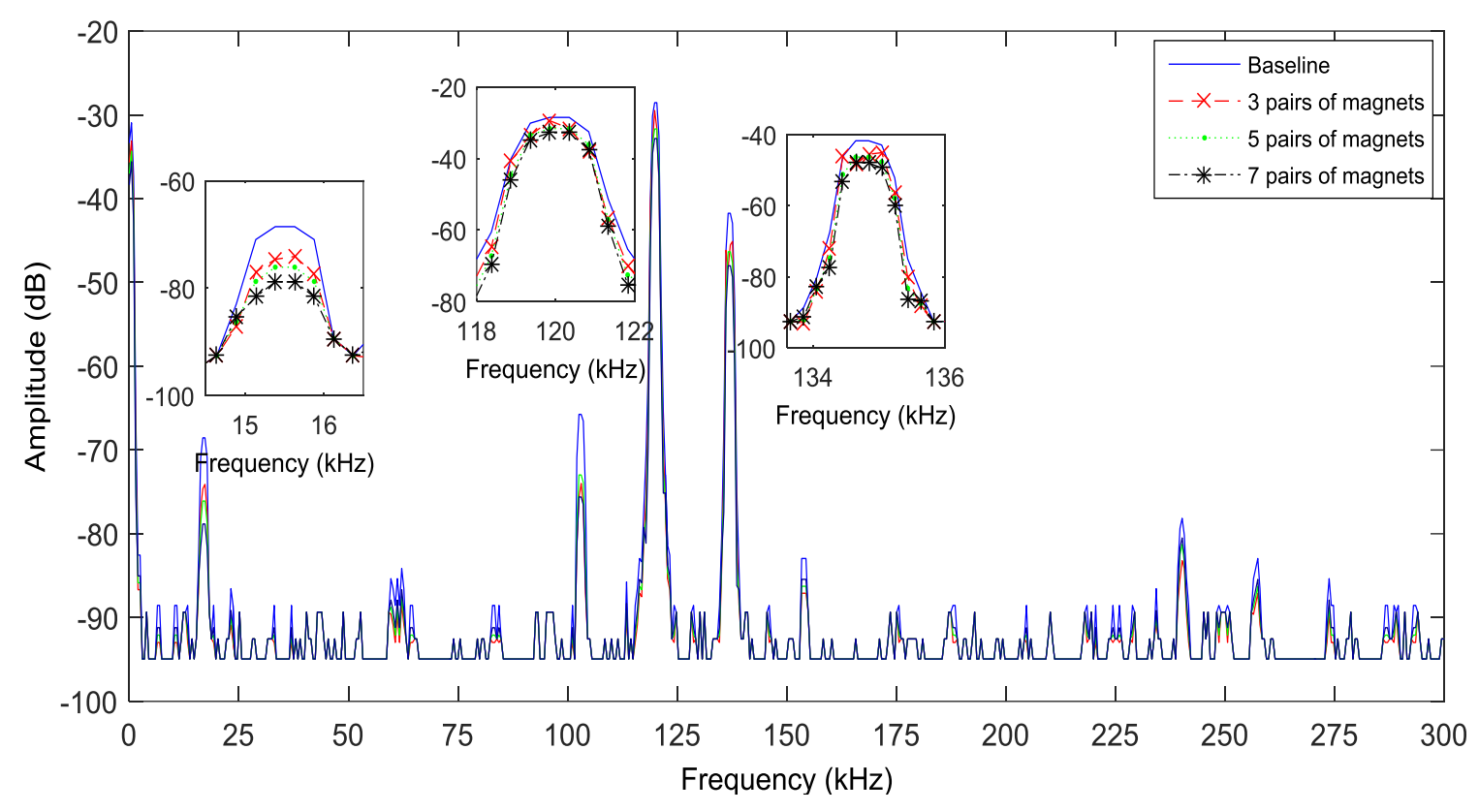

(a) 


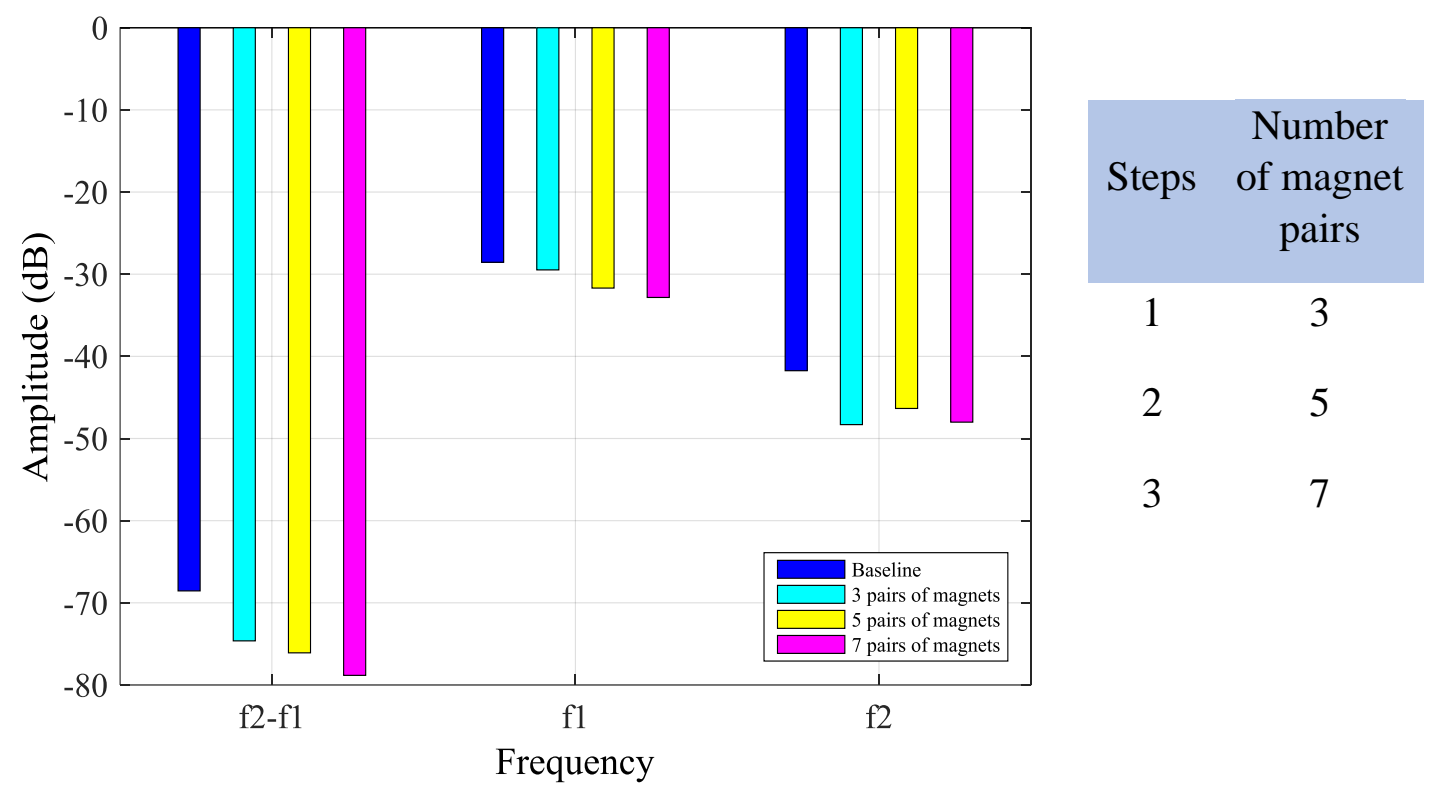

(b)

Figure 76 Comparing the spectra of the signal of the sensor at different compressive forces. a) Spectra of the signal of the sensor at 4 compressive forces and the spikes at the key frequencies. b) The maximum amplitude at the three key frequencies under different loads

In another experimental procedure, one of the excitation frequency was kept at $120 \mathrm{kHz}$. Instead of applying a harmonic signal, a sweep-sine wave from $125 \mathrm{kHz}$ to $150 \mathrm{kHz}$ was applied to the second exciter (Figure75). The signal of the PZT at the bottom was sampled and its spectrogram was obtained. Theoretically, the response signal should appear in frequencies of difference which means a line starts at $5 \mathrm{kHz}$ and reaches to $30 \mathrm{kHz}$ if the system behaves nonlinear and create the heterodyne effect. The line at the top of the spectrogram appeared around $10 \mathrm{kHz}$ and reached to $30 \mathrm{kHz}$. This line indicates that instead of $135 \mathrm{kHz}$, many other frequencies between $130 \mathrm{kHz}$ and $150 \mathrm{kHz}$ could be used for the excitation of the second exciter. This means broad frequency ranges can be applied to increase sensitivity to various defects. 


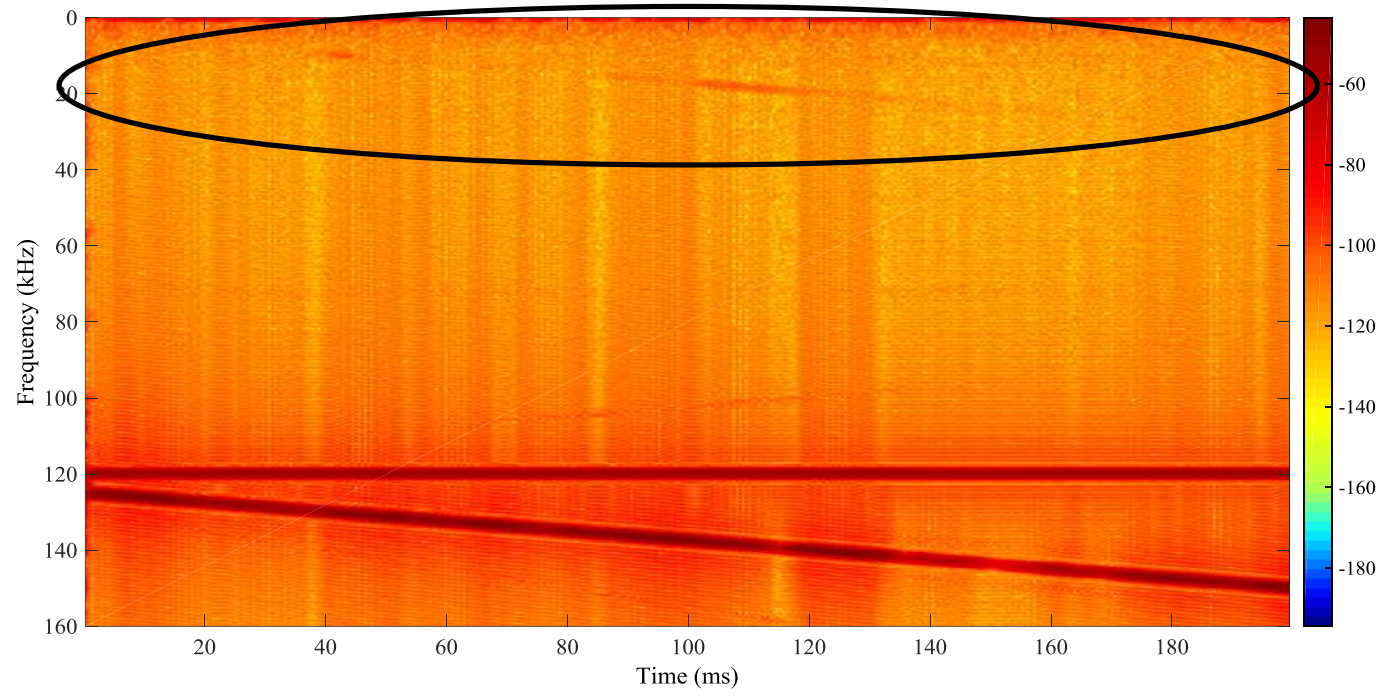

Figure 77 Spectrogram of the sensor at the bottom plate when the sweep sine wave was applied to one of the exciters.

\subsubsection{Detection of various contamination levels in composite bonds}

In order to detect the various levels of contamination in composite bonds, the experimental setup shown in Figure4 was used and it was tried to determine the optimal excitation frequencies. Then, the selected excitation frequencies were utilized to detect the different size of the aluminum foil between two composite panels with the help of the amplitude of the spike at the difference of the excitation frequencies. In the course of the experiment, it was shown that heterodyning effect can perform effectively for the detection of the contaminations in composite bonds as a nonlinear SHM method, respectively.

By placing two composite plates on top of each other and a sheet of aluminum foil between them and four pairs of magnets to keep the panels together, the experimental setup in Figure69 was prepared. The PZT on the top plate was excited with a sweep sine wave from $50 \mathrm{kHz}$ to $550 \mathrm{kHz}$. The spectrogram of the PZT signal at the bottom is presented in 
Figure76. The structure showed the major nonlinear behavior around $250 \mathrm{kHz}$. This frequency in addition to two other frequencies with $20 \mathrm{kHz}$ difference, $230 \mathrm{kHz}$, and 270 $\mathrm{kHz}$, were selected as the excitation signal for the next step.

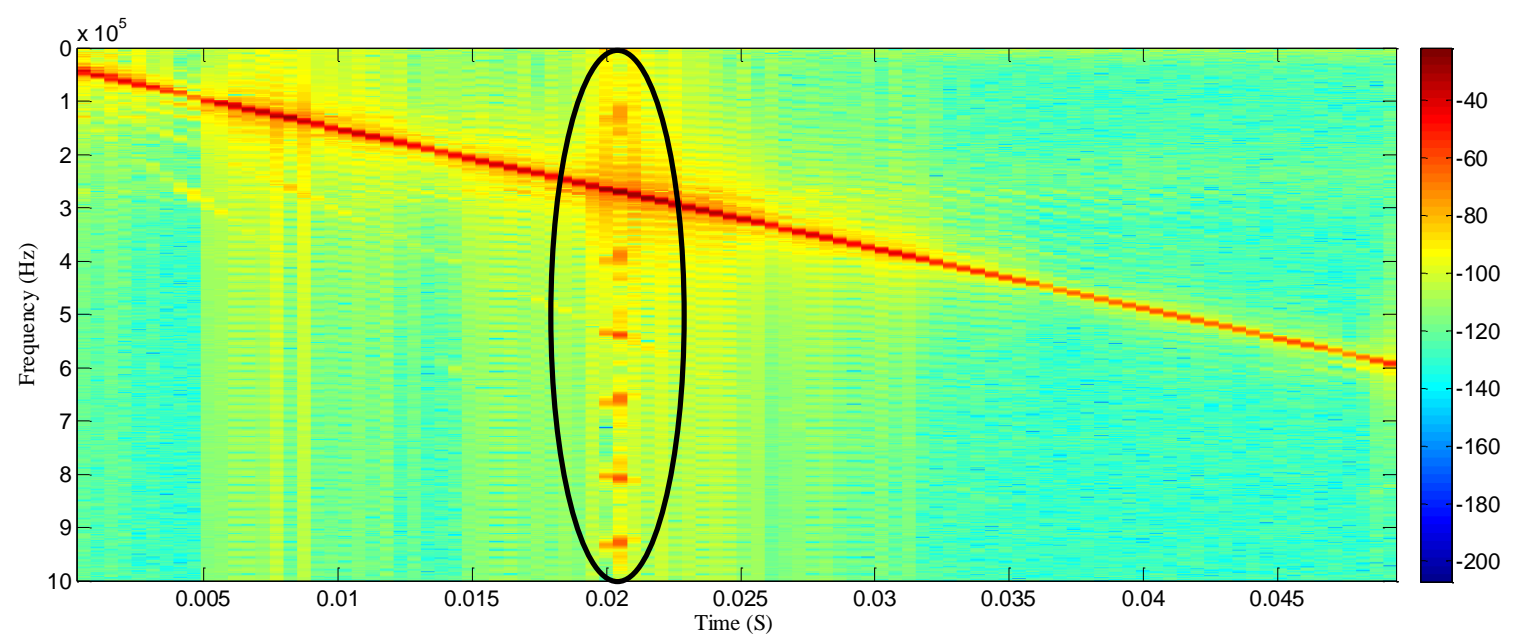

Figure 78 Time-frequency spectrum to determine optimum excitation frequency

In this step, two PZTs on the top plate were excited with $230 \mathrm{kHz}, 250 \mathrm{kHz}$, and $270 \mathrm{kHz}$ separately using $20 \mathrm{~V}$ peak to peak voltage for excitation frequencies. The PZT attached to the bottom plate recorded the response signal with the $1 \mathrm{MHz}$ sampling frequency. The spectrum was calculated for three different contamination sizes. First, the 6" by 6" aluminum foil was used as a contamination between two composite panels. Later, the experiment was repeated when the 8 " by 8 " and 10 " by 10 " aluminum foils were utilized. The spectrums of the PZT signals at the bottom was calculated using FFT and is presented in Figure 77. In this plot, the spikes around three excitation frequencies $(230 \mathrm{kHz}, 250 \mathrm{kHz}$, and $270 \mathrm{kHz}$ ) can clearly be seen. By zooming in at the difference of the excitation 
frequencies, $20 \mathrm{kHz}$, it can be seen that the amplitude of the spike increased when the contamination size was increased (Figure77).

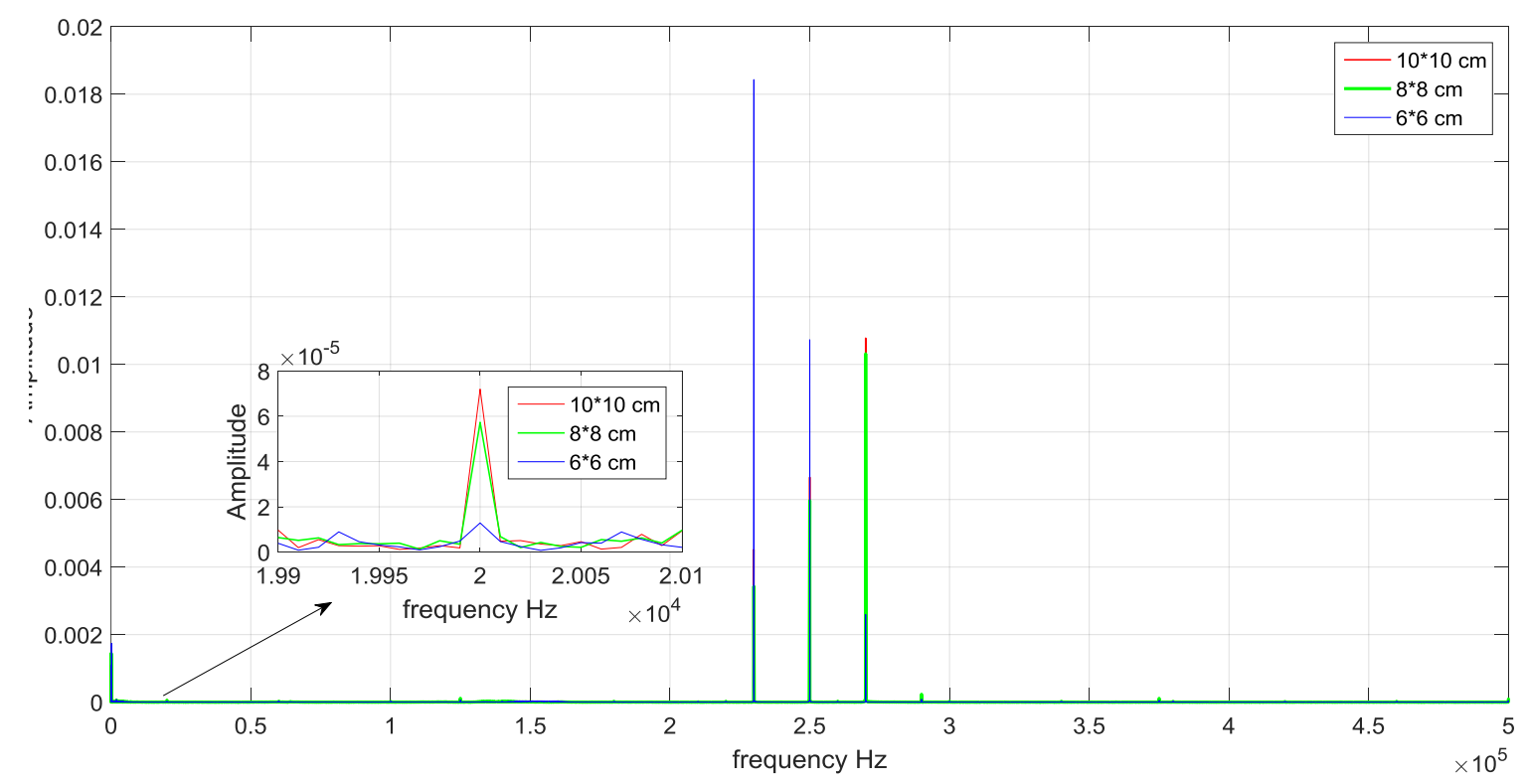

Figure 79 Comparing FFT results between different levels of contamination in the heterodyning method

\subsubsection{Conclusions}

Typically, composite materials are joined together with adhesives or fasteners. Weak bonding and delamination can remarkably decrease the strength of the structure and may lead to failure. Many SHM methods have been developed for detection of structural defects, minimizing the cost of maintenance and to improve safety. Recently, it has been shown that certain types of damage including debonding, cracks and delaminations change the linear behavior of a structure into nonlinear and this fact led to the introduction of nonlinear methods in SHM. In these methods, by monitoring the existence of nonlinear behavior in a structure, it is possible to detect these types of defects in their early stage of 
development. Besides, the nonlinearity signatures can be used for quantification between different levels of damage. In these approaches, two different actuators are used to excite the structure at very low and high frequencies. The proposed method has the potential to detect different types of the damages and it is not limited to the combination of a high and a low frequency, which can simplify the selection of excitation frequencies.

In this study, in the first step, the heterodyne effect was used to identify the debonded region when adhesives were used for joining. The debonded region between two coupons was successfully detected with the application of the heterodyning effect. When the excitation signals went through the well-bonded regions of two composite coupons, the system behaved like a linear system and only the excitation frequencies appeared in the response. However, a conspicuous spike appeared at the difference of the excitation frequencies when the same excitation signals traveled through the specimen with the debonded region. Since not every two frequency combinations can show similar interaction with various types of defects, excitation of the system with a sweep sine wave was proposed for identification of the practical excitation frequencies for the heterodyning method.

The same method was then used to evaluate the level of nonlinearity of composite plates held together by different numbers of magnetic pairs. The heterodyne effect creates new frequencies when the structure is excited with two appropriate excitation frequencies which are resulted from nonlinearity in the system. The change of the compressive forces was also detected with the proposed SHM method. The amplitude of the spike at the difference frequency decreased when higher compressive forces were applied by increasing the number of magnet pairs, which more effectively compressed the plates together. 
Lastly, for investigating the bond strength in composite materials, various contamination levels in composite bonds were investigated using the heterodyning method. The change in the size of the contamination between two composite panels was detected using both SHM approaches. As a result, the heterodyne effect seems to be a promising approach in the development of the effective system for composite bond inspection.

Implementation of the heterodyne effect introduces some advantages into SHM process. First of all, since this method is not limited to the combination of a high and a low frequency, the practical excitation frequencies can be selected conveniently. Besides, in some cases, it would be possible to get rid of baseline or reference signal since the change of the system characteristics from linear to nonlinear is the major concern although baseline data may be used to identify the level of the nonlinearity. Finally, for future applications, the excited region can be controlled electronically by selecting the excitation frequencies, a number of waves and delay between the pulses at the exciters in order to localize the inspection area. 


\subsection{Validation of heterodyning method using Comsol software}

In this study, it was tried to validate the experimental result of the heterodyning method for the detection of debonded regions by the help of a finite element software. Heterodyning method is a structural health monitoring method that is developed for the detection of various types of nonlinear damages including delamination, debonding and, crack. The heterodyne effect may be utilized for the evaluation of debonded area when the linear characteristics of the system change to nonlinear. The light contact in the bonding zone can result in this conversion from linear to nonlinear behavior. The nonlinear system responds to two appropriate excitation frequencies with new frequencies. For some nonlinear systems, the output has these new frequencies at the subtraction and summation of excitation frequencies. This is called heterodyne effect.

In this study, COMSOL was used to simulate the proposed heterodyne effect methods. It was shown that in the presence of debonding the structure behaves like a nonlinear system and new frequencies are generated. The new frequencies can be observed at the summation, subtraction, and other harmonics of the excitation frequencies.

\subsubsection{Introduction}

Extracting information from the structural response and analyzing the data have always been an enormous challenge in all structural health monitoring approaches. To facilitate these procedures, it would be reasonable to use computational models in order to support and validate our experimental results. By using numerical models, we are not only able to reduce the costs and time during the development of structural health monitoring methods, but also it is conceivable to improve the accuracy of the SHM approaches by considering 
more parameters associated to the systems. In recent years, there have been different researches to simulate SHM techniques using piezoelectric (PZT) materials as sensors and actuators [179-183]. Since the complexity of the structures can cause high computational cost, most of the works in this area use the finite element method for thin plates and shells structures to be considered as a surface [184-188].

Based on heterodyning effect, the response of a pristine structure to the excitation frequencies only has the input frequencies. However, the response of a damaged structure has the input frequencies and additional new frequencies at the summation, subtraction and some other harmonics of the excitation frequencies [189-193].

A theoretical background for the heterodyne effect was explained in the previous chapter. In this study, by considering a simple experimental setup including two plates staying on top of each other to simulate a weak bond, debonding are detected through monitoring the development of new harmonics at the difference of the excitation frequencies. COMSOL Multi-physics software was utilized to develop a numerical model for the simulation of our experimental setup.

\subsubsection{Experimental setup}

In this study, piezoelectric device module of COMSOL was used to simulate our piezoelectric transducers which were used as both sensor and actuator. Figure 78 shows a schematic of two mating thin aluminum plate with three cylindrical piezoelectric transducers bonded to them. As it can be seen, two PZT transducers were attached on the top aluminum plate where they are going to be the two single frequency exciters. On the other side of the bottom layer, the sensing PZT was attached. AS it was explained in the previous chapter, two separate signals with the different frequencies will be applied to the 
exciters and the receiver will collect the response of the system which gives us a mixture of excitation frequencies, the summation, subtraction and some other harmonics of the excitation frequencies in the presence of debonding between two plates.
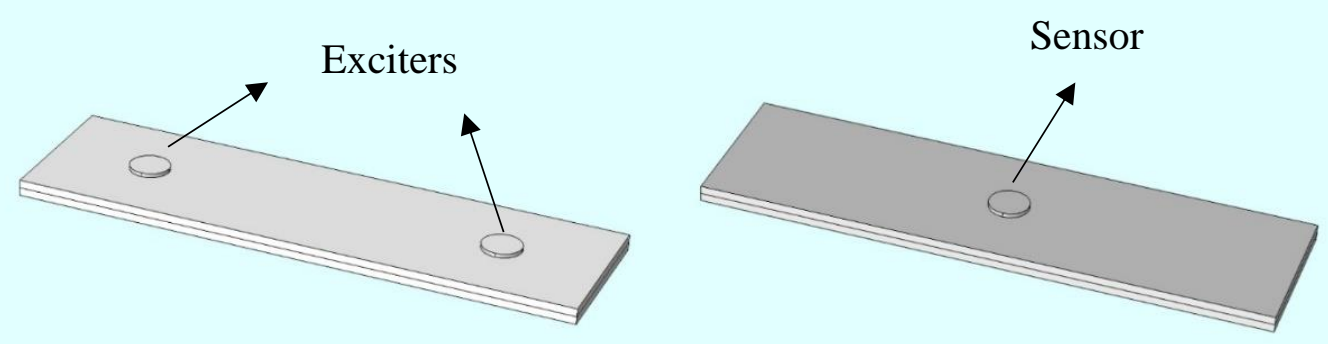

Figure 80 Experimental setup

Table 3 Dimensions of plates and PZTs

$\begin{array}{cc}\text { Name } & \text { Value } \\ \text { Length of plates } & 0.28 \mathrm{~m} \\ \text { Width of plates } & 0.08 \mathrm{~m} \\ \text { Height of plates } & 0.004 \mathrm{~m} \\ \text { Radius of PZTs } & .01 \mathrm{~m} \\ \text { Height of PZTs } & 0.002 \mathrm{~m} \\ \text { Voltage } & 100 \mathrm{~V} \\ \text { First excitation frequency } & 1.7 \mathrm{E} 5 \mathrm{~Hz} \\ \text { Second excitation frequency } & 1.9 \mathrm{E} 5 \mathrm{~Hz} \\ \text { The distance between two plates } & 0-0.012 \mathrm{um}\end{array}$

In this study, two types of materials including aluminum and carbon fiber composite for the two plates were investigated. The model was created in COMSOL's piezoelectric 
device module and time domain and frequency domain study were used. Lead Zirconate Titanate (PZT-4) with a density of $7500 \mathrm{~kg} / \mathrm{m}^{\wedge} 3$ was the chosen material for PZT transducers. The boundary condition of all four sides of the plates defined fixed constraints and everywhere else was free. The lower surface of PZTs which is attached to the plates was considered as ground with a zero charge and upper surface of exciters was charged with the sin waves. The upper surface of the sensor was connected to the probe to be monitored. As it can be seen in Figure below, the model meshed with free tetrahedral elements when the minimum mesh size was set at 450 um and the maximum mesh size was set at $10500 \mathrm{um}$.

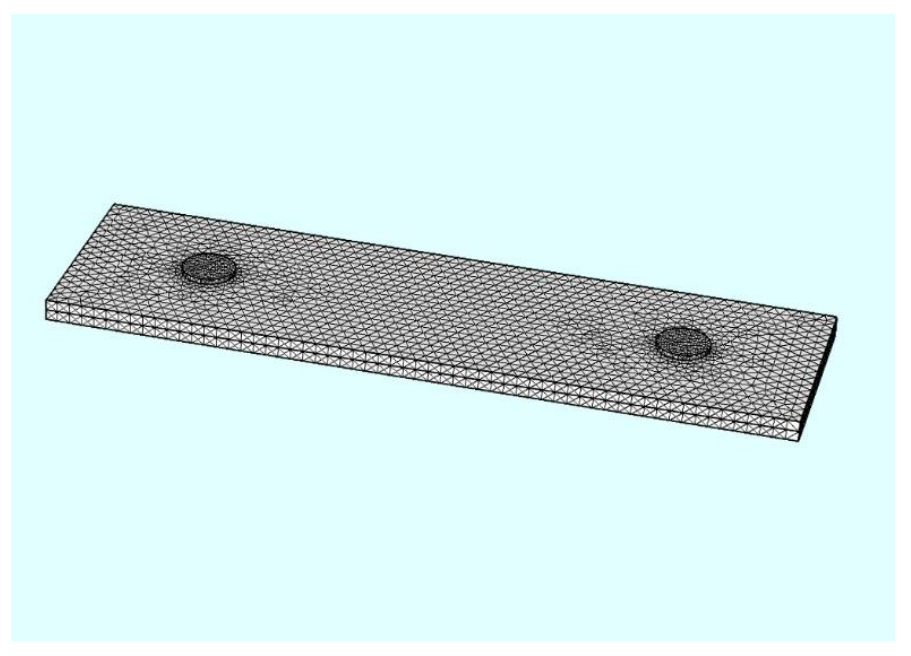

Figure 81 Meshed structure

In the heterodyning method, the structure is excited with two single frequency signals and the time domain response of the system will be captured. Then, the Fast Fourier Transform (FFT) of the response signal will be calculated. To simulate this process, two separate single frequency signals were applied to the PZT exciters and in time domain study, the 
response signal was captured. Then, by using the time to frequency study, the FFT of the response signal was obtained.

\subsubsection{Simulation results}

In Figures below, the time and frequency domain plots for both input and output signals from the probe points were shown. At first, just a single excitation signal was used in order to show the transmission of a signal from one point to another on the surface of the plate. Then, by using two excitation signals and changing the distance between two plates, the concept of heterodyning effect method for bond inspection was investigated.

\subsubsection{Aluminum plates}

In this setup, implementation of heterodyning method for two mating aluminum plates with the density of $2700 \mathrm{~kg} / \mathrm{m}^{\wedge} 3$, modulus of elasticity of $70 \mathrm{GPa}$, and Poisson's ratio of 0.33 were investigated.

\section{a) Single excitation}

In order to illustrate the transmission of the wave on the surface of the plates, the structure was excited using a single frequency signal. The excitation signal was shown in Figures 80 and 81. 


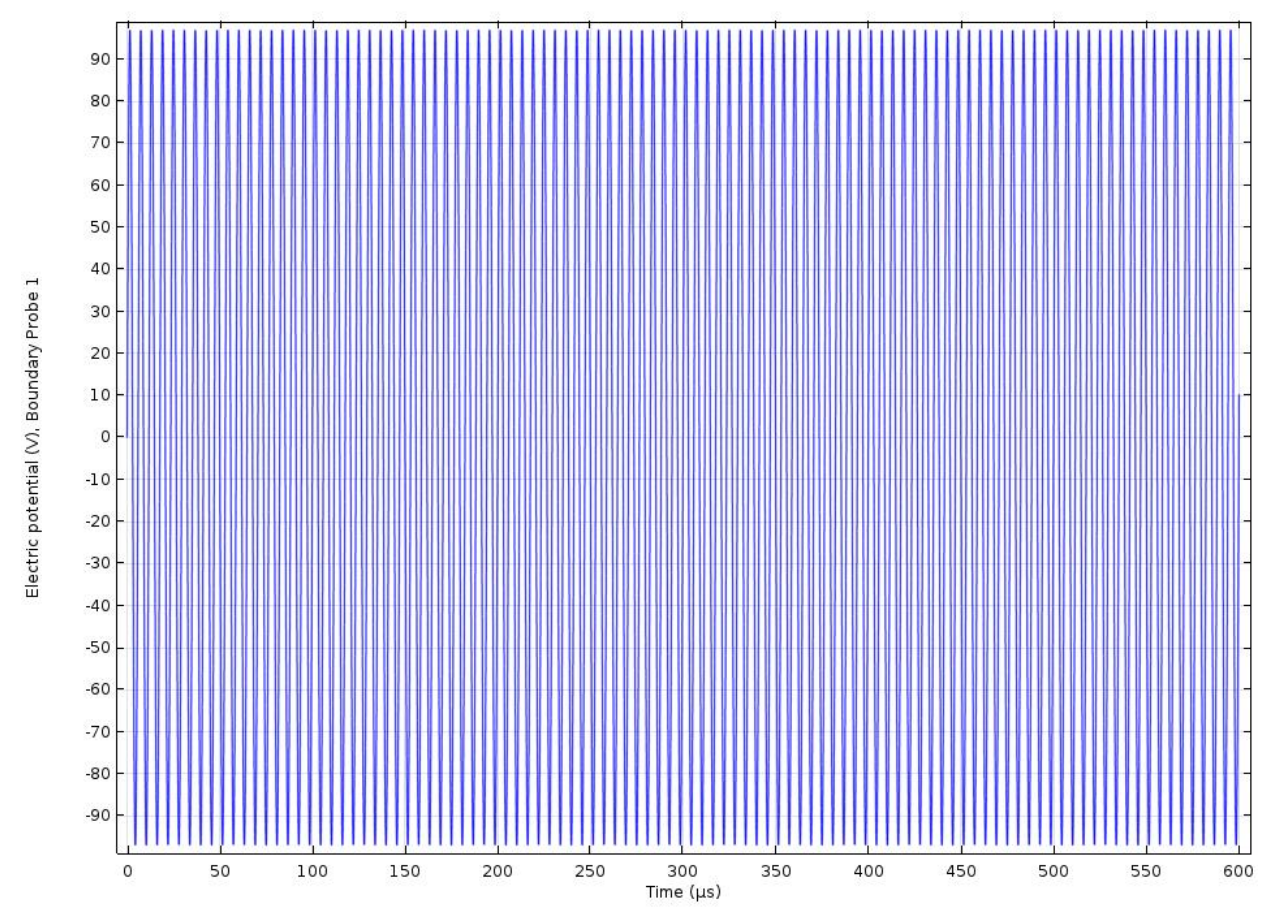

Figure 82 time domain plot for single frequency excitation signal

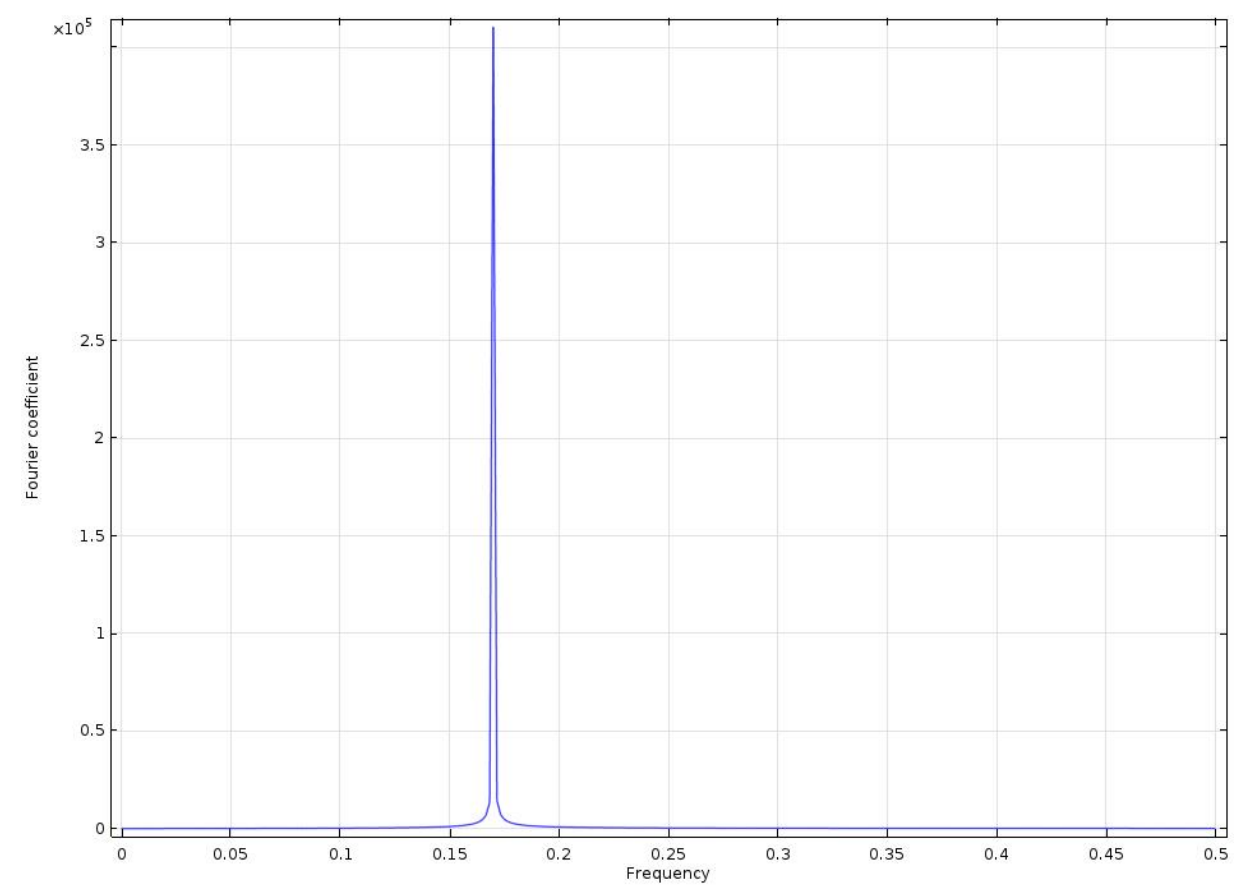

Figure 83 frequency domain plot for single frequency excitation signal 
The time and frequency plot of the response signal for the single frequency excitation signal was represented in Figures 82 and 83.

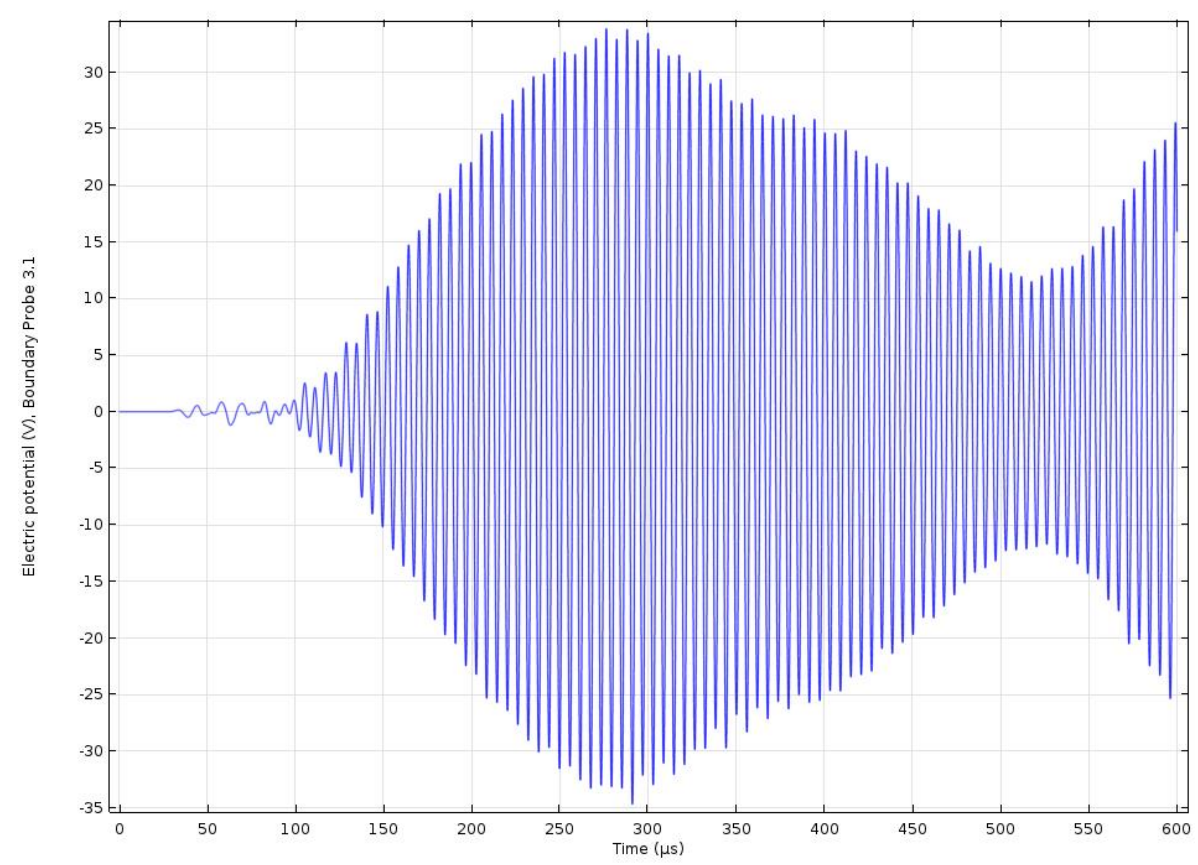

Figure 84 time domain plot for the response signal for single frequency excitation

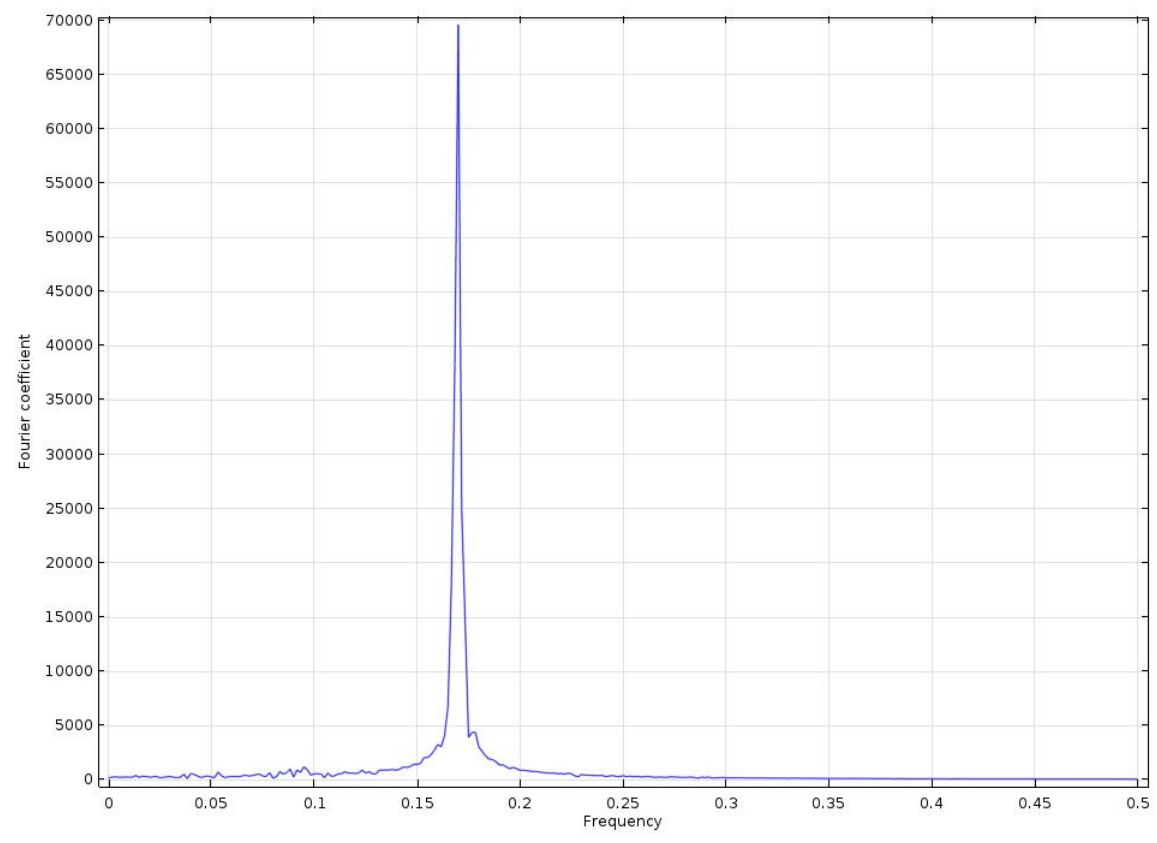

Figure 85 frequency domain plot for the response signal for single frequency excitation signal 


\section{a) Double excitation}

In this step, two PZTs on the top plate were used as exciters with frequencies of $170 \mathrm{kHz}$ and $190 \mathrm{kHz}$ and $100 \mathrm{~V}$ peak to peak voltage. The signal of the PZT attached to the bottom plate was sampled at $1 \mathrm{MHz}$. First, the response of the structure was obtained when there was no distance between two plates which means there is no debonding and as result no nonlinearity in the system.

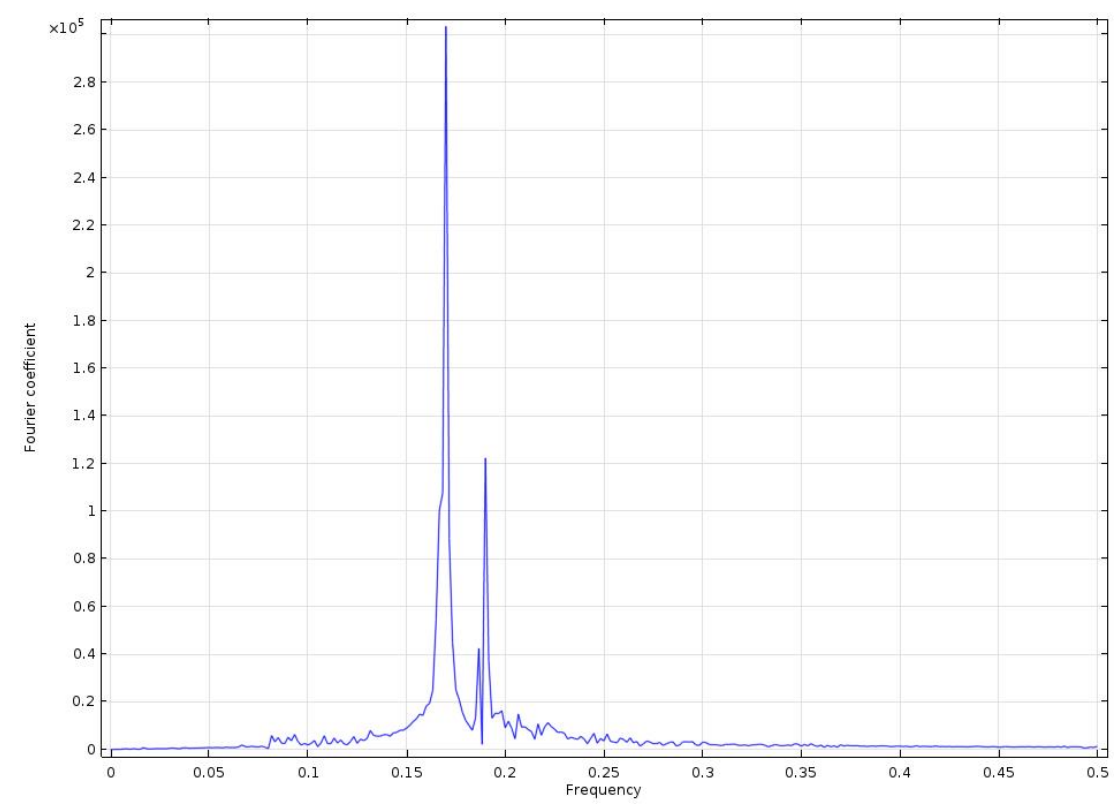

Figure 86 response of the system when there is no debonding

In the next step, by adding a 0.005 um distance between two plates, a small debonding between two layers was simulated. The frequency response of the system for the small debonding was shown in Figure 85. 


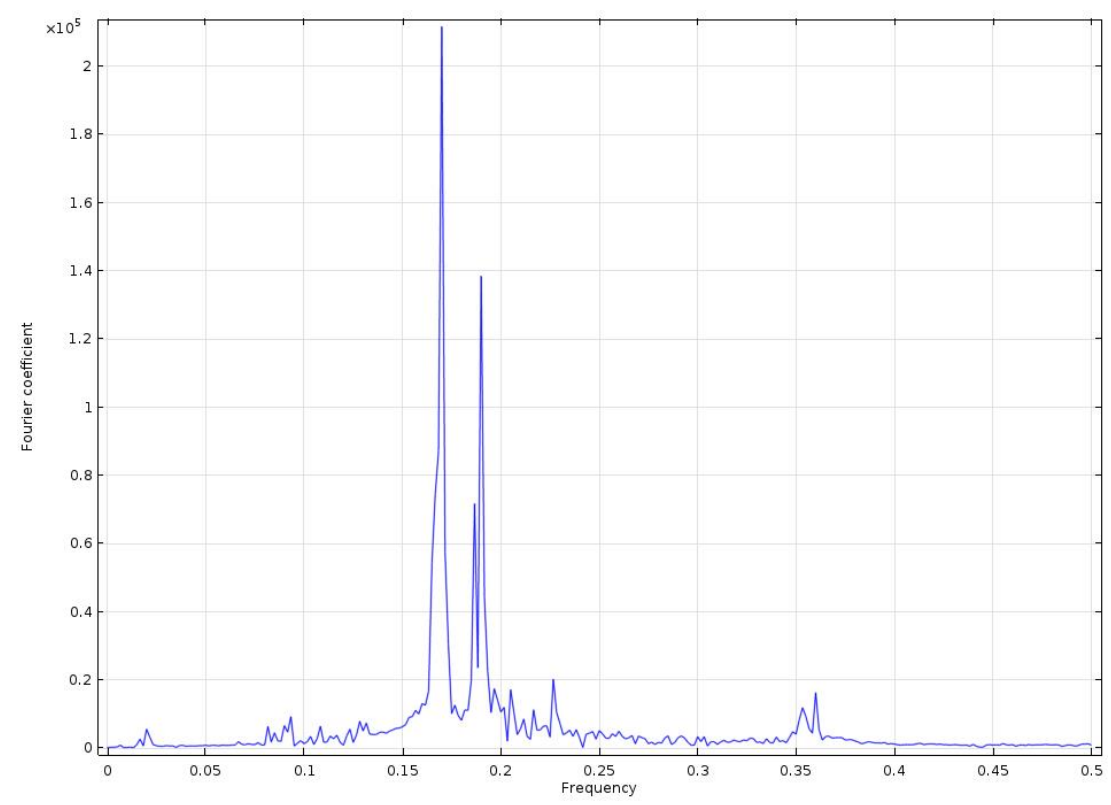

Figure 87 frequency response of the system for 0.005 um distance between two plates

As it was expected, in presence of debonding, a small peak at the frequency of difference of two excitation frequencies appeared. Then, the distance between two plates was increased from 0.005 to 0.012 um to simulate a bigger debonding between two layers. The frequency response of the structure for the new debonding was shown in Figure 86. 


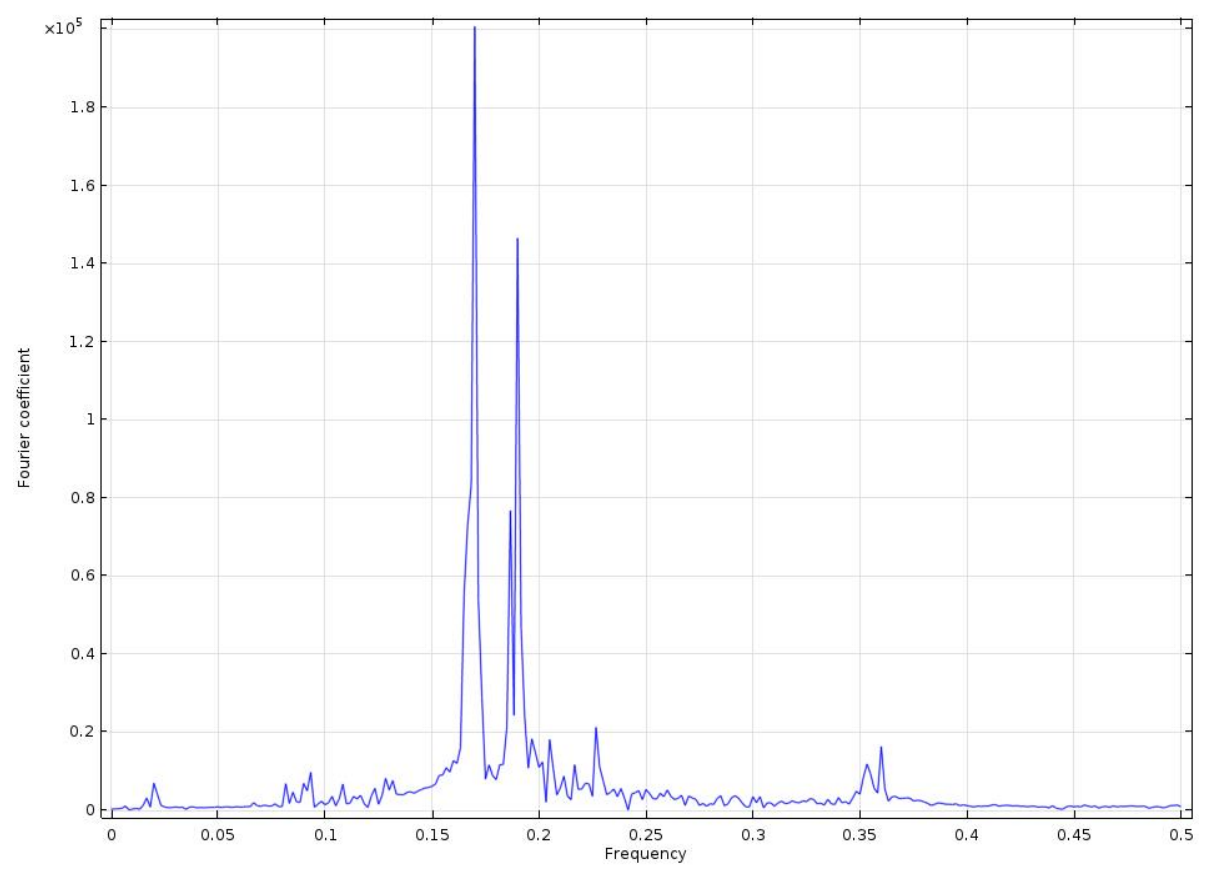

Figure 88 frequency response of the system for 0.012 um distance between two plates

As it can be seen, by increasing the distance between two plates the amplitude of the peak at the frequency of difference of two excitation frequencies was increased.

\subsubsection{Composite panels}

In another setup, the heterodyning method was utilized to investigate debonding between two composite panels with the density of $160 \mathrm{~kg} / \mathrm{m}^{\wedge} 3$, modulus of elasticity of 70GPa, and Poisson's ratio of 0.1 .

\section{a) Single excitation}

First, the transmission of the wave on the surface of the composite panels was tested when the structure was excited using a single frequency signal. The excitation signal was shown in Figures 87 and 88. 


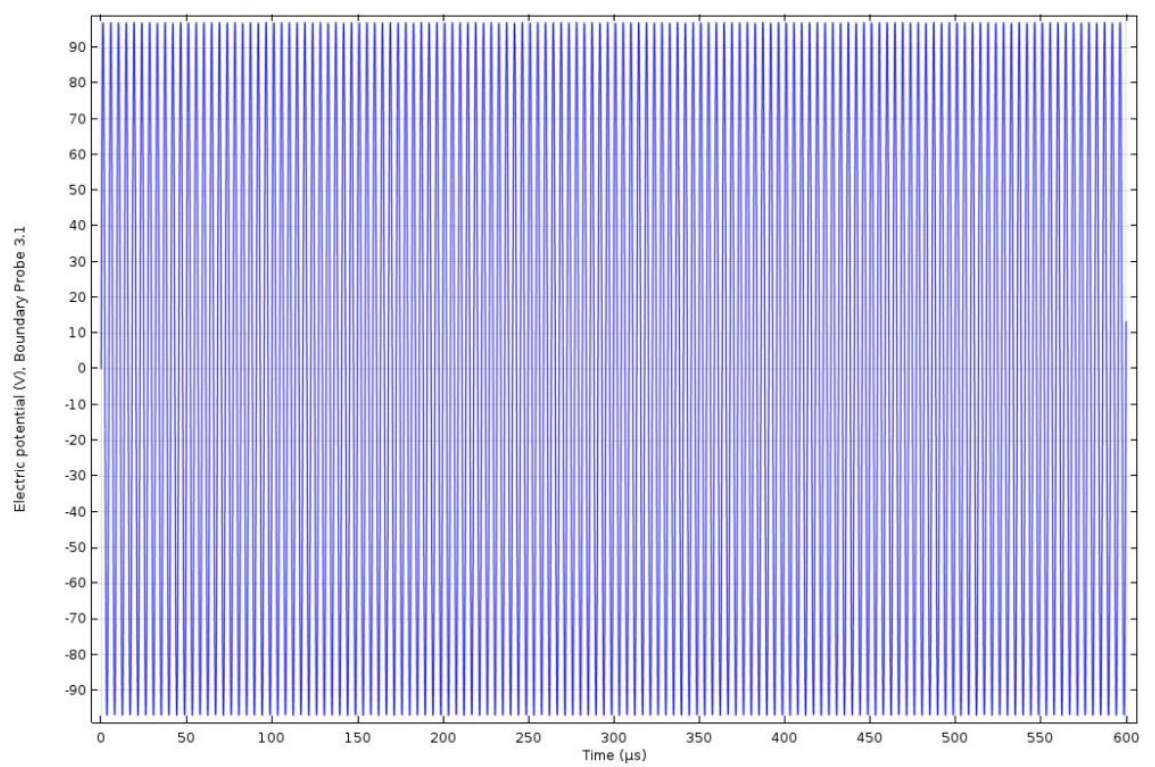

Figure 89 Time domain plot for single frequency excitation signal

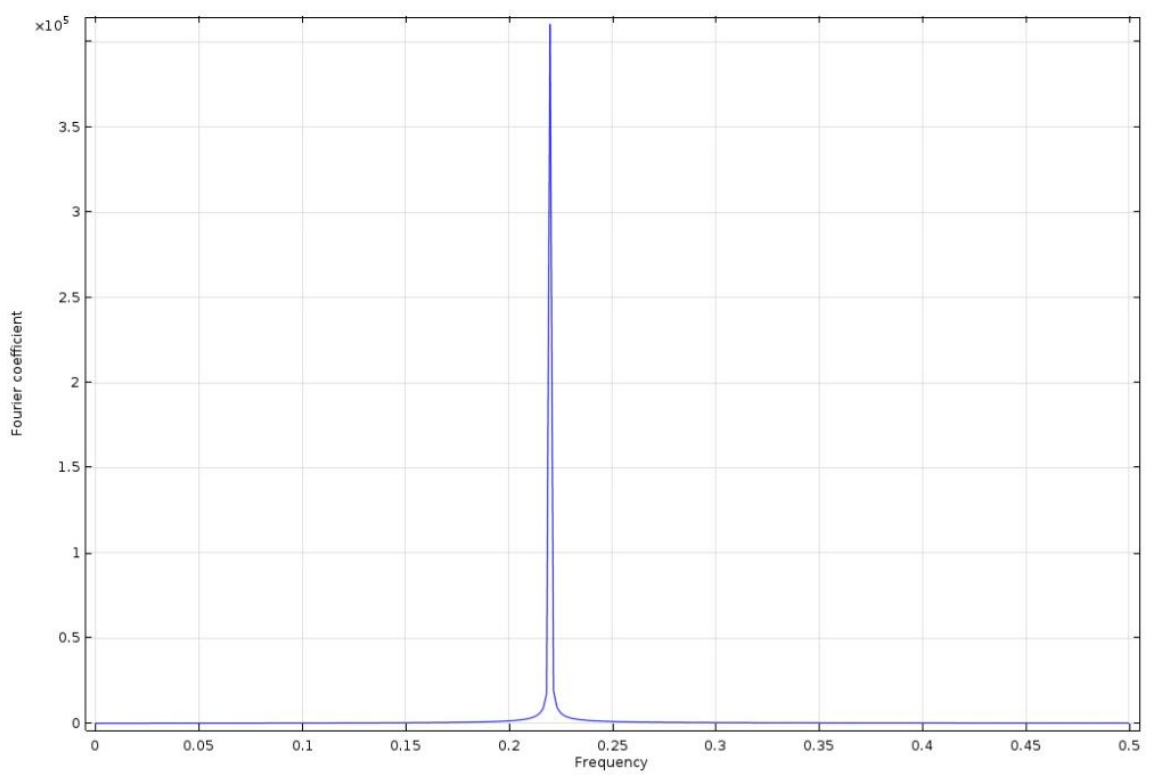

Figure 90 Frequency domain plot for single frequency excitation signal

The time and frequency plot of the response signal for the single frequency excitation signal is provided in Figures 89 and 90. 


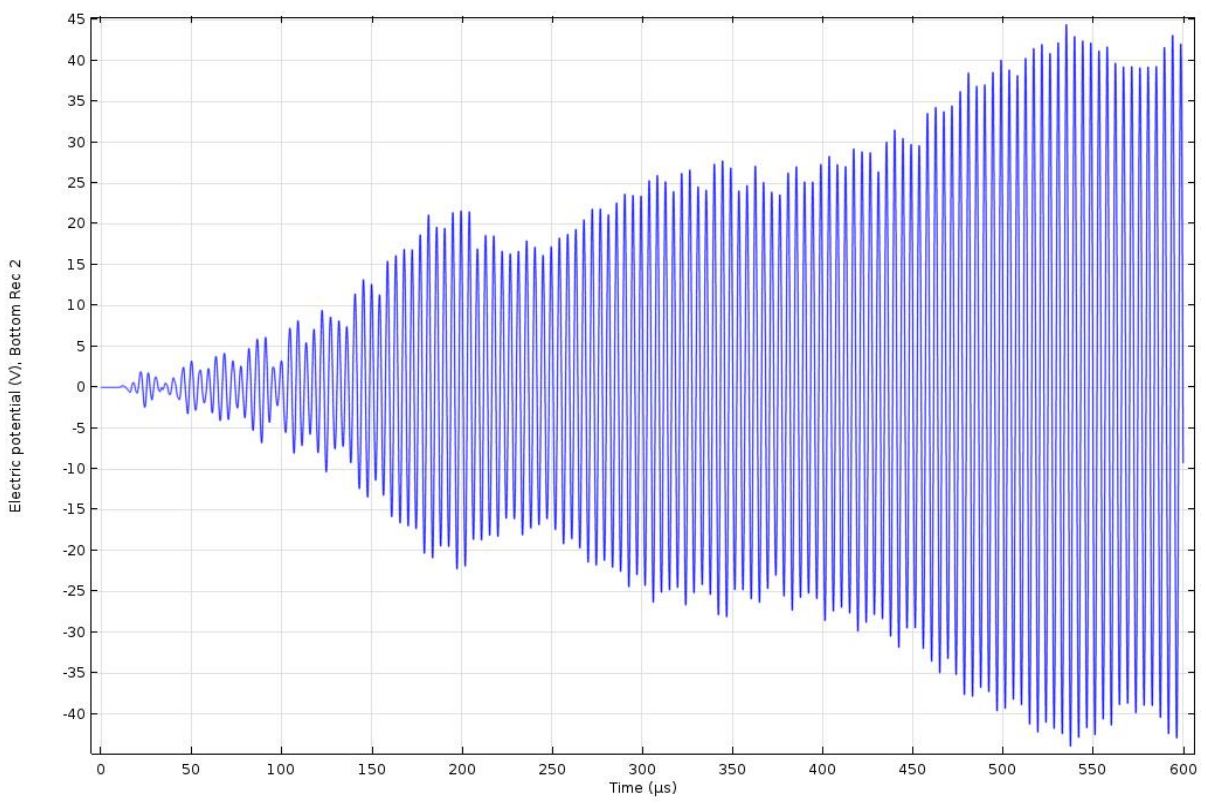

Figure 91 Time-Frequency domain plot for single frequency excitation signal

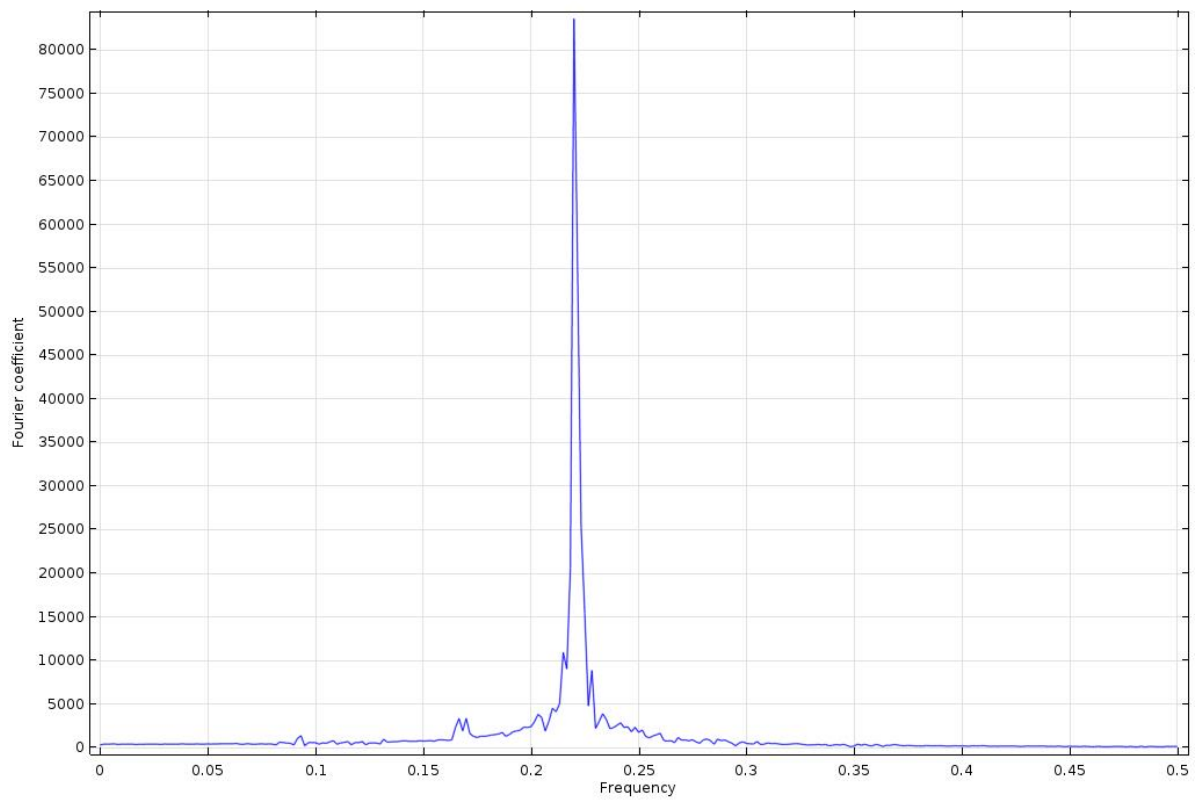

Figure 92 Frequency domain plot for single frequency excitation signal 


\section{b) Double excitation}

This time, $220 \mathrm{kHz}$ and $240 \mathrm{kHz}$ with a $200 \mathrm{~V}$ peak to peak voltage were chosen as the excitation signals. The PZT attached to the bottom plate was used as the sensor to sample the response signal using $1 \mathrm{MHz}$ sampling frequency. First, the response of the structure was obtained when there was no distance between two panels which means there is no debonding and as result no nonlinearity in the system.

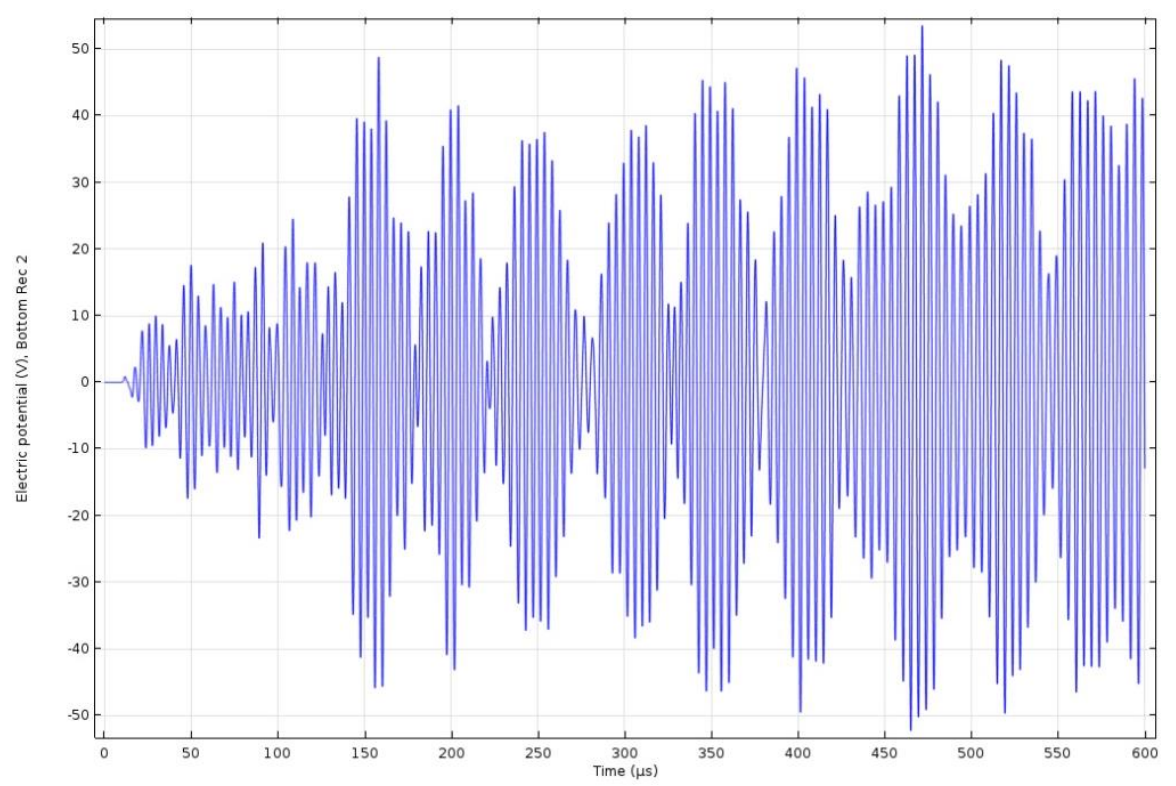

Figure 93 Time domain plot for double frequency excitation signals with no debonding 


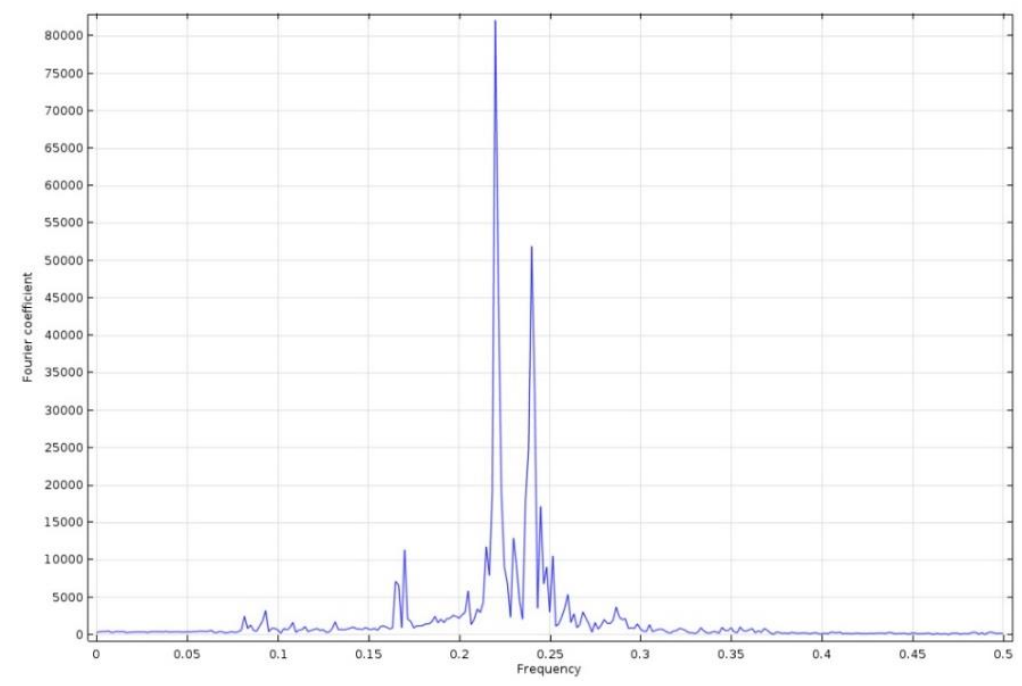

Figure 94 Frequency domain plot for double frequency excitation signals with no debonding

Then, in order to create nonlinearity in the system and simulate debonding in the structure, 0.005 um distance between two composite panels was created and expectedly, a small peak at the frequency of difference of two excitation frequencies was appeared (see Figures 93 and 94).

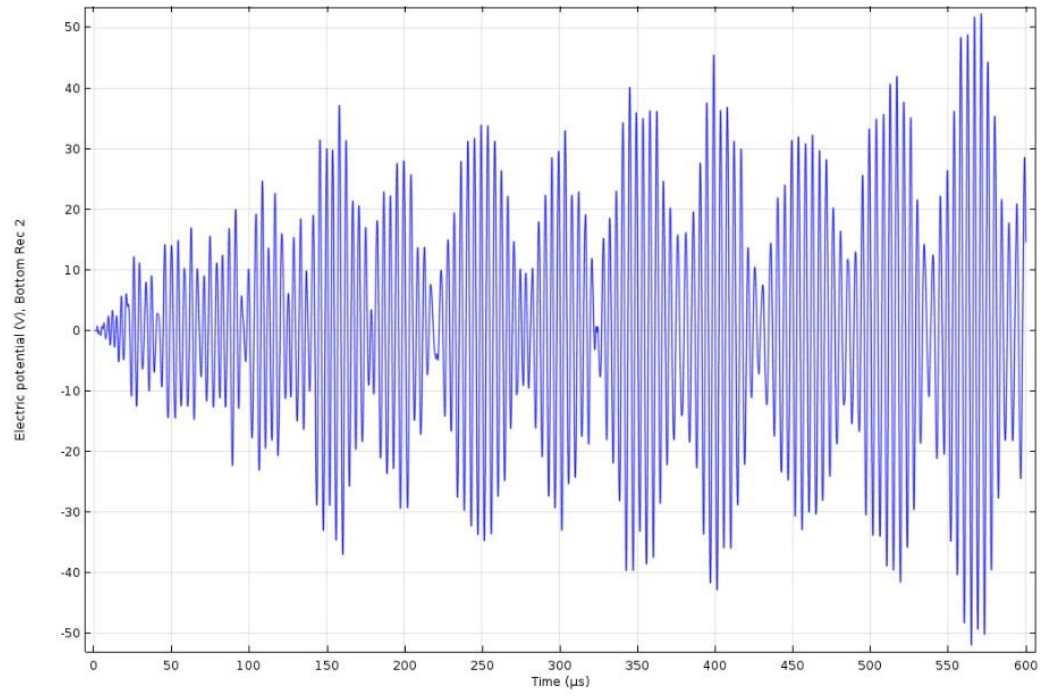

Figure 95 Time domain plot for double frequency excitation signals with 0.005 um debonding 


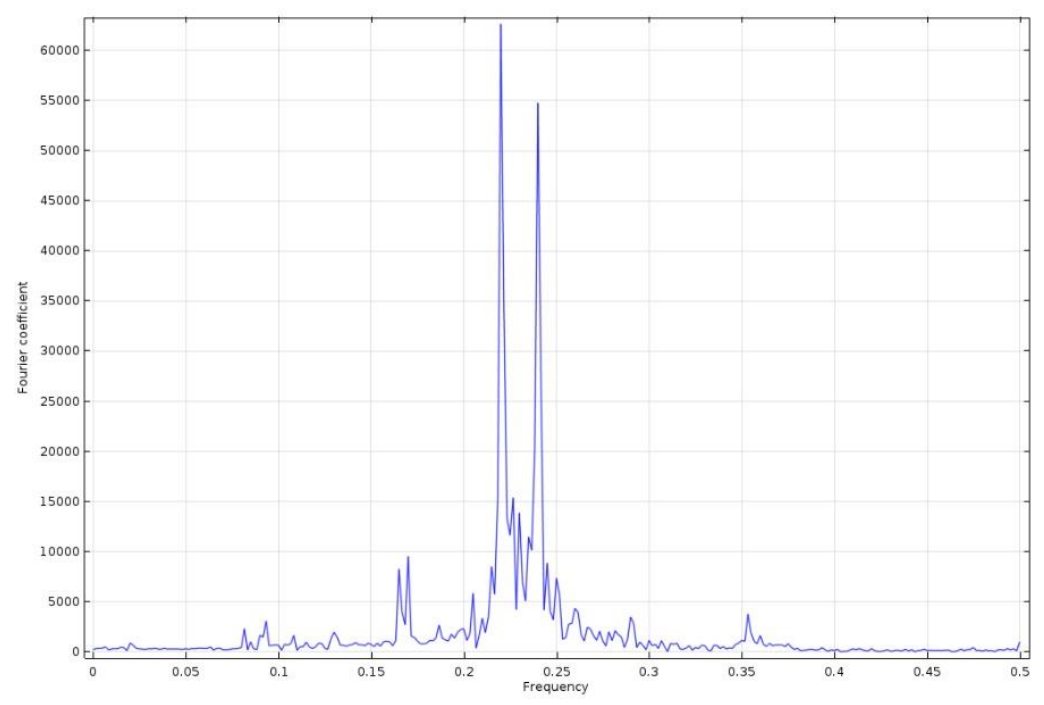

Figure 96 Frequency domain plot for double frequency excitation signals with 0.005 um debonding

For the next step, the distance between two composite panels was increased from 0.005 to $0.012 \mathrm{um}$. The frequency response of the structure for the new debonding was shown in the Figure below. As it can be seen, the amplitude of the FFT at the frequency of the difference of the excitation frequencies was increased (see Figures 95 and 96).

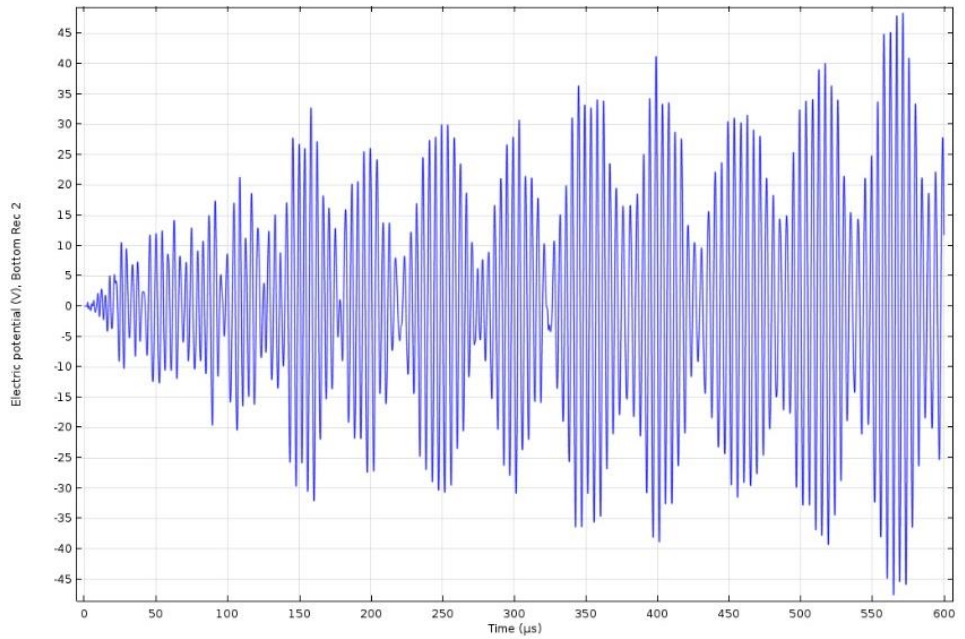

Figure 97 Time domain plot for double frequency excitation signals with $0.012 \mathrm{um}$ debonding 


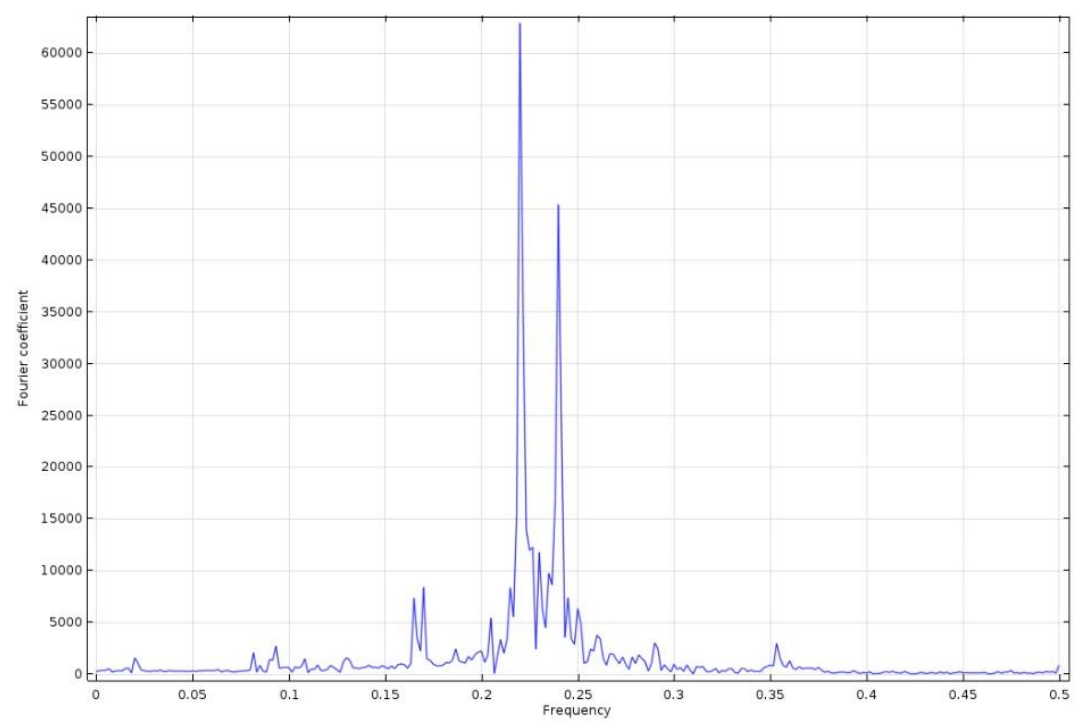

Figure 98 Frequency domain plot for double frequency excitation signals with 0.012 um debonding

As it was shown in the table below, by increasing the distance between two aluminum and composite plates, the amplitude of the spike at the frequency of the difference was increased:

Table 4 Amplitude of the spike at the frequency of the difference

\begin{tabular}{|c|c|c|}
\hline \multirow{2}{*}{$\begin{array}{c}\text { The distance between two } \\
\text { plates (um) }\end{array}$} & \multicolumn{2}{|c|}{ The amplitude of the spike at the frequency of the } \\
& \multicolumn{2}{|c|}{ difference } \\
\cline { 2 - 3 } & Aluminum & Composite \\
\hline 0 & 700 & 300 \\
\hline 0.005 & 4400 & 900 \\
\hline 0.012 & 5600 & 1600 \\
\hline
\end{tabular}




\subsubsection{Conclusion}

In nonlinear SHM methods, the transformation of the structure from the linear state into the nonlinear state will be monitored since certain types of damage including debonding, cracks and delaminations change the linear behavior of a structure into nonlinear.

In this study, the experimental result of the heterodyning method for the detection of debonded regions was validated by the help of a finite element software. COMSOL Multiphysics software was utilized to develop a numerical model for the simulation of heterodyning effect method when a simple experimental setup including two plates staying on top of each other was created to simulate a weak bond.

The heterodyne effect created new frequencies when the structure was excited with two appropriate excitation frequencies which are resulted from nonlinearity in the system. Then debonding was detected through monitoring the development of new harmonics at the difference of the excitation frequencies. As it was shown in the results, by an increase of the distance between two plates, the amplitude of the spike at the difference frequency also increased. 


\section{CHAPTER 5}

\section{RESULTS AND DISCUSSION}

\subsection{Linear methods}

In the linear method chapter, the possibility of using SuRE method for load monitoring applications was validated first. A surface bonded piezoelectric disk was used as an exciter and the laser scanning vibrometer and PZT transducer were used, respectively, as noncontact and contact approaches to recording response signals at scanning points. It was observed that SuRE method shows a monotonic behavior to changes in applied load after applying a different variation of loads. As it can be seen in tables below, by increasing the applied loads, the SSD values have also increased, and reasonable sensitivity to change of load was observed.

Table 5 Load monitoring using PZT for data collection

\begin{tabular}{|c|c|c|c|c|}
\hline \multirow{2}{*}{\multicolumn{2}{|c|}{$\begin{array}{c}\text { Load monitoring using PZT for } \\
\text { data collection }\end{array}$}} & \multicolumn{3}{|c|}{ Applied load (Increasing from F1 to F3) } \\
\hline & & F1 & F2 & F3 \\
\hline \multirow{3}{*}{ SSD values } & Single load & 0.79 & 0.91 & 1 \\
\hline & Sets of loads & 0.63 & 0.89 & 1 \\
\hline & Loose bolt & 0.83 & 0.85 & 0.93 \\
\hline
\end{tabular}


Table 6 Load monitoring using laser vibrometer for data collection

\begin{tabular}{|c|c|c|c|c|}
\hline \multicolumn{2}{|c|}{$\begin{array}{c}\text { Load monitoring using laser } \\
\text { vibrometer for data collection }\end{array}$} & \multicolumn{2}{|c|}{ Applied load (Increasing from F1 to F3) } \\
\cline { 2 - 5 } & Single load & 0.81 & F2 & F3 \\
\hline \multirow{3}{*}{ SSD values } & Sets of loads & 0.65 & 0.91 & 1 \\
\cline { 2 - 5 } & Loose bolt & 0.83 & 0.855 & 0.93 \\
\cline { 2 - 5 } & & & & 1 \\
\hline
\end{tabular}

In the next experimental setup, the possibility of using different damage indexes for the SuRE method in the monitoring of milling operation was investigated. Although, it was shown that SuRE method shows a decent sensitivity to the changes in both width and length of milling operation (Table. 6), the possibility of using another criterion, instead of SSD, in order to get rid of the need for baseline or reference signal, was studied (Table. 7). It was observed that other criteria are not as sensitive as SSD value to the change of the length and width of milling operation, but geometric mean, harmonic mean and 5th momentum value could be a promising alternative for SSD value in SuRE method especially when the baseline or reference signal is not available.

Table 7 SSD values in milling operation

\begin{tabular}{|c|c|c|c|c|c|c|c|c|c|c|c|c|c|c|c|c|c|c|c|}
\hline \multicolumn{20}{|c|}{ SSD values } \\
\hline \multicolumn{20}{|c|}{ Length of the milling operation } \\
\hline \multicolumn{5}{|c|}{ Undamaged } & \multicolumn{5}{|c|}{3 in } & \multicolumn{5}{|c|}{4 in } & \multicolumn{5}{|c|}{5 in } \\
\hline 10 & 9 & 10 & 9 & 50 & 100 & 75 & 76 & 77 & 125 & 190 & 105 & 150 & 155 & 170 & 215 & 110 & 220 & 160 & 215 \\
\hline \multicolumn{20}{|c|}{ The width of the milling operation } \\
\hline \multicolumn{5}{|c|}{ Undamaged } & \multicolumn{5}{|c|}{0.3 in } & \multicolumn{5}{|c|}{0.7 in } & \multicolumn{5}{|c|}{ 1in } \\
\hline 10 & 8 & 9 & 8 & 50 & 100 & 80 & 70 & 90 & 110 & 165 & 110 & 150 & 150 & 160 & 215 & 140 & 240 & 180 & 170 \\
\hline
\end{tabular}


Table 8 5th Momentum result in central point

\begin{tabular}{|c|c|c|c|}
\hline \multicolumn{4}{|c|}{ Length of the milling operation } \\
\hline $\begin{array}{c}\text { 5th Momentum } \\
\text { result in central } \\
\text { point }\end{array}$ & $\mathbf{3}$ in & $\mathbf{4}$ in & $\mathbf{5}$ in \\
\cline { 2 - 4 } & 1250 & 2050 & 7700 \\
\hline \multicolumn{4}{|c|}{ The width of the milling operation } \\
\hline $\begin{array}{c}\text { 5th Momentum } \\
\text { result in central } \\
\text { point }\end{array}$ & $\mathbf{0 . 3}$ in & $\mathbf{0 . 7}$ in & 1in \\
\cline { 2 - 4 } & 800 & 2700 & 9700 \\
\hline
\end{tabular}

Finally, the surface response to excitation (SuRE) method was used for the detection of simulated contamination between two composite plates as a linear SHM method and it was reasonably sensitive to the changes of the contamination size.

Table 9 SSD values for different contamination sizes

\begin{tabular}{|c|c|c|c|}
\hline \multirow{2}{*}{ bond inspection } & \multicolumn{3}{|c|}{ Contamination sizes } \\
\cline { 2 - 4 } & $\mathbf{6 \times 6} \mathbf{c m}$ & $\mathbf{8 \times 8} \mathbf{~ c m}$ & $\mathbf{1 0 \times 1 0} \mathbf{~ c m}$ \\
\hline SSD values & 0.65 & 1.25 & 2.5 \\
\hline
\end{tabular}

\subsection{Nonlinear method}

Since nonlinear SHM approaches show high sensitivity to small defects and based on recent researches some types of damage including debonding and delaminations change the linear behavior of structure into nonlinear, it nonlinear method chapter, the heterodyning method was utilized to monitor nonlinear characteristics of a damaged structure. In this study, three different scenarios were considered. In the first step, the 
heterodyne effect was used to identify the debonded region when adhesives were used for joining and debonded region between two coupons was successfully detected (Table. 9). Then, in order to evaluate the level of nonlinearity, two composite plates held together by different numbers of magnetic pairs and the change of the compressive forces was also detected with the proposed SHM method (Table. 10). In the last experimental result, the heterodyning method was utilized as a nonlinear SHM method to investigate the bond strength in composite materials when various contamination levels in composite bonds were applied (Table. 11).

Table 10 Detection of debonding

\begin{tabular}{|c|c|c|}
\hline $\begin{array}{c}\text { Detection of } \\
\text { debonding }\end{array}$ & Bonded region & Debonded region \\
\hline $\begin{array}{c}\text { The amplitude of the } \\
\text { spike at f1-f2 }\end{array}$ & 0.00002 & 0.00008 \\
\hline
\end{tabular}

Table 11 Evaluation of the compressive forces on the composite plates

\begin{tabular}{|c|c|c|c|}
\hline \multirow{2}{*}{$\begin{array}{c}\text { Evaluation of the compressive } \\
\text { forces on the composite plates }\end{array}$} & \multicolumn{3}{|c|}{ Number of magnet pairs } \\
\cline { 2 - 4 } & $\begin{array}{c}\text { Three pairs of } \\
\text { magnets }\end{array}$ & $\begin{array}{c}\text { Five pairs of } \\
\text { magnet }\end{array}$ & $\begin{array}{c}\text { Seven pairs of } \\
\text { magnet }\end{array}$ \\
\hline Amplitude of the spike at f1-f2 & $-73 \mathrm{~dB}$ & $-77 \mathrm{~dB}$ & $-80 \mathrm{~dB}$ \\
\hline
\end{tabular}

Table 12 Detection of different sizes of contamination

\begin{tabular}{|c|c|c|c|}
\hline \multirow{2}{*}{$\begin{array}{c}\text { Detection of different } \\
\text { sizes of contamination }\end{array}$} & $\mathbf{3}$ Contamination sizes \\
\cline { 2 - 4 } & $\mathbf{6 \times 6} \mathbf{~ c m}$ & $\mathbf{8 \times 8} \mathbf{~ c m}$ & $\mathbf{1 0 \times 1 0} \mathbf{~ c m}$ \\
\hline $\begin{array}{c}\text { Amplitude of the spike at } \\
\text { f1-f2 }\end{array}$ & 0.00001 & 0.000056 & 0.000075 \\
\hline
\end{tabular}


As a result, the heterodyne effect seems to be a promising approach in the development of the effective system for composite bond inspection.

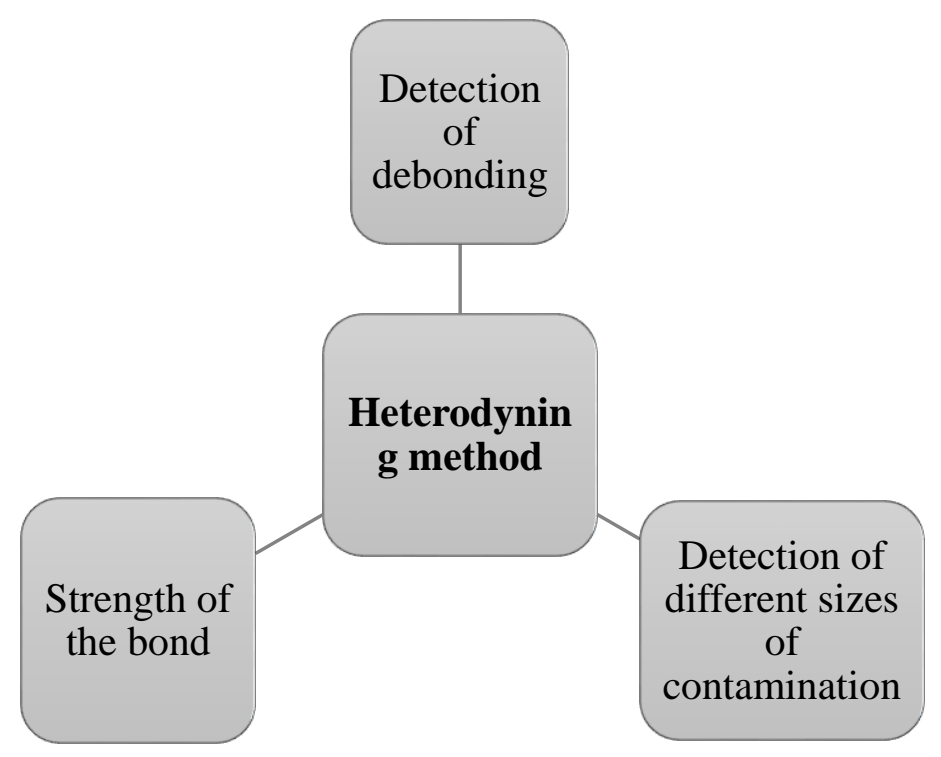

\subsection{Comparison}

The majority of available wide range frequency approaches such as SuRE method are based on monitoring linear characteristics of structures. In this approach, the analysis is mainly performed in frequency domain since the response cannot be easily interpreted in the time domain. As it was shown in linear method chapter, SuRE method can be effectively used for load monitoring, damage detection and also composite bond inspection applications, however, there is always a need for baseline and reference data in this method. Attempts to remove the need for prior knowledge information by means of various signal processing techniques failed to produce results with the same accuracy.

On the other hand, the nonlinear SHM approaches, such as heterodyning method, monitor nonlinear characteristics of a damaged structure. There is no need for baseline data in these methods and they show higher sensitivity to small defects. However, they also have their 
own drawbacks. They are only sensitive to the specific type of damages that change the linear behavior of structure into nonlinear. Besides, since sensitivities of different frequencies to various potential damages are not the same, selecting the appropriate excitation frequency that fits a particular type of the defect is essential. 


\section{CHAPTER 6}

\section{CONCLUSIONS AND FUTURE DIRECTIONS}

\subsection{Conclusions}

Structural health monitoring methods can be a significant help for the detection of the structural defects in early stages and they play a pivotal role in maintaining the required level of integrity and safety in various industries. Development of more accurate and costeffective SHM techniques has been a challenge for researchers in last few years.

In this thesis, a broad range of researches in structural health monitoring (SHM) and their applications in various industries such as aerospace and mechanical structures were investigated. Firstly, in the introduction chapter, motivations and basic concepts were explained and investigation performed by several researchers were reviewed. Then, as the main goal of this dissertation, in order to improve the existing SHM approaches for new applications and also develop a reliable and cost-effective SHM system, various scenarios for fault detection were designed. Since ceramic piezoelectric wafer transducers are mostly smaller cheaper, and more compact compared to the common transducers which used in SHM methods, PZT transducers were chosen as actuators and sensors for all experimental setups.

The major contributions resulting from the research in this thesis are listed below:

1) Surface response to excitation (SuRE) method has been established as a low-cost alternative for Electromechanical Impedance method. Since It has been shown in several types of research that the dynamic response of the structure is not only 
sensitive to defects but it is also sensitive to loading, in this study, the possibility of using SuRE method for load monitoring applications was investigated

2) By using PZT and laser vibrometer as a sensor for recording the response of the system, it was shown that the result from contact and non-contact sensors are conspicuously similar in pattern except for the fact that the amplitude of the laser response is so much smaller than the amplitude of PZT response. it implies that the massive networks of surface bonded sensors that are normal in impedance-based monitoring of large structures could be avoided by using non-contact sensors. As a result, the SuRE method seems to be a promising approach in the development of non-contact load monitoring systems especially for applications that bonded sensors will interfere with their normal performance.

3) In this study, the modification of the SuRE method was attempted by evaluating the possibility of using different damage indexes instead of the sum of the square of difference (SSD) in the monitoring of milling operation in order to get rid of the need for baseline or reference signal. Several signal processing functions were tested. As a result, geometric, harmonic mean, and 5th momentum values were found a promising alternative for SSD value in SuRE method especially for some applications that the baseline or reference signal is not available.

4) Since some specific defects including debonding, cracks and delaminations change the linear behavior of a structure into nonlinear, in recent years, the nonlinear methods in SHM were introduced. In these methods, by monitoring the existence of nonlinear behavior in a structure, it is possible to detect these types of defects in their early stages. Besides, the nonlinearity signatures can be used for quantification 
between different levels of damage. In the existent nonlinear methods, two different actuators are used to excite the structure at very low and high frequencies and there is no systematic approach for the selection of excitation frequencies. In this study, heterodyning effect method was proposed which has the potential to detect different types of the damages and it is not limited to the combination of a high and a low frequency, which can simplify the selection of excitation frequencies.

5) High strength-to-weight ratio and durability against corrosion, makes composite materials a prefer choice in high tech applications. Adhesives or fasteners are the most common ways for linking these materials. In this study, the heterodyne effect was used to identify the debonded region between two composite panels which were bonded together using adhesives. Besides, the same method was used to investigate the bond strength between two composite panels by evaluating the level of compressive force that holds two composite plates together.

6) Since the partial separation of bonded regions or their delamination drastically reduce the strength of the composite structures and it may lead to failure, in this study, the change in the size of the contamination between two composite panels was examined using the SuRE and heterodyning method.

7) To reduce the costs and time during the development of structural health monitoring methods and also improve its accuracy, it would be reasonable to use computational approaches to validate the experimental results. In order to validate the experimental result of the heterodyning method for the detection of debonded regions, in this study, a finite element software (Comsol) were utilized. 


\subsection{Recommendations for Future Research}

In this dissertation, the SuRE method was modified in order to eliminate the need for baseline data and also a heterodyning method for inspection of composite bonds was developed. I also used Comsol simulation for validation of the heterodyning method. There are still several matters worthy of consideration to further advance in this study. Suggested directions for future research are listed below:

1) In this study, the SuRE method was used for load detection, part-based monitoring and also the quantification of different applied loads and severities of damages by the help of single or multiple sensing points in the small aluminum plates. Since the SuRE method was originally developed for the monitoring of the damage for thin plates, by using larger plates to avoid the waves coming from the edge of the plates, it would be possible to improve the accuracy of the method.

2) It was shown that scanning laser vibrometer is able to be used as a non-contact sensing approach for the SuRE method. By using multiple scanning points with help of the scanning laser vibrometer, the future work should focus on the estimation of the location of the load or defect.

3) By looking at the result of the SuRE method for the part-based monitoring and with the help of multiple sensing points, the method has the potential to be used for the detection of the corrosion in molds.

4) Heterodyning effect method was utilized for the detection of delamination in composite bonds. The pairs of strong magnets were employed for the simulation of the adhesively bonded composite panels. This method can be applied to real adhesively bonded composite panels. 
5) Considering the frequency of difference used in heterodyning effect method, which is in the audible range, it would be possible to using this approach for sensor free detection of nonlinear behavior in composite structures.

6) Future investigations on the localization of delamination should be another area for the future work regarding the heterodyning effect method to focus on.

7) Simulation models can provide the opportunity to investigate the other parameters that may have a significant effect on the results. The effect of size and shape of the piezoelectric transducers on the wave transition can be studied. Also, implementation of heterodyning effect for different type of materials and various kind of composites must be studied.

8) By using COMSOL models, it would be possible to explore the implementation of heterodyning effect method for more complicated and realistic scenarios when the structure is not as simple as two mating plates. 


\section{REFERENCES}

[1] M. Varmazyar, N. Haritos, M. Kirley, and T. Peterson, "A One Stage Damage Detection Technique Using Spectral Density Analysis and Parallel Genetic Algorithms," Key Eng. Mater., vol. 558, pp. 1-11, Jun. 2013.

[2] H. Van der Auweraer and B. Peeters, "International Research Projects on Structural Health Monitoring: An Overview,” Struct. Heal. Monit. An Int. J., vol. 2, no. 4, pp. 341-358, Dec. 2003.

[3] S. Grondel, J. Assaad, C. Delebarre, and E. Moulin, "Health monitoring of a composite wingbox structure," Ultrasonics, vol. 42, no. 1-9, pp. 819-824, Apr. 2004.

[4] Y. . Koh, W. . Chiu, and N. Rajic, "Integrity assessment of composite repair patch using propagating Lamb waves," Compos. Struct., vol. 58, no. 3, pp. 363-371, Nov. 2002.

[5] K. A. Lakshmanan and D. J. Pines, "Modeling damage in rotorcraft flexbeams using wave mechanics," Smart Mater. Struct., vol. 6, no. 3, pp. 383-392, Jun. 1997.

[6] K. P. Chong, N. J. Carino, and G. Washer, "Health monitoring of civil infrastructures," Smart Mater. Struct., vol. 12, no. 3, pp. 483-493, Jun. 2003.

[7] R. C. Tennyson, A. A. Mufti, S. Rizkalla, G. Tadros, and B. Benmokrane, "Structural health monitoring of innovative bridges in Canada with fiber optic sensors," Smart Mater. Struct., vol. 10, no. 3, pp. 560-573, Jun. 2001.

[8] H.-N. Li, D.-S. Li, and S.-Y. Wang, "Study and Application of Health Monitoring by Fiber Optic Sensors in Civil Engineering," in Aging Management and Component Analysis, 2003, vol. 2003, pp. 217-224.

[9] V. Giurgiutiu, J. Redmond, D. Roach, and K. Rackow, "Active Sensors for Health Monitoring of Aging Aerospace Structures." 
[10] E. J. Blaise and F.-K. Chang, "\&lt;title\&gt;Built-in damage detection system for sandwich structures under cryogenic temperatures\&lt;/title\&gt;," 2002, vol. 4701, pp. 97-107.

[11] G. Victor, "Structural health monitoring with piezoelectric wafer active sensors predictive modeling and simulation,” Incas Bull., vol. 2, no. 3, pp. 31-44, 2010.

[12] “Incident Statistics | PHMSA.” [Online]. Available: https://www.phmsa.dot.gov/hazmat-program-management-data-and-statistics/dataoperations/incident-statistics. [Accessed: 08-Jan-2018].

[13] "NASA - Report of Columbia Accident Investigation Board, Volume I."

[14] A. Raghavan and C. E. S. Cesnik, "Review of Guided-wave Structural Health Monitoring," vol. 39, 2007.

[15] C. Santulli, "Post-impact damage characterisation on natural fibre reinforced composites using acoustic emission," NDT E Int., vol. 34, no. 8, pp. 531-536, Dec. 2001.

[16] G. N. Morscher, "Modal acoustic emission of damage accumulation in a woven $\mathrm{SiC} / \mathrm{SiC}$ composite," Compos. Sci. Technol., vol. 59, no. 5, pp. 687-697, Apr. 1999.

[17] W. Sachse and K. Y. Kim, "Quantitative acoustic emission and failure mechanics of composite materials," Ultrasonics, vol. 25, no. 4, pp. 195-203, Jul. 1987.

[18] H. Jeong and Y.-S. Jang, "Wavelet analysis of plate wave propagation in composite laminates," Compos. Struct., vol. 49, no. 4, pp. 443-450, Aug. 2000.

[19] V. Giurgiutiu, "Tuned Lamb Wave Excitation and Detection with Piezoelectric Wafer Active Sensors for Structural Health Monitoring," J. Intell. Mater. Syst. Struct., vol. 16, no. 4, pp. 291-305, 2005. 
[20] H. Kwun, G. M. Light, S. Kim, R. H. Peterson, and R. L. Spinks, "Title: Permanently Installable, Active Guided-Wave Sensor for Structural Health Monitoring."

[21] J.-B. Ihn and F.-K. Chang, "Pitch-catch Active Sensing Methods in Structural Health Monitoring for Aircraft Structures," Struct. Heal. Monit. An Int. J., vol. 7 , no. 1, pp. 5-19, Mar. 2008.

[22] X. Lin and F. G. Yuan, "Experimental Study Applying a Migration Technique in Structural Health Monitoring," Struct. Heal. Monit. An Int. J., vol. 4, no. 4, pp. 341-353, Dec. 2005.

[23] B. Xu and V. Giurgiutiu, "Single Mode Tuning Effects on Lamb Wave Time Reversal with Piezoelectric Wafer Active Sensors for Structural Health Monitoring," J. Nondestruct. Eval., vol. 26, no. 2-4, pp. 123-134, Nov. 2007.

[24] K. Rave, "Acoustic Emission Testing and Acousto-Ultrasonics for Structural Health Monitoring." Siegen University, 2014

[25] L. M. (Leonid M. Brekhovskikh, Waves in layered media. Academic Press, 1980.

[26] J. L. Rose, "Ultrasonic Waves in Solid Media," http://dx.doi.org/10.1121/1.428552, Mar. 2000.

[27] K. E.-A. Van Den Abeele, P. A. Johnson, and A. Sutin, "Nonlinear Elastic Wave Spectroscopy (NEWS) Techniques to Discern Material Damage, Part I: Nonlinear Wave Modulation Spectroscopy (NWMS)," Res. Nondestruct. Eval., vol. 12, no. 1, pp. 17-30.

[28] K. E.-A. Van Den Abeele, J. Carmeliet, J. A. Ten Cate, and P. A. Johnson, "Nonlinear Elastic Wave Spectroscopy (NEWS) Techniques to Discern Material Damage, Part II: Single-Mode Nonlinear Resonance Acoustic Spectroscopy,” Res. Nondestruct. Eval., vol. 12, no. 1, pp. 31-42, Jan. 2000. 
[29] B. Culshaw, S. G. Pierce, and W. J. Staszekski, "Condition monitoring in composite materials: An integrated systems approach,” Proc. Inst. Mech. Eng. Part I J. Syst. Control Eng., vol. 212, no. 3, pp. 189-202, May 1998.

[30] D. C. Betz, G. Thursby, B. Culshaw, and W. J. Staszewski, "Lamb wave detection and source location using fiber Bragg gratin rosettes," 2003, vol. 5050, p. 117.

[31] "Health Monitoring of Piping and Plate Using the Magnetostrictive Sensor (MsS) Guided-Wave Technology.” [Online]. Available: http://www.ndt.net/article/mendt03/48/48.htm. [Accessed: 19-Jan-2018].

[32] F. L. Degertekin and B. T. Khuri- Yakub, "Single mode Lamb wave excitation in thin plates by Hertzian contacts," http://oasc12039.247realmedia.com/RealMedia/ads/click_lx.ads/www.aip.org/pt/a dcenter/pdfcover_test/L-37/1923910458/x01/AIPPT/APL_ArticleDL_1217/scilight7171640x440.gif/434f71374e315a556e61414141774c75?x, Aug. 1998.

[33] S. G. Institution of Electrical Engineers. and B. Culshaw, IEE proceedings. A, Science, measurement and technology., vol. 145, no. 5. IEE, 1991.

[34] C. Y. K. Chee, L. Tong, and G. P. Steven, "A Review on the Modelling of Piezoelectric Sensors and Actuators Incorporated in Intelligent Structures," J. Intell. Mater. Syst. Struct., vol. 9, no. 1, pp. 3-19, Jan. 1998.

[35] A. Preumont, Vibration Control of Active Structures, vol. 179. Dordrecht: Springer Netherlands, 2011.

[36] H. Fekrmandi, J. Rojas, J. Campbell, I.N. Tansel, B. Kaya, S. Taskin, Inspection of the Integrity of a Multi-Bolt Robotic Arm Using a Scanning Laser Vibrometer and Implementing the Surface Response to Excitation Method (SuRE), International Journal of Prognostics and Health Management, 5 (2014) 1-10.

[37] V. Giurgiutiu, Structural health monitoring: with piezoelectric wafer active sensors, Academic Press, 2007. 
[38] A. Raghavan, C.E. Cesnik, Review of guided-wave structural health monitoring, Shock and Vibration Digest, 39 (2007) 91-116.

[39] F. Wu, H.-L. Chan, F.-K. Chang, Ultrasonic guided wave active sensing for monitoring of split failures in reinforced concrete, Structural Health Monitoring, (2015) 1475921715591876.

[40] G. Park, H. Sohn, C.R. Farrar, D.J. Inman, Overview of piezoelectric impedancebased health monitoring and path forward, (2003).

[41] N.E. Cortez, V. Jozue Filho, F.G. Baptista, A new microcontrolled structural health monitoring system based on the electromechanical impedance principle, Structural Health Monitoring, 12 (2013) 14-22.

[42] J. Yang, Y. Chen, Y. Xiang, X. Jia, Free and forced vibration of cracked inhomogeneous beams under an axial force and a moving load, Journal of Sound and Vibration, 312 (2008) 166-181.

[43] R. Ruotolo, C. Surace, P. Crespo, D. Storer, Harmonic analysis of the vibrations of a cantilevered beam with a closing crack, Computers \& structures, 61 (1996) 10571074.

[44] D. Patil, S. Maiti, Detection of multiple cracks using frequency measurements, Engineering Fracture Mechanics, 70 (2003) 1553-1572.

[45] E. Douka, S. Loutridis, A. Trochidis, Crack identification in beams using wavelet analysis, International Journal of Solids and Structures, 40 (2003) 3557-3569.

[46] A. Morassi, Identification of a crack in a rod based on changes in a pair of natural frequencies, Journal of Sound and Vibration, 242 (2001) 577-596.

[47] S. Bosse, A. Lechleiter, Structural health and load monitoring with materialembedded sensor networks and self-organizing multi-agent systems, Procedia Technology, 15 (2014) 668-690. 
[48] G. Owolabi, A. Swamidas, R. Seshadri, Crack detection in beams using changes in frequencies and amplitudes of frequency response functions, Journal of sound and vibration, 265 (2003) 1-22.

[49] J. Fu, C. Tan, F. Li, Quantitative electromechanical impedance method for nondestructive testing based on a piezoelectric bimorph cantilever, Smart Materials and Structures, 24 (2015) 065038.

[50] G. Park, H.H. Cudney, D.J. Inman, Impedance-based health monitoring of civil structural components, Journal of infrastructure systems, 6 (2000) 153-160.

[51] D.M. Peairs, G. Park, D.J. Inman, Improving accessibility of the impedance-based structural health monitoring method, Journal of Intelligent Material Systems and Structures, 15 (2004) 129-139.

[52] J. Kim, B.L. Grisso, D.S. Ha, D.J. Inman, A system-on-board approach for impedance-based structural health monitoring, The 14th International Symposium on: Smart Structures and Materials \& Nondestructive Evaluation and Health Monitoring, International Society for Optics and Photonics, 2007, pp. 65290O$652900-65299$.

[53] F.G. Baptista, A new impedance measurement system for PZT-based structural health monitoring, Instrumentation and Measurement, IEEE Transactions on, 58 (2009) 3602-3608.

[54] B. Xu, V. Giurgiutiu, A low-cost and field portable electromechanical (E/M) impedance analyzer for active structural health monitoring, DTIC Document, 2005.

[55] H.J. Lim, M.K. Kim, H. Sohn, C.Y. Park, Impedance based damage detection under varying temperature and loading conditions, NDT \& E International, 44 (2011) 740-750. 
[55] Z.A. Jassim, N.N. Ali, F. Mustapha, N.A. Jalil, A review on the vibration analysis for a damage occurrence of a cantilever beam, Engineering Failure Analysis, 31 (2013) 442-461.

[56] A. Baghalian, S. Tashakori, V. Y. Senyurek, M. Unal, D. McDaniel, and I. N. Tansel, "Development of comprehensive heterodyne effect based inspection (CHEBI) method for inclusive monitoring of cracks," Measurement, vol. 128, pp. 89-95, Nov. 2018.

[57] H. Fekrmandi, I. Tansel, R. Gonzalez, S. Rojas, D. Meiller, K. LIindsay, A. Bagahalian, S. Tashaskori, Implementation of the Surface Response to Excitation (SuRE) Method with DSP's for Detection of the Damage of Thick Blocks, Structural Health Monitoring 2015, (2015).

[58] S. Roy, P. Ladpli, F.-K. Chang, Load monitoring and compensation strategies for guided-waves based structural health monitoring using piezoelectric transducers, Journal of Sound and Vibration, 351 (2015) 206-220.

[59] V.G. Annamdas, J.H. Pang, K. Zhou, B. Song, Efficiency of electromechanical impedance for load and damage assessment along the thickness of lead zirconate titanate transducers in structural monitoring, Journal of Intelligent Material Systems and Structures, 24 (2013) 2008-2022.

[60] V. Giurgiutiu, C.A. Rogers, Recent advancements in the electromechanical (E/M) impedance method for structural health monitoring and NDE, 5th Annual International Symposium on Smart Structures and Materials, International Society for Optics and Photonics, 1998, pp. 536-547.

[61] P. Thrassos Panidis, I. Pavelko, V. Pavelko, S. Kuznetsov, I. Ozolinsh, Bolt-joint structural health monitoring by the method of electromechanical impedance, Aircraft Engineering and Aerospace Technology: An International Journal, 86 (2014) 207-214. 
[62] G. Park, D.J. Inman, Structural health monitoring using piezoelectric impedance measurements, Philosophical Transactions of the Royal Society of London A: Mathematical, Physical and Engineering Sciences, 365 (2007) 373-392.

[63] M. Demetgul, V. Y. Senyurek, R. Uyandik, I. N. Tansel, and O. Yazicioglu, "Evaluation of the health of riveted joints with active and passive structural health monitoring techniques," Measurement, vol. 69, pp. 42-51, 2015.

[64] V. Giurgiutiu, a. Zagrai, and J. Jing Bao, "Piezoelectric Wafer Embedded Active Sensors for Aging Aircraft Structural Health Monitoring," Struct. Heal. Monit. vol. 1, no. 1, pp. 41-61, 2002.

[65] W. J. Staszewski, S. Mahzan, and R. Traynor, "Health monitoring of aerospace composite structures - Active and passive approach,” Compos. Sci. Technol., vol. 69, no. 11-12, pp. 1678-1685, 2009.

[66] A Galvagni and P. Cawley, "The reflection of guided waves from simple support in pipes," J. Acoust. Soc. ..., vol. 129, no. September, pp. 1869-1880, 2011.

[67] D. N. Alleyne and P. Cawley, "The excitation of Lamb waves in pipes using drycoupled piezoelectric transducers,” J. Nondestruct. Eval., vol. 15, no. 1, pp. 11-20, 1996.

[68] S. Tashakori, A. Baghalian, M. Unal, H. Fekrmandi, volkan y şenyürek, D. McDaniel, and I. N. Tansel, "Contact and non-contact approaches in load monitoring applications using surface response to excitation method," Measurement, vol. 89, pp. 197-203, 2016.

[69] H. Fekrmandi, M. Unal, A. Baghalian, S. Tashakori, K. Oyola, A. Alsenawi, and I. N. Tansel, "A non-contact method for part-based process performance monitoring in end milling operations,” Int. J. Adv. Manuf. Technol., Jul. 2015.

[70] V. Giurgiutiu and A. Zagrai, "Electro-mechanical impedance method for crack detection in metallic plates,” Proc. SPIE - Int. Soc. Opt. Eng., vol. 4335, no. October, pp. 131-142, 2001. 
[71] G. Park, H. H. Cudney, and D. J. Inman, "Feasibility of using impedance-based damage assessment for pipeline structures,” Earthq. Eng. Struct. Dyn., vol. 30, no. 10, pp. 1463-1474, 2001.

[72] J. Min, S. Park, C. B. Yun, C. G. Lee, and C. Lee, "Impedance-based structural health monitoring incorporating neural network technique for identification of damage type and severity,” Eng. Struct., vol. 39, pp. 210-220, 2012.

[73] S. R. Hamzeloo, M. Shamshirsaz, and S. M. Rezaei, "Damage detection on hollow cylinders by Electro-Mechanical Impedance method: Experiments and Finite Element Modeling,” Comptes Rendus - Mec., vol. 340, no. 9, pp. 668-677, 2012.

[74] W. Zhou, F. G. Yuan, and T. Shi, "Guided torsional wave generation of a linear inplane shear piezoelectric array in metallic pipes," Ultrasonics, vol. 65, pp. 69-77, 2016.

[75] K. Diamanti and C. Soutis, "Structural health monitoring techniques for aircraft composite structures,” Prog. Aerosp. Sci., vol. 46, no. 8, pp. 342-352, 2010.

[76] M. Carboni, A. Gianneo, and M. Giglio, "A Lamb waves based statistical approach to structural health monitoring of carbon fibre reinforced polymer composites," Ultrasonics, vol. 60, pp. 51-64, 2015.

[77] B. S. Ben, B. a. Ben, K. a. Vikram, and S. H. Yang, "Damage identification in composite materials using ultrasonic based Lamb wave method," Measurement, vol. 46, no. 2, pp. 904-912, 2013.

[78] J.-H. Lee and S.-J. Lee, “Application of laser-generated guided wave for evaluation of corrosion in carbon steel pipe,” NDT E Int., vol. 42, no. 3, pp. 222 $227,2009$.

[79] K. Liu, Z. Wu, Y. Jiang, Y. Wang, K. Zhou, and Y. Chen, "Guided waves based diagnostic imaging of circumferential cracks in small-diameter pipe," Ultrasonics, vol. 65, pp. 34-42, 2016. 
[80] A. Baltazar, E. Rojas, and R. Mijarez, "Structural Health Monitoring in Cylindrical Structures Using Helical Guided Wave Propagation,” Phys. Procedia, vol. 70, pp. 686-689, 2015.

[81] D. K. Stoyko, N. Popplewell, and A. H. Shah, "Detecting and describing a notch in a pipe using singularities," Int. J. Solids Struct., vol. 51, no. 15-16, pp. 2729-2743, 2014.

[82] Z. Liu, C. He, B. Wu, X. Wang, and S. Yang, "Circumferential and longitudinal defect detection using $\mathrm{T}(0,1)$ mode excited by thickness shear mode piezoelectric elements," Ultrasonics, vol. 44, no. SUPPL., pp. 1135-1138, 2006.

[83] M. H. S. Siqueira, C. E. N. Gatts, R. R. Da Silva, and J. M. A. Rebello, "The use of ultrasonic guided waves and wavelets analysis in pipe inspection," Ultrasonics, vol. 41, no. 10, pp. 785-797, 2004.

[84] M. Ratassepp, S. Fletcher, and M. J. S. Lowe, "Scattering of the fundamental torsional mode at an axial crack in a pipe.," J. Acoust. Soc. Am., vol. 127, no. 2, pp. 730-740, 2010.

[85] R. Carandente and P. Cawley, "The effect of complex defect profiles on the reflection of the fundamental torsional mode in pipes," NDT E Int., vol. 46, no. 1, pp. $41-47,2012$.

[86] R. Ahmad and T. Kundu, "Structural health monitoring of steel pipes under different boundary conditions and choice of signal processing techniques," Adv. Civ. Eng., vol. 2012, 2012.

[87] F. Li, Z. Liu, X. Sun, H. Li, and G. Meng, "Propagation of guided waves in pressure vessel," Wave Motion, vol. 52, pp. 216-228, 2015.

[88] T. Wang, C. Yang, L. Ye, D. Spray, and Y. Xiang, "Evaluation of guided wave propagation in steel pipes," Recent Adv. Struct. Integr. Anal. - Proc. Int. Congr., pp. 255-260, 2014. 
[89] H. W. Kim, H. J. Lee, and Y. Y. Kim, "Health monitoring of axially-cracked pipes by using helically propagating shear-horizontal waves," NDT E Int., vol. 46, no. 1, pp. 115-121, 2012.

[90] Taheri, Hossein, Jikai Du, and Fereidoon Delfanian. "Experimental Observation of Phased Array Guided Wave Application in Composite Materials." Materials Evaluation 75.10 (2017): 1308-1316.

[91] Mittal, G., Rhee, K. Y., Miškovic-Stankovic, V., \& Hui, D. (2017). Reinforcements in multi-scale polymer composites: Processing, properties, and applications. Composites Part B: Engineering.

[92] Taheri, Hossein, Mohammad Rashid Bin Mohammad Shoaib, Lucas W. Koester, Timothy A. Bigelow, Peter C. Collins, and Leonard J. Bond. "Powder-based additive manufacturing-a review of types of defects, generation mechanisms, detection, property evaluation and metrology." International Journal of Additive and Subtractive Materials Manufacturing 1, no. 2 (2017): 172-209.

[93] Yao, S.S., Jin, F.L., Rhee, K.Y., Hui, D. and Park, S.J.,. Recent advances in carbonfiber-reinforced thermoplastic composites: A review. Composites Part B: Engineering, Vol. 142, :241-250

[94] Mohan, V.B., Lau, K.T., Hui, D. and Bhattacharyya, D., 2018. Graphene-based materials and their composites: a review on production, applications and product limitations. Composites Part B: Engineering. vol 142. 200-220.

[95] Bruno, L., 2017. Mechanical characterization of composite materials by optical techniques: A review. Optics and Lasers in Engineering. 104 (2018) 192-203.

[96] Santhanakrishnan Balakrishnan, V. and Seidlitz, H., 2018. Potential repair techniques for automotive composites: A review. 145 (2018) 28-38.

[97] Dubuc B, Ebrahimkhanlou A, Salamone S. Computation of propagating and nonpropagating guided modes in nonuniformly stressed plates using spectral methods. The Journal of the Acoustical Society of America. 2018 Jun;143(6):3220-30. 
[98] Nasrollahi, Amir, Wen Deng, Zhaoyun Ma, and Piervincenzo Rizzo. "Multimodal structural health monitoring based on active and passive sensing." Structural Health Monitoring Structural Health Monitoring 2018, Vol. 17(2) 395-409

[99] S. Farhangdoust, A.B. Mehrabi, S.F.A. Mowsavi, "NDT Methods Applicable to Health Monitoring of ABC Closure Joints," 27th Research Symposium - The American Society for Non-destructive Testing (ASNT), Orlando, Fl, 26-29 March, 2018.

[100] Ebrahimkhanlou A, Salamone S. Single-Sensor Acoustic Emission Source Localization in Plate-Like Structures Using Deep Learning. Aerospace. 2018 May 1;5(2):50.

[101] D.T. Pham, R.S. Gault, (1998) “A comparison of rapid prototyping technologies," International Journal of Machine Tools \& Manufacture Vol. 38, pp.1257-1287

[102] N.A. Waterman, P. Dickens, (1994) "Rapid product development in the USA, Europe and Japan,” World Class Design to Manufacture Vol.1, Iss:3, pp. 27-36.

[103] Lin, Liang S (2002) “Rapid prototyping through scanned point data," Int J Prod Res, Vol. 40, Iss:2, pp.293-310.

[104] Wohlers T (2004) "Rapid prototyping, tooling, and manufacturing state of the industry" Wohlers Report 2004, Wholer Associates, Fort Collins.

[105] Shan Z, Yan Y, Guan L (2003) Rapid manufacture of metal tooling by rapid prototyping. Int J Adv Manuf Technol Vol. 21, Iss:7, pp.469-475.

[106] M. Asadi-Eydivand, M. Solati-Hashjin, A. Farzad, and N. A. A. Osman (2016), Effect of technical parameters on porous structure and strength of $3 \mathrm{D}$ printed calcium sulfate prototypes. Robotics and Computer-Integrated Manufacturing, 37,57-67.

[107] Y.-C. Lin, and T. Chen (2017) A ubiquitous manufacturing network system. Robotics and Computer-Integrated Manufacturing, 45, 157-167. 
[108] B. Berman, "3-D printing: The new industrial revolution," Bus. Horiz., vol. 55, no. 2, pp. 155-162, 2012.

[109] Hsin-Chieh Wu, Tin-Chih Toly Chen, (2018) "Quality control issues in 3D-printing manufacturing: a review", Rapid Prototyping Journal, Vol. 24 Issue: 3, pp.607-614, https://doi.org/10.1108/RPJ-02-2017-0031.

[110] N. Li, Y. Li, and S. Liu, "Rapid prototyping of continuous carbon fiber reinforced polylactic acid composites by 3D printing," J. Mater. Process. Technol., vol. 238, pp. 218-225, 2016.

[111] D. N. Silva, M. G. De Oliveira, E. Meurer, M. I. Meurer, J. V. L. da Silva, and A. Santa-Bárbara (2008) Dimensional error in selective laser sintering and 3D-printing of models for craniomaxillary anatomy reconstruction. Journal of CranioMaxillofacial Surgery, 36(8), 443-449.

[112] Chillara, V.K., Cho, H., Hasanian, M. and Lissenden, C.J., 2015. "Effect of load and temperature changes on nonlinear ultrasonic Measurements: Implications for SHM.” In 10th International Workshop on Structural Health Monitoring: System Reliability for Verification and Implementation, IWSHM 2015. DEStech Publications.

[113] He, J., Li, D., Lu, B., Wang, Z. and Zhang, T., 2006. Custom fabrication of a composite hemi-knee joint based on rapid prototyping. Rapid prototyping journal, 12(4), pp.198-205.

[114] Smith, R.A., 2009. Composite defects and their detection. Materials science and engineering, 3, pp.103-143.

[115] L. Ding, C. Shih, Z. Liang, C. Zhang, and B. Wang, "In situ measurement and monitoring of whole-field permeability profile of fiber preform for liquid composite molding processes," Compos. Part A Appl. Sci. Manuf., vol. 34, no. 8, pp. 779-789, 2003. 
[116] R. L. Crane and G. Dillingham, “Composite bond inspection,” J. Mater. Sci., vol. 43, no. 20, pp. 6682-6694, 2008.

[117] G. Boopathy, G. Surendar, A. Nema, and T. P. P. Anand, "Review on nondestructive testing of composite materials in aircraft applications," Int. J. Mech. Eng. Technol., vol. 8, no. 8, pp. 1334-1342, 2017.

[118] B. Uy, "Modern design, construction and maintenance of composite steel- concrete structures: Australian experiences," Electron. J. Struct. Eng., no. December, pp. 42-48, 2007.

[119] Z. B. Zabinsky, M. E. Tuttle, and C. Khompatraporn, "A case study: composite structure design optimization,” Glob. Optim., vol. 85, pp. 507-528, 2006.

[120] C. Lissenden and J. Rose, "Structural Health Monitoring of Composite Laminates Through Ultrasonic Guided Wave Beam Forming,” NATO Appl. Vehilcel Technol. Plate, pp. 1-14, 2008.

[121] K. B. Katnam, L. F. M. Da Silva, and T. M. Young, "Bonded repair of composite aircraft structures: A review of scientific challenges and opportunities," Prog. Aerosp. Sci., vol. 61, pp. 26-42, 2013.

[122] D. Vértesy, "A Critical Assessment of Quality and Validity of Composite Indicators of Innovation,” Oecd Blue Sky Iii Forum Sci. Innov. Indic., pp. 1-20, 2016.

[123] G. Georgeson, "Trends in R \& D for Nondestructive Evaluation of In-Service Aircraft," 5th Int. Conf. NDT Aerosp., no. November, pp. 13-15, 2013.

[124] A. Raimondo and A. Riccio, "Inter-laminar and intra-laminar damage evolution in composite plates with skin-stringer debonding under compression," Compos. Part B Eng., vol. 94, pp. 139-151, Jun. 2016.

[125] P. K. Majumdar, M. Y. Bhuiyan, J. Clifford, F. H. Haider, and K. L. Reifsnider, "Multi-Physical Description of Material State Change in Composite Materials," Proc. Soc. Adv. Mater. Process Eng., no. July, pp. 1-11, 2015. 
[126] E. Bayraktar, S. D. Antolovich, and C. Bathias, "New developments in nondestructive controls of the composite materials and applications in manufacturing engineering,” J. Mater. Process. Technol., vol. 206, no. 1-3, pp. 30-44, Sep. 2008.

[127] I. G. Scott and C. M. Scala, "A review of non-destructive testing of composite materials," NDT Int., vol. 15, no. 2, pp. 75-86, Apr. 1982.

[128] P. Brandão, V. Infante, A. M. Deus, and S. Gholizadeh, "Thermo-mechanical modeling of a high pressure turbine blade of an airplane gas turbine engine A review of non-destructive testing methods of composite materials," Sci. Procedia Struct. Integr. Struct. Integr. Procedia, vol. 1, no. 0, pp. 50-57, 2016.

[129] S. Gholizadeh, "A review of non-destructive testing methods of composite materials," Procedia Struct. Integr., vol. 1, pp. 50-57, 2016.

[130] L. Greve and A. K. Pickett, "Modelling damage and failure in carbon/epoxy noncrimp fabric composites including effects of fabric pre-shear," Compos. Part A Appl. Sci. Manuf., vol. 37, no. 11, pp. 1983-2001, Nov. 2006.

[131] R. L. Rito, A. D. Crocombe, and S. L. Ogin, "Health monitoring of composite patch repairs using CFBG sensors: Experimental study and numerical modelling," Compos. Part A Appl. Sci. Manuf., vol. 100, pp. 255-268, Sep. 2017.

[132] R. Jones and S. Galea, "Health monitoring of composite repairs and joints using optical fibres," Compos. Struct., vol. 58, no. 3, pp. 397-403, Nov. 2002.

[133] W. Roth and V. Giurgiutiu, "Structural health monitoring of an adhesive disbond through electromechanical impedance spectroscopy,” Int. J. Adhes. Adhes., vol. 73, pp. 109-117, Mar. 2017.

[134] K. I. Salas and C. E. S. Cesnik, "Guided wave structural health monitoring using CLoVER transducers in composite materials," Smart Mater. Struct., vol. 19, no. 1, p. 15014, Jan. 2010. 
[135] P. Kudela, W. Ostachowicz, and A. Żak, "Damage detection in composite plates with embedded PZT transducers,” Mech. Syst. Signal Process., vol. 22, no. 6, pp. 1327-1335, Aug. 2008.

[136] A. Baghalian, S. Tashakori, H. Fekrmandi, M. Unal, V. Y. Senyurek, D. McDaniel, and I. N. Tansel, "Implementation of the Surface Response to Excitation Method for Pipes,” Springer International Publishing, 2017, pp. 261266.

[137] S. Tashakori, A. Baghalian, M. Unal, V. Y. Senyurek, H. Fekrmandi, D. McDaniel, and I. N. Tansel, "Load Monitoring Using Surface Response to Excitation Method,” Springer International Publishing, 2017, pp. 209-214.

[138] A. Baghalian, S. Tashakori, J. R. Soto, V. Y. Senyurek, I. N. Tansel, and B. Uragun, "Internal defect detection in hollow cylindrical structures using the Surface Response to Excitation (SuRE) Method," in 2017 8th International Conference on Recent Advances in Space Technologies (RAST), 2017, pp. 523527.

[139] S. Tashakori, A. Baghalian, J. Cuervo, V. Y. Senyurek, I. N. Tansel, and B. Uragun, "Inspection of the machined features created at the embedded sensor aluminum plates," in 2017 8th International Conference on Recent Advances in Space Technologies (RAST), 2017, pp. 517-522.

[140] A. Baghalian, S. Tashakori, V. Y. Senyurek, D. Mcdaniel, H. Fekrmandi, and I. N. Tansel, "Non - Contact Quantification of Longitudinal and Circumferential Defects in Pipes using the Surface Response to Excitation (SuRE) Method,” Int. J. Progn. Heal. Manag., pp. 2153-2648, 2017.

[141] A. Riccio, M. Damiano, A. Raimondo, G. Di Felice, and A. Sellitto, “A fast numerical procedure for the simulation of inter-laminar damage growth in stiffened composite panels," Compos. Struct., vol. 145, pp. 203-216, Jun. 2016. 
[142] A. Raimondo and A. Riccio, "Inter-laminar and intra-laminar damage evolution in composite panels with skin-stringer debonding under compression," Compos. Part B Eng., vol. 94, pp. 139-151, Jun. 2016.

[143] E. Pietropaoli and A. Riccio, "A Global/Local Finite Element Approach for Predicting Interlaminar and Intralaminar Damage Evolution in Composite Stiffened Panels Under Compressive Load,” Appl. Compos. Mater., vol. 18, no. 2, pp. 113-125, Apr. 2011.

[144] J. Baqersad, P. Poozesh, C. Niezrecki, and P. Avitabile, "A Noncontacting Approach for Full-Field Strain Monitoring of Rotating Structures," J. Vib. Acoust., vol. 138, no. 3, p. 31008, Apr. 2016.

[145] T. Akinci, "The Defect Detection in Ceramic Materials Based on Time-Frequency Analysis by Using the Method of Impulse Noise,” Arch. Acoust., vol. 36, no. 1, pp. 77-85, Jan. 2011.

[146] K. Aizawa, P. Poozesh, C. Niezrecki, J. Baqersad, M. Inalpolat, and G. Heilmann, "An acoustic-array based structural health monitoring technique for wind turbine blades," 2015, p. 94371P.[

[147] J. J. Scholey, P. D. Wilcox, M. R. Wisnom, and M. I. Friswell, "Quantitative experimental measurements of matrix cracking and delamination using acoustic emission,” Compos. Part A Appl. Sci. Manuf., vol. 41, no. 5, pp. 612-623, 2010.

[148] A. Kahirdeh, C. Sauerbrunn, and M. Modarres, "Acoustic emission entropy as a measure of damage in materials," 2016, p. 60007.

[149] C. Sauerbrunn, A. Kahirdeh, H. Yun, and M. Modarres, "Damage Assessment Using Information Entropy of Individual Acoustic Emission Waveforms during Cyclic Fatigue Loading,” Appl. Sci., vol. 7, no. 6, p. 562, May 2017.

[150] M. Bhuiyan, Y. Shen, and V. Giurgiutiu, "Guided Wave Based Crack Detection in the Rivet Hole Using Global Analytical with Local FEM Approach,” Materials (Basel)., vol. 9, no. 7, p. 602, Jul. 2016. 
[151] M. Yeasin Bhuiyan, Y. Shen, and V. Giurgiutiu, "Interaction of Lamb waves with rivet hole cracks from multiple directions," Proc. Inst. Mech. Eng. Part C J. Mech. Eng. Sci., vol. 231, no. 16, pp. 2974-2987, Aug. 2017

[152] H. Fekrimandi, I. Nur Tansel, R. Gonzalez, S. Rojas, D. Meiller, K. Lindsay, A. Baghalian, and S. Tashakori, "Implementation of the Surface Response to Excitation (SuRE) Method with DSP's for Detection of the Damage of Thick Blocks," in Structural Health Monitoring 2015, 2015.

[153] Z. Sharif Khodaei, Q. Liu, and M. H. Aliabadi, "Influence of Adhesive Layer on Actuation of Lamb Wave Signals," Key Eng. Mater., vol. 525-526, pp. 617-620, Nov. 2012.

[154] O. Karpenko, D. Gerges, H. Mahmoodul, L. Udpa, and S. S. Udpa, "Novel Mode Decomposition Algorithms for Lamb Wave Signal Analysis in Online Monitoring of Structures,” E-Journal Adv. Maint., vol. 5, no. 1, pp. 51-61, 2013.

[155] Z. Sharif Khodaei, R. Rojas-Diaz, and M. H. Aliabadi, "Lamb-Wave Based Technique for Impact Damage Detection in Composite Stiffened Panels," Key Eng. Mater., vol. 488-489, pp. 5-8, Sep. 2011.

[156] V. Y. Senyurek, A. Baghalian, S. Tashakori, D. McDaniel, and I. N. Tansel, "Localization of multiple defects using the compact phased array (CPA) method," J. Sound Vib., vol. 413, pp. 383-394, Jan. 2018.

[157] B. Wu, "A Time-Reversal Defect- Identifying Method for Guided Wave Inspection in Pipes," vol. 130, no. May, pp. 1-8, 2008.

[158] C. H. Wang, J. T. Rose, and F.-K. Chang, "A synthetic time-reversal imaging method for structural health monitoring," Smart Mater. Struct., vol. 13, no. 2, pp. 415-423, 2004.

[159] Y. Jin, D. Zhao, and Y. Ying, "Time reversal data communications on pipes using guided elastic waves: Part I. Basic principles,” 2011, p. 79840B. 
[160] T. Leutenegger and J. Dual, "Non-destructive testing of tubes using a time reverse numerical simulation (TRNS) method," Ultrasonics, vol. 41, no. 10, pp. 811-822, 2004.

[161] M. M. Alamdari, J. Li, and B. Samali, "Damage Localisation Using Symbolic Time Series Approach,” Springer International Publishing, 2014, pp. 109-115.

[162] K. E. -a. Van Den Abeele, P. a. Johnson, and A. Sutin, "Nonlinear Elastic Wave Spectroscopy (NEWS) Techniques to Discern Material Damage, Part II: SingleMode Nonlinear Resonance Acoustic Spectroscopy," Res. Nondestruct. Eval., vol. 12, no. 1, pp. 17-30, 2000.

[163] G. Zumpano and M. Meo, "Damage detection in an aircraft foam sandwich panel using nonlinear elastic wave spectroscopy," Comput. Struct., vol. 86, no. 3-5, pp. 483-490, 2008.

[164] G. Zumpano and M. Meo, "Damage localization using transient non-linear elastic wave spectroscopy on composite structures,” Int. J. Non. Linear. Mech., vol. 43, no. 3, pp. 217-230, 2008.

[165] M. Meo, U. Polimeno, and G. Zumpano, "Detecting damage in composite material using nonlinear elastic wave spectroscopy methods," Appl. Compos. Mater., vol. 15, no. 3, pp. 115-126, 2008.

[166] M. Meo and G. Zumpano, "Nonlinear elastic wave spectroscopy identification of impact damage on a sandwich plate," Compos. Struct., vol. 71, no. 3-4, pp. 469474, 2005.

[167] U. Polimeno and M. Meo, "Understanding the effect of boundary conditions on damage identification process when using non-linear elastic wave spectroscopy methods," Int. J. Non. Linear. Mech., vol. 43, no. 3, pp. 187-193, 2008.

[168] K. Van Den Abeele, "Multi-mode nonlinear resonance ultrasound spectroscopy for defect imaging: an analytical approach for the one-dimensional case.," J. Acoust. Soc. Am., vol. 122, no. 1, pp. 73-90, 2007. 
[169] P. A. Johnson and A. Sutin, "Nonlinear elastic wave NDE I. Nonlinear resonant ultrasound spectroscopy and slow dynamics diagnostics,” AIP Conf. Proc., vol. 760, pp. 377-384, 2005.

[170] X. Liu, Z. Dao, J. Zhu, W. Qu, X. Gong, K. Van Den Abeele, and L. Ma, "Localization of material defects using nonlinear resonant ultrasound spectroscopy under asymmetric boundary conditions," Phys. Procedia, vol. 3, no. 1, pp. 55-61, 2010.

[171] L. Straka, Y. Yagodzinskyy, M. Landa, and H. Hänninen, “Detection of structural damage of aluminum alloy 6082 using elastic wave modulation spectroscopy," NDT E Int., vol. 41, no. 7, pp. 554-563, 2008.

[172] P. Liu, H. Sohn, T. Kundu, and S. Yang, "Noncontact detection of fatigue cracks by laser nonlinear wave modulation spectroscopy (LNWMS),” NDT E Int., vol. 66, pp. 106-116, 2014.

[173] N. Houhat and V. Tournat, "One-dimensional Parametric Study of Damage Detection in a Solid Material using a Nonlinear Wave Modulation Spectroscopy (NWMS) Technique," no. Icee, pp. 1-4, 2015.

[174] T.-C. Poon, “DETECTION | Heterodyning," in Encyclopedia of Modern Optics, 2005, pp. 201-206.

[175] K. Geren, M. Papineau, and C. Routh, "Heterodyne autocorrelation guidance system," US Pat. 3,836,951, 1974.

[176] J. H. McElroy, "Infrared heterodyne solar radiometry.," Appl. Opt., vol. 11, no. 7, pp. 1619-1622, 1972.

[177] E. Norris, “Acoustic heterodyne device and method," US Pat. 5,889,870, 1999.

[178] D. Gabor, “Theory of communication. Part 1: The analysis of information,” Electr. Eng. - Part III Radio Commun. Eng. J. Inst., vol. 93, no. 26, pp. 429-441, 1946. 
[179] M. Sartorato, R. de Medeiros, D. Vandepitte, and V. Tita, "Computational model for supporting SHM systems design: Damage identification via numerical analyses,” Mech. Syst. Signal Process., vol. 84, pp. 445-461, Feb. 2017.

[180] C. Yang and S. O. Oyadiji, "Damage detection using modal frequency curve and squared residual wavelet coefficients-based damage indicator,” Mech. Syst. Signal Process., vol. 83, pp. 385-405, Jan. 2017.

[181] N. Grip, N. Sabourova, and Y. Tu, "Sensitivity-based model updating for structural damage identification using total variation regularization," Mech. Syst. Signal Process., vol. 84, pp. 365-383, Feb. 2017.

[182] R. de Medeiros, M. Sartorato, D. Vandepitte, and V. Tita, "A comparative assessment of different frequency based damage detection in unidirectional composite plates using MFC sensors," J. Sound Vib., vol. 383, pp. 171-190, Nov. 2016.

[183] M. Pedram, A. Esfandiari, and M. R. Khedmati, "Damage detection by a FE model updating method using power spectral density: Numerical and experimental investigation,” J. Sound Vib., vol. 397, pp. 51-76, Jun. 2017.

[184] Y. Shen and V. Giurgiutiu, "Combined analytical FEM approach for efficient simulation of Lamb wave damage detection," Ultrasonics, vol. 69, pp. 116-128, Jul. 2016.

[185] A. S. Rizi, S. Hedayatrasa, X. Maldague, and T. Vukhanh, "FEM modeling of ultrasonic vibrothermography of a damaged plate and qualitative study of heating mechanisms,” Infrared Phys. Technol., vol. 61, pp. 101-110, Nov. 2013.

[186] J. Xiang and M. Liang, “A two-step approach to multi-damage detection for plate structures,” Eng. Fract. Mech., vol. 91, pp. 73-86, Sep. 2012. 
[187] Y. Alkassar, V. K. Agarwal, and E. Alshrihi, "Simulation of Lamb Wave Modes Conversions in a Thin Plate for Damage Detection," Procedia Eng., vol. 173, pp. 948-955, Jan. 2017.

[188] A. H. Alavi, H. Hasni, N. Lajnef, and K. Chatti, "Damage growth detection in steel plates: Numerical and experimental studies,” Eng. Struct., vol. 128, pp. 124-138, Dec. 2016.

[189] A. Baghalian, V. Y. Senyurek, S. Tashakori, D. McDaniel, and I. N. Tansel, “A Novel Nonlinear Acoustic Health Monitoring Approach for Detecting Loose Bolts,” J. Nondestruct. Eval., vol. 37, no. 2, p. 24, Jun. 2018.

[190] S. Tashakori, A. Baghalian, V. Y. Senyurek, M. Unal, D. McDaniel, and I. N. Tansel, "Implementation of heterodyning effect for monitoring the health of adhesively bonded and fastened composite joints,” Appl. Ocean Res., vol. 72, 2018.

[191] A. Baghalian, S. Tashakori, V. Y. Senyurek, M. Unal, and I. N. Tansel, "Novel approaches for loose bolt detection with and without sensors using heterodyning effect," in Structural Health Monitoring 2017: Real-Time Material State Awareness and Data-Driven Safety Assurance - Proceedings of the 11th International Workshop on Structural Health Monitoring, IWSHM 2017, 2017, vol. 1.

[192] S. Tashakori, A. Baghalian, V. Y. Senyurek, M. Unal, and I. N. Tansel, "Heterodyning effect in composites bond inspection," in Structural Health Monitoring 2017: Real-Time Material State Awareness and Data-Driven Safety Assurance - Proceedings of the 11th International Workshop on Structural Health Monitoring, IWSHM 2017, 2017, vol. 1.

[193] S. Tashakori, A. Baghalian, V. Y. Senyurek, S. Farhangdoust, D. McDaniel, I. N. Tansel, "Composites bond inspection using heterodyne effect and SuRE methods," Schock and Vibration, Vol. 2018, 2018. 
VITA

\section{SHERVIN TASHAKORI}

\section{EDUCATION}

2004-2009

B.S. Electrical Engineering- QIAU

Qazvin, Iran

2010-2013

M.S. Mechatronics Engineering (Robotics)- QIAU

Qazvin, Iran

2013- 2018

$\mathrm{PhD}$ Candidate, Mechanical Engineering

Florida International University

Miami, Florida, USA

- Dissertation Year Fellowship (DYF), FIU, Spring 2018.

- Doctoral Evidence Acquisition (DEA) Fellowship, FIU, Summer 2017.

Publications:

1. S. Tashakori, A. Baghalian, M. Unal, H. Fekrmandi, volkan y şenyürek, D. McDaniel, and I. N. Tansel, "Contact and non-contact approaches in load monitoring applications using surface response to excitation method,” Measurement, vol. 89, pp. 197-203, 2016.

2. S. Tashakori, A. Baghalian, V. Y. Senyurek, M. Unal, D. McDaniel, and I. N. Tansel, "Implementation of heterodyning effect for monitoring the health of adhesively bonded and fastened composite joints," Appl. Ocean Res., vol. 72, pp. 51-59, Mar. 2018.

3. H. Fekrmandi, M. Unal, A. Baghalian, S. Tashakori, K. Oyola, A. Alsenawi, and I. N. Tansel, "A non-contact method for part-based process performance monitoring in end milling operations,” Int. J. Adv. Manuf. Technol., 2015.

4. A. Baghalian, S. Tashakori, V. Y. Senyurek, D. Mcdaniel, H. Fekrmandi, and I. N. Tansel, "Non-Contact Quantification of Longitudinal and Circumferential Defects in Pipes using the Surface Response to Excitation (SuRE) Method,” Int. J. Progn. Heal. Manag., pp. 2153-2648, 2017.

5. Baghalian, S. Tashakori, V. Y. Senyurek, M. Unal, D. McDaniel, and I. N. Tansel, "Development of comprehensive heterodyne effect based inspection (CHEBI) method for inclusive monitoring of cracks," Measurement, vol. 128, pp. 89-95, Nov. 2018.A. 
6. Baghalian, V. Y. Senyurek, S. Tashakori, D. McDaniel, and I. N. Tansel, "A Novel Nonlinear Acoustic Health Monitoring Approach for Detecting Loose Bolts," J. Nondestruct. Eval., vol. 37, no. 2, p. 24, Jun. 2018.

7. V. Y. Senyurek, A. Baghalian, S. Tashakori, D. McDaniel, and I. N. Tansel, "Localization of multiple defects using the compact phased array (CPA) method," J. Sound Vib., vol. 413, pp. 383-394, Jan. 2018.

8. S. Tashakori, A. Baghalian, V. Y. Senyurek, S. Farhangdoust, D. McDaniel, I. N. Tansel, "Composites bond inspection using heterodyne effect and SuRE methods," Schock and Vibration, Vol. 2018, 2018.

9. S. Tahakori, A. Baghalian, M. Unal, Y şenyürek4, H. Fekrmandi, D. McDaniel, I.N. Tansel, "Load Monitoring Using Surface Response to Excitation Method" SEM 13th International Congress \& Exposition on Experimental and Applied Mechanics, June 69, 2016, Orlando, Florida USA.

10. A. Baghalian, S. Tahakori, H. Fekrmandi, M. Unal, Y şenyürek4, D. McDaniel, I.N. Tansel, "Implementation of the Surface Response to Excitation method for pipes," SEM 13th International Congress \& Exposition on Experimental and Applied Mechanics, June 6-9, 2016, Orlando, Florida USA.

11. S. Tashakori, A. Baghalian, J. Cuervo, V. Y. Senyurek, I. N. Tansel, and B. Uragun, "Inspection of the machined features created at the embedded sensor aluminum plates," in 2017 8th International Conference on Recent Advances in Space Technologies (RAST), 2017, pp. 517-522.

12. A. Baghalian, S. Tashakori, J. R. Soto, V. Y. Senyurek, I. N. Tansel, and B. Uragun, "Internal defect detection in hollow cylindrical structures using the Surface Response to Excitation (SuRE) Method," in 2017 8th International Conference on Recent Advances in Space Technologies (RAST), 2017, pp. 523-527.

13. S. Tahakori, A. Baghalian, Volkan Y. Senyurek, M. Unal, D. McDaniel, I.N. Tansel, "Inspection of the Composite Bonds by Implementing the Heterodyne effect" (IWSHM2017- Stanford University - Conference proceedings)

14. A. Baghalian, S. Tahakori, Volkan Y. Senyurek, M. Unal, I.N. Tansel, "Novel Approaches for Loose Bolt Detection with and without Sensors Using Heterodyning Effect" (IWSHM2017- Stanford University - Conference proceedings)

15. H. Fekrmandi, I. Nur Tansel, R. Gonzalez, S. Rojas, D. Meiller, K. Lindsay, A. Baghalian, and S. Tashakori, "Implementation of the Surface Response to Excitation (SuRE) Method with DSP's for Detection of the Damage of Thick Blocks" 10th 